UNIVERSIDADE DE SÃO PAULO

FACULDADE DE ECONOMIA, ADMINISTRAÇÃO E CONTABILIDADE DEPARTAMENTO DE ADMINISTRAÇÃO PROGRAMA DE PÓS-GRADUAÇÃ̃ EM ADMINISTRAÇÃo

A RELAÇÃO ENTRE ÍNDICE DE SENTIMENTO DE MERCADO E AS TAXAS DE RETORNO DAS AÇÕES:

UMA ANÁLISE COM DADOS EM PAINEL

Claudia Emiko Yoshinaga

Orientador: Prof. Dr. José Roberto Securato 
Profa. Dra. Suely Vilela

Reitora da Universidade de São Paulo

Prof. Dr. Carlos Roberto Azzoni

Diretor da Faculdade de Economia, Administração e Contabilidade

Prof. Dr. Adalberto Américo Fischmann

Chefe do Departamento de Administração

Prof. Dr. Lindolfo Galvão de Albuquerque

Coordenador do Programa de Pós-Graduação em Administração 
CLAUDIA EMIKO YOSHINAGA

\section{A RELAÇÃO ENTRE ÍNDICE DE SENTIMENTO DE MERCADO E AS TAXAS DE RETORNO DAS AÇÕES: UMA ANÁLISE COM DADOS EM PAINEL}

Tese apresentada ao Departamento de Administração da Faculdade de Economia, Administração e Contabilidade da Universidade de São Paulo como requisito parcial para a obtenção do título de Doutora em Administração.

Orientador: Prof. Dr. José Roberto Securato 
Tese defendida e aprovada no Departamento de Administração da Faculdade de Economia, Administração e Contabilidade da Universidade de São Paulo - Programa de Pós-graduação em Administração, pela seguinte comissão examinadora:

Prof. Dr. José Roberto Securato (Presidente)

Prof. Dr. Rubens Famá - FEA/USP

Prof. Dr. Lucas Ayres Barreira de Campos Barros - FEA/USP

Profa. Dra. Andrea Maria Accioly Fonseca Minardi - Insper

Prof. Dr. William Eid Junior - FGV/SP

FICHA CATALOGRÁFICA

Elaborada pela Seção de Processamento Técnico do SBD/FEA/USP

Yoshinaga, Claudia Emiko

A Relação entre Índice de Sentimento de Mercado e as Taxas de Retorno das Ações: uma Análise com Dados em Painel / Claudia Emiko Yoshinaga - São Paulo, 2009.

$162 \mathrm{p}$.

Tese (Doutorado) - Universidade de São Paulo, 2009.

Bibliografia.

1. Finanças 2. Mercado de capitais 3. Painel (Pesquisa e planejamento) I. Universidade de São Paulo. Faculdade de Economia, Administração e Contabilidade. II. Título. 
Aos meus pais, Ciro e Emília, pelo apoio e pela dedicação de toda uma vida. 


\section{Agradecimentos}

There is nothing better than the encouragement of a good friend.

Jean Jacques Rousseau

Muitas foram as pessoas que contribuíram ao longo da minha formação e que, sem dúvida, foram importantes para a elaboração deste trabalho. A estas pessoas agradeço profundamente. Entretanto, um agradecimento especial faz-se necessário àqueles que contribuíram de maneira mais próxima nesta jornada:

- ao Prof. Dr. José Roberto Securato, meu orientador no curso de Doutorado, pelos ensinamentos nas disciplinas do curso de pós-graduação e na convivência ao longo destes anos na FEA. Transmitiu não apenas conhecimentos acadêmicos, essenciais à condução desta pesquisa, mas também didáticos, que foram fundamentais na minha formação e na carreira docente;

- ao Prof. Dr. Rubens Famá, meu orientador no curso de Mestrado e membro da banca, por ter me apresentado ao mundo das Finanças Comportamentais, que deram origem a esta pesquisa, além de transmitir conhecimento e confiança necessários à sua conclusão.

- ao Prof. Dr. Lucas Ayres Barreira de Campos Barros, membro da banca, pelas sugestões oferecidas no exame de qualificação e pelas discussões sobre os métodos econométricos adequados para esta tese. Seu exemplo de dedicação à pesquisa e disponibilidade para a troca de ideias são uma referência para os pesquisadores em Finanças.

- ao Prof. Dr. William Eid Junior e à Profa. Dra. Andrea Maria Accioly Fonseca Minardi, por aceitarem o convite para participar da avaliação desta tese, e pelas críticas e sugestões que serão importantes para o desdobramento deste estudo.

- aos meus professores nos cursos de graduação, mestrado e doutorado na FEA-USP, em especial aos Professores Doutores Abraham Sin Oih Yu, Antonio Zoratto Sanvicente e Maria Aparecida Gouvea, pelo convívio acadêmico e pelos ensinamentos transmitidos.

- aos funcionários da FEA-USP, especialmente aos da Seção de Pós-Graduação e do Serviço de Biblioteca e Documentação, a quem recorri diversas vezes e sempre fui atendida com muita prontidão e gentileza. 
- aos profissionais que ajudaram a complementar minha formação acadêmica durante o curso de doutorado, através da vivência no ambiente empresarial, especialmente a: Carlos Atushi Nakamuta, Paulo Beltrão Fraletti e Sandra Guerra.

- aos meus inicialmente colegas e hoje grandes amigos da FEA-USP, com quem dividi as alegrias e as agruras da vida acadêmica: André Luiz Oda, André Taue Saito, Eduardo Pozzi Lucchesi, Fabrício Caprio Macastropa, Fernanda Furuta, Héber Pessoa da Silveira, Junio Fuentes, Patrícia Oda, Raquel de Freitas Oliveira e Rodrigo Takashi Okimura. Devo um agradecimento mais que especial ao Francisco Henrique Figueiredo de Castro Junior, que contribuiu ativamente para esta tese, tanto quanto à forma, com suas aulas sobre $\mathrm{LT}_{\mathrm{E}} \mathrm{X}$ e suas implementações, como também ao conteúdo, trocando ideias e discutindo as inúmeras versões preliminares do documento.

- aos meus queridos BetaFriends, pelo incentivo e carinho irrestrito, além de tornarem a vida mais leve e divertida.

Finalmente, um agradecimento ao maior ativo e ao maior passivo que tenho: minha família. Dela emanaram os valores e princípios que me orientam e que são exemplo de dedicação, esforço e perseverança. É a ela quem mais devo ser grata pelas conquistas feitas até hoje. Seu apoio e carinho foram essenciais para que eu pudesse seguir este caminho. Aos meus pais, Ciro e Emília, e à minha irmã, Esther, agradeço o amor, afeto e torcida em todos os momentos. 
"I do not know what I may appear to the world; but to myself I seem to have been only like a boy playing on the seashore, and diverting myself in now and then finding of a smoother pebble or a prettier shell than ordinary, whilst the great ocean of truth lay all undiscovered before me."

Isaac Newton 


\title{
Resumo
}

\author{
YOSHINAGA, C. E. A Relação entre Índice de Sentimento de Mercado e as \\ Taxas de Retorno das Ações: uma Análise com Dados em Painel. 162p. Tese \\ (Doutorado) - Faculdade de Economia, Administração e Contabilidade, Universidade de \\ São Paulo, São Paulo, 2009.
}

Na teoria clássica de finanças, o sentimento do investidor não é considerado um fator importante sobre os preços das ações. Embora a existência do sentimento do investidor não seja negada, as teorias normalmente partem do princípio de que, em mercados financeiros competitivos, comportamentos de agentes quase-racionais são rapidamente eliminados. Esta tese tem o objetivo de investigar a relação entre o sentimento de mercado e as taxas de retorno futuras das ações. É proposta uma metodologia para a criação de um índice de sentimento específico para o mercado brasileiro com uso da análise de componentes principais. Com o objetivo de verificar a relação deste índice de sentimento com as taxas de retorno das ações, foi estimado um modelo de apreçamento em que esta variável foi incluída, para o período de 1999 a 2008. A amostra foi composta por empresas não-financeiras com ações listadas na BOVESPA, com uma negociabilidade mínima que garantisse observações suficientes e representativas para validar os resultados encontrados na pesquisa. O modelo de apreçamento foi estimado por GMM, levando em consideração o índice de sentimento de mercado, o risco sistêmico das empresas (medido pelo beta) e fatores como tamanho, índice market-to-book, alavancagem, momentum e crescimento da receita. Empregaram-se diferentes procedimentos para estimar os parâmetros dos modelos empíricos formulados, com o propósito de isolar influências espúrias, ocasionadas pela presença de heterogeneidade não-observada, pela existência de eventuais observações extremas ou mesmo pela possível endogeneidade dos regressores. Os resultados deste estudo empírico sugerem que o sentimento é um fator relevante no apreçamento das ações no mercado brasileiro. A relação negativa e significante entre o índice de sentimento e as taxas de retorno, encontrada consistentemente em diferentes modelos, indica um padrão de reversão nas taxas de retornos, ou seja, após um período de sentimento positivo, o impacto nas taxas de retorno no período seguinte é negativo, e vice-versa.

Palavras-chave: Índice de Sentimento de Mercado, Modelo de Apreçamento, Dados em Painel. 


\section{Abstract}

YOSHINAGA, C. E. The Relationship between Market Sentiment Index and Stock Returns: a Panel Data Analysis. 162p. Thesis (Doctoral) - Faculdade de Economia, Administração e Contabilidade, Universidade de São Paulo, São Paulo, 2009.

In classical finance theory investor sentiment is not considered an important factor in asset pricing. Although the existence of investor sentiment is not denied, theories assume that in competitive markets quasi-rational behavior is quickly offset by rational agents. The main goal of this thesis is to investigate the relationship between investor sentiment and future stock return rates. It is proposed a methodology to create a sentiment index specifically to the Brazilian market using principal components analysis. In order to analyze the relationship between this sentiment index and the future stock returns, it was estimated a pricing model including this variable for the period comprehending 1999 to 2008. Considering a negotiability restriction to assure representative and sufficient observations to validate a pricing model, the sample consisted of non-financial firms listed at BOVESPA. The pricing model was estimated by GMM considering the sentiment index, systematic risk (market beta) and factors as firm size, market-to-book ratio, leverage and return predictability measured by momentum or income growth. Different estimation procedures were applied to find empirical models coefficients which are less affected by spurious influence such as unobserved heterogeneity, outliers or possible regressors endogeneity. Results of the empirical study suggest that sentiment is a relevant factor in Brazilian asset pricing models. A negative and statistically significant relationship between the sentiment index and stock returns was consistently found in different models especifications. These findings suggest the existence of a reversion pattern in stock returns, meaning that after a positive sentiment period, the impact on subsequent stock returns is negative and vice-versa.

Keywords: Market Sentiment Index, Pricing Model, Panel Data Analysis. 
AUTORIZO A REPRODUÇÃO E DIVULGAÇÃO TOTAL OU PARCIAL DESTE TRABALHO, POR QUALQUER MEIO CONVENCIONAL OU ELETRÔNICO, PARA FINS DE ESTUDO E PESQUISA, DESDE QUE CITADA A FONTE.

Esta tese foi formatada em $\mathrm{HT}_{\mathrm{E}} \mathrm{X}$, com estilo de citação $\mathrm{ABNT}_{\mathrm{E}} \mathrm{X}$. 


\section{Sumário}

Lista de Tabelas $\quad 5$

$\begin{array}{ll}\text { Lista de Quadros } & 7\end{array}$

Lista de Acrônimos $\quad 9$

Lista de Símbolos $\quad 13$

1 Introdução 15

1.1 Formulação da Situação Problema . . . . . . . . . . . . . . . . . . 15

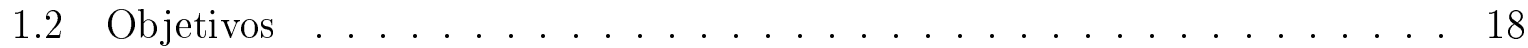

1.3 Justificativa e Contribuições . . . . . . . . . . . . . . . . . . . . . 18

1.4 Hipótese Formulada . . . . . . . . . . . . . . . . . 20

1.5 Delimitações . . . . . . . . . . . . . . . . . 20

1.6 Descrição dos Capítulos . . . . . . . . . . . . . . . 21

2 Fundamentação Teórica $\quad 23$

2.1 Das Finanças Clássicas às Finanças Comportamentais . . . . . . . . . . . 23

2.1.1 Racionalidade e Homogeneidade das Expectativas dos Investidores . 24

2.1.2 Mercados Eficientes . . . . . . . . . . . . . . . 24

2.1.3 Modelos Clássicos de Apreçamento . . . . . . . . . . . . 27

2.1.4 Finanças Comportamentais . . . . . . . . . . . . 30

2.1.5 Modelos Comportamentais de Apreçamento . . . . . . . . . . 36

2.2 Sentimento dos Investidores . . . . . . . . . . . . . . . . . 39

2.2.1 Definição de Sentimento . . . . . . . . . . . . . . 39

2.2.2 Pesquisas de Opinião . . . . . . . . . . . . . . . . 41

2.2.3 Proxies de Mercado para Sentimento . . . . . . . . . . . 44

2.2.3.1 Liquidez ....................... 45

2.2.3.2 Prêmio de Dividendos . . . . . . . . . . . . 46 
2.2.3.3 Quantidade de IPOs e Retorno Médio dos IPOs . . . . . . 48

2.2.3.4 Percentual de ações nas novas emissões . . . . . . . . . . 49

2.2.3.5 Proporção de Altas e Baixas . . . . . . . . . . . 50

2.2.3.6 Insider Trading . . . . . . . . . . . . . 51

2.2.3.7 Proporção de Put-Call . . . . . . . . . . . . . 51

2.2.3.8 Closed-End Fund Discount $(C E F D)$. . . . . . . . 52

2.2.3.9 Fluxo de Movimentação nos Fundos de Investimento . . . 54

2.2.3.10 Volatilidade Implícita nas Opções . . . . . . . . . . . . . 56

2.2.3.11 Humor do Investidor . . . . . . . . . . . . . . 57

2.2 .4 Índices de Sentimento . . . . . . . . . . . . . . . 58

3 Método da Pesquisa Empírica $\quad 63$

3.1 Modelos de Apreçamento . . . . . . . . . . . . . . 65

3.2 População, Amostragem e Coleta de Dados . . . . . . . . . . . . 66

3.3 Definição Operacional das Variáveis . . . . . . . . . . . . . 67

3.3.1 Variáveis do Índice de Sentimento . . . . . . . . . . . . . . 67

3.3.1.1 Quantidade e Retorno dos IPOs . . . . . . . . 67

3.3.1.2 Percentual de ações nas novas emissões . . . . . . . . 68

3.3.1.3 Turnover das Ações . . . . . . . . . . . . . 68

3.3.1.4 Prêmio de Dividendos . . . . . . . . . . . 68

3.3.1.5 Proporção de Altas e Baixas . . . . . . . . . . . 69

3.3.2 Variáveis do Modelo de Apreçamento . . . . . . . . . . . . 69

3.3.2.1 Taxa de Retorno das Ações . . . . . . . . . . . . 69

3.3.2.2 Beta de Mercado ............... 69

3.3.2.3 Tamanho da Empresa .............. 70

3.3.2.4 Valor de Mercado sobre Patrimônio Líquido da Empresa 71

3.3.2.5 Endividamento . . . . . . . . . . . . . 71

3.3.2.6 Previsibilidade dos Retornos . . . . . . . . . . 71

3.3.2.7 Setor de Atividade . . . . . . . . . . . . 72

3.3.2.8 Dummies de Trimestre . . . . . . . . . . . . 72

3.4 Construção do Índice de Sentimento . . . . . . . . . . . . . . . 72

3.4.1 Análise de Componentes Principais . . . . . . . . . . . 72

3.4.2 Temporalidade e Sinal Esperado das Variáveis . . . . . . . . . . 76

3.5 Investigação Empírica do Modelo de Apreçamento . . . . . . . . . . . 77

3.5.1 Modelos Tradicionais para Dados em Painel . . . . . . . . . . . 79 
3.5.2 Método dos Momentos Generalizado . . . . . . . . . . . . . 81

3.5.2.1 GMM em Diferenças . . . . . . . . . . . 85

3.5.2.2 GMM Sistêmico . . . . . . . . . . . . 87

3.6 Alternativas Robustas de Análise . . . . . . . . . . . . . 88

3.7 Limitações do Modelo Empírico . . . . . . . . . . . . . . . . . 89

3.7 .1 Amostragem . . . . . . . . . . . . . . 89

3.7 .2 Definição Operacional das Variáveis . . . . . . . . . . . . . 89

3.7.3 Especificação do Modelo . . . . . . . . . . . . . . . . . . 90

4 Resultados $\quad 91$

4.1 Índice de Sentimento . . . . . . . . . . . . . . . . . . . 91

4.1.1 Estatísticas Descritivas . . . . . . . . . . . . . . 91

4.1 .2 Componentes Principais . . . . . . . . . . . . . . 92

4.2 Modelo de Apreçamento . . . . . . . . . . . . . . . . . . 96

4.2.1 Estatísticas Descritivas . . . . . . . . . . . . . . 96

4.2 .2 Modelo Linear Geral . . . . . . . . . . . . . . . . 97

4.2.2.1 Resultados dos Modelos Estáticos . . . . . . . . . . 100

4.2.2.2 Resultados dos Modelos Dinâmicos . . . . . . . . . . . 109

4.2.2.3 Análise de Robustez . . . . . . . . . . . . . . 116

4.3 Síntese dos Principais Resultados . . . . . . . . . . . . . 118

5 Conclusão $\quad 121$

$\begin{array}{lr}\text { Referências } & 127\end{array}$

$\begin{array}{ll}\text { A Índice de Sentimento } & 141\end{array}$

B Modelo de Apreçamento $\quad 143$

B.1 Amostra do Modelo de Apreçamento . . . . . . . . . . . . . . . 143

B.2 Resumo das Variáveis . . . . . . . . . . . . . . . . . . 151

B.3 Resultados das estimações com variáveis Winsorizadas . . . . . . . . . . 152

$\begin{array}{ll}\text { Índice Remissivo de Autores } & 161\end{array}$ 


\section{Lista de Tabelas}

4.1 Estatísticas descritivas das variáveis de sentimento . . . . . . . . . . . 92

4.2 Correlação entre $S E N T_{10}$ e as variáveis de sentimento . . . . . . . . . 92

4.3 Autovalores dos componentes principais com variáveis de sentimento . . . . 93

4.4 Estatísticas descritivas do índice de sentimento SENT . . . . . . . . 95

4.5 Matriz de correlação de SENT e suas variáveis . . . . . . . . . . 96

4.6 Estatísticas descritivas das variáveis de controle . . . . . . . . . . 97

4.7 Testes de exogeneidade estrita dos regressores: modelos estáticos . . . . . . 99

4.8 Testes de raiz unitária para painéis das variáveis de controle . . . . . . 100

4.9 Testes de raiz unitária para $S E N T \ldots \ldots$. . . . . . . . . . 101

4.10 Resultados das estimações por GMM: Modelo 01 . . . . . . . . . . . . . 103

4.11 Resultados das estimações por GMM: Modelo 02 . . . . . . . . . . . 105

4.12 Resultados das estimações por GMM: Modelo 03 . . . . . . . . . . . 107

4.13 Resultados das estimações por GMM: Modelo 04 . . . . . . . . . . . . 108

4.14 Resultados das estimações por GMM: Modelo 05 . . . . . . . . . . . . 111

4.15 Resultados das estimações por GMM: Modelo 06 . . . . . . . . . . . . . 112

4.16 Resultados das estimações por GMM: Modelo 07 . . . . . . . . . . . . . 114

4.17 Resultados das estimações por GMM: Modelo 08 . . . . . . . . . . . . 115

4.18 Coeficientes estimados para a variável SENT para os modelos com variáveis Winsorizadas . . . . . . . . . . . . . . . . . . 117

A.1 Intervalos de confiança dos autovalores com as variáveis de sentimento . . . 141

A.2 Autovalores calculados para a determinação da quantidade de componentes 141

B.1 Empresas que compõem a amostra do modelo de apreçamento . . . . . . 143

B.2 Setores de atividade das empresas da amostra . . . . . . . . . . 150

B.3 Resultados das estimações por GMM com variáveis Winsorizadas: Modelo Estático 01 . . . . . . . . . . . . . . . . . . 152 
B.4 Resultados das estimações por GMM com variáveis Winsorizadas: Modelo Estático 02 . . . . . . . . . . . . . . . . . . . . 153

B.5 Resultados das estimações por GMM com variáveis Winsorizadas: Modelo Estático 03 . . . . . . . . . . . . . . . . . . . 154

B.6 Resultados das estimações por GMM com variáveis Winsorizadas: Modelo Estático 04 . . . . . . . . . . . . . . . . . . 155

B.7 Resultados das estimações por GMM com variáveis Winsorizadas: Modelo Dinâmico 05 . . . . . . . . . . . . . . . . . . . . 156

B.8 Resultados das estimações por GMM com variáveis Winsorizadas: Modelo Dinâmico 06 . . . . . . . . . . . . . . . . . . 157

B.9 Resultados das estimações por GMM com variáveis Winsorizadas: Modelo Dinâmico 07 . . . . . . . . . . . . . . . . . . 158

B.10 Resultados das estimações por GMM com variáveis Winsorizadas: Modelo Dinâmico 08 . . . . . . . . . . . . . . . . . . 159 


\section{Lista de Quadros}

2.1 Objeções comuns às abordagens psicológica e racional para o apreçamento

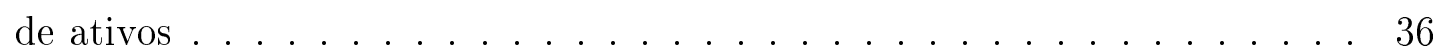

3.1 Temporalidade e Sinal Esperado das Variáveis que compõem o Índice de Sentimento ........................... 77

4.1 Variáveis utilizadas nos modelos estáticos . . . . . . . . . . . . . . 98

4.2 Variáveis utilizadas nos modelos dinâmicos . . . . . . . . . . . . . . 98

B.1 Definições resumidas de algumas variáveis . . . . . . . . . . . . 151 


\section{Lista de Acrônimos}

2SLS

A

AAII

$\mathrm{ACP}$

ADF

APT

AT

BE

BOVESPA

BSI

CAPM

CBOE

CCAPM

CEFD

CNI

CRESC

CRSP

CVM

D

DB

DBAM

DBAT

DEB

DIV

DJIA

EA

EF

EGMM

EMSI
Two-Stage Least Squares

Volume Total de Emissão de Ações

American Association of Individual Investors

Análise de Componentes Principais

Teste Dick-Fuller Aumentado

Arbitrage Pricing Theory

Ativo Total da Empresa

Book Equity

Bolsa de Valores de São Paulo

Bearish Sentiment Index

Capital Asset Pricing Model

Chicago Board Options Exchange

Consumption CAPM

Closed-End Fund Discount

Confederação Nacional da Indústria

Taxa de Variação da Receita Líquida Operacional

The Center for Research in Security Prices

Comissão de Valores Mobiliários

Empresa Pagadora de Dividendos

Dívida Bruta

Dívida Bruta sobre o Ativo a Mercado da Empresa

Dívida Bruta sobre o Ativo Total da Empresa

Volume Total de Emissão de Dívida

Prêmio de Dividendos

Dow Jones Industrial Average

Efeitos Aleatórios

Efeitos Fixos

Estimador GMM Eficiente

Equity Market Sentiment Index 
Fecomercio Federação do Comércio do Estado de São Paulo

Fecomércio-RJ Federação do Comércio do Estado do Rio de Janeiro

FGV Fundação Getulio Vargas

GMM Generalized Method of Moments

GMM-Dif GMM em Diferenças

GMM-Sys GMM Sistêmico

HME Hipóteses de Mercados Eficientes

HML High minus Low

i.i.d. Independentes e Identicamente Distribuídos

IBOVESPA Índice BOVESPA

ICAPM CAPM Intertemporal

ICC Índice de Confiança do Consumidor

IEC Índice de Expectativas do Consumidor

II Investors Intelligence

INEC Índice Nacional de Expectativas do Consumidor

IPO Initial Public Offering

ME Market Equity

MOM Momentum

MQO Mínimos Quadrados Ordinário

NAV Net Asset Value

ND Empresa Não-pagadora de Dividendos

NEG Índice de Negociabilidade

NIPO Quantidade de IPOs

NYSE New York Stock Exchange

OLS Ordinary Least Squares

P Preço da Ação

PCR Put-Call Ratio

PL Patrimônio Líquido da Empresa

POLS Pooled OLS

PP Teste Phillips-Perron

R Taxa de Retorno da Ação

RIPO Retorno Médio dos IPOs no Primeiro Dia de Negociação

RLO Receita Líquida Operacional

S Proporção de Emissão de Ações em Relação ao Total de Emissões (Dívidas e Ações) 


$\begin{array}{ll}\text { S\&P500 } & \text { Standard \& Poor's } 500 \\ \text { SAD } & \text { Seasonal Affective Disorder } \\ \text { SEC } & \text { Sondagem de Expectativas do Consumidor } \\ \text { SENT } & \text { Índice de Sentimento } \\ \text { SMB } & \text { Small minus Big } \\ & \text { Total Net Asset } \\ \text { TNA } & \text { Total Net Flow } \\ \text { TNF } & \text { Trading Index } \\ \text { TRIN } & \text { Turnover de Ações } \\ \text { TURN } & \text { Up minus Down } \\ & \\ \text { UMD } & \text { Market Volatility Index } \\ \text { VIX } & \text { Valor de Mercado da Empresa } \\ \text { VM } & \text { Índice Valor de Mercado sobre Patrimônio Lí- } \\ \text { VMPL } & \text { quido da Empresa }\end{array}$




\section{Lista de Símbolos}

$\arg \min _{a}[$.$] \quad Argumento a que minimiza uma função$

$\beta_{i} \quad$ Variância sistêmica entre a taxa de retorno do ativo $i$ e a carteira de mercado

$\mathbb{C}[. ;$.$] \quad Operador matemático da covariância entre$ duas séries

$\Delta[$.$] \quad Operador matemático da diferença finita de$ uma função em diferentes instantes de tempo

$\frac{d}{d \mathbf{Y}}($.$) \quad Primeira derivada de uma função em relação$ a $Y$

$\epsilon_{i, t} \quad$ Termo de erro total da empresa $i$ no trimestre $t$, dado por $\eta_{i}+v_{i, t}$

$\eta_{i} \quad$ Heterogeneidade não-observada específica da empresa $i$

$\mathbb{E}[\cdot] \quad$ Operador matemático da esperança não condicionada de uma entidade

$\iota \quad$ Vetor de 1's

$\ln A T_{i, t} \quad$ Logaritmo natural do ativo total da empresa $i$ na data $t$

$\ln R L O_{i, t} \quad$ Logaritmo natural da receita líquida operacional da empresa $i$ na data $t$

$\ln V M_{i, t} \quad$ Logaritmo natural do valor de mercado da empresa $i$ na data $t$

$\bar{x} \quad$ Valor médio de uma variável $x$

$\Omega_{i, t} \quad$ Conjunto de variáveis de controle da empresa $i$ no trimestre $t$

$P_{i}^{*} \quad$ Preço justo do ativo $i$ na data $t$

$P_{i} \quad$ Preço do ativo $i$ na data $t$

plim Convergência em probabilidade 
$R_{i} \quad$ Taxa de retorno do ativo $i$

$R_{m} \quad$ Taxa de retorno da carteira de mercado

$\mathrm{T}$

Símbolo de transposição de um vetor ou matriz

$v_{i, t} \quad$ Termo de erro aleatório da empresa $i$ no trimestre $t$

$\mathbb{V}[$.$] \quad Operador matemático da variância de uma sé-$ rie

assint $\mathbb{V}[$.$] \quad Operador matemático da variância assintótica$ de uma série 


\section{Capítulo 1}

\section{Introdução}

It is those who know little, and not those who know much, who so positively assert that this or that problem will never be solved by science.

Charles Darwin

\subsection{Formulação da Situação Problema}

Dentre as principais questões que vêm sendo debatidas em finanças está a validade das premissas assumidas por suas teorias tradicionais, em particular a questão da racionalidade dos agentes econômicos. Neste contexto, surgiram diversos trabalhos com objetivo de aprimorar os modelos teóricos dominantes, incorporando aspectos comportamentais antes desconsiderados. Estas linhas de pesquisa deram origem a um novo e promissor campo de estudo denominado finanças comportamentais. O notável crescimento desta abordagem não-tradicional tem sido motivado, em especial, pela tentativa de explicação satisfatória de fenômenos regularmente observados nos mercados financeiros e incompatíveis com as predições dos modelos tradicionais.

Uma das premissas colocadas por estes modelos de apreçamento clássicos é a de que existe uma expectativa homogênea entre os investidores sobre a distribuição de probabilidades dos fluxos de caixa dos ativos, e que a análise e escolha de alternativas de investimentos baseiam-se unicamente nos seus fluxos antecipados, sendo que todos os investidores processam as informações, supostamente iguais para todos, de uma mesma forma. Estas colocações não condizem com o que é observado no mercado financeiro, ficando cada vez 
mais evidente a necessidade de se testarem outros modelos de apreçamento que incorporem estas características das preferências e características particulares de cada investidor, conforme apresentado por Lancaster (1966).

Diversos estudos empíricos vêm se acumulando na área das finanças comportamentais ao longo dos últimos anos. Eles revelam que as teorias de finanças aceitas e utilizadas até hoje, cujas bases estão fundamentadas na racionalidade total de seus agentes, são incapazes de explicar satisfatoriamente certos fenômenos financeiros observados na prática. Experimentos realizados por psicólogos cognitivistas revelam que os seres humanos estão frequentemente sujeitos a importantes vieses cognitivos e não se comportam segundo o paradigma clássico inspirado pela maximização da utilidade esperada.

Baker e Wurgler (2007) colocam que a teoria tradicional de finanças, baseada em investidores isentos de emoções, que forçam sempre os preços dos ativos a igualar o valor presente líquido descontado dos fluxos de caixa futuros, tem encontrado cada vez mais dificuldade para explicar os acontecimentos. As dificuldades da teoria tradicional quanto à sua validade empírica sugerem duas abordagens possíveis. A primeira é a reformulação das mesmas sem, no entanto, abandonar o pressuposto de racionalidade dos agentes. A segunda consiste na mudança de paradigma, a partir do reconhecimento de que as pessoas nem sempre se comportam racionalmente.

Nesta tese, o construto de sentimento será genericamente definido como tudo aquilo que provoca variação nos preços dos ativos e que não é justificado por alterações nos fluxos de caixa futuros e ou no risco do investimento a partir do conteúdo informacional que o investidor dispõe (ZHANG, 2008). Crises como as bolhas de Internet ocorridas ao final da década de 1990, em que as ações de empresas altamente arriscadas, especulativas e de tecnologia de difícil avaliação atingiram preços extremamente elevados, sugerem que o sentimento do investidor pode influenciar os preços dos ativos.

As pesquisas iniciais na área, ocorridas a partir da década de 1980, tinham por objetivo atestar, de diversas maneiras, que o mercado de ações como um todo sofria de desvios de apreçamento. Ainda sem um arcabouço teórico consolidado, estudiosos procuravam por anomalias ao mercado eficiente, como reversão dos preços à uma média (DE BONDT; THALER, 1985; POTERBA; SUMMERS, 1988; FAMA; FRENCH, 1988) ou volatilidade excessiva no índice de mercado não justificada pela volatilidade dos fundamentos das empresas (SHILLER, 1981).

Neste contexto, os estudos tentam ir além da mera constatação de que sentimento do investidor afeta ou não os preços das ações (BLACK, 1986; DE LONG et al., 1990; SHLEIFER; SUMMERS, 1990; LAKONISHOK; SHLEIFER; VISHNY, 1991; SHEFRIN; STATMAN, 1994; BARBERIS; SHLEIFER; VISHNY, 1998; DANIEL; HIRSHLEIFER; SUBRAHMANYAM, 1998; HONG; 
STEIN, 1999). Trabalhos nesta linha de pesquisa ultimamente têm proposto alternativas de medir esta variável de difícil captação direta e tentam quantificar o seu efeito nos preços das ações.

Desta maneira, aumentam cada vez mais a urgência e a importância de se desenvolverem novos modelos de apreçamento de ativos, uma vez que os modelos tradicionais ou clássicos apresentam algumas deficiências evidenciadas por diversos estudos empíricos. No entanto, embora esses modelos tenham algumas falhas já identificadas, seu uso ainda é bastante difundido, uma vez que modelos inovadores ainda não foram aceitos amplamente, dado que sua validade ainda é questionada por muitos acadêmicos.

Estudos mais recentes tentam prover explicações mais aprofundadas para a influência do sentimento nos mercados financeiros, considerando os dois tipos de investidores, seguindo a classificação de De Long et al. (1990): os arbitradores racionais, livres da influência do sentimento e os investidores "irracionais"1, vulneráveis ao sentimento exógeno. Ambos atuam no mercado de maneira competitiva e definem preços e retornos esperados.

Mas a atuação dos racionais é limitada em diversos aspectos, seja na curta janela de oportunidade ou quanto aos custos e riscos de transacionar, ocasionando o desvio dos preços de seu valor fundamental. Nesta abordagem, o apreçamento falho advém de dois fatores: (i) mudança de sentimento dos investidores irracionais ou (ii) restrições à arbitragem por parte dos investidores racionais.

Focando no item que se refere ao investidor que não segue um padrão de decisão totalmente racional, dada a sua racionalidade limitada e que está sujeito à influência do sentimento, a proposta da tese é, primeiramente, discutir uma forma de mensurar o sentimento do investidor, ao sugerir um índice de sentimento para o mercado brasileiro. Em seguida, este índice será utilizado num modelo de apreçamento de ativos, com o propósito de verificar se medidas de sentimento podem melhorar a explicação das taxas de retorno das ações. Deseja-se buscar uma resposta para o seguinte problema de pesquisa: o sentimento de mercado é um fator relevante para explicar a taxa de retorno esperada dos ativos financeiros negociados na Bolsa de Valores de São Paulo (BOVESPA)?

\footnotetext{
${ }^{1}$ A utilização da expressão "irracional" sugere "não perfeitamente racional", e não a ideia de que os investidores sejam totalmente isentos de racionalidade.
} 


\section{$1.2 \quad$ Objetivos}

O objetivo geral desta tese é investigar, empiricamente, a existência de uma relação entre o sentimento do investidor ${ }^{2}$ e a taxa de retorno esperada de ativos financeiros negociados na BOVESPA.

De maneira mais específica, deseja-se:

(a) justificar a utilização de aspectos comportamentais dos investidores nos modelos de apreçamento de ativos;

(b) fornecer uma metodologia para a criação de um índice de sentimento do mercado, adaptado para o mercado brasileiro;

(c) gerar novas evidências empíricas, com métodos de estimação adequados para sustentar os argumentos propostos, com a possível sugestão de novos caminhos para esta linha de pesquisa.

\subsection{Justificativa e Contribuições}

A base do que se chama de Moderna Teoria de Finanças foi iniciada no trabalho de Markowitz (1952), que define a fronteira eficiente de ativos. Pouco mais tarde, Sharpe (1964), a partir do conceito de fronteira eficiente, utilizou como premissas do Capital Asset Pricing Model (CAPM) que investidores sempre buscam alocar seus investimentos racionalmente, buscando a maximização de utilidade e com aversão ao risco.

Saito e Bueno (2007) colocam que este modelo, devido à sua aparente simplicidade de estimação, é amplamente utilizado por profissionais e acadêmicos, sendo ensinado nos cursos de Finanças em todos os níveis, do básico ao avançado. Desde a sua criação, há uma extensa linha de estudos que objetivam testar a validade deste modelo. Fama e French (2004) argumentam que os problemas empíricos do $C A P M$ são decorrentes das premissas simplificadoras assumidas no seu desenvolvimento. Os testes empíricos estão relacionados a três decorrências da relação entre a taxa de retorno esperada e o $\beta$ do ativo: (i) taxas de retorno esperadas dos ativos são linearmente relacionadas aos seus $\beta \mathrm{s}$, sendo que não há outra variável com poder explicativo; (ii) prêmio do $\beta$ é positivo, ou seja, a taxa de retorno esperada da carteira de mercado excede a taxa de retorno esperada dos

\footnotetext{
${ }^{2}$ A literatura não faz distinção entre sentimento do investidor e sentimento do mercado, usando a expressão Investor Sentiment para se referir à expectativa de retornos das ações no mercado de maneira agregada. Nesta tese, também não será feita distinção entre as duas expressões.
} 
ativos não-correlacionados com o retorno do mercado; e (iii) ativos não-correlacionados com o mercado terão taxas de retorno esperadas igual à taxa livre de risco, e o prêmio do risco de mercado será dado por $\mathbb{E}\left[R_{m, t+1}\right]-R_{f}$.

Como não há um consenso quanto à validade do modelo, dado que resultados inconclusivos ou mesmo contraditórios são encontrados, este é um assunto que deve ainda continuar a ser investigado. Há uma divergência por parte dos estudos tanto nos parâmetros utilizados (por exemplo, a definição do ativo livre de risco e a carteira de mercado) como nas técnicas estatísticas empregadas para a estimação do $\beta$. Segundo Saito e Bueno (2007), poucos estudos utilizam a metodologia correta para a estimação, como a metodologia em duas passagens (2SLS) de Fama e MacBeth (1973) ou mesmo o Método dos Momentos Generalizado $(\mathrm{GMM})^{3}$ de Hansen (1982).

A atestação de resultados contrários ao esperado pela teoria tradicional, comumente denominados de anomalias, colocam em questão a validade do CAPM (BASU, 1977; BANZ, 1981; FAMA; FRENCH, 2007). A não-validação do modelo como adequado para a determinação da taxa de retorno esperada dos ativos poderia indicar a existência de variáveis omitidas. Neste cenário, a pesquisa por modelos de apreçamento de ativos deve ser continuamente desenvolvida, com o objetivo de se proporcionar base empírica que fomente a discussão do tema. Especificamente, pesquisas empíricas com dados de mercados emergentes se deparam com obstáculos adicionais, como a falta de disponibilidade de dados históricos relevantes para o estudo, ou mesmo taxas de retorno com distribuição normal (BEKAERT et al., 1998). Justifica-se, assim, a tentativa de se encontrar uma especificação complementar ao $C A P M$, com a inclusão de um índice que representa o sentimento do mercado, controlando-se por outros efeitos já verificados em pesquisas anteriores.

Um ponto importante a ser destacado, quando se fala da elaboração de uma tese, é a questão de apresentar contribuições que possam ser consideradas relevantes para a pesquisa acadêmica. Severino (1993, p. 109-112) coloca que uma tese de doutoramento deve ser pessoal, autônoma, criativa e rigorosa. Por pessoal, entende-se que o assunto deva ser uma problemática vivenciada pelo pesquisador, quanto à relevância e significação das questões abordadas. Deve ser autônoma, ou seja, fruto do esforço do próprio pesquisador, o que não implica o desconhecimento ou desprezo da contribuição alheia, mas refere-se à capacidade de estabelecer um inter-relacionamento com outros pesquisadores, resultados e inclusive fatos, validando ou negando a relevância das contribuições alheias. Tem que ser criativa, no sentido de ser até mesmo um pouco audaciosa, para avançar em novas ideias e colaborar no avançar do desenvolvimento da ciência. Por fim, a tese deve ser rigorosa, exigindo-se logicidade e competência. Além da disciplina imposta pela metodologia geral

\footnotetext{
${ }^{3}$ Será utilizada a sigla GMM, de Generalized Method of Moments, considerando esta ser a denominação mais comumente encontrada nos textos, mesmo em língua portuguesa.
} 
do conhecimento e das metodologias específicas das várias ciências, requer-se também a disciplina do compromisso do pesquisador.

Do ponto de vista internacional, esta tese fará a aplicação de um índice de sentimento em um modelo de apreçamento de forma ainda não realizada por outros estudos, até onde se tem conhecimento. A estimação através de GMM, com o intuito de atestar a influência do sentimento nos retornos esperados dos ativos é inédita. Como contribuições nacionais, deve-se destacar a proposta de um índice de sentimento com dados brasileiros, além de verificar se este fator mostra-se relevante para as ações brasileiras.

\subsection{Hipótese Formulada}

Conforme já apresentado na Seção 1.2, o objetivo principal desta tese é identificar, para as empresas que têm ações negociadas na BOVESPA, se existe alguma relação entre o sentimento do investidor, medido por um índice a ser proposto, e a sua taxa de retorno esperada.

Para atender a esse objetivo, foi formulada a seguinte hipótese, apresentada na sua forma nula:

$H_{0}$ : Não existe relação entre o índice de sentimento e a taxa de retorno esperada das ações, líquida dos efeitos de fatores de risco comumente utilizados nas pesquisas acadêmicas.

Para verificar a relação entre o sentimento e os preços das ações, que constitui o objetivo principal da pesquisa, é necessário selecionar variáveis que representem características relacionadas ao sentimento do investidor, além de definir os procedimentos metodológicos para a criação do índice de sentimento.

A hipótese de existência de alguma relação entre essas medidas é verificada por meio da aplicação de testes estatísticos de associação. A descrição detalhada da criação do índice e dos testes estatísticos utilizados, assim como um detalhamento da metodologia, podem ser encontrados no Capítulo 3.

\subsection{Delimitações}

Pode-se imaginar que o mercado observe outros fatores de risco, além dos que estão relacionados nesta tese. Por exemplo, os investidores podem considerar outras evidências 
quaisquer para formar a opinião sobre o desempenho futuro do mercado, além dos sugeridos por esta pesquisa. A seleção de variáveis para medir o sentimento do investidor fundamenta-se em estudos empíricos anteriores, sendo utilizadas então as consideradas mais relevantes e aplicáveis para o mercado brasileiro.

Há uma outra delimitação relevante quanto ao objeto da pesquisa em função da disponibilidade de informações para os testes estatísticos, limitando-se o objeto da pesquisa para as empresas listadas na BOVESPA, entre 1999 e 2008. O período amostral cobre todo o período de tempo em que existem dados relativos a emissões de ações e de dívida pelas empresas e divulgados pela Comissão de Valores Mobiliários (CVM).

\subsection{Descrição dos Capítulos}

Esta tese está organizada em cinco capítulos e dois apêndices. Este primeiro faz uma breve introdução ao tema da pesquisa, descrevendo e justificando a relevância do assunto e o objetivo do trabalho. Destacam-se também as contribuições pretendidas com a tese. A seguir, a Fundamentação Teórica apresenta o corpo conceitual que sustenta o desenvolvimento da pesquisa e traz uma revisão da literatura sobre o tema, apresentando, também, pesquisas empíricas realizadas sobre sentimento dos investidores. O terceiro capítulo, Método da Pesquisa Empírica, detalha a construção do índice de sentimento e sua inclusão no modelo de apreçamento de ativos. Discute também os aspectos teóricos quanto à estimação econométrica dos modelos. O capítulo 4 apresenta os resultados obtidos na pesquisa e, por fim, o último expõe as conclusões, acompanhadas de recomendações para estudos futuros. Outras informações complementares, mas que não são essenciais ao texto da tese, podem ser encontradas nos apêndices. 


\section{Capítulo 2}

\section{Fundamentação Teórica}

The only way to have real success in science, the field I'm familiar with, is to describe the evidence very carefully without regard to the way you feel it should be. If you have a theory, you must try to explain what's good and what's bad about it equally. In science, you learn a kind of standard integrity and honesty.

Richard Feynman

\subsection{Das Finanças Clássicas às Finanças Comportamen- tais}

Nas finanças clássicas, os preços dos ativos refletem as expectativas futuras de resultados da empresa. Neste caso, não há espaço para o sentimento do investidor, pois mudanças de preço seriam consequência apenas de novas informações sobre os fluxos de caixa futuros e/ou taxas de juros, sendo totalmente aleatórias e não-previsíveis. A justificativa principal para ignorar a existência de sentimento está fundamentada nas premissas que esta vertente assume, ao defender o natural desaparecimento de investidores com comportamentos sub-ótimos no mercado financeiro. As características que garantem um mercado sem oportunidades prolongadas de arbitragem (compra de um ativo simultânea à venda de outro, por meio de uma operação com ganhos e isenta de riscos) estão relacionadas à racionalidade e homogeneidade das expectativas dos investidores e mercados informacionalmente eficientes. 


\subsubsection{Racionalidade e Homogeneidade das Expectativas dos In- vestidores}

As teorias clássicas de finanças, em sua quase totalidade, foram construídas a partir de uma abordagem tradicional cujo paradigma central é a racionalidade dos indivíduos. Mais especificamente, assume-se que os agentes que atuam nos mercados financeiros são capazes de atualizar corretamente suas crenças após receberem novas informações e que suas decisões são consistentes com o conceito de utilidade esperada subjetiva proposta por von Neumann e Morgenstern (1944) e por Savage (1954). Em outras palavras, isto seria refletido em decisões baseadas em projeções não-enviesadas sobre eventos futuros, buscando atender da melhor maneira possível aos seus próprios interesses.

Sob esta perspectiva, os gestores poderiam supor que os mercados de capitais são eficientes e que os preços refletem toda a informação disponível acerca dos fundamentos de valor da empresa. Analogamente, investidores poderiam assumir que os gestores agem no seu melhor interesse, reagindo racionalmente a incentivos traçados por contratos de remuneração, limitados por mecanismos de governança ou de controle. Investidores são considerados racionais quando suas decisões de investimento objetivam a maximização da utilidade esperada, calculada com o uso de probabilidades subjetivas. A racionalidade está presente no fato de as pessoas conseguirem calcular precisamente estas probabilidades de maneira não-enviesada.

Ross (2002) afirma que os dois pilares das finanças clássicas são: (i) os mercados eficientes conforme formalizado por Fama (1970) e a teoria de apreçamento de ativos e (ii) a nãoarbitragem, que dificultaria a obtenção de retornos anormais em mercados financeiros, uma vez que os preços refletiriam toda a informação que os agentes de mercado possuem. Os investidores qualificados, na visão tradicional de finanças, são formadores de preços, possuem crenças corretas, têm aversão ao risco constante e são maximizadores de riqueza. Shefrin (2005) afirma que há investidores chamados qualificados no mercado financeiro que, na abordagem comportamental, ainda formam preços dos ativos no mercado, porém na maioria dos casos, não tomam decisões totalmente livres de erros.

\subsubsection{Mercados Eficientes}

Conforme Perobelli, Perobelli e Arbex (2000), o preço de uma ação representa o equilíbrio entre as forças de oferta e demanda no mercado acionário. Desta forma, os preços são indicadores das expectativas futuras dos agentes com relação à lucratividade e desempenho das empresas, considerando que os agentes se valem das informações disponíveis para 
a formação desses preços. A Hipótese de Mercados Eficientes (HME) pressupõe que mudanças nos preços devem ser originadas por processos aleatórios, uma vez que existe o uso eficiente de um conjunto de informações na previsão do comportamento futuro dos preços de uma determinada ação. De acordo com Fama (1970), um mercado em que os preços dos ativos sempre refletem completamente toda a informação disponível é definido como eficiente.

Assim, a HME pressupõe que não deve existir nenhum padrão sistemático de comportamento para as mudanças dos preços. Se houvesse algum padrão recorrente de qualquer tipo, investidores poderiam reconhecê-lo e usá-lo para prever o comportamento futuro deles. Caso isso fosse possível, haveria a possibilidade, para aqueles que identificassem esses padrões, de conseguirem retornos anormais. No entanto, de acordo com a HME, a simples tentativa de usar tais padrões sistemáticos faria com que eles fossem eliminados.

Na visão de muitos financistas, mesmo que parte dos agentes dos mercados financeiros atue de forma irracional, a HME prevalecerá. Seu argumento baseia-se essencialmente em duas assertivas: (i) se houver um desvio dos preços dos ativos em relação a seus valores corretos, cria-se uma oportunidade atrativa de lucros; (ii) agentes racionais aproveitarão rapidamente esta oportunidade, conduzindo os preços de volta aos seus valores de equilíbrio, situação na qual o preço e o valor fundamental do ativo são iguais. A este mecanismo de correção de distorções no mercado dá-se o nome de arbitragem.

Rubinstein (2001) sugere três categorias de racionalidade dos mercados:

(a) mercados maximamente racionais, em que todos os agentes são racionais, e como consequência, as transações no mercado seriam menos frequentes;

(b) mercados racionais, em que os preços são definidos como se os investidores fossem todos racionais. Para isso, nem todos os seus agentes necessitam ser racionais, desde que estes consigam operar de maneira a definir racionalmente o preço dos ativos; e

(c) mercados minimamente racionais, em que se aceita a hipótese de que os mercados não são racionais mas, ainda assim, não há oportunidades de retornos anormais para os investidores racionais.

Desta forma, Rubinstein (2001) argumenta, assim como Alchian (1950), que os investidores "quase-racionais" ${ }^{4}$ se autodestroem ao transacionarem excessivamente, incorrendo em elevados custos de transação. Assim, automaticamente, permanecerão no mercado apenas

\footnotetext{
${ }^{4}$ Sil e Doherty (2000, p. 44) definem a expressão como um meio-termo entre considerar a cognição humana totalmente analítica, como faz a economia neoclássica, e totalmente intuitiva, desprovida de raciocínio.
} 
os investidores racionais. Thaler (2000), por outro lado, argumenta que os investidores irracionais podem enriquecer, ao contrário do esperado caso a HME fosse verdadeira. Conforme Shefrin (2005), a inserção de aspectos comportamentais na pesquisa de finanças depende do levantamento das implicações das premissas comportamentais para os preços de equilíbrio. Se as oportunidades de arbitragem fossem perfeitamente possíveis, as discrepâncias de preços seriam eliminadas sem nenhum risco, tornando secundária a racionalidade como premissa para a existência de um mercado eficiente.

No entanto, Shleifer e Vishny (1997) rebateram este argumento, discutindo que há diferenças relevantes entre o mundo formalizado nas teorias financeiras e o mundo real. Segundo eles, a arbitragem como mecanismo livre de risco, que garantiria a eficiência do mercado sem a necessidade de capital, é irreal. Além disso, poucos investidores seriam especializados o suficiente para atuarem como arbitradores profissionais. Shleifer e Vishny (1997) defendem que a arbitragem no mercado de capitais não é perfeita e que, consequentemente, os preços podem estar supervalorizados ou subvalorizados. Gestores racionais eventualmente poderiam captar estes desvios de preços e tomar decisões que encorajassem ou respondessem aos preços incorretos, como a captação de recursos através da emissão de títulos.

Segundo a teoria tradicional, a formação dos preços segue sem saltos, sendo então um processo contínuo. Samuelson (1970) demonstrou que o modelo de Markowitz (1952) tem uma simplificação em que a condição de mudança contínua de preços é necessária, o que não é um fato constatado nos mercados. Mandelbrot e Hudson (2004) também comentam sobre a hipótese utilizada de que os preços seguem um movimento browniano, conforme proposto por Bachelier (1900).

Ao incorporar o movimento browniano, utilizado pela física na descrição do movimento aleatório de partículas em um meio fluido, para explicar a variação de preços de um ativo no mercado financeiro, assumem-se como verdades: (i) independência dos eventos, ou seja, o preço de hoje não depende de nenhuma informação passada; (ii) estacionariedade das variações de preços; e (iii) distribuição normal das taxas de retorno da ação.

Matematicamente, o preço $P_{t}$ de um determinado ativo na data $t$ é igual à expectativa de fluxos de caixa futuros, $P_{t+1}^{*}$, condicionada à toda informação $I$ disponível no período t. Conforme Fama (1965), a HME assume que o preço atual é a melhor previsão do fluxo de caixa futuro da ação, sendo que qualquer variação no seu preço deve ser consequência de nova informação sobre o seu valor fundamental $P_{t+1}^{*}$, dado que todas as informações anteriores já estariam contempladas em $P_{t}$. Isto pode ser escrito de maneira concisa como:

$$
P_{t}=\mathbb{E}_{t}\left[P_{t+1}^{*} \mid I_{t}\right]
$$


sendo $\mathbb{E}_{t}[$.$] o operador de esperança na data t$ e $P_{t+1}^{*}$ representa o preço justo do ativo, dado pelo valor em $t+1$ dos fluxos de caixa futuros descontados.

Desta forma, o preço futuro da ação é formado por um componente previsível e um componente imprevisível, e a melhor informação que se tem sobre o preço em $t+1$ é $P_{t}$ :

$$
P_{t+1}=P_{t}+v_{t+1}
$$

em que $v_{t}$ representa o erro da previsão e $\mathbb{E}\left[v_{t+1}\right]=0$, ou seja, o erro não deve ser correlacionado com nenhuma outra informação no período $t$ pois, se não, esta deveria já estar incorporada ao preço $P_{t}$.

Barberis, Shleifer e Vishny (1998) colocam que se, de fato, o processo de formação de preços fosse considerado um passeio aleatório, conforme a equação (2.2), não seria possível prever os retornos, uma vez que esta premissa assume que não há qualquer informação sobre a ação que já não esteja incorporada em seu preço atual. Desta forma, se os investidores vislumbram alguma previsibilidade, é porque acreditam que os preços seguem um modelo diferente do passeio aleatório, ao formarem suas expectativas. No modelo proposto por eles, dada uma informação sobre os lucros de uma empresa, o investidor atualiza as suas opiniões sobre o preço futuro usando o Teorema de Bayes. No entanto, fosse o processo de formação de preços de fato aleatório, como prediz a HME, a informação não teria nenhum valor preditivo sobre a variação futura.

Embora a constatação da existência de um processo de formação de preços sistematicamente falho seja apresentada em diversos trabalhos acadêmicos, sua causa é ainda uma questão bastante controversa, uma vez que a verificação empírica é bastante complexa, levando autores a defenderem o lado racional e atacar o lado comportamental e vice-versa ${ }^{5}$. Será dado um enfoque mais específico no lado comportamental, considerando-se o foco desta tese, mas também destacando-se as tentativas dos estudiosos da abordagem racional para explicar os fenômenos observados.

\subsubsection{Modelos Clássicos de Apreçamento}

Modelos com o objetivo de se obter preços para os ativos sempre remontam ao artigo de Bernoulli $(1954)^{6}$, cuja principal contribuição para esta linha de pesquisa foi relacionar o valor de um bem não ao seu preço, mas sim à sua utilidade. Com isto, ele partiu

\footnotetext{
${ }^{5}$ Para uma revisão das pesquisas feitas na área tradicional, consulte Fama (1998); leia Hirshleifer (2001) para uma apresentação dos estudos na área comportamental.

${ }^{6}$ Embora a versão original, em latim, seja datada de 1738 , foi publicada uma versão traduzida para o inglês em 1954 .
} 
do pressuposto de que aumentos na riqueza implicam aumentos na utilidade, que são inversamente relacionados à quantidade de bens que o indivíduo possui e que existe um trade-off entre as mudanças esperadas na riqueza e o risco associado a estas oportunidades. Esta abordagem foi utilizada no desenvolvimento da Teoria da Utilidade Esperada de von Neumann e Morgenstern (1944) e Savage (1954).

Knight (1921) distinguiu os conceitos de risco e de incerteza, sendo risco normalmente associado a situações em que é possível expressar a aleatoriedade em termos de probabilidades numéricas, sejam estas objetivas ou subjetivas às crenças individuais. A incerteza, por sua vez, está associada a situações em que não é possível conhecer ou mesmo associar os resultados a uma distribuição de probabilidades. Dentro deste contexto, Arrow e Debreu (1954) desenvolveram um modelo de equilíbrio que parte da premissa de mercados completos, ou seja, um sistema em que todos os agentes conseguem transacionar seus bens entre si, direta ou indiretamente. Desta forma, seria possível se proteger individualmente contra eventos futuros, o que incentivaria os investidores a assumirem mais riscos e tornar-se-ia fundamental o estudo de alocação de ativos.

O artigo de Markowitz (1952) revolucionou o estudo de finanças ao distinguir a variância dos preços de ativos individuais e suas contribuições no risco de carteiras, demonstrando a importância de se evitar a alocação em ativos com alta covariância entre si. Seu trabalho foi complementado pelo Teorema da Separação de Tobin (1958), que identificou a carteira eficiente do investidor individual, considerando que haverá uma alocação em um ativo líquido, livre de risco, e uma carteira com ativos de risco, dependendo de seu nível de aversão ao risco.

Treynor (1961), em um manuscrito não publicado na época ${ }^{7}$, elaborou um modelo em que o risco é incorporado ao valor de mercado do ativo. Sharpe (1964) demonstrou que, por meio da diversificação dos investimentos, uma parte do risco do ativo (risco próprio) era passível de eliminação, restando um componente que não seria eliminado mesmo por meio de uma alocação eficiente dos ativos. O resultado final, o $C A P M$, com as contribuições de Lintner (1965) e Mossin (1966), é o modelo mais utilizado para determinar a taxa de retorno esperada de qualquer ativo financeiro.

A partir de então, algumas variações foram criadas, com o objetivo de relaxar algumas das rígidas premissas do modelo, sem grandes alterações no mesmo. Conforme Sharpe, Gordon e Bailey (1995, p. 162), as premissas são:

1. os investidores avaliam suas carteiras usando como parâmetros de decisão os retornos

\footnotetext{
${ }^{7}$ Embora o artigo seja amplamente citado como Treynor (1961), conforme nota de rodapé em Dimson e Mussavian (1999), o próprio autor comenta que é provável que o ano de conclusão do trabalho tenha sido em 1962.
} 
esperados e os desvios-padrão de seus ativos em um horizonte de um período;

2. os investidores são insatisfeitos e, portanto, escolhem sempre as carteiras de maior retorno esperado quando as demais características são semelhantes;

3. os investidores são avessos ao risco e, portanto, escolhem sempre as carteiras de menor desvio-padrão quando as demais características são semelhantes;

4. os ativos individuais são infinitamente divisíveis, significando que um investidor pode comprar uma fração de um ativo caso queira;

5. existe uma taxa livre de risco na qual os investidores podem tanto aplicar recursos quanto tomar empréstimos;

6. impostos e custos de transação são irrelevantes;

7. todos os investidores têm o mesmo horizonte de avaliação de investimentos;

8. a taxa livre de risco é a mesma para todos os investidores;

9. não há custos para a obtenção de informações e elas estão, instantaneamente, disponíveis para todos; e

10. os investidores têm expectativas homogêneas, o que significa que têm as mesmas percepções em relação aos retornos esperados, desvios-padrão e covariâncias dos ativos.

Uma outra versão do $C A P M$ foi desenvolvida por Black (1972), na qual é eliminada a necessidade da premissa que requer que os investidores possam aplicar ou tomar emprestado à taxa livre de risco. Esta versão do modelo foi chamada de zero-beta. Outra versão, proposta por Mayers (1972), demonstra que mesmo quando a carteira de mercado inclui ativos não-transacionados, o modelo permanece o mesmo. A validade teórica do modelo, segundo Williams (1977), mantém-se mesmo quando a premissa de homogeneidade de expectativas de retornos é relaxada.

O CAPM intertemporal (ICAPM) de Merton (1973) foi desenvolvido para suprir a restrição de que o tempo deveria ser discreto, considerando o tempo uma variável contínua. Esta foi uma grande contribuição para os modelos de finanças, que até então eram todos estáticos, permitindo uma abordagem mais realista a um fenômeno dinâmico por natureza. Um resultado importante deste estudo foi a constatação por Merton (1973) de que o modelo tradicional do $C A P M$ explicava os retornos esperados dos ativos em condições muito específicas apenas, e que a situação macroeconômica também influencia o investidor, não dependendo somente de sua riqueza. Mais tarde, Breeden (1979) incorporou a 
diferença entre a riqueza e o consumo, e desenvolveu um novo modelo que ficou conhecido como o Consumption $C A P M(C C A P M)$, no qual os betas são medidos em relação ao fluxo do consumo agregado, e não da riqueza agregada do mercado.

Ross (1976) desenvolveu um modelo de fatores chamado de Arbitrage Pricing Theory $(A P T)$, acrescentando outros componentes ao modelo de Sharpe, que só contava com o prêmio de risco de mercado como único fator de risco sistêmico. O APT, por ser um modelo multifatores, gerou uma série de pesquisas sobre quais e quantos fatores deveria haver e as justificativas para a inclusão ou não destes no modelo. Um dos primeiros estudos desta linha foi Roll e Ross (1980), que utilizaram análise fatorial para determinar quatro fatores estatisticamente significantes para o mercado norte-americano. Como estes foram determinados através de técnica estatística multivariada, o resultado do estudo foi que os fatores por eles encontrados têm um elevado grau de explicação dos retornos, porém com a desvantagem de não possuírem um maior significado econômico que justifiquem a sua presença.

Nesta linha de pesquisa, outros trabalhos tentaram encontrar evidências de que determinados fatores de risco explicam os retornos dos ativos. Pesquisadores iniciaram a constatação de anomalias do $C A P M$, tentando comprovar a influência de outras variáveis além do $\beta$, como tamanho da empresa (BANZ, 1981), índice de preço-lucro (BASU, 1977) e índice book-to-market (FAMA; FRENCH, 1992).

Apesar de diversas evidências empíricas atestarem desvios com relação a este padrão estritamente racional de comportamento dos agentes, a teoria tradicional possui a significativa vantagem da simplicidade e facilidade de modelagem do ponto de vista do pesquisador. Não obstante, a validade deste conjunto teórico para descrever o comportamento dos mercados é, como sempre, uma hipótese a ser testada. Se as teorias baseadas no agente racional apresentadas até então fossem capazes de explicar satisfatoriamente os mais importantes fenômenos investigados pela literatura de finanças, não haveria razão para se questionar seus fundamentos e propor abordagens alternativas. Dentro deste contexto, houve o crescimento das pesquisas que tentam atestar a influência de variáveis comportamentais relacionadas a modelos tradicionais de finanças, dando origem às finanças comportamentais.

\subsubsection{Finanças Comportamentais}

Na definição de Camerer (2003), a linha de pesquisa comportamental em economia e finanças emergiu da inevitável necessidade de relaxar a premissa de racionalidade perfeita. A tentativa de se incorporar a existência de mercados imperfeitos ou mesmo o custo da 
informação vem sendo um grande e lento desafio, mas que vem demonstrando sua validade por meio de pesquisas empíricas.

Para Diamond e Vartiainen (2007, p. 1), o conceito de finanças e economia comportamentais é um grande guarda-chuva de abordagens que pretendem estender a teoria para incorporar atributos relevantes do comportamento humano normalmente ignorados na teoria tradicional. Foram os trabalhos de dois psicólogos israelenses, Daniel Kahneman e Amos Tversky, sobre como as pessoas escolhem em condições de incerteza que levaram ao desenvolvimento da linha de pesquisa chamada de finanças comportamentais, a partir de meados da década de 1960. Os padrões de comportamento humano por eles discutidos sempre estiveram presentes nos seres humanos, mas nunca antes haviam sido captados da forma que os dois psicólogos apresentaram.

Shleifer e Summers (1990) foram os primeiros a definir os limites à arbitragem e a psicologia como os dois pilares fundamentais sobre os quais se constrói a abordagem de finanças comportamentais. Os limites à arbitragem estão relacionados com a dificuldade que os investidores racionais podem enfrentar para desfazerem distorções provocadas por investidores menos racionais (SHLEIFER; VISHNY, 1997) e, segundo Lee, Shleifer e Thaler (1991, p. 81), estas restrições levam os investidores a encurtarem o horizonte de análise do investimento e se preocuparem com o preço de revenda da ação, e não apenas com o valor presente do seu fluxo de dividendos. A psicologia, por sua vez, descreve com mais detalhe os possíveis desvios da racionalidade pura que podem responder por estas distorções. Para Thaler e Barberis (2003), desvios em relação ao comportamento racional são intrínsecos à natureza humana e devem ser incorporados à análise econômica como uma extensão natural dos modelos tradicionais, uma vez que as evidências sugerem tanto que os agentes são capazes de cometer certa variedade de erros sistemáticos, como também que as distorções deles advindas têm importantes implicações econômicas. Uma boa descrição sobre os vieses cognitivos e como eles afetam a percepção das pessoas na hora de avaliar decisões pode ser encontrada em Bazerman (2006) e resumidamente em Yoshinaga et al. (2008).

Statman (1999) considera a teoria clássica de finanças um tanto pretensiosa, ao querer responder todas as perguntas de finanças com um mínimo de ferramentas. Contrariando Miller (1986), que defende a racionalidade no equilíbrio de mercado, nas finanças em geral e nos dividendos, Statman (1999) acredita que as evidências de diversas anomalias indicam a necessidade de uma reconstrução da teoria financeira. Segundo ele, muitos acreditam que as finanças comportamentais incorporaram a psicologia às finanças quando, na verdade, a psicologia nunca esteve desagregada. Shefrin (2001) afirma que as finanças tradicionais baseiam-se em três conceitos para a prática da gestão baseada em valor: (i) comportamento racional, (ii) modelo de formação dos preços dos ativos $(C A P M)$, 
conforme proposto por Sharpe (1964), Lintner (1965) e Mossin (1966) e (iii) mercados eficientes.

Assim, os defensores das finanças comportamentais argumentam que forças psicológicas interferem nos três componentes do paradigma tradicional. A sustentação do discurso está na constatação de que os indivíduos nem sempre agem de maneira racional, que os prêmios de risco de mercado não são totalmente determinados pelo risco sistêmico $\beta$ e que os preços de mercado nem sempre estão plenamente alinhados com os fundamentos da empresa (SHEFRIN, 2005). Seguindo esta ideia, Fuller (1998) define finanças comportamentais como a integração entre a economia e finanças clássicas com a psicologia e as ciências de teoria da decisão.

Existem dois entraves comportamentais no processo de maximização do valor, sendo um interno e outro externo à companhia. O primeiro deles é chamado por Shefrin (2001) de custos comportamentais. Estes tendem a comprometer a criação de valor, pois são perdas no valor associadas aos erros que gestores (administração interna) cometem devido a imperfeições cognitivas e influências emocionais. Já os obstáculos externos vêm de erros comportamentais de analistas e de investidores (agentes do mercado), gerando um espaço entre os valores fundamentais e os preços de mercado. Para Shefrin (2001), gestores normalmente não conseguem incorporar este fator de erro externo nas suas tomadas de decisão. Há, no entanto, a linha de estudos de market timing, que analisam a tentativa dos gestores em prever o desempenho do mercado, seja para ações individuais ou mesmo para o mercado como um todo (MERTON, 1981, p. 363-364).

Da mesma forma que Shefrin (2001), Baker, Ruback e Wurgler (2006) argumentam que há duas abordagens distintas para a pesquisa na área de finanças comportamentais: (i) uma que foca principalmente na racionalidade não-completa dos investidores, chamada de racionalidade limitada por Simon (1955), que assume que as decisões financeiras de investimento e financiamento são reações racionais a erros de apreçamento no mercado e (ii) racionalidade não-absoluta dos gestores, que estão sujeitos a vieses julgamentais nas decisões corporativas.

É a partir da constatação desta lacuna na teoria clássica de finanças que vêm se desenvolvendo as finanças comportamentais, que tentam incorporar nos modelos tradicionais algumas diferenças de comportamento dos indivíduos acerca de situações diferentes, seja em relação aos resultados ou mesmo quanto à forma com que a decisão é apresentada. Um ponto levantado por Bernstein (2007) é o quanto a teoria clássica ainda permanece válida e reinante após os ataques das finanças comportamentais. A principal contribuição por trás do trabalho de Markowitz (1952) foi demonstrar que a administração de recursos é um negócio arriscado, e as finanças comportamentais aprofundaram a compreensão de 
como os investidores decidem e como interagem entre si em situações de incerteza. Isso não quer dizer que a validade de toda a teoria tradicional tenha sido jogada por terra, mas sim que a teoria deve evoluir e tentar incorporar variáveis, até então desconsideradas, que se mostrarem relevantes nas pesquisas.

Uma crítica comumente feita às finanças comportamentais reside justamente no fato de que, ainda que existam investidores não-racionais no mercado, a eficiência do mercado estaria garantida, devido à presença de arbitradores. Tanto num mercado racional quanto num mercado eficiente, se existirem diferenças entre o preço de uma ação e o seu valor fundamental, serão desvios aleatórios rapidamente corrigidos.

Neste sentido, Rubinstein (2001) afirma que a condição de racionalidade total não precisa ser necessariamente cumprida para que se garanta o bom funcionamento do mercado. Ele afirma que mesmo que não se possa garantir o apreçamento correto ${ }^{8}$ dos ativos, as oportunidades de serem obtidos ganhos anormais ainda não existiriam, pois seriam rapidamente eliminadas pelos arbitradores, concordando com Fama (1991) e Ross (2002). Mullainathan e Thaler (2000) afirmam que evidências das duas últimas décadas demonstram que a ideia destes economistas era, ironicamente, otimista em excesso.

A proposta dos estudiosos da área de finanças comportamentais é justamente incorporar outros fatores que exprimam parte do comportamento dos investidores na teoria clássica de finanças. Mandelbrot e Hudson (2004) argumentam que algumas premissas assumidas pela teoria financeira ortodoxa podem ser consideradas absurdas, se analisadas isoladamente. Uma das premissas contestadas é a de que os investidores têm expectativas homogêneas, têm os mesmos objetivos de investimento e desejam investir pelo mesmo prazo. Seria supor que, dadas as mesmas informações acerca de uma empresa ao mesmo tempo para as pessoas, o que já seria uma situação improvável, todas decidiriam da mesma forma. Nesta linha, consequentemente, uma vez que todos têm os mesmos objetivos, todos querem maximizar a própria riqueza. Sob esta premissa, não haveria explicação para a existência de filantropos, pois ninguém abdicaria de sua riqueza sem esperar algum retorno monetário.

Como contraposição, conforme Bernstein (2007), os fundamentos das finanças comportamentais estão relacionados à teoria do prospecto, em que as probabilidades são substituídas por pesos subjetivos e os valores são atribuídos aos ganhos e às perdas em vez de serem relacionados aos resultados finais.

Complementando este conceito, Baker e Wurgler (2006) afirmam que as finanças clássicas não preveem espaço para o sentimento dos investidores. Ou, quando a existência de

\footnotetext{
${ }^{8}$ No sentido de que os preços são definidos como se todos os investidores agissem racionalmente.
} 
investidores quase-racionais ainda é aceita pelos estudos tradicionais, argumenta-se que a atuação dos indivíduos racionais, que buscam a diversificação de sua carteira de investimentos com o uso de todo o conhecimento estatístico disponível, é suficiente para eliminar as intervenções não-racionais, não causando nenhum impacto nos preços.

Considerando a premissa de homogeneidade dos investidores, não deveriam existir diferentes perfis no mercado, por exemplo, investidores de longo prazo e day traders; ou investidores em ações do tipo value, que buscam a valorização de ações de empresas que apresentaram baixa performance no passado, e growth, que apresentaram uma boa performance no passado e que, portanto, geram uma expectativa de boa performance no futuro. Considerar todos os investidores homogêneos facilita bastante a formulação matemática dos modelos. Quando se aumenta a quantidade de tipos de investidores, mesmo que sejam apenas dois, a teoria deve encontrar uma formalização que justifique ambos os comportamentos e explicar a escolha do investidor.

Um exemplo ilustrativo de expectativas distintas de investidores é o apresentado por Keynes (1936) que, para explicar as flutuações de preços das ações, utiliza a analogia do mercado de ações com um concurso hipotético de beleza promovido por um jornal. Nesta comparação, os leitores são convidados a eleger os rostos mais bonitos entre todas as competidoras do concurso, e aqueles que escolherem a moça mais votada concorrem a um prêmio.

Uma estratégia ingênua por parte dos leitores seria escolher a garota que lhes parecesse particularmente a mais bonita; no entanto, um participante mais sofisticado, que tentasse maximizar a sua chance de ganhar o prêmio, tentaria adivinhar a opinião da maioria quanto à beleza das moças e faria a sua votação baseando-se na sua intuição quanto à percepção pública. Desta forma, pode-se estender a análise para uma situação na qual todos tentam aumentar suas probabilidades de ganho do prêmio sempre decidindo com base na percepção da maioria. Como colocado pelo autor, a questão não é escolher o rosto que, na opinião pessoal do leitor, é o mais belo do concurso. O que se tenta fazer é antecipar a expectativa de opinião da grande maioria.

Não é o caso de escolher quais, na opinião individual [de cada leitor], são realmente as mais bonitas, nem mesmo quais [garotas] a média das opiniões genuinamente acredita serem as mais bonitas. Chegamos ao terceiro estágio em que dedicamos nossas inteligências em antecipar o que a média das opiniões espera que a média das opiniões seja. ${ }^{9}$ (KEYNES, 1936)

\footnotetext{
${ }^{9}$ It is not a case of choosing those which, to the best of one's judgment, are really the prettiest, nor even those which average opinion genuinely thinks the prettiest. We have reached the third degree where we devote our intelligences to anticipating what average opinion expects the average opinion to be.
} 
Aplicando-se este conceito para o mercado financeiro, investidores estabelecem preços para as ações baseando-se não no que eles acreditam ser o valor fundamental do papel, mas sim no que eles acreditam ser a opinião futura da maioria das pessoas. Torna-se mais relevante tentar prever a opinião do mercado que encontrar o preço justo dos ativos.

Um modelo bastante utilizado como explicação alternativa à HME é o dos investidores irracionais (noise traders). Black (1986) define investidor irracional como aquele que usa o ruído ${ }^{10}$ como informação relevante.

Assumindo-se a presença destes investidores no mercado, na visão de De Long et al. (1990), justifica-se a permanência de preços incorretos uma vez que os especuladores racionais são avessos ao risco e têm prazos limitados de atuação, não desejando se expor a riscos não-diversificáveis. Segundo Mullainathan e Thaler (2000), na presença de investidores irracionais, os arbitradores normalmente se beneficiam mais ao operar na direção que leva os preços a um desvio maior que no sentido de tentar corrigir os preços. Estaria justificada a existência de eventos improváveis conforme a teoria clássica, como as bolhas especulativas. Em um mundo racional, os preços das ações não atingiriam valores não justificados pelos fundamentos das empresas.

Além das bolhas, Shleifer (2000, p. 10) cita outro exemplo comumente observado no mercado financeiro que não é explicável pela teoria tradicional: investidores seguirem estratégias que afirmam prever o desempenho futuro das ações. Tal feito não seria possível em um cenário em que as alterações nos preços das ações são aleatórias e completamente imprevisíveis. Outra constatação é a negociação intensiva de papéis no mercado, uma vez que expectativas homogêneas não causariam tantas divergências de opiniões quanto ao preço, e não haveria tantas operações de compra e venda. Da mesma forma, se houvesse aleatoriedade nos choques de preços, investidores não adotariam estratégias de reversão ou manutenção dos preços. Armstrong (1980) exemplifica, inclusive, com a situação em que as pessoas estão dispostas a pagar recursos para videntes, mesmo que seu poder de previsão seja notadamente ruim.

Na teoria de finanças, tem-se uma série de argumentos que defendem a visão clássica, de mercados eficientes, assim como uma série de evidências a favor da inclusão de aspectos comportamentais na análise de preços no mercado. O Quadro 2.1 apresenta, de maneira sintética, as colocações tanto contra a abordagem racional como contra a comportamental:

\footnotetext{
${ }^{10}$ Diversas são as definições dadas por Black (1986) para este termo, mas, de maneira geral, todas se encaixam na primeira que ele apresenta: ruído é aquilo que torna as observações imperfeitas.
} 
Quadro 2.1 - Objeções comuns às abordagens psicológica e racional para o apreçamento de ativos

\begin{tabular}{|l|l|}
\hline Objeções à Abordagem Psicológica & Objeções à Abordagem Racional \\
\hline Vieses psicológicos são arbitrários & $\begin{array}{l}\text { Racionalidade na teoria financeira requer } \\
\text { habilidades de cálculo "impossíveis" }\end{array}$ \\
\hline $\begin{array}{l}\text { Experimentos que verificam a existência } \\
\text { dos vieses cognitivos não são significativos }\end{array}$ & $\begin{array}{l}\text { Evidências observadas não reforçam a pre- } \\
\text { missa de comportamento racional }\end{array}$ \\
\hline $\begin{array}{l}\text { É fácil "pescar" vieses cognitivos em dados } \\
\text { ex-post }\end{array}$ & $\begin{array}{l}\text { É fácil selecionar estruturas e imperfeições } \\
\text { de mercado em dados ex-post }\end{array}$ \\
\hline $\begin{array}{l}\text { Investidores racionais eliminam o mau } \\
\text { apreçamento por meio de operações de ar- } \\
\text { bitragem }\end{array}$ & $\begin{array}{l}\text { Investidores irracionais impossibilitam o } \\
\text { apreçamento eficiente }\end{array}$ \\
\hline $\begin{array}{l}\text { Investidores racionais decidem melhor e fi- } \\
\text { cam mais ricos }\end{array}$ & $\begin{array}{l}\text { Investidores irracionais assumem mais ris- } \\
\text { cos e ficam mais ricos }\end{array}$ \\
\hline $\begin{array}{l}\text { Investidores confusos aprendem à sua ma- } \\
\text { neira como tomar boas decisões }\end{array}$ & $\begin{array}{l}\text { Investidores precisos aprenderão como to- } \\
\text { mar más decisões }\end{array}$ \\
\hline $\begin{array}{l}\text { Previsibilidade aparente de retornos é es- } \\
\text { púria, então modelos psicológicos de pre- } \\
\text { visão são infundados }\end{array}$ & $\begin{array}{l}\text { Previsibilidade aparente de retornos é es- } \\
\text { púria, então modelos racionais de previsão } \\
\text { são infundados }\end{array}$ \\
\hline
\end{tabular}

Fonte: Traduzido de Hirshleifer (2001)

\subsubsection{Modelos Comportamentais de Apreçamento}

Determinar quais fatores explicam os retornos dos ativos individuais é um dos objetivos principais da pesquisa em finanças. A teoria de apreçamento de ativos tenta identificar quais fatores são relevantes no momento de se estimar os retornos esperados, sendo de vital importância para o entendimento de como funcionam os mercados de capitais. Ross (2002) define anomalia todos os problemas empíricos na modelagem de formação de preços, que utiliza como hipótese nula a validade do modelo clássico de apreçamento e suas premissas acessórias.

Alguns dos estudos (DE BONDT; THALER, 1985, 1987; JEGADEESH; TITMAN, 1993; ELTON; GRUBER; BUSSE, 1998) relevantes na área de finanças comportamentais mostram que em uma economia na qual agentes racionais e irracionais interagem entre si, a irracionalidade pode influenciar significativamente os preços dos ativos. Não obstante, para que possam produzir predições mais detalhadas, os modelos comportamentais precisam especificar a forma da irracionalidade dos agentes, ou seja, de que maneira seu comportamento 
diverge da teoria normativa tradicional. A psicologia desempenha um papel fundamental, ao fornecer o embasamento teórico que explica os vieses cognitivos que influenciam as preferências, o comportamento e as decisões das pessoas ${ }^{11}$.

Pesquisas recentes na área das finanças comportamentais (BARBERIS; SHLEIFER; VISHNY, 1998; NEAL; WHEATLEY, 1998; BROWN; CLIFF, 2005; BAKER; WURGLER, 2006) sugerem que o sentimento dos investidores leva a padrões sistemáticos de falhas no apreçamento dos ativos. Como estas dificilmente são identificadas, estudos empíricos buscam a validação de fatores de correção nos modelos já desenvolvidos e amplamente utilizados. Barberis, Shleifer e Vishny (1998) propõem uma alternativa, baseada em ideias da psicologia, considerando que investidores cometem erros ao processar novas informações. Caso as reações dos investidores sejam falhas e sistemáticas, ao refazerem suas projeções de preços dos ativos, há a possibilidade de obtenção de ganhos. Apesar de não estar definido de maneira consensual na literatura de finanças, sentimento refere-se aos desvios em relação ao valor fundamental: a sobrerreação (overreaction) e a subreação (underreaction), que são apresentadas a seguir.

De Bondt e Thaler (1985) evidenciaram o fenômeno de os investidores reagirem exageradamente a notícias, desviando os preços para além da faixa que seria explicada por parâmetros essencialmente racionais. $\mathrm{O}$ viés psicológico que pode explicar esta reação é a heurística da representatividade, pesquisada por Tversky e Kahneman (1974), e utilizada como forma de simplificar a análise dos problemas. Conforme definido por Shefrin e Belotti (2007), a representatividade é uma heurística que se refere ao julgamento baseado em estereótipos. Por exemplo, avaliar positivamente uma ação por acreditarem que empresas que apresentem um determinado atributo (por exemplo, práticas de responsabilidade social, governança corporativa) sempre são empresas rentáveis.

Assim, imagina-se que, dada uma notícia positiva sobre uma empresa, os investidores tendem a ficar excessivamente otimistas, levando os preços a patamares acima do seu valor fundamental. Num momento seguinte, ao perceberem o otimismo exacerbado, os preços cairiam para corrigir o desvio. Analogamente, dada uma notícia ruim, um pessimismo exagerado pode levar a uma brusca queda, seguida por um aumento nos preços para corrigir o excesso de desvalorização além do valor fundamental.

Pode-se formalizar a sobrerreação por meio da seguinte equação:

$$
\mathbb{E}\left[R_{t+1} \mid z_{t}=B\right]<\mathbb{E}\left[R_{t+1} \mid z_{t}=R\right]
$$

tal que $R_{t+1}$ é a taxa de retorno da ação em $t+1$ e $z_{t}$ é uma notícia sobre a empresa, que pode ser boa (B) ou ruim (R). A equação demonstra que a sobrerreação prediz taxas de

\footnotetext{
${ }^{11}$ Para maiores detalhes nesta área da ciência comportamental, ver Stanovich e West (2000).
} 
retorno esperadas superiores para as ações que apresentarem uma notícia anterior ruim em relação à situação em que são precedidas por uma notícia boa. Caso a sobrerreação ocorra, a estratégia é comprar ações com desempenho ruim, pois estas sofrerão correção e subirão, e seguindo a mesma lógica, vender as ações que subiram.

A hipótese testada por De Bondt e Thaler (1985) foi a de que a sobrerreação seria verdadeira se fosse comprovada estatisticamente que, em qualquer momento, a diferença no desempenho das carteiras perdedoras e das carteiras vencedoras é significante. Para tanto, foi aplicado um teste $t$ para duas amostras com número igual de observações. Resultados validaram a hipótese formalizada na equação (2.3), pois encontraram que o retorno em $t+1$ das ações com baixa performance (cuja notícia divulgada em $t$ tenha sido tinha sido ruim) foi superior ao retorno em $t+1$ das ações com alta performance (cuja notícia em $t$ tenha sido boa).

Uma outra vertente de estudos analisa o evento de subreação, que ocorre quando há uma demora na incorporação das informações por parte dos investidores, levando a uma mudança de preços mais lenta. Em termos práticos, acredita-se que o que ocorre é exatamente o contrário da sobrerreação, sendo que as ações em alta tendem a permanecer em alta e as em baixa, tendem a continuar em queda. O argumento é embasado no viés de conservadorismo, que consiste em supor que as pessoas, uma vez que formam as suas impressões, demoram a mudar de opinião diante de novas evidências. Nesta situação, investidores permanecem céticos a novas informações e atualizam as suas opiniões gradualmente.

A subreação pode ser representada pela seguinte equação:

$$
\mathbb{E}\left[R_{t+1} \mid z_{t}=B\right]>\mathbb{E}\left[R_{t+1} \mid z_{t}=R\right]
$$

tal que $R_{t+1}$ é o retorno da ação em $t+1$ e $z_{t}$ é uma notícia sobre a empresa, que pode ser boa (B) ou ruim (R). A equação demonstra que a subreação prediz retornos esperados superiores para as ações que apresentarem uma notícia anterior boa que para as ações precedidas por uma notícia ruim. Ao contrário da sobrerreação, a subreação defende a compra das ações com desempenho recente bom e venda das ações com performance ruim.

Estudos acadêmicos e evidências empíricas (DE BONDT; THALER, 1985, 1987; JEGADEESH, 1990; JEGADEESH; TITMAN, 1993; CAMPBELL, 2000; HIRSHLEIFER, 2001) demonstram a ocorrência regular de ambos os efeitos nos preços dos ativos. Há um desafio para os acadêmicos e defensores da linha das Finanças Comportamentais em fornecer um modelo que explique a formação de crenças dos investidores e que seja compatível com a ocorrência desses eventos.

Hirshleifer (2001) afirma que a tarefa central dos modelos de formação de preços é exami- 
nar as relações entre os retornos esperados e o risco, mas incorporando o fato de que existem erros de avaliação por parte dos investidores (BARBERIS; SHLEIFER; VISHNY, 1998; DANIEL; HIRSHLEIFER; SUBRAHMANYAM, 1998; HONG; STEIN, 1999; GERBER; HENS; VOGT, 2002).

\subsection{Sentimento dos Investidores}

Inicialmente, será definido o conceito de sentimento do investidor apresentado na literatura disponível, para depois discutir-se como ele pode ser modelado e posteriormente mensurado para que seja então incorporado em modelos de formação de preços. Baker e Wurgler (2007) explicam que uma mudança no sentimento do investidor pode desencadear uma sequência de eventos, que vai desde o estabelecimento de novos padrões na negociação dos ativos até a ação oportunista de executivos das empresas, ao tomarem decisões de financiamento em função de informações privilegiadas.

\subsubsection{Definição de Sentimento}

Conforme Zhang (2008), sentimento pode ser definido genericamente como todas as crenças errôneas que influenciam os investidores quanto ao preço dos ativos. Para Smidt (1968), é a influência do sentimento que leva à existência de bolhas especulativas. Já para Zweig (1973), está relacionado aos vieses cognitivos dos investidores. Lee, Shleifer e Thaler (1991) definem o sentimento dos investidores como o componente de suas expectativas sobre os retornos dos ativos que não são justificadas pelos seus fundamentos.

Para Shiller (1984), o comportamento dos investidores leva comumente a flutuações nos preços dos ativos, sem nenhum embasamento lógico que as justifique. Black (1986) chamou de "noise trader sentiment" as expectativas dos investidores sobre os retornos dos ativos que não estão lastreadas nos seus fundamentos. Seguindo esta lógica, Baker e Wurgler (2006) colocam que a principal responsável pelas oscilações de preços é a dificuldade de avaliação da empresa, uma vez que os investidores não possuem expectativas homogêneas como preconiza a HME. Desta forma, empresas sem um histórico de lucros com um aparente potencial de crescimento ilimitado, permitem que haja investidores que defendam, com argumentos igualmente plausíveis, avaliações que variem de um valor muito baixo a um valor elevado, conforme o seu sentimento. Em outro extremo, empresas estáveis, com amplo histórico de resultados e pagamentos constantes de dividendos, estão menos vulneráveis à especulação, dado que a faixa de preços apurados pelos investidores e analistas é bem menos ampla. 
De Long et al. (1990) afirmam que como as opiniões futuras dos investidores não são previsíveis, o que inibiria a arbitragem, os preços divergem significativamente do seu valor fundamental mesmo quando não há risco fundamental. Uma das conclusões encontradas pelos autores foi que a arbitragem não elimina os efeitos de ruído, pois o ruído em si cria risco, e este não é facilmente eliminado pela diversificação como o risco idiossincrático dos ativos pode ser reduzido com a alocação eficiente das ações em carteiras de investimentos.

Barberis, Shleifer e Vishny (1998) definem sentimento ao proporem um modelo da formação de crenças dos investidores, a partir da divulgação de novas notícias sobre as empresas. Resultados demonstraram que aspectos psicológicos como o conservadorismo e a representatividade afetam a maneira com que os preços são estabelecidos no mercado financeiro. Baker e Stein (2004) definem sentimento como um apreçamento errôneo de um ativo, o que demanda a definição do que seria o preço real do ativo. Considerando-se um mercado em que há dois grupos de investidores, um com expectativas racionais e outro com percepções enviesadas, pode-se definir sentimento como a diferença na avaliação entre estes dois grupos (LEE; SHLEIFER; THALER, 1991; BAKER; STEIN, 2004; BROWN; CLIFF, 2005).

Para Baker e Wurgler (2007), sentimento é uma crença sobre os fluxos de caixa futuros e sobre o risco da empresa que não é justificada pelos fatos disponíveis. A questão de como o sentimento dos investidores afeta os preços dos ativos no mercado ainda gera opiniões diversas. Duas são as possibilidades que explicam a existência destes desvios: ou os indivíduos usam corretamente informações erradas ou indivíduos usam incorretamente informações corretas. A primeira alternativa assume que os investidores ajustam as suas crenças sobre os fundamentos incorporando os ruídos, e a segunda assume que estes o fazem com uso limitado de ferramentas estatísticas.

Brown e Cliff (2005) apresentam dois argumentos que reforçam a ideia de que o sentimento é relevante e que deve ser cuidadosamente analisado: (i) sentimento é uma variável que tende a ser persistente no tempo, visto que o otimismo é reforçado e propagado à medida em que cada vez mais pessoas aderem à tendência; (ii) a arbitragem pode até ser capaz de eliminar estratégias lucrativas de curto prazo, mas não é capaz de corrigir desvios de preços no longo prazo.

A medição do sentimento pode ser feita por meio de uma variável latente, pois conforme Hair Jr. et al. (1998), "construto ou variável latente não pode ser diretamente medida, mas pode ser representada ou medida por uma ou mais variáveis". Desta forma, uma maneira proposta pelos pesquisadores para medir a expectativa dos investidores quanto às perspectivas de os preços subirem ou caírem no mercado seria consolidando em um índice de sentimento do mercado. Diversas são as justificativas para a associação de uma determinada variável ao construto de sentimento. Algumas destas medidas diretas e indiretas 
são discutidas nas seções 2.2.2 e 2.2.3 a seguir. Hardy (apud NEAL; WHEATLEY, 1998) argumenta que normalmente investidores individuais estão sujeitos a erros, de maneira que as transações no mercado fracionário fornecem uma boa previsão do sentimento do investidor quanto aos preços das ações. Neste mercado em que ações são transacionadas em quantidades menores que os lotes-padrão, o investidor típico é pessoa física, considerada não qualificada conforme nomenclatura da CVM, e estaria mais sujeito à influência do sentimento. Vale destacar que, em princípio, não haveria motivos para existir um mercado específico para negociações menores, uma vez que se supõe na teoria clássica que os ativos são perfeitamente divisíveis e negociáveis.

Serão apresentadas, a seguir, algumas medidas que são utilizadas como propostas para medir o conceito de sentimento, seja por meio de pesquisa direta ou variáveis secundárias.

\subsubsection{Pesquisas de Opinião}

Entre todas as medidas disponíveis, a opinião dos investidores deveria ser considerada a melhor delas, uma vez que esta seria uma medida explícita do sentimento. Entretanto, dados provenientes de pesquisas junto ao público são vistos com alguma reserva pela comunidade acadêmica, em função da potencial diferença entre o que é respondido em uma pesquisa e como de fato os respondentes se comportam na realidade. Uma dificuldade adicional é que o acesso a este tipo de recurso nem sempre é possível para os estudos realizados, além de se contar com outros obstáculos comuns a pesquisas, como amostra selecionada, quantidade de respondentes, critérios de formulação das perguntas, entre outros.

Uma das pesquisas de sentimento mais conhecidas é a chamada US Advisors'Sentiment, publicada semanalmente pela empresa Investors Intelligence desde 1963. A pesquisa Advisors' Sentiment reporta as opiniões sobre o mercado divulgadas em mais de 100 relatórios feitos por analistas de investimento independentes (que não possuem vínculo com corretoras ou fundos de investimento), levantando o percentual de expectativas de baixas, altas e manutenção de preços.

Um outro índice, chamado Bearish Sentiment Index $(B S I)^{12}$, mede a proporção de analistas de mercado que estão pessimistas quanto aos preços futuros em relação ao total de opiniões levantadas. O índice, que reflete o pessimismo dos analistas, é medido a cada

\footnotetext{
${ }^{12} \mathrm{~A}$ denominação de bull, que significa touro, ou bear, que significa urso, para descrever a tendência do mercado otimista e pessimista, respectivamente, está relacionada ao movimento que estes animais fazem ao partir para o ataque: o touro utiliza a sua cabeça, em um movimento de baixo para cima; enquanto o urso ataca com suas patas de cima para baixo.
} 
instante $t$ conforme a seguinte equação:

$$
B S I_{t}=\frac{B E A R S_{t}}{B E A R S_{t}+B U L L S_{t}}
$$

em que $B E A R S_{t}$ e $B U L L S_{t}$ são as proporções de opiniões pessimistas e otimistas dos analistas, respectivamente, no momento $t$.

Outras medidas também construídas a partir de opiniões dos participantes do mercado financeiro são os índices de confiança do consumidor. Estes são elaborados a partir de respostas sobre as expectativas futuras em termos de nível de gastos, podendo ser utilizados para antecipar possíveis impactos do consumo sobre a demanda agregada. Normalmente, estas séries podem ser preditoras dos níveis de atividade, demonstrando maior ou menor otimismo dos indivíduos sobre o desempenho da economia.

A Universidade de Yale, sob supervisão do Prof. Robert Shiller ${ }^{13}$, coleta periodicamente questionários sobre o comportamento dos investidores norte-americanos desde 1984. A partir desta pesquisa, quatro índices são calculados e divulgados: (i) Índice de Confiança para um Ano, que indica a expectativa de que o mercado subirá no próximo ano; (ii) Índice de Confiança de Reversão (buy-on-dips), que indica que os preços reverterão após um dia de queda; (iii) Índice de Confiança de Quebra (crash), que apura a crença de que não haverá colapso no mercado financeiro no horizonte de seis meses e (iv) Índice de Confiança de Avaliação, que indica o quanto os investidores acreditam que as ações estejam sub-avaliadas na bolsa de valores.

No Brasil, há o Índice de Confiança do Consumidor (ICC) da Federação do Comércio do Estado de São Paulo (Fecomercio), o Índice de Expectativas do Consumidor (IEC) da Federação do Comércio do Estado do Rio de Janeiro (Fecomércio-RJ), o Índice Nacional de Expectativas do Consumidor (INEC) da Confederação Nacional da Indústria (CNI) e a Sondagem de Expectativas do Consumidor (SEC) da Fundação Getulio Vargas (FGV). Bentes (2006) discute a origem destes índices de confiança brasileiros, bem como a metodologia de aferição de cada um deles.

Fisher e Statman (2003) testam a relação entre os índices de confiança do consumidor e o sentimento do investidor. Uma vez que os índices de confiança medem o grau de otimismo da população quanto ao estado atual e futuro da economia, sendo influenciado diretamente por variações nas taxas de juros, inflação e desemprego, estes podem indicar, eventualmente, o desempenho futuro das ações. Teoricamente, não haveria previsibilidade do desempenho das ações por meio do grau de confiança do consumidor, visto que as variações no mercado de ações ocorrem em antecipação às mudanças macroeconômicas.

\footnotetext{
${ }^{13}$ Maiores informações sobre os questionários que são aplicados e as séries históricas destes índices estão disponíveis em: http://icf.som.yale.edu/financial_data/confidence_index/index.shtml.
} 
Já Otoo (1999) comenta que retornos elevados de ações podem incentivar a confiança do consumidor em dois aspectos: (i) maiores retornos promovem maior riqueza, que aumenta a confiança do consumidor e (ii) retornos elevados no mercado financeiro indicam uma maior renda, uma vez que o mercado de capitais é um sinalizador do desempenho da economia.

Solt e Statman (1988) discutem sobre a validade do índice do BSI, apresentado na equação (2.5), como preditor dos preços das ações no mercado a partir de uma expectativa ruim dos analistas, testando se o coeficiente deste índice de sentimento mostrava-se positivo e significante em uma regressão cuja variável dependente era o retorno futuro acumulado das próximas 4, 26 ou 52 semanas do índice Dow Jones (DJIA). A amostra analisada incluiu as ações que compuseram o DJIA, no período de janeiro de 1963 a setembro de 1985 . Caso o $B S I$ fosse um bom indicador para o uso da estratégia contrária, um valor elevado do índice estaria associado ao aumento no DJIA, levando a um coeficiente $b$ positivo na seguinte equação:

$$
R_{t, t+n}=a+b B S I_{t}+v_{t}
$$

para $n=4,26$ ou 52 semanas, sendo $R_{t, t+n}$ a taxa de retorno do DJIA entre os instantes de tempo $t$ e $t+n$; $a$ é o intercepto e $v_{t}$ é o termo de erro em $t$. Resultados indicaram que não havia nenhuma relação significante entre o índice e o retorno do mercado para quaisquer dos períodos. O coeficiente $b$ encontrado não foi estatisticamente diferente de zero.

Ao tentar inverter a causalidade, com o objetivo de verificar se haveria um efeito contrário, ou seja, se a opinião dos analistas era uma resposta ao desempenho anterior do DJIA, resultados interessantes foram encontrados. A equação foi reformulada para:

$$
R_{t-n, t}=c+d B S I_{t}+v_{t}
$$

para $n=4,26$ ou 52 semanas. Neste teste, o coeficiente $d$, relacionado ao índice $B S I$, mostrou-se negativo e estatisticamente significante, demonstrando que os analistas emitem opiniões mais pessimistas (aumento no $B S I$ ) depois de um período de queda do índice DJIA nas últimas semanas (redução em $R_{t-n, t}$ ). Mais que isto, neste trabalho, Solt e Statman (1988) demonstraram que o índice de sentimento é explicado pelo retorno histórico do mercado, não sendo possível atestar que ele tenha qualquer poder preditivo.

Na mesma linha, Brown e Cliff (2005) testaram duas hipóteses para verificar o impacto de características comportamentais dos investidores nos preços dos ativos, verificando se o excesso de otimismo antecede períodos de sobrevalorização no mercado e se o nível elevado de sentimento é seguido por períodos com retornos cumulativos baixos, considerando 
que há uma reversão dos preços, tendendo ao seu valor intrínseco. O primeiro teste usa o nível de sentimento, medido pelo índice Investors Intelligence $(I I)$, como uma variável explicativa nos erros de apreçamento. O coeficiente encontrado para esta variável foi significante, o que indica uma valorização excessiva durante os períodos de sentimento positivo. Um segundo teste considera o mercado e os modelos de avaliação como um sistema cointegrado. Resultados indicaram que os retornos são negativamente relacionados ao sentimento, mesmo controlando-se por variáveis normalmente utilizadas em modelos de apreçamento.

Fisher e Statman (2003) analisaram o impacto dos índices de confiança do consumidor no retorno das ações, especificamente: (i) índices de confiança do consumidor apurados pela Universidade de Michigan e pelo Conference Board, com o objetivo de investigar a relação entre taxas de retorno e a confiança do consumidor e (ii) utilizando uma outra medida para sentimento do investidor, publicada pela Associação Americana de Investidores Individuais (AAII). No mercado brasileiro, Domingues (2008) criou um índice próprio de sentimento do investidor, levantando diariamente opiniões de analistas sobre o desempenho esperado do pregão no dia seguinte. Para a realização dos testes de previsibilidade de retornos diários, foram analisados modelos baseados em regressões lineares, em que a variável dependente era o retorno do Índice BOVESPA (IBOVESPA) em $t$, e a variável independente era a medida de sentimento em $t-1$. Utilizando dados diários do período entre $05 / 07 / 2005$ e 28/12/2007, os resultados apresentados indicaram ser possível antecipar oscilações futuras do IBOVESPA a partir dos resultados desta pesquisa conduzida pelo autor.

\subsubsection{Proxies de Mercado para Sentimento}

Além do levantamento de opiniões, uma outra abordagem possível para lidar com conceitos que são de difícil observação direta é por meio da utilização de variáveis latentes. Considerando que o sentimento do investidor é um construto teórico, a utilização de variáveis observáveis para a sua inferência é uma prática bastante comum nas ciências sociais. Tarling (2008) cita, por exemplo, a utilização de variáveis latentes para medir conceitos como alienação, inteligência, medo da criminalidade, confiança nos negócios e custo de vida, uma vez que não há uma escala de medida natural para estes construtos. Uma quantidade grande de variáveis observáveis pode ser agregada para representar um único conceito latente, facilitando a compreensão dos dados.

Comparando com a utilização de pesquisas de opinião, há os defensores do uso de dados secundários (variáveis observáveis) como medidas mais precisas para serem utilizadas em estudos, pois os dados são reflexos de transações efetivas dos investidores, e não são meras 
intenções relatadas em levantamentos de opinião. Pesquisadores tratam, com um certo grau de suspeita, as medidas de sentimento obtidas por meio de pesquisas de opinião, conforme colocado por Baker e Wurgler (2007, p. 135). Há, eventualmente, o risco de estas medidas indiretas não serem consideradas boas proxies para a variável cujo efeito deseja-se capturar.

Nas seções a seguir, serão apresentadas algumas das variáveis já utilizadas em outros estudos como proxies para o sentimento do investidor, mostrando-se os argumentos dados pelos seus respectivos autores para justificar a sua aplicação.

\subsubsection{Liquidez}

A relação entre liquidez e retornos de ações, tanto individualmente como de maneira agregada, é alvo de uma série de estudos nas últimas décadas (AMIHUD; MENDELSON, 1986; JONES, 2002; PÁSTOR; STAMBAUGH, 2003; BAKER; STEIN, 2004). A justificativa tradicional para o fato de a liquidez afetar as taxas de retorno está relacionada com o reconhecimento por parte dos investidores que, em algum momento, terão que se desfazer dos ativos e, quando o fizerem, deparar-se-ão com custos de transação. Um ponto ainda criticado pelos estudiosos é que trabalhos empíricos demonstram que este desconto nos preços é muitas vezes superior aos custos de transação.

O modelo testado por Baker e Stein (2004) parte da premissa de que diferenças de liquidez entre firmas estão associadas a diferenças nos retornos esperados, o que justificaria a afirmação de que a liquidez é um fator que deve ser considerado no apreçamento de ativos. Duas premissas são adotadas neste modelo: a de que existem restrições (fricções) no mercado e que existem investidores quase-racionais excessivamente otimistas. A quantidade de ações negociadas em si, ou mesmo a liquidez do papel no mercado indicam opiniões do investidor. Scheinkman e Xiong (2003) encontraram que o volume negociado está diretamente relacionado a diferenças de expectativas, indicando maiores dificuldades na avaliação do preço por parte dos investidores.

A medida mais tradicional de liquidez utilizada nos estudos, está relacionada à quantidade em negociação (turnover) e é dada pela equação a seguir:

$$
T U R N_{t}=\frac{n_{t}}{N_{t}}
$$

em que $n_{t}$ é a quantidade de papéis negociados na data $t$ e $N_{t}$ é o total médio de ações listado no período $t$.

Como uma alternativa à medida apresentada na equação (2.8), Baker e Wurgler (2006) uti- 
lizaram o logaritmo natural da variável $T U R N$ com o objetivo de suavizar as medidas extremas e dessazonalizaram-na, utilizando a média móvel dos últimos 5 anos. Argumenta-se que existe uma relação entre a liquidez das ações e o nível de sentimento do mercado, considerando que há maior participação dos investidores irracionais, aumentando a liquidez no mercado, quando estes estão otimistas; consequentemente, alta liquidez é sinalização de uma sobrevalorização. Jones (2002) fez uma investigação entre o turnover e outras medidas de liquidez do mercado de ações com os retornos dos ativos, encontrando que altos níveis de negociação antecedem momentos de retornos inferiores na bolsa. Apesar de se supor que exista uma explicação parcialmente racional, é razoável admitir que pode haver uma parcela que não é justificada pelos fundamentos.

\subsubsection{Prêmio de Dividendos}

De acordo com a teoria clássica, Miller e Modigliani (1961) provaram que a política de dividendos da empresa é irrelevante para o preço da ação, em um mercado de capitais completo e eficiente. Isto ocorreria porque para o investidor seria indiferente a escolha entre receber dividendos ou obter ganhos de capital com a valorização da ação, e a arbitragem asseguraria este equilíbrio. No entanto, o que se observa é que, sejam por motivações psicológicas ou mesmo institucionais, as empresas que são caracterizadas como boas pagadoras de dividendos são vistas pelos investidores como estáveis, por apresentarem um fluxo de pagamentos constante, e a demanda por elas varia conforme a perspectiva do mercado.

Além disso, a arbitragem não consegue gerar o equilíbrio que deveria ocorrer entre empresas que pagam e que não pagam dividendos e, mais ainda, observa-se que os gestores respondem ao mercado pagando mais dividendos quando os investidores sinalizam preferência às empresas pagadoras (BAKER; WURGLER, 2004). Considerando que as empresas pagadoras de dividendos normalmente são maiores, mais lucrativas e com menores oportunidades de crescimento, esta variável pode ser utilizada como uma forma de medir a demanda dos investidores por empresas com este conjunto de características. Além disso, um fluxo mais constante de pagamento de dividendos pode ser comparado ao fluxo de pagamento de cupons de títulos de dívida, dando aos investidores uma maior sensação de segurança.

Para apurar o que seria o prêmio de dividendos, Baker e Wurgler (2004) utilizam quatro proxies:

- a diferença dos logaritmos da média dos índices market-to-book, apurados conforme Fama e French (2001), das empresas pagadoras e não-pagadoras de dividendos; 
- diferença nos preços das classes de ações da empresa Citizens Utilities': (i) uma que paga dividendos em dinheiro e (ii) outra que remunera dividendos em ações, seguindo o exemplo de De Long (1978) e Poterba (1986);

- o efeito médio no retorno dos preços das ações, medido por um teste de eventos a partir do anúncio de pagamento de dividendos e

- diferença entre os retornos futuros das ações pagadoras e não-pagadoras de dividendos, analisados em um backtest.

Espera-se que as três primeiras proxies tenham um efeito positivo na demanda por empresas pagadoras, e que a última tenha um efeito negativo. A primeira medida, considerada a principal das quatro e também utilizada em Baker e Wurgler (2006), é calculada por:

$$
D I V_{t}=\ln \left(\frac{A T_{D, t}-P L_{D, t}+V M_{D, t}}{A T_{D, t}}\right)-\ln \left(\frac{A T_{N D, t}-P L_{N D, t}+V M_{N D, t}}{A T_{N D, t}}\right),
$$

tal que os termos $D$ e $N D$ são utilizados para definir as empresas pagadoras e não pagadoras de dividendos, respectivamente; $A T$ é o ativo total contábil da empresa; $V M$ é o valor de mercado da empresa, dado pelo preço de fechamento da ação multiplicado pela quantidade de ações e $P L$ é o valor contábil do patrimônio líquido da empresa.

Para agregar as razões de market-to-book de todas as empresas pagadoras e das nãopagadoras, Baker e Wurgler (2004) calcularam uma média aritmética simples e uma média ponderada pelo valor de mercado. A segunda medida foi a partir de um caso específico de uma empresa, a Citizens Utilities', que possuía duas classes de ações que pagavam dividendos de mesmo valor monetário, no período de 1956 até 1989, mas com formas de pagamento distintas: dinheiro e ações. Segundo a teoria clássica de dividendos, não deveria haver uma variação no preço relativo das duas ações. Seu cálculo também envolve a diferença dos logaritmos dos preços das duas ações.

A terceira medida foi o efeito médio do anúncio de início de pagamento de dividendos, obtido pela metodologia de estudo de evento proposta por Campbell, Lo e MacKinlay (1997). Foi utilizada como data do evento o dia em que a empresa registra na base de dados do Center for Research in Security Prices (CRSP) a declaração de que vai pagar dividendos e analisou-se a janela de três dias antes até três dias após o evento para apurar o retorno anormal da empresa que começa a pagar dividendos. Por fim, a quarta e última medida é a diferença entre os retornos futuros no índice ponderado das empresas pagadoras e não-pagadoras.

Segundo a teoria de catering, existe uma propensão dos gestores das empresas a pagar dividendos para aproveitar a demanda dos investidores por empresas pagadoras, apesar 
de a teoria proposta por Miller e Modigliani (1961) afirmar que investidores seriam indiferentes entre dividendos ou ganhos de capital. Caso esta influência nos gestores seja comprovada, pode-se supor que uma alta taxa de novas empresas pagadoras será seguida por uma redução na diferença de retornos entre empresas pagadoras e não-pagadoras, como decorrência do aumento dos preços das ações pagadoras, consequência da maior demanda por dividendos. Uma das conclusões de Baker e Wurgler (2004) é que a demanda dos investidores por dividendos pode ser explicada pelo sentimento do investidor, ao analisar a relação entre os descontos nos fundos fechados (closed-end fund discount, $C E F D)$ e o prêmio de dividendos.

\subsubsection{Quantidade de IPOs e Retorno Médio dos IPOs no primeiro dia de negociação}

A oferta pública inicial, também referida como IPO (do inglês, Initial Public Offering), é o evento que marca a primeira venda de ações de uma empresa no mercado de bolsa. Diversos fenômenos relacionados aos IPOs podem ser justificados pelo sentimento do mercado, partindo-se do pressuposto que muitos gestores tentam explorar o momento correto para captar recursos com a venda de ações (market timing). Nesta lógica, a quantidade de aberturas de capital de empresas acompanha os períodos de sobre e subvalorização do mercado. Ljungqvist, Nanda e Singh (2006) associam as principais anomalias relacionadas aos IPOs à existência de investidores quase-racionais.

De acordo com Ritter e Welch (2002) e Baker e Wurgler (2006), tanto a quantidade de ofertas realizadas bem como o retorno das ações no seu primeiro dia de negociação em bolsa são indicadores bastante sensíveis ao sentimento do mercado de capitais, sendo que uma grande onda de ofertas e um elevado retorno no primeiro dia de bolsa são citados como uma sinalização do entusiasmo do investidor.

Grandes variações nos preços destas ações ainda é um fato inusitado, uma vez que o preço de lançamento é formado junto aos bancos de investimento, que têm informações sobre os investidores interessados no papel. Baker e Wurgler (2006) definiram a variável NIPO como a quantidade de ofertas públicas iniciais realizadas no período de um ano e a variável $R I P O$ como a média dos retornos do primeiro dia dos IPOs realizados.

Para verificar as causas da flutuação do volume de $I P O$ s no mercado ao longo do tempo, Lowry (2003) testou se a demanda agregada por capital das empresas, os custos de emissão de ações e o nível de otimismo do investidor, ou seja, seu sentimento, explicaria a variação observada. Resultados indicaram que tanto a demanda como o nível de sentimento são determinantes relevantes no volume emitido, e que os custos de emissão são significantes 
mas de pouco impacto econômico. Consequentemente, o custo da emissão se reduz, incentivando as empresas a fazer mais aberturas de capital. A hipótese de sentimento do investidor considera que a elevação do nível otimismo induz os investidores a pagarem pelas ações além de seu valor fundamental.

\subsubsection{Percentual de ações nas novas emissões}

No clássico artigo de Modigliani e Miller (1958), em que é demonstrada a irrelevância da estrutura de capital das empresas para o seu valor, assume-se que os mercados são eficientes. Entretanto, caso esta não seja uma premissa válida, é de se supor que a decisão de financiamento torna-se relevante. Existem três maneiras pelas quais as empresas podem se financiar: por meio de dívidas (capital de terceiros), emissão de ações (capital próprio) ou mesmo por meio da absorção dos lucros gerados internamente pelas operações.

As premissas assumidas por Modigliani e Miller (1958) partem de um mundo sem fricções, ou seja, não são considerados impostos, existência de informação assimétrica, ou qualquer custo de transação. Buscando-se o corpo de trabalhos publicados posteriormente sobre o assunto, verifica-se que cada uma das friç̧ões não consideradas no trabalho inicial foi gradativamente adicionada à teoria de custo de capital: presença de impostos (MODIGLIANI; MILLER, 1963), custos de agência (JENSEN; MECKLING, 1976), custos de falência (DE ANGELO; MASULIS, 1980), informação assimétrica (MYERS, 1984) e custos de transação (WILLIAMSON, 1988).

Fama e French (2005, p. 549-550) argumentam que, segundo o modelo tradicional, as empresas identificam o seu nível ótimo de endividamento e, a partir disso, avaliam os custos e benefícios da emissão adicional de dívida. Na avaliação dos prós e contras de captar recursos de terceiros, entrariam na análise não apenas os benefícios fiscais decorrentes da dedutibilidade das despesas financeiras, mas também os custos de falência e dos problemas de agência. Por outro lado, de acordo com o pecking order, proposto por Myers (1984), as empresas possuem uma hierarquia de preferências pela forma de financiamento. Elas preferem financiar-se primeiramente com recursos gerados internamente, em seguida preferem contrair dívidas e, por último, optam pela emissão de ações.

No entanto, evidências empíricas demonstram que a emissão de ações nem sempre é utilizada como última alternativa de financiamento, havendo flutuações na oferta ao longo do tempo. Baker e Stein (2004) analisam a relação entre o volume de ações emitidas e o sentimento do investidor, e concluem que os gestores tentam escolher o momento de emitir novas ações, pois acreditam que quando o otimismo dos investidores está em alta, há sobrevalorização das ações que deve ser aproveitada. 
Nos artigos de Lucas e McDonald (1990) e Baker e Wurgler (2000), são apresentadas evidências de que a proporção de emissões de ações em relação ao total de emissões feitas, de ações e de dívida, possa ser um bom preditor do retorno do mercado de ações norte-americano. Esta medida tem a vantagem de ser mais ampla, por englobar todas as empresas e não apenas as empresas que iniciam sua listagem em bolsa (NIPO):

$$
S_{t}=\frac{A_{t}}{A_{t}+D E B_{t}}
$$

em que $A_{t}$ é o volume total captado pelas empresas por meio de emissão de ações na data $t$ e $D E B_{t}$ corresponde ao volume total captado por meio de emissão de dívida na data $t$.

Baker e Wurgler (2006) utilizam o percentual de ações emitidas no total de novas emissões como uma medida do sentimento do mercado, encontrando que altos percentuais de emissão de ações predizem baixos retornos. Tal resultado sugere que gestores decidem rebalancear a sua estrutura de financiamento na tentativa de reduzir, sempre que possível, o custo de capital da empresa.

\subsubsection{Proporção de Altas e Baixas}

Um outro índice também utilizado para avaliar a percepção do mercado é o chamado Trading Index (TRIN), ou Indicador Arms, em homenagem ao seu criador, Richard Arms, na década de 1970 (WANG; KESWANI; TAYLOR, 2006), dado por:

$$
T R I N_{t}=\frac{Q_{A, t}}{Q_{B, t}} \times \frac{V_{B, t}}{V_{A, t}}=\frac{V_{B, t}}{Q_{B, t}} \div \frac{V_{A, t}}{Q_{A, t}}
$$

em que $Q_{A, t}$ é a quantidade de ações em alta na data $t ; Q_{B, t}$ é a quantidade de ações em baixa na data $t$; $V_{A, t}$ é o volume financeiro de ações em alta na data $t$ e $V_{B, t}$ é o volume financeiro de ações em baixa na data $t$.

Esta proporção de altas e baixas pode ser interpretada como a razão entre o volume médio de ações em baixa e o volume médio de ações em alta. Se o índice for maior que um, estão sendo transacionadas mais ações em queda que ações em alta, indicando um mercado pessimista. Analogamente, um índice menor que um reflete maior volume de ações em alta sendo negociados em relação à quantidade de negócios em baixa, o que demonstraria um mercado otimista. 


\subsubsection{Insider Trading}

Considerando que há informação assimétrica no mercado e que os próprios executivos são os que mais informações detêm acerca do valor fundamental da empresa, pode-se deduzir que decisões que estes tomam em suas carteiras de investimento pessoais devem revelar suas opiniões sobre eventuais falhas no apreçamento da ação da empresa que administram. Desta forma, a proporção de negociações feitas por pessoas diretamente ligadas à administração da companhia pode ter um componente relacionado a sentimento. Seyhun (1990) investigou a presença de operações feitas pelos insider traders na época do Crash da Bolsa de Nova Iorque (NYSE), em outubro de 1987, partindo do pressuposto de que estes conseguem prever variações específicas no preço da ação de suas próprias empresas.

Sendo que os fluxos de caixa da empresa são influenciados primeiramente por fatores específicos da empresa, mas também por condições do setor e da conjuntura econômica, investigar as negociações feitas por administradores e outros funcionários devem refletir os efeitos tanto da economia como de aspectos idiossincráticos da firma. Baker e Wurgler (2007) colocam que os executivos das empresas, tendo as melhores informações sobre eventos que possam influenciar o preço da ação e o incentivo para aproveitar-se desta assimetria, podem sinalizar movimentos futuros nos fundamentos das empresas.

Seyhun (1990) calculou esta proporção de duas formas:

$$
P R A T_{t}=\frac{N P_{t}}{\left(N P_{t}+N S_{t}\right)} \quad \text { e } \quad S P R A T_{t}=\frac{S P_{t}}{\left(S P_{t}+S S_{t}\right)}
$$

em que $P R A T_{t}$ é a fração entre compras e vendas realizadas por insiders na data $t$, sendo $N P_{t}$ o número de compras (quantidade de transações) realizadas no período $t$ e $N S_{t}$, o número de vendas no mesmo período. Analogamente, $S P R A T_{t}$ é relação entre a quantidade de ações compradas e vendidas por insiders, dada pela razão entre a quantidade de ações compradas $\left(S P_{t}\right)$ e quantidade de ações vendidas $\left(S S_{t}\right)$, em uma data $t$.

\subsubsection{Proporção de Put-Call}

Apesar de as opções normalmente serem relacionadas à alavancagem e serem lembradas por sua flexibilidade, poucos as utilizam como ferramentas de previsão, uma vez que estão ligadas à expectativa de preços futuros das ações. Um dos indicadores mais utilizados com relação à perspectiva futura do mercado é a proporção de put-call $(P C R)$, que corresponde à relação entre o volume de opções de venda e de opções de compra no mercado financeiro em que são transacionados. Bandopadhyaya (2006) cita que de todos os PCRs utilizados 
nos estudos, o mais recorrente é o coletado pela bolsa de Chicago, Chicago Board Options Exchange $(C B O E)$, que calcula o seguinte índice para todas as ações individualmente, bem como para os índices de ações:

$$
P C R_{t}=\frac{P u t_{t}}{\text { Call }_{t}}
$$

tal que $P u t_{t}$ é o volume total de contratos de opções de venda negociados na data $t$ e Call $_{t}$ é o volume de contratos de opções de compra movimentados na data $t$.

Um volume grande de compradores de opções de venda pode sinalizar a opinião do mercado de que o seu nível máximo está próximo e que até a data do exercício deverá estar mais baixo. Da mesma forma, um grande número de compradores de opções de compra indicam uma expectativa de que o mercado está próximo do mínimo. Wang, Keswani e Taylor (2006) colocam que a compra de opções de venda está relacionada ao sentimento pessimista por parte dos investidores, que querem proteger de suas posições à vista ou mesmo especular uma baixa do mercado.

Quando existe um excesso de otimismo no mercado e o nível de transações especulativas é alto, o índice de put-call é baixo; quando os investidores estão pessimistas, a especulação em opções de venda torna-se excessiva, e o índice apresenta valores mais elevados. No Brasil, a variedade limitada de opções de compra lançadas no mercado e um mercado praticamente ilíquido de opções de venda restringem a utilização do $P C R$ como uma variável para estudos empíricos.

\subsubsection{Closed-End Fund Discount (CEFD)}

Um dos enigmas de finanças bastante discutido e considerado um desafio às finanças clássicas, conforme Ross (2002), está relacionado aos closed-end funds, fundos fechados que investem em outros ativos negociados publicamente em bolsa. Diferentemente de um fundo tradicional de ações, que também aplica a maior parte do seu patrimônio em ativos listados, um fundo fechado emite uma quantidade fixa de cotas, que são negociadas em bolsa. Um investidor que deseje sair desta aplicação, deve vender suas cotas a um outro investidor, e não apenas ser reembolsado pelo valor líquido dos ativos que estão no fundo. De acordo com Lee, Shleifer e Thaler (1991), o enigma está na constatação empírica de que ações das cotas do fundo fechado são negociadas a preços diferentes do valor líquido dos ativos (Net Asset Value - NAV) que o compõem, o que pode ser considerado uma anomalia, caso se aceite a ideia de que os mercados são eficientes e as oportunidades de arbitragem são raras.

Diversos são os argumentos utilizados pelos pesquisadores para explicar tal diferença entre 
os preços de mercado das cotas do fundo e do valor líquido dos ativos (valor fundamental do ativo), geralmente questionando se a metodologia utilizada para avaliar os ativos na carteira do fundo não sobrevalorizam o valor real dos ativos. Explicações utilizando a teoria tradicional destacam três principais fatores para tal diferença: custos de agência, despesas com impostos e taxas e iliquidez dos ativos (MALKIEL, 1977). Custos de agência levariam a um descolamento de preços caso os custos administrativos do fundo fechado fossem elevados a ponto de reduzir o valor dos ativos da carteira do fundo. O argumento fiscal está no fato de que provisões de imposto sobre ganhos de capital não-realizados não são capturadas nos cálculos convencionais do valor líquido dos ativos, o que também poderia explicar a diferença de preços. Por fim, um último ponto discutido é que alguns fundos podem ter restrições à negociação dos ativos, impondo limites à negociação dos papéis da carteira, o que levaria à redução da liquidez do fundo e, consequentemente, à valorização excessiva no cálculo do valor líquido das ações em relação ao fundo.

Embora estes fatores sejam lógicos e de fato possam explicar parte das diferenças observadas, Lee, Shleifer e Thaler (1991) constatam que alguns itens permanecem sem explicação, focando no aspecto comportamental como justificativa para a anomalia:

(a) por que estes fundos são criados?

(b) por que há investidores dispostos a comprar estes papéis, sendo que normalmente suas cotas são negociadas com um deságio em relação ao seu valor líquido?

(c) quais são as razões para a flutuação do desconto ao longo do tempo e das diferenças nos retornos no fundo quando comparado aos fundos abertos?

Uma suposição feita por Lee, Shleifer e Thaler (1991) quanto ao modelo proposto por De Long et al. (1990) ao aplicá-lo para os fundos fechados, é que os investidores quaseracionais têm maior propensão a comprar e transacionar as cotas destes fundos que os investidores racionais. Estes últimos tendem a adquirir os ativos individuais e não cotas de fundos de ações. Se o grupo de compradores fosse o mesmo, eventuais influências do sentimento nos investidores afetariam tanto as cotas dos fundos fechados como os ativos individuais que compõem a carteira, não causando, consequentemente, variações no desconto entre os preços da cota e do $N A V$ dos fundos.

A explicação da existência do deságio está no fato de que é mais arriscado investir no fundo que nas ações diretamente, e considerando que o risco é sistêmico, a taxa de retorno exigida pelos cotistas deve ser superior à taxa de retorno direta dos mesmos ativos. Desta forma, os fundos devem, na média, transacionar suas cotas com um desconto em relação ao seu $N A V$, para incentivar investidores a comprarem-nas. Variações nestes descontos seriam então explicadas por mudanças no sentimento dos investidores, estando diretamente 
relacionadas ao grau de pessimismo dos investidores acerca das taxas de retorno futuras: $C E F D$ são maiores quando há um sentimento de pessimismo; e menores quando há um otimismo sobre o desempenho do mercado.

Para ilustrar, suponha que os investidores quase-racionais estejam otimistas e elevem os preços do fundo fechado para o seu valor fundamental. Uma vez que o valor fundamental do fundo é equivalente ao seu $N A V$, esta diminuição no $C E F D$ pode ser facilmente relacionada ao excesso de otimismo do mercado. Analogamente, o pessimismo implicará em cotas do fundo sendo vendidas com maiores descontos, uma vez que os cotistas desejarão sair do investimento.

Lee, Shleifer e Thaler (1991) coletaram os valores semanais do $N A V$ por cota, o preço da ação e o $C E F D$ de 20 fundos fechados para o período de julho de 1956 até dezembro de 1985. Apuraram, mensal e anualmente, um índice de desconto agregado de todos os fundos, ponderados pelos seus respectivos $N A V \mathrm{~s}$. Compararam este índice ao desempenho das ações de empresas menores, partindo do princípio de que empresas menores, assim como os fundos fechados, são compradas principalmente por investidores individuais. E os resultados do teste aplicado por eles comprovam que existe uma correlação entre o sentimento e o desempenho de ações de empresas pequenas e fundos fechados.

Uma sequência de argumentações sobre este trabalho iniciou-se com Chen, Kan e Miller (1993), que questionaram o estudo de Lee, Shleifer e Thaler (1991) quanto à utilização do $C E F D$ como proxy para sentimento dos investidores e relacionar que tais efeitos podem também ser verificados em ações de empresas pequenas, que são transacionadas e detidas principalmente por investidores individuais. Críticas foram rebatidas em Chopra et al. (1993a, 1993b), reafirmando a questão de que o sentimento do investidor influencia os retornos e que este deve ser considerado, juntamente com novas hipóteses, para avançar na teoria de finanças. Para retomar o assunto, anos mais tarde, Elton, Gruber e Busse (1998) não encontraram evidências de que o CEFD serve como medida de sentimento do pequeno investidor.

Uma premissa que deve ser validada para a utilização do CEFD como medida de sentimento recai sobre o público investidor deste tipo de fundo. Para que de fato as flutuações nos preços deste fundo estejam diretamente relacionadas ao sentimento, supõe-se que a maior parcela dos cotistas seja formada por investidores individuais.

\subsubsection{Fluxo de Movimentação nos Fundos de Investimento}

Segundo Brown et al. (2003), utilizar instrumentos que meçam o fluxo de recursos financeiros entre fundos de investimento é especificamente relevante na pesquisa comportamental, 
uma vez que estes permitem a separação entre a medida do sentimento e a taxa de retorno dos ativos. Os modelos comportamentais partem do pressuposto de que as ações causadas pelo sentimento do investidor afetam os retornos dos ativos. Portanto, utilizar medidas distintas de retornos é útil para analisar a relação. Para cada fundo $i$ na data $t$, Brown et al. (2003) calcularam o fluxo de movimentação pela seguinte equação:

$$
F_{i, t}=\frac{T N A_{i, t}-T N A_{i, t-1} \times N A V_{i, t}}{N A V_{i, t-1}}
$$

em que $T N A_{i, t}$ é o ativo total do fundo e $N A V_{i, t}$ é o valor do ativo líquido $(N A V)$ do fundo $i$ na data $t$. Considerando-se que as aplicações e os resgates são registrados no final do dia, não há o efeito de fluxos de movimentações intra-diárias.

Depois de calculado o fluxo individual de cada fundo a cada período, os fluxos foram agregados, apurando-se um fluxo total líquido $\left(T N F_{g, t}\right)$ para cada categoria $g$ de fundos:

$$
T N F_{g, t}=\sum_{i \in g} F_{i, t}
$$

O fluxo médio e ponderado dos fundos por categoria, $E W A P F_{g, t}$, é dado pela média dos fluxos normalizados pelo $T N A$ do dia anterior de cada fundo:

$$
E W A P F_{g, t}=\frac{1}{N_{g, t}} \sum_{i \in g} \frac{F_{i, t}}{T N A_{i, t-1}}
$$

em que $N_{g, t}$ é a quantidade de fundos na categoria $g$ no dia $t$.

Uma migração de fluxos de fundos de renda fixa para fundos de renda variável demonstra o otimismo por parte dos investidores quanto às perspectivas futuras do mercado financeiro. Analogamente, um fluxo no sentido inverso indica receio quanto ao desempenho das ações, o que sinalizaria pessimismo dos indivíduos.

Apesar de esta variável potencialmente indicar a expectativa do investidor sobre o desempenho futuro dos mercados, os dados disponíveis em sistemas sobre os fundos de investimento brasileiros não permitem um fácil levantamento de informações como o $N A V$ do fundo.

Goetzmann, Massa e Rouwenhorst (1999) fizeram um levantamento do fluxo diário de 1000 fundos dos Estados Unidos por um período de 18 meses e, com o uso da análise fatorial, identificaram fatores sistêmicos que explicavam uma parcela significativa da variação do fluxo. Este resultado sugere a existência de um componente comum ao comportamento dos cotistas dos fundos. Resultados indicaram que parte da movimentação ocorre por causa 
do sentimento dos investidores quanto a variações no prêmio do risco de mercado. A relevância do fator comportamental foi testada ao se incorporar as variáveis relacionadas ao fluxo de fundos como regressores no modelo de apreçamento multifatorial de Fama e MacBeth (1973), sendo estes regressores responsáveis por explicar $45 \%$ da variação transversal dos retornos.

Brown et al. (2003) utilizaram os fluxos de aplicações e resgates dos fundos nos Estados Unidos e no Japão como instrumentos para medir o nível de sentimento do investidor. Verificaram se as operações de investimento nos fundos de ações e de renda fixa estavam relacionadas ao otimismo ou pessimismo do mercado. Resultados indicaram que, nos dois países, os fluxos de aplicação nos fundos de ações eram positivamente correlacionados com o otimismo do mercado.

\subsubsection{Volatilidade Implícita nas Opções}

Os preços das opções sofrem um aumento quando a volatilidade esperada do preço do ativo-objeto cresce. Utilizando-se modelos de apreçamento de opções como o desenvolvido por Black e Scholes (1973), pode ser encontrada a volatilidade implícita do ativo-objeto em função do preço das opções no mercado. Nos Estados Unidos, um dos indicadores utilizados para se analisar a volatilidade é o Market Volatility Index (VIX) da CBOE.

Assim como o DJIA ou o Standard \& Poor's 500 (S\&P500), este é um índice de ações, só que mede volatilidade destas, e não os preços. O VIX foi introduzido em 1993, e mede a volatilidade implícita de 100 ações que compõem o S\&P500. No entanto, a série histórica do VIX foi elaborada retroativamente desde janeiro de 1986, o que permitiu uma análise do período do Crash de Outubro de 1987.

Dois motivos levaram à sua criação: (i) ser uma referência de mercado para a volatilidade de curto prazo e (ii) ser um índice-padrão para os contratos de futuros e opções de volatilidade. Uma boa referência sobre o histórico do VIX, bem como sua metodologia de cálculo, pode ser encontrada em Whaley (2008).

O VIX também é chamado de "medida de medo do investidor", e por isso é considerado também uma medida de sentimento. Segundo Whaley (2008), uma demanda maior por compra de opções de venda funciona como uma espécie de seguro para o preço da carteira, sinalizando maior preocupação por parte do investidor contra potenciais perdas na bolsa.

Para verificar se existe relação entre a variação diária no VIX e o índice S\&P500, além de testar se de fato variações no VIX são maiores em termos absolutos quando o mercado 
cai, Whaley (2008) analisou a seguinte equação:

$$
R V I X_{t}=\beta_{0}+\beta_{1} R S P X_{t}+\beta_{2} R S P X_{t}^{-}+\epsilon_{t}
$$

em que $R V I X_{t}$ é a taxa de variação diária do $V I X, R S P X_{t}$ é a taxa de variação no índice S\&P500 e $R S P X_{t}^{-}$é uma variável binária que assume valor 1 se o mercado estiver em queda e 0 , caso contrário.

Para que a suposição seja verdadeira, o intercepto da equação não deve ser estatisticamente diferente de 0 e os coeficientes angulares devem ser negativos, o que foi verificado no estudo de Whaley (2008). Este resultado demonstra que o VIX tem uma relação mais evidente com o pessimismo do mercado, mostrando que o investidor acredita que haverá maiores variações no futuro diante de uma queda no índice de mercado do que diante de altas.

\subsubsection{Humor do Investidor}

Na pesquisa sobre quais medidas já foram consideradas relacionadas ao sentimento do investidor, foram encontrados, inclusive, alguns estudos que buscam atestar uma relação entre o desempenho das ações na bolsa de valores e mudanças exógenas no humor e biorritmo das pessoas, alterações no clima, ou mesmo no estado geral de felicidade da população.

São utilizadas como variáveis tudo aquilo que pode influenciar estes fatores e que é passível de aferição, como temperatura, horário de verão (período de tempo com claridade) (KAMSTRA; KRAMER; LEVI, 2003), nível de cobertura de nuvens no céu (HIRSHLEIFER; SHUMWAY, 2003), estação do ano, desempenho de times de futebol em campeonatos (EDMANS; GARCIA; NORLI, 2007; PALOMINO; RENNEBOOG; ZHANG, 2008), entre outros.

Hirshleifer e Shumway (2003) encontram uma relação entre o percentual de cobertura de nuvens e os preços das ações. Há outros estudos, como Kamstra, Kramer e Levi (2003), que relacionam fatos como o solstício de inverno e retornos decrescentes e a reversão deste processo à medida em que a duração do período claro passa a ser maior, reforçando o efeito de depressão sazonal (Seasonal Affective Disorder - SAD) que influencia o humor de algumas pessoas.

Estas medidas, por aferirem influências ainda questionadas no comportamento do investidor, devem ser utilizadas com cautela. Considerando que nesta tese buscar-se-á utilizar as medidas mais reconhecidas na literatura, estas medidas foram apenas mencionadas para 
ilustrar o que já foi levantado como variável explicativa dos preços dos ativos no mercado, mas não serão objeto de estudo nesta pesquisa.

\subsection{4 Índices de Sentimento}

Considerando a variedade de medidas já utilizadas em estudos anteriores e discutidas na seção anterior, pode-se construir a partir delas um índice de sentimento agregado.

Para escolher quais destas variáveis serão utilizadas para montar o índice, um fator limitador é, sem dúvida, a disponibilidade dos dados. Alguns números não estão facilmente disponíveis para os pesquisadores, ou mesmo nem existem por um período longo, o que pode ser considerada uma limitação importante na amplitude do estudo.

Bandopadhyaya e Jones (2006) propuseram a construção de um índice de sentimento de mercado que tenta capturar o apetite dos investidores por risco no mercado financeiro a partir de dados públicos, criando o Equity Market Sentiment Index (EMSI) para um grupo de 242 empresas cujo valor de mercado varia entre US\$ 2 e 42 bilhões. Para cada ação, foram calculados os seus retornos diários, que posteriormente foram pareados com a volatilidade histórica dos cinco dias anteriores e então aferida a correlação de postos de Spearman, conforme a equação:

$$
E M S I=\frac{\sum\left(R_{i r}-\bar{R}_{r}\right)\left(R_{i v}-\bar{R}_{v}\right)}{\left[\sum\left(R_{i r}-\bar{R}_{r}\right)^{2} \sum\left(R_{i v}-\bar{R}_{v}\right)^{2}\right]^{\frac{1}{2}}} \times 100, \quad-100 \leq E M S I \leq+100 .
$$

em que $R_{i r}$ e $R_{i v}$ são os postos dos retornos diários e da volatilidade histórica para cada ativo $i$, respectivamente, e $\bar{R}_{r}$ e $\bar{R}_{v}$ são o retorno e volatilidade médios da população. Testes foram feitos com o objetivo de verificar se o EMSI ou o próprio índice de mercado defasado seriam boas variáveis explicativas para o índice futuro. Resultados indicaram que o sentimento do investidor parece influenciar mais as variações no curto prazo que o próprio momentum (retorno passado) do índice.

Brown e Cliff (2005) analisaram o impacto do sentimento no apreçamento de ativos por meio da seguinte equação de regressão da taxa de retorno média futura de $k$ períodos contra a variável de sentimento e outras variáveis de controle, utilizando dados mensais de janeiro de 1963 a dezembro de 2000:

$$
\frac{\left(r_{t+1}+\ldots+r_{t+k}\right)}{k}=\alpha+\Theta^{\top} \mathbf{z}_{t}+\beta \text { Sent }_{t}+\epsilon_{t}
$$

em que $k=6,12,24$ ou 36 meses; $\alpha$ é o intercepto; $\mathbf{z}_{t}$ é o vetor de variáveis de controle 
em $t$. As variáveis de controle, com o objetivo de separar a variação que é explicada por fatores racionais, foram:

- retorno dessazonalizado do título público norte-americano com vencimento em um mês ou, alternativamente, a diferença entre os retornos dos títulos públicos com vencimento em 1 e em 3 meses;

- spread a termo entre as rentabilidades do título de 10 anos e de 3 meses;

- spread de crédito, dado pela diferença de taxas entre um título de rating Baa e um Aaa;

- taxa de pagamento de dividendos das empresas listadas no índice CRSP nos últimos 12 meses;

- taxa de inflação;

- fator SMB, relativo ao prêmio pelo tamanho da empresa;

- fator HML, relativo ao prêmio pelo book-to-market e

- fator UMD, relativo ao prêmio pelo momentum.

Para a variável de sentimento, Sent, Brown e Cliff (2005) construíram quatro modelos utilizando combinações distintas de variáveis de sentimento baseadas na pesquisa da Investor's Intelligence, relacionada à opinião de aproximadamente 130 relatórios de analistas sobre o desempenho do mercado com três opiniões possíveis: viés de alta, de baixa ou neutro. O primeiro modelo considerado utilizou a proporção de altas em relação aos que tinham alguma opinião de alteração de cenário: Altas/(Altas + Baixas). Para o segundo caso, utilizaram duas variáveis: o percentual de opiniões neutras e a relação \%Altas/\%Baixas. O terceiro modelo considerou a proporção de Neutras em relação à soma de Altas e Baixas e a mesma relação \%Altas/\%Baixas do modelo 2.

Por fim, no último modelo, divide-se a variável de sentimento em duas: a quantidade de opiniões positivas e a quantidade de opiniões negativas. Resultados indicam que as variáveis relacionadas ao pessimismo mostraram-se significantes para as regressões de longo prazo, e que a neutralidade não se mostrou relevante.

Verma e Soydemir (2008) elaboraram duas séries de índices de sentimento, uma dos investidores individuais e outra dos investidores institucionais. Para cada categoria, eles 
decompuseram o sentimento em duas partes, uma sendo uma resposta racional aos fundamentos e outra supostamente sendo irracional, utilizando o seguinte modelo:

$$
\begin{aligned}
& \text { Sent }_{\text {indiv }}=\gamma_{0}+\boldsymbol{\gamma} \mathbf{z}_{t}+\xi_{t} \\
& \text { Sent }_{\text {instit }}=\theta_{0}+\boldsymbol{\theta} \mathbf{z}_{t}+v_{t}
\end{aligned}
$$

em que $\gamma_{0}$ e $\theta_{0}$ são termos constantes, $\boldsymbol{\gamma}$ e $\boldsymbol{\theta}$ são parâmetros relacionados ao componente racional do sentimento e $\xi_{t}$ e $v_{t}$ são termos de erros aleatórios que seriam o componente irracional de sentimento. Sent $t_{\text {indiv }}$ e $S e n t_{\text {instit }}$ representam as mudanças nos sentimentos de investidores individuais e institucionais, respectivamente, no momento $t$, medidos pela pesquisa semanal de opinião da $A A I I$, para investidores individuais e da Investors' Intelligence (II) para investidores institucionais. $\mathbf{z}_{t}$ são as variáveis de controle do modelo de apreçamento utilizadas por eles, a saber:

- crescimento econômico;

- taxas de juros de curto prazo;

- prêmio de risco econômico;

- variáveis de expectativas econômicas futuras;

- ciclo dos negócios;

- taxa de pagamento de dividendos;

- inflação;

- excesso de retorno da carteira de mercado;

- prêmio pelo tamanho da empresa $(S M B)$;

- prêmio em função do índice book-to-market $(H M L)$;

- prêmio do fator de momentum (UMD);

- flutuação do câmbio.

Depois de construídas as séries temporais de sentimento, analisaram-se as relações destas variáveis com o prêmio pelo risco de mercado, medido pelo índice de Sharpe. Os resultados apontam que, conforme o esperado pelos modelos de apreçamento comportamentais, há uma reação positiva e significante do sentimento racional com o prêmio de risco de mercado. 
Baker e Wurgler $(2006,2007)$ criaram um índice de sentimento baseando-se em seis das variáveis anteriormente apresentadas: $C E F D$, turnover das ações, quantidade de IPOs, taxa de retorno dos $I P O$ s no primeiro dia de negociação, percentual de emissão de ações e o prêmio de dividendos. Aplicaram a técnica estatística multivariada de componentes principais, que será detalhada na seção 3.4.1, para determinar a equação do índice de sentimento.

Uma vez determinada a série histórica do índice de sentimento, foi analisado o seu impacto nas taxas de retornos dos ativos. Para isso, foram coletados retornos mensais durante o período de 1963 a 2001 e as ações foram então agrupadas em carteiras, ordenadas em decis conforme algumas características das empresas:

- momentum, dado pelo retorno bruto acumulado de 11 meses anteriores, do período $t-12$ a $t-2$

- valor de mercado da empresa;

- tempo de existência da empresa;

- retorno sobre o patrimônio líquido, se lucro > 0; se não, 0;

- taxa de pagamento de dividendos, se dividendos pagos > 0; se não, 0;

- tangibilidade de ativos, como medida para a dificuldade de avaliação da empresa (utilizando $\sigma$, desvio-padrão dos retornos mensais dos últimos 12 meses);

- despesas com pesquisa e desenvolvimento sobre o total do ativo da empresa;

- índice book-to-market e

- taxa de crescimento nas vendas.

Baker e Wurgler (2006) analisaram então o comportamento das taxas médias de retorno dos decis, conforme o sentimento apurado no início do período. Uma das conclusões observadas foi que, quando o sentimento do período anterior está abaixo da média, as ações de empresas pequenas apresentam retornos subsequentes altamente positivos, mas quando o sentimento do período anterior está acima da média, não há influência nenhuma na taxa de retorno do período seguinte. Outras evidências neste sentido foram encontradas também para outras características, além do tamanho da empresa. Por exemplo, quando há pessimismo no mercado, no período seguinte: (i) ações de empresas jovens apresentam taxas de retorno maiores que de empresas mais antigas; (ii) empresas de maior volatilidade rendem mais que empresas de risco menor; (iii) empresas não-pagadoras de dividendos têm melhor desempenho que empresas pagadoras. Quando o otimismo está elevado, os 
padrões observados invertem. Ou seja, atributos que em diversos estudos anteriores não se mostraram significantes em termos de poder preditivo das taxas de retorno futuras, mostraram-se relevantes em seu estudo, desde que condicionados ao nível de sentimento no período anterior.

O modelo testado por Baker e Wurgler (2006) incluiu este índice criado, controlando-se por dois efeitos: (i) o impacto genérico do sentimento do investidor em todas as ações e (ii) o impacto genérico das características da firma ao longo do período de tempo analisado, separando as ações em decis de acordo com as características citadas acima:

$$
R_{X_{i, t=H i g h, t}}-R_{X_{i, t=L o w, t}}=a_{0}+a_{1} T_{t-1}+\mathbf{b}_{1}^{\top} \mathbf{x}_{i, t-1}+\mathbf{b}_{2}^{\top} T_{t-1} \mathbf{x}_{i, t-1}
$$

em que o índice $i$ identifica as empresas; $t$ representa o tempo, $R_{X_{i, t=H i g h, t}}$ é a taxa de retorno média dos 3 primeiros decis classificados conforme a característica $X$ no período $t ; R_{X_{i, t=L o w, t}}$ é a taxa de retorno média dos 3 últimos decis classificados conforme a característica $X$ no período $t ; \mathbf{x}_{i, t}$ é um vetor de diferenças entre decis high e low para cada uma das características da empresa $i$ no instante de tempo $t$ e $T$ é uma proxy para o sentimento. O coeficiente $a_{1}$ captura o efeito genérico do sentimento em todas as ações, e o vetor de coeficientes $\mathbf{b}_{1}$, o efeito genérico dos atributos das firmas. O foco principal do estudo é sobre o vetor de coeficientes $\mathbf{b}_{2}$, que indica se há ou não influência do sentimento no corte transversal dos retornos.

Para assegurar maior robustez aos resultados, foi analisado também um modelo similar à equação (2.22), mas incluindo como variáveis de controle alguns dos fatores de risco mais utilizados em modelos de apreçamento: os fatores propostos por Fama e French (1992) - relacionados ao $\beta$, ao índice book-to-market e em relação ao tamanho - e um fator adicional relacionado a momentum. Resultados encontrados indicam que quando o nível de sentimento em um determinado ano é elevado, as taxas de retorno no ano subsequente para empresas pequenas, mais voláteis, não-rentáveis e não-pagadoras de dividendos são menores e vice-versa. 


\title{
Capítulo 3
}

\section{Método da Pesquisa Empírica}

\author{
"These [scientists] are men with bold ideas, but \\ highly critical of their own ideas; they try to find \\ whether their ideas are right by trying first to find \\ whether their ideas are not perhaps wrong. They \\ work with bold conjectures and severe atempts at \\ refuting their own conjectures."
}

Popper apud Taleb (2004, p. 127)

Conforme Severino (1993, p. 115):

Uma tese de doutoramento deve realmente colocar e solucionar um problema, demonstrando hipóteses formuladas e convencendo os leitores mediante a apresentação de razões fundadas na evidência dos fatos e na coerência do raciocínio lógico.

De acordo com Popper (1975, p. 27), um cientista, teórico ou experimental, formula enunciados e verifica-os um a um. Quando está no campo das ciências empíricas, especificamente, a pesquisa envolve a formulação de hipóteses ou sistemas de teorias, que são submetidos a testes, sendo confrontados com a experiência, através dos recursos de observação e experimentação. Para Kerlinger (1980), duas são as características fundamentais da ciência: a objetividade e sua natureza empírica.

Uma pesquisa empírica, conforme Popper (1975, p. 40), deve possuir três atributos: (i) deve ser sintética, representar um mundo possível (não-contraditório); (ii) deve satisfazer o critério de demarcação, sendo um mundo de experiência possível e, por fim, (iii) diferente, 
de alguma forma, de outros sistemas empíricos semelhantes como sendo representativo do nosso mundo de experiência. Para este último quesito, o importante é certificar que é possível aplicar uma abordagem hipotético-dedutiva.

Uma descrição dos métodos de abordagem é apresentada em Marconi e Lakatos (2003, p. 79):

(a) método indutivo - cuja aproximação dos fenômenos caminha geralmente para planos cada vez mais abrangentes, indo das constatações mais particulares às leis e teorias (conexão ascendente);

(b) método dedutivo - que, partindo das teorias e leis, na maioria das vezes prediz a ocorrência dos fenômenos particulares (conexão descendente);

(c) método hipotético-dedutivo - que se inicia pela percepção de uma lacuna nos conhecimentos, acerca da qual formula hipóteses e, pelo processo de inferência dedutiva, testa a predição da ocorrência de fenômenos abrangidos pela hipótese;

(d) método dialético - que penetra o mundo dos fenômenos através da sua ação recíproca, da contradição inerente ao fenômeno e da mudança dialética que ocorre na natureza e na sociedade.

Assim, o método empregado nesta tese é o hipotético-dedutivo, em que se parte da definição do problema e da construção de conjecturas, que deverão ser testadas pela observação e experimentação. A formulação de hipóteses deve considerar o fato de que a metodologia científica exige que os enunciados devem ser suscetíveis a serem julgados quanto à sua verdade ou à sua falsidade. Como citado por Schlick (apud POPPER, 1975), "um enunciado genuíno deve ser passível de verificação conclusiva", ou mesmo por Waismann (apud POPPER, 1975):

Se não houver meio possível de determinar se um enunciado é verdadeiro, esse enunciado não terá significado algum, pois o significado de um enunciado confunde-se com o método de sua verificação.

Desta forma, a hipótese a ser verificada nesta tese, apresentada sob a forma nula, $H_{0}$, é: não existe relação entre o índice de sentimento e a taxa de retorno esperada das ações de empresas listadas na BOVESPA, líquida dos efeitos de fatores de risco comumente utilizados nas pesquisas acadêmicas. 


\subsection{Modelos de Apreçamento}

O modelo de apreçamento mais utilizado, tanto academicamente como pelos profissionais de mercado, é o CAPM de Sharpe (1964) e Lintner (1965). Como colocado por Fama e French (2004), o atrativo do modelo é que suas predições sobre retorno esperado e risco são bastante intuitivas. Entretanto, os autores colocam que devem ser tomadas algumas precauções no momento de se testarem os modelos, uma vez que muitos dos estudos que atestam a falha do $C A P M$ podem ser questionados quanto a problemas na implementação empírica, o que invalidaria os resultados.

Testes de validação do $C A P M$ estão baseados nas seguintes premissas: (i) as taxas de retorno esperadas dos ativos são linearmente relacionadas aos seus $\beta \mathrm{s}$, sendo que não há outra variável com poder explicativo; (ii) o prêmio do $\beta$ é positivo, ou seja, a taxa de retorno esperada da carteira de mercado excede a taxa de retorno dos ativos não-correlacionados com a taxa de retorno da carteira de mercado; e (iii) ativos não-correlacionados com o mercado terão taxas de retorno esperadas igual à taxa de retorno do ativo livre de risco, e o prêmio do risco de mercado será dado por $\mathbb{E}\left[R_{m, t+1}\right]-R_{f}$. A maior parte dos primeiros testes empíricos usaram abordagem de corte de dados transversal ou de séries temporais, separadamente.

Estes testes iniciais do modelo $C A P M$ focavam no intercepto e no coeficiente do $\beta$, sendo o intercepto a taxa livre de risco, $R_{f}$ e o coeficiente $\beta$ do prêmio de risco de mercado, $\mathbb{E}\left[R_{m, t+1}\right]-R_{f}$. Há algumas críticas em relação ao procedimento metodológico feito em diversos estudos, sendo recomendada a estimação em dois passos (2SLS), conforme sugerida por Black, Jensen e Scholes (1972) e Fama e MacBeth (1973). No primeiro passo, estimam-se os $\beta_{i, t}$ por meio de regressões temporais. Como colocado por Fama e MacBeth (1973), há um primeiro potencial problema de erro nas variáveis, pois o CAPM é formulado com base no valores reais da medida de risco $\beta_{i, t}$, mas os testes empíricos utilizam $\widehat{\beta}_{i, t}$ :

$$
\widehat{\beta}_{i, t}=\frac{\widehat{\mathbb{C}}\left[R_{i, t} ; R_{m, t}\right]}{\widehat{\mathbb{V}}\left[R_{m, t}\right]}
$$

tal que $\widehat{\mathbb{C}}\left[R_{i, t} ; R_{m, t}\right]$ e $\widehat{\mathbb{V}}\left[R_{m, t}\right]$ são as estimativas de $\mathbb{C}\left[R_{i, t}, R_{m, t}\right]$ e de $\mathbb{V}\left[R_{m}\right]$, obtidas a partir dos retornos observados e $R_{m, t}$ é o índice de mercado da bolsa de valores local no período $t$.

Os coeficientes $\widehat{\beta}_{i, t}$ são então condensados em uma matriz $\widehat{\boldsymbol{\beta}}_{i}$, de dimensão $N \times 1$, em que $N$ é a quantidade de empresas. No segundo passo da estimação, testa-se o CAPM pela 
seguinte equação, conforme Black, Jensen e Scholes (1972) e Fama e MacBeth (1973):

$$
\mathbf{R}_{i}-R_{f} \iota=\theta_{0}+\theta_{1} \widehat{\boldsymbol{\beta}}_{i}+\boldsymbol{\varepsilon}_{i}
$$

em que deseja verificar se $\theta_{0}$ é igual a zero e $\theta_{1}$ é igual ao prêmio de risco de mercado. Na equação, $\mathbf{R}_{i}$ é um vetor $T \times 1$ dos retornos de $T$ períodos da empresa $i$; $\iota$ é um vetor $T \times 1$ de 1 's; $\widehat{\boldsymbol{\beta}}_{i}$ é o vetor $T \times 1$ de $\widehat{\beta}_{i, t}$; e $\boldsymbol{\varepsilon}_{i}$ é o vetor $T \times 1$ de erros, com a condição de que $\mathbb{E}\left[\varepsilon_{i} \mid R_{m}, R_{f}\right]=0$.

A validade do modelo $C A P M$ foi testada em diversos estudos, sendo sugerida a inclusão de outros fatores de risco que melhorassem a explicação da taxa de retorno esperada dos ativos, como tamanho (BANZ, 1981), alavancagem (BHANDARI, 1988), book-to-market (FAMA; FRENCH, 1992) e momentum (CARHART, 1997). Estes fatores já identificados na literatura serão incluídos no modelo empírico como variáveis de controle, além da inclusão do índice de sentimento, conforme explicado na seção 3.3.2.

\subsection{População, Amostragem e Coleta de Dados}

Kerlinger (1980, p. 90) define população como o conjunto de todos os objetos ou elementos sob consideração e amostra como uma porção de uma população, geralmente aceita como representativa da população. Compõem a população de interesse desta pesquisa todas as empresas com ações regularmente negociadas na BOVESPA, no período de 01 de janeiro de 1999 a 31 de dezembro de 2008.

A escolha desse período deu-se em virtude dos seguintes fatores: (i) corresponde a uma fase de relativa estabilidade econômica, sendo 2008 o último ano completo com informações disponíveis; e (ii) fornece um número suficientemente grande de dados para a análise estatística das variáveis envolvidas na pesquisa. A amostra desta tese inclui 285 empresas com ações negociadas na BOVESPA, com a condição de que houvesse pelo menos um ano de cotações disponíveis. Isto implica que a empresa deve apresentar a série de cotações com data de início anterior a 31/12/2007 e último negócio posterior a 31/12/2000.

Algumas das variáveis utilizadas para a construção do índice de sentimento referem-se a dados do mercado como um todo, mas há variáveis que dependem do levantamento individual de empresas para depois serem consolidadas, conforme será discutido nesta seção 3.3.1 e suas subseções. A amostra de empresas das quais foram extraídos dados para calcular as variáveis do índice de sentimento foram montadas trimestralmente, para as variáveis turnover e TRIN, e anualmente, para a variável prêmio de dividendos. 
A falta de frequência de preços de negociação dificulta a determinação do preço correto. Desta forma, como regra para a formação da amostra, a empresa deveria apresentar um índice de negociabilidade, no respectivo ano analisado, de pelo menos 0,01 . O índice de negociabilidade, $N E G_{i, t}$, conforme calculado pela BOVESPA, é dado por:

$$
N E G_{i, t}=\frac{d_{i, t}}{D_{t}} \sqrt{\frac{n_{i, t}}{N_{t}} \times \frac{v_{i, t}}{V_{t}}}
$$

tal que $d_{i, t}$ é o número de dias em que houve pelo menos um negócio com a ação da empresa $i$ no período $t ; D_{t}$ é o número total de dias em que houve negociação na bolsa no período $t ; n_{i, t}$ é a quantidade de negócios envolvendo a ação da empresa $i$ no período $t$; $N_{t}$ é a quantidade total de negócios de todas as ações da bolsa no período $t ; v_{i, t}$ é o volume financeiro dos negócios realizados com a ação da empresa $i$ no período $t$; e $V_{t}$ é o volume financeiro total dos negócios realizados com todas as ações no período $t$.

Nos casos em que a empresa apresenta mais de uma classe de ações negociada na BOVESPA, foi selecionada a que possui maior negociação no último mês disponível (critério disponibilizado pelo sistema de dados Economática). A exigência desta restrição dá-se em função da utilização de dados contábeis como variáveis de controle da empresa, uma vez que estes seriam os mesmos para ações distintas.

\subsection{Definição Operacional das Variáveis}

A seguir, estão descritas as definições operacionais das variáveis utilizadas nesta tese, subdivididas entre as variáveis utilizadas para o cálculo do Índice de Sentimento e as variáveis do modelo de apreçamento.

\subsubsection{Variáveis do Índice de Sentimento}

Os dados levantados para o cálculo do índice de sentimento foram coletados para cada trimestre, de 1999 a 2008. Todos os dados foram extraídos do banco de dados Economática, salvo menção contrária.

\subsubsection{Quantidade e Retorno dos IPOs}

A quantidade de ofertas públicas iniciais, $N I P O_{t}$, foi levantada a partir do dia de início de cotações, sendo totalizadas a cada trimestre. Os retornos do primeiro dia de cotação 
na bolsa, $R I P O_{t}$, foram calculados como a média das variações percentuais entre o preço de fechamento da ação e seu preço de lançamento neste dia.

\subsubsection{Percentual de ações nas novas emissões}

Esta medida, $S_{t}$, é considerada mais ampla que a anterior, $N I P O_{t}$, por englobar todas as empresas e não somente as empresas que iniciam sua listagem em bolsa. Sua equação é dada por:

$$
S_{t}=\frac{A_{t}}{A_{t}+D E B_{t}}
$$

em que $A_{t}$ é o volume financeiro total emitido através da oferta de ações, primárias ou secundárias; e $D E B_{t}$ é o volume financeiro total emitido através de oferta de debêntures e notas promissórias, primárias e secundárias, conforme registros de ofertas junto à CVM. As operações foram levantadas individualmente, sendo a variável calculada por trimestre.

\subsubsection{Turnover das Ações}

O índice de turnover adotado, $T U R N_{t}$, foi calculado para cada trimestre conforme a seguinte equação:

$$
T U R N_{t}=\frac{n_{t}}{N_{t}}
$$

em que a variável $n_{t}$ é dada pelo somatório das quantidades de títulos negociados no trimestre em questão e $N_{t}$ é a soma total de ações em circulação (outstanding shares) ao encerramento de cada trimestre $t$.

\subsubsection{Prêmio de Dividendos}

A variável $D I V_{t}$ pretende apurar a diferença entre o prêmio de empresas pagadoras e não-pagadoras de dividendos, medida da seguinte forma:

$$
D I V_{t}=\ln \left(\frac{A T_{D, t}-P L_{D, t}+V M_{D, t}}{A T_{D, t}}\right)-\ln \left(\frac{A T_{N D, t}-P L_{N D, t}+V M_{N D, t}}{A T_{N D, t}}\right),
$$

tal que os índices $D$ e $N D$ são utilizados para definir as empresas pagadoras e nãopagadoras de dividendos, respectivamente; $A T$ é o ativo contábil total da empresa; $V M$ é o valor de mercado da empresa, dado pelo preço de fechamento da ação multiplicado pela quantidade de ações e $P L$ é o valor contábil do patrimônio líquido da empresa. 
Como o pagamento de dividendos é informado apenas nos demonstrativos anuais, a amostra de empresas pagadoras e não-pagadoras de dividendos variou apenas a cada ano, assumindo a mesma categoria para os quatro trimestres do ano. Para agregar as razões de market-to-book de todas as empresas pagadoras e das não-pagadoras, foi calculada uma média ponderada pelo valor de mercado de cada empresa.

\subsubsection{Proporção de Altas e Baixas}

O índice chamado TRIN, ou Indicador Arms, foi calculado da seguinte forma:

$$
T R I N_{t}=\frac{V_{B, t}}{Q_{B, t}} \div \frac{V_{A, t}}{Q_{A, t}}
$$

em que $Q_{A, t}$ é a quantidade de ações em alta na data $t ; Q_{B, t}$ é a quantidade de ações em baixa na data $t ; V_{A, t}$ é o volume financeiro de ações em alta na data $t$ e $V_{B, t}$ é o volume financeiro de ações em baixa na data $t$.

\subsubsection{Variáveis do Modelo de Apreçamento}

\subsubsection{Taxa de Retorno das Ações}

A taxa de retorno da ação da empresa $i$ no trimestre $t$ foi calculada da seguinte forma:

$$
R_{i, t}=\ln \frac{P_{i, t}}{P_{i, t-1}}
$$

em que $P_{i, t}$ é a cotação de fechamento da ação da empresa $i$ no período $t$, ajustada por proventos (dividendos, bonificações, direitos de subscrição, desdobramentos ou agrupamentos).

\subsubsection{Beta de Mercado}

Para se obter o beta de mercado da ação da empresa $i$ no período $t, \beta_{i, t}$, realizou-se uma regressão linear entre a série de taxas de retornos da ação da empresa, $R_{i, t}$, como variável dependente e a série de taxas de retorno do índice de mercado, $R_{m}$, como variável independente. O beta de mercado da ação corresponde ao coeficiente angular da reta de regressão e pode ser dado também por:

$$
\beta_{i, t}=\frac{\mathbb{C}\left[R_{i, t} ; R_{m, t}\right]}{\mathbb{V}\left[R_{m, t}\right]}
$$


em que $\mathbb{C}\left[R_{i, t} ; R_{m, t}\right]$ é a covariância da série de taxas de retorno da empresa $i$ com a série de taxas de retorno da carteira de mercado e $\mathbb{V}\left[R_{m, t}\right]$ é a variância das taxas de retorno da carteira de mercado para o mesmo período. As séries de retornos são compostas pelos 104 últimos retornos semanais, com a condição de que eram necessários pelo menos 60 pontos para que fosse calculado o $\beta$ para um determinado trimestre.

Para as empresas que apresentaram mais de um tipo de ação negociada na BOVESPA, foi selecionada a ação que apresentou maior volume negociado no último mês de dados disponíveis. A classe selecionada para cada empresa da amostra é apresentada na Tabela B.1 no Apêndice B, na página 143. Como referência para o índice de mercado, foi utilizado o Índice da Bolsa de Valores de São Paulo (IBOVESPA), considerando que este é o índice mais utilizado no mercado.

\subsubsection{Tamanho da Empresa}

Tamanho da empresa é um controle bastante utilizado nos modelos de apreçamento, sendo comumente considerado um fator de risco. Um dos primeiros estudos relacionando o tamanho da empresa como um fator a ser incluído no CAPM foi Banz (1981). Neste trabalho, o autor encontrou que empresas com valor de mercado menores apresentaram retornos ajustados ao risco maiores que empresas de maior valor de mercado, sugerindo a deficiência no modelo tradicional de apreçamento ao desconsiderarem esta variável.

Nesta tese, o tamanho da empresa será definido por três variáveis, a serem inseridas alternativamente no modelo:

(a) logaritmo natural do ativo total contábil da empresa, ln $A T_{i, t}$. A utilização do logaritmo tem a vantagem de diminuir os valores extremos da série - principalmente considerando que a amostra apresenta algumas empresas de porte muito superior à média - e ainda levar a uma medida de mesma ordem de grandeza das demais variáveis utilizadas no estudo;

(b) logaritmo natural do valor de mercado da empresa, $\ln V M_{i, t}$, dado pela somatória das cotações ajustadas por proventos das ações ordinárias e preferenciais, multiplicadas pelas respectivas quantidades; e

(c) logaritmo natural da receita líquida operacional da empresa, $\ln R L O_{i, t}$. 


\subsubsection{Valor de Mercado sobre Patrimônio Líquido da Empresa}

Além do tamanho, Fama e French (1992) utilizaram como fator de risco o índice book-tomarket equity, $B E / M E$, dado pela razão entre o valor contábil da ação e o seu respectivo valor de mercado, encontrando que quanto maior for $B E / M E$ da empresa, maior a sua taxa de retorno. Nesta tese, será calculado o inverso de $B E / M E$, o chamado market-tobook:

$$
V M P L_{i, t}=\frac{V M_{i, t}}{P L_{i, t}}
$$

tal que $V M_{i, t}$ é o valor de mercado da empresa $i$ na data $t$, calculado conforme descrito na Seção 3.3.2.3 e $P L_{i, t}$ é o valor contábil do patrimônio líquido da empresa $i$ ao final do período $t$.

\subsubsection{Endividamento}

Bhandari (1988) foi o autor de um dos primeiros estudos a evidenciar a relação positiva entre a proporção de dívida e os retornos das ações, mesmo quando controlada pelo risco sistêmico, $\beta$. A relação sugere que os investidores exigem maiores retornos de ações de empresas mais endividadas. Consequentemente, o endividamento seria um fator de risco ausente no $C A P M$, uma vez que o efeito do $\beta$ alavancado não foi suficiente na explicação das taxas de retorno.

Nesta tese, o endividamento será definido por duas variáveis, a serem inseridas alternativamente no modelo:

(a) DBAT: dívida bruta ( $D B$, dada pela soma dos financiamentos de curto e longo prazos e das debêntures de curto e longo prazos emitidas pelas empresas) sobre o ativo total contábil, $D B_{i, t} / A T_{i, t}$; e

(b) $D B A M$ : dívida bruta sobre o ativo a valor de mercado, dada pela razão entre $D B$ e o ativo a valor de mercado da empresa: $D B_{i, t} /\left(A T_{i, t}-P L_{i, t}+V M_{i, t}\right)$.

\subsubsection{Previsibilidade dos Retornos}

Embora a teoria clássica afirme que não é possível prever os retornos futuros, uma vez que os choques de preços são aleatórios e toda a informação relevante disponível já está incorporada nos preços de hoje, existem estratégias de investimentos que tentam explorar 
a possível previsibilidade. Para tentar analisar a robustez da relevância do índice de sentimento no modelo de apreçamento, líquida das estratégias mais utilizadas, serão inseridas alternativamente as seguintes variáveis:

(a) variável de momentum, $M O M_{i, t}$, dada pela taxa de retorno da ação em $t-1$. Embora, como colocado por Baker e Wurgler (2006), não exista uma teoria que relacione diretamente o retorno passado com a eventual dificuldade de apreçamento, a variável será utilizada como um controle para que os resultados sejam independentes das falhas de apreçamento mais conhecidas. O fator momentum foi incorporado ao modelo de três fatores de Fama e French (1992) por Carhart (1997);

(b) taxa de crescimento da receita líquida no último trimestre, $C R E S C_{i, t}$, definida como a taxa de variação percentual da Receita Líquida da empresa $i$ de $t-1$ a $t$.

\subsubsection{Setor de Atividade}

Utilizando-se a classificação do sistema Economática, as empresas são subdivididas em vinte setores de atividade. Cada setor será representado por uma variável dummy, que assume valor 1 quando a empresa for de determinado setor, e 0 caso contrário. Foram excluídas da amostra as empresas do setor Finanças e Seguros, dada a característica diferenciada destas empresas quanto à estrutura de endividamento. Desta forma, a amostra é formada por empresas de 19 setores da economia, conforme mostrado na Tabela B.2, no Apêndice B.

\subsubsection{Dummies de Trimestre}

Variáveis binárias, que são definidas como $d \operatorname{Trim}_{t}=1$ no $t$-ésimo trimestre e $d \operatorname{Trim}_{t}=0$, caso contrário, com $t=1, \ldots, 40$. A inserção destas variáveis tem por propósito capturar eventuais choques macroeconômicos que impactaram todo o conjunto de empresas no período analisado pelo estudo.

\subsection{Construção do Îndice de Sentimento}

\subsubsection{Análise de Componentes Principais}

Para a construção do índice de sentimento, é preciso definir qual é a técnica estatística mais adequada para ser utilizada, considerando os dados disponíveis e o objetivo da pesquisa. 
Neste trabalho, optou-se pela aplicação da técnica multivariada de análise de componentes principais (ACP). Conforme Johnson e Wichern (2002), a ACP tem por objetivo a explicação da estrutura de covariâncias de um grupo de variáveis através de combinações lineares destas, com o propósito de reduzir e proporcionar melhor interpretação dos dados.

Apesar do fato de uma quantidade $k$ de componentes ser necessária para explicar a variabilidade total do sistema, tal que $k$ é a quantidade total de variáveis, na maioria dos casos, uma quantidade $n<k$ de componentes principais é responsável por grande parte da variabilidade original das $k$ variáveis.

A utilização da abordagem de componentes principais pode auxiliar a interpretação dos dados, revelando interações entre as variáveis que antes não eram tão evidentes. Na grande maioria dos estudos, esta análise é um passo intermediário na investigação de outras relações maiores. Para este trabalho, ela será aplicada com o objetivo de se calcular um índice de sentimento, que servirá como variável independente no passo seguinte, que é a estimação de um modelo de apreçamento.

A análise de componentes principais é uma combinação linear específica de $k$ variáveis aleatórias $X_{1}, X_{2}, X_{3}, \ldots, X_{k}$. Geometricamente, estas combinações lineares representam a seleção de um novo sistema de coordenadas obtidas a partir da rotação do sistema original com $X_{1}, X_{2}, X_{3}, \ldots, X_{k}$ como eixo de coordenadas. Os novos eixos representam as direções com a variabilidade máxima e fornecem uma descrição mais simples e parcimoniosa da estrutura de covariância. Os componentes principais dependem unicamente da matriz de covariâncias $\boldsymbol{\Sigma}$ (ou da matriz de correlações das variáveis).

Seja o vetor aleatório $\mathbf{X}^{\mathbf{\top}}=\left[X_{1}, X_{2}, X_{3}, \ldots, X_{k}\right]$, com uma matriz de covariâncias $\mathbf{\Sigma}$ com autovalores $\lambda_{1} \geq \lambda_{2} \geq \cdots \geq \lambda_{k} \geq 0$.

Considere as combinações lineares:

$$
\begin{gathered}
Y_{1}=\mathbf{a}_{1}^{\top} \mathbf{X}=a_{11} X_{1}+a_{12} X_{2}+\cdots+a_{1 k} X_{k} \\
Y_{2}=\mathbf{a}_{2}^{\top} \mathbf{X}=a_{21} X_{1}+a_{22} X_{2}+\cdots+a_{2 k} X_{k} \\
\vdots \\
Y_{k}=\mathbf{a}_{k}^{\top} \mathbf{X}=a_{k 1} X_{1}+a_{k 2} X_{2}+\cdots+a_{k k} X_{k}
\end{gathered}
$$

Desta forma, tem-se:

$$
\begin{array}{rlrl}
\mathbb{V}\left[Y_{n}\right] & =\mathbf{a}_{n}^{\top} \boldsymbol{\Sigma} \mathbf{a}_{n} & i & =1,2, \ldots, k \\
\mathbb{C}\left[Y_{n}, Y_{k}\right] & =\mathbf{a}_{n}^{\top} \boldsymbol{\Sigma} \mathbf{a}_{k} & i & =1,2, \ldots, k
\end{array}
$$


Formarão os componentes principais aquelas combinações lineares não-correlacionadas $Y_{1}, Y_{2}, \ldots, Y_{k}$ que apresentarem as maiores variâncias, calculadas conforme a equação (3.12). O primeiro componente principal será a combinação linear com a variância máxima, que maximiza a equação $\mathbb{V}\left[Y_{n}\right]=\mathbf{a}_{n}^{\top} \mathbf{\Sigma} \mathbf{a}_{n}$. Como $\mathbb{V}\left[Y_{n}\right]$ pode ser aumentada através da multiplicação do termo $a_{n}$ por uma constante, faz-se necessária a restrição de que a soma dos quadrados dos coeficientes seja unitária.

Definem-se, desta forma, os componentes principais:

- primeiro componente principal: combinação linear de $\mathbf{a}_{1}^{\top} \mathbf{X}$ que maximiza $\mathbb{V}\left[\mathbf{a}_{1}^{\top} \mathbf{X}\right]$, sujeita a $\mathbf{a}_{1}^{\top} \mathbf{a}_{1}=1$

- segundo componente principal: combinação linear de $\mathbf{a}_{2}^{\top} \mathbf{X}$ que maximiza $\mathbb{V}\left[\mathbf{a}_{2}^{\top} \mathbf{X}\right]$, sujeita a $\mathbf{a}_{2}^{\top} \mathbf{a}_{2}=1$ e $\mathbb{C}\left[\mathbf{a}_{1}^{\top} \mathbf{X}, \mathbf{a}_{2}^{\top} \mathbf{X}\right]=0$;

- $n$-ésimo componente principal: combinação linear de $\mathbf{a}_{n}^{\top} \mathbf{X}$ que maximiza $\mathbb{V}\left[\mathbf{a}_{n}^{\top} \mathbf{X}\right]$, sujeita a $\mathbf{a}_{n}^{\top} \mathbf{a}_{n}=1$ e $\mathbb{C}\left[\mathbf{a}_{n}^{\top} \mathbf{X}, \mathbf{a}_{k}^{\top} \mathbf{X}\right]=0$, para $n<k$.

A geração dos componentes principais é vulnerável à escala das variáveis que são inseridas no modelo. Desta forma, Rencher (2001) comenta que a unidade de medida das variáveis deve ser um item de atenção do pesquisador. Sugere, quando possível, que todas estejam na mesma unidade ou, quando estas apresentarem diferentes escalas de medição, que seja utilizada a padronização como recurso antes de extrair os autovalores e autovetores.

Um procedimento equivalente a trabalhar com as variáveis padronizadas é extrair os componentes principais a partir da matriz de correlação $(\boldsymbol{\rho})$ das variáveis originais, e não da matriz de covariâncias $\boldsymbol{\Sigma}$. Jolliffe (2002) comenta que, caso haja diferenças significativas entre as variâncias das variáveis que formam o componente, aquelas com maiores variâncias dominarão os componentes principais iniciais.

Segundo Washington, Karlaftis e Mannering (2003), os passos para a análise de componentes principais são: padronizar todas as variáveis para compor a matriz; calcular a matriz de covariâncias, que é equivalente à matriz de correlações após a padronização (JOHNSON; WICHERN, 2002, p. 434); determinar os autovalores e os autovetores correspondentes da matriz de correlações (os parâmetros do $i$-ésimo componente principal são dados pelo autovetor, enquanto a variância é dada pelo autovalor); descartar os componentes que explicam apenas uma pequena parcela da variabilidade dos dados.

A proporção da variância total que é explicada pelo primeiro componente principal é dada por $\lambda_{1} / \sum\left(\lambda_{n}\right)$. O propósito da ACP é substituir as variáveis originais por uma quantidade menor de componentes sem incorrer em grande perda informacional. Desta forma, 
espera-se que com os primeiros componentes já se obtenha uma parcela significativa da variabilidade dos dados, o que pode ser comprovado através do scree plot ${ }^{14}$ dos componentes, que apresenta $\widehat{\lambda}_{i}$ no eixo das ordenadas e a quantidade de componentes no eixo das abcissas.

Visualmente, no scree plot, recomenda-se considerar na análise os componentes gerados até o ponto em que os autovalores dos componentes restantes forem de valores baixos e de mesmo tamanho, formando o chamado "cotovelo" do gráfico. Entretanto, a quantidade de componentes principais que deve ser utilizada nas análises não é definida apenas pelos valores relativos dos autovalores (variâncias dos componentes da amostra, utilizando-se do scree plot), mas também pela variância total explicada pelos componentes e pela interpretação dos componentes e sua relação com o assunto pesquisado. Jolliffe (2002, p. 113) coloca que o percentual da variação explicada pela quantidade de componentes que devem permanecer na análise variará de acordo com particularidades dos dados analisados.

Um método também utilizado na literatura para determinar a quantidade de componentes a serem retidos no modelo de ACP é a regra de Kaiser (1960), que afirma que deverão ser utilizados no modelo todos os componentes que apresentarem autovalores maiores que 1. A justificativa está no fato de que se todas as variáveis forem não-correlacionadas entre si, cada autovalor seria igual a 1. Jolliffe (2002, p. 114) afirma que se $\lambda_{i}<1$, então o componente traz menos informação que as variáveis originais e não deve ser utilizado.

Uma outra técnica usual é a Análise Paralela (Parallel Analysis), desenvolvida por Horn (1965). O procedimento proposto permite que o pesquisador determine a significância dos componentes, as cargas das variáveis e a estatística do modelo. Assim, o teste consistirá na comparação dos autovalores gerados do modelo pesquisado contra matrizes de dimensões idênticas geradas aleatoriamente por simulação numérica. Os componentes cujos autovalores forem maiores que os seus respectivos gerados a partir dos dados simulados deverão permanecer no modelo. Caso contrário, podem ser provavelmente considerados espúrios (FRANKLIN et al., 1995).

Além da quantidade de componentes a serem utilizados, deve-se atentar para as variáveis utilizadas na modelagem. Um cuidado adicional deve ser tomado com relação ao valor do último autovalor obtido. Um valor demasiadamente pequeno pode indicar uma dependência linear não-observada das variáveis originais (JOHNSON; WICHERN, 2002, p. 449). Caso isto ocorra, uma ou mais variáveis são redundantes no modelo e devem ser excluídas.

A técnica de ACP, que é utilizada para a formação do índice, deve levar em consideração dois potenciais problemas: a temporalidade das variáveis em relação ao índice construído

\footnotetext{
${ }^{14}$ Esta terminologia, atribuída a Cattell (1966), apesar de Jolliffe (2002) comentar que já era de uso comum, literalmente refere-se às pedras que ficam no sopé de uma montanha bem inclinada.
} 
e a possível influência de outras variáveis omitidas na formação do componente. Estes itens serão discutidos nas seções a seguir.

\subsubsection{Temporalidade e Sinal Esperado das Variáveis}

A ideia central desta pesquisa é verificar a influência do sentimento na formação de preços. Torna-se primeiramente necessário definir como o sentimento será medido, dado que este é um construto de difícil mensuração direta. Foram então coletadas proxies para o sentimento do investidor que pudessem ser utilizadas em séries temporais. A partir da relação de variáveis utilizadas nos estudos recentes (BROWN; CLIFF, 2005; BAKER; WURGLER, 2006; WANG; KESWANI; TAYLOR, 2006; BAKER; WURGLER, 2007), e da disponibilidade destas informações no mercado brasileiro, foram obtidas as variáveis S, NIPO, RIPO, $T U R N, D I V$ e TRIN. Uma questão importante a ser observada na construção de um índice é a temporalidade das variáveis, se elas devem ser contemporâneas ou defasadas, visto que algumas delas devem apresentar reflexos de alterações no sentimento antes que outras (BROWN; CLIFF, 2004; BAKER; WURGLER, 2007).

Para determinar qual a temporalidade das variáveis na formação do índice de sentimento, é estimado, num primeiro momento, o modelo com todas as variáveis e suas defasagens. A partir deste índice de primeiro estágio, é calculada a matriz de correlações entre este índice e todas as variáveis, incluindo também suas defasagens. O objetivo é avaliar qual é o instante de tempo de cada uma das variáveis de sentimento que deve ser selecionado para a composição do índice parcimonioso. Permanece no índice o instante de tempo ( $t$ ou $t-1)$ que apresentar maior correlação com o índice de primeiro estágio. Uma vez determinado o instante de tempo de cada uma das variáveis de sentimento, é então calculado o índice de sentimento parcimonioso, com apenas seis variáveis.

Do ponto de vista teórico, imagina-se que variáveis que estão relacionadas ao comportamento do investidor devem antecipar o sentimento do mercado, ou seja, espera-se que $R I P O_{t-1}, T U R N_{t-1}, D I V_{t-1}$ e $T R I N_{t-1}$ apresentem maior correlação com o índice de sentimento que seus valores contemporâneos. Por outro lado, variáveis que refletem o comportamento das empresas, como $S_{t}$ e $N I P O_{t}$, devem apresentar relação contemporânea com o sentimento do mercado, devendo estas variáveis em nível serem mais correlacionadas com o índice que suas respectivas defasagens.

Com relação aos sinais esperados das variáveis, prevê-se que as variáveis relacionadas a uma maior movimentação do volume de ações em geral, estejam diretamente relacionadas ao sentimento do mercado. Desta forma, $S$ e NIPO, que representam uma maior oferta de ações por parte das empresas, bem como $T U R N$, que indica maior negociação na bolsa 
e $R I P O$, que sinaliza um maior incentivo para investimentos em bolsa, devem apresentar sinal positivo.

Já as variáveis $D I V$ e $T R I N$, por sua vez, devem apresentar relação negativa com o sentimento. Acredita-se que empresas pagadoras de dividendos têm menos oportunidades de crescimento, e a procura por elas deve ocorrer de maneira mais acentuada na época em que o mercado está pessimista. Tal relação parte do princípio de que, em momentos menos otimistas, os investidores preferirão receber os recursos em suas mãos, por meio do pagamento de dividendos, que vê-los reinvestidos na empresa em projetos que podem ser arriscados e com menor chance de êxito. Por outro lado, quando o mercado está otimista, a procura deve ser maior por empresas com maiores oportunidades de investimento que, consequentemente, pagam menos dividendos. A variável TRIN, da mesma forma, tem uma relação inversa com o sentimento, sendo um maior valor um indicativo da perspectiva de um mercado pessimista e vice-versa.

Resumidamente, a temporalidade e o sinal esperado das variáveis de sentimento na construção do índice estão apresentados no Quadro 3.1.

Quadro 3.1 - Temporalidade e Sinal Esperado das Variáveis que compõem o Índice de Sentimento

\begin{tabular}{lcc}
\hline Variável & Temporalidade & Sinal Esperado \\
\hline$S$ & $\mathrm{t}$ & + \\
$N I P O$ & $\mathrm{t}$ & + \\
$R I P O$ & $\mathrm{t}-1$ & + \\
$T U R N$ & $\mathrm{t}-1$ & + \\
$D I V$ & $\mathrm{t}-1$ & - \\
$T R I N$ & $\mathrm{t}-1$ & - \\
\hline
\end{tabular}

\subsection{Investigação Empírica do Modelo de Apreçamento}

Uma vez definida a construção da medida de sentimento, um outro ponto importante é a discussão acerca do método de estimação a ser empregado, considerando as vantagens de um método em relação a outro e eventuais restrições para a aplicação no estudo. Ao se estabelecer um modelo de relacionamento estatístico entre variáveis de interesse da pesquisa, é importante destacar a questão da potencial endogeneidade das variáveis. A exogeneidade está relacionada à condição de que os regressores não sejam correlacionados com os termos de erro da equação. Segundo Wooldridge (2002, p. 50), a presença de variáveis com problemas de endogeneidade leva à estimação de parâmetros inconsistentes no modelo e suas principais causas são: 
(a) variáveis omitidas: não-inclusão de variáveis no modelo de regressão que sejam correlacionadas com os regressores e a variável dependente;

(b) erro de medida dos regressores: é possível que a variável de interesse não seja observável, tendo-se à disposição uma medida imperfeita que pode não apresentar correlação com a variável de resposta da mesma forma que o seu valor real, além de eventualmente ser correlacionada com o erro; e

(c) simultaneidade: variáveis regressoras podem ser simultaneamente determinadas com a variável dependente.

Com o objetivo de reduzir problemas de endogeneidade, serão inseridas no modelo de regressão algumas variáveis de controle sugeridas por estudos téoricos e empíricos anteriores, dummies de tempo e também serão utilizados regressores defasados e variáveis instrumentais. Wooldridge (2002, p. 83-84) define que um regressor, para ser considerado uma variável instrumental, deve ser: (i) não-correlacionado com o erro do modelo a ser estimado e (ii) parcialmente correlacionado com a variável endógena.

Nas próximas seções, serão discutidos métodos de estimação de coeficientes para dados em painel, considerando que a amostra possui uma dimensão transversal, representada pelas empresas $(i=1, \ldots, N)$, e uma dimensão longitudinal, representada por uma série temporal ( $t=1, \ldots, T$ períodos). Esta técnica permite a observação de diversas empresas ao longo do tempo, o que permite a identificação de relações dinâmicas e controle de heterogeneidade não-observada.

A amostra analisada nesta tese compõe um painel não-balanceado, ou seja, não há observações disponíveis de todas as empresas para todos os períodos $\left(T_{i} \neq T\right.$, para algumas empresas $i$ ). Embora alguns cuidados devam ser considerados quando a estimação não é realizada em um painel balanceado (WOOLDRIDGE, 2002, p. 250), a vantagem de não se impor a restrição de que só permanecem na amostra as empresas com observações em todos os períodos reduz o chamado viés de sobrevivência. Isto permite que empresas que foram alvo de fusões ou aquisições, tiveram processos de falência, abertura ou fechamento de capital ao longo do período estudado possam compor a amostra.

Outra questão importante são as propriedades assintóticas dos estimadores de um modelo com dados em painel, em que a dimensão longitudinal $T$ deve ser fixa e a dimensão transversal $N \rightarrow \infty$. De maneira mais prática, Wooldridge (2002, p. 251) coloca que se o $N$ for suficientemente grande em relação ao $T$, pode-se assumir independência no corte transversal e considerar as propriedades assintóticas válidas. 
A relação entre as variáveis de interesse da pesquisa pode ser representada conforme a equação a seguir:

$$
R_{i, t}=\theta_{0}+\psi S E N T_{t-1}+\boldsymbol{\omega}^{\top} \Omega_{i, t}+\epsilon_{i, t}, \quad i=1, \ldots, N \quad \text { e } \quad t=1, \ldots, T,
$$

tal que $R_{i, t}$ é a taxa de retorno do ativo $i$ em $t ; S E N T_{t-1}$ é o índice de sentimento em $t-1 ; \psi$ é o coeficiente associado ao índice de sentimento; $\Omega_{i, t}$ representa o vetor das $k$ variáveis de controle; e $\boldsymbol{\omega}^{\boldsymbol{\top}}$ é o vetor de dimensão $(1 \times k)$, transposto, de parâmetros das variáveis de controle. Por definição, $\epsilon_{i, t}$, termo de erro, não deve ser correlacionado com os regressores.

A verificação empírica da equação (3.14) pode ser feita de diferentes maneiras. Alexander (2008, p. 11) afirma que o sucesso de um modelo de apreçamento multifatores depende tanto da escolha dos fatores de risco como do método de estimação dos coeficientes do modelo. Na maioria dos casos, é utilizada a abordagem de painéis de dados, com dimensão transversal (empresas) grande e dimensão longitudinal (tempo) fixa. Os métodos de estimação que podem ser aplicados para dados em painel serão apresentados nas seções a seguir.

\subsubsection{Modelos Tradicionais para Dados em Painel}

Tradicionalmente, modelos com dados em painel utilizam os métodos de estimação de dados agrupados $(P O L S)$, efeitos aleatórios (EA) e efeitos fixos (EF). No método de estimação de dados agrupados, Pooled $O L S$, todo o conjunto de dados é utilizado nas regressões utilizando o método de Mínimos Quadrados Ordinário (MQO), desconsiderando o instante de tempo $t$. Desta forma, a regressão será composta por $N \times T$ observações e a estimação será consistente se $N \rightarrow \infty$ e $T$ for fixo. Se o modelo estiver bem-especificado, as variáveis regressoras não serão correlacionadas com o termo de erro.

No entanto, caso o termo de erro seja correlacionado com as variáveis ao longo do tempo, os parâmetros estimados apresentarão erros-padrão com viés, o que compromete os resultados do modelo. A heterogeneidade não-observada pode levar à estimação de parâmetros enviesados, uma vez que aspectos omitidos no modelo, mas que afetam tanto a variável de resposta como as variáveis regressoras, podem proporcionar uma correlação entre os termos de erro e as variáveis explicativas.

A heterogeneidade não-observada pode ser, por exemplo, caracterizada pela imagem da empresa percebida pelo mercado ou mesmo a qualidade da gestão da empresa. Para considerar este aspecto, normalmente recorre-se à estimação de dados em painel com efeitos 
aleatórios e efeitos fixos. A utilização de modelos com dados em painel permite contornar o problema da heterogeneidade não-observada, ao analisar o modelo apresentado na equação (3.14) e incorporar a existência de efeitos específicos no modelo por meio da inclusão de um intercepto para cada empresa $i$, igual para todos os períodos $t$. Wooldridge (2002, p. 251-252) afirma que este efeito pode ser considerado fixo ou aleatório.

O modelo é de EA quando se assume que o efeito não-observado não é correlacionado com os regressores. Esta hipótese de não-correlação do efeito não-observado com as demais variáveis é a distinção entre os modelos de EA e EF.

Alternativamente, o modelo de efeitos fixos também considera a existência de efeitos nãoobservados, mas permite que o termo de efeito não-observado seja correlacionado com os regressores. Isto permite uma forma limitada de endogeneidade, mas não necessariamente atende a condição de exogeneidade estrita (CAMERON; TRIVEDI, 2009). No entanto, a modelagem com procedimentos de efeitos fixos impede a utilização de regressores que são constantes para uma mesma empresa ao longo do tempo. Isto porque o modelo não é capaz de distinguir os efeitos observáveis que foram invariantes no tempo (como, por exemplo, o setor de atividade da empresa) dos efeitos não-observáveis. Uma possibilidade para lidar com este problema é a inclusão no modelo de variáveis de interação entre variáveis constantes no tempo (setor de atividade), com regressores de variação temporal (dummies de tempo).

Embora estes sejam os métodos tradicionalmente utilizados para a estimação com dados em painel, para que suas estimativas sejam consistentes é preciso que haja a exogeneidade estrita dos regressores. Isto significa que o termo de erro do modelo é não-correlacionado com as variáveis explicativas em todos os instantes do tempo. Para verificar a condição de exogeneidade estrita dos regressores e atestar a validade da estimação por efeitos aleatórios e fixos, Wooldridge (2002, p. 285) propõe dois testes de exogeneidade estrita, um baseado no estimador de primeira diferença e outro no estimador de EF.

A hipótese nula do teste de exogeneidade estrita usando primeiras diferenças é: $H_{0}: \gamma=0$, conforme equação 3.15 .

$$
\Delta \mathbf{R}_{i, t}=\Delta \mathbf{x}_{i, t} \boldsymbol{\beta}+\mathbf{w}_{i, t} \boldsymbol{\gamma}+\Delta \boldsymbol{\epsilon}_{i, t}, \quad t=2, \ldots, T,
$$

em que $R_{i, t}$ é a taxa de retorno do ativo $i$ no instante $t ; \mathbf{w}_{i, t}$ é um subconjunto de $\mathbf{x}_{i, t}$, formado pela variável $S E N T_{t-1}$ e o conjunto $\Omega_{i, t}$ de variáveis de controle, excluindo as dummies de tempo, $\boldsymbol{\epsilon}_{i, t}$ é erro do ativo $i$ no instante $t$ e $\Delta$ é o operador matemático da diferença entre as variáveis nos instantes $t$ e $t-1$.

Já no teste de exogeneidade estrita usando efeitos fixos, a hipótese nula é $H_{0}: \boldsymbol{\delta}=0$, 
conforme a equação 3.16 .

$$
\mathbf{R}_{i, t}=\mathbf{x}_{i, t} \boldsymbol{\beta}+\mathbf{w}_{i, t+1} \boldsymbol{\delta}+\boldsymbol{\eta}_{i}+\boldsymbol{v}_{i, t}, \quad t=1, \ldots, T-1,
$$

em que $R_{i, t}$ é a taxa de retorno do ativo $i$ no instante $t ; \mathbf{w}_{i, t}$ é um subconjunto de $\mathbf{x}_{i, t}$, formado pela variável $S E N T_{t-1}$ e o conjunto $\Omega_{i, t}$ de variáveis de controle, excluindo as dummies de tempo; $\boldsymbol{\eta}_{i}$ é a heterogeneidade não-observada do ativo $i$; e $\boldsymbol{v}_{i, t}$ é o erro aleatório do ativo $i$ no instante $t$.

Desta forma, este teste é fundamental para justificar a utilização destes métodos para a estimação dos modelos, pois apesar dos estudos em geral iniciarem a apresentação de seus resultados com modelos estimados por $P O L S$, e prosseguirem para análise de dados em painel com EA e EF, estes apresentam resultados que são consistentes apenas na hipótese de exogeneidade estrita dos regressores ${ }^{15}$.

\subsubsection{Método dos Momentos Generalizado}

Os métodos de estimação apresentados até aqui podem ser considerados inapropriados caso as variáveis explicativas sejam endógenas. Desta forma, é necessário algum controle para lidar com possíveis problemas de simultaneidade e a causalidade reversa, especialmente nos estudos na área de finanças (BARROS, 2005). Dentro deste contexto, métodos dinâmicos de estimação com utilização de dados em painel, conforme metodologia proposta por Arellano e Bond (1991), Arellano e Bover (1995) e Blundell e Bond (1998) vêm crescendo nos últimos tempos. Os modelos dinâmicos são aqueles que apresentam, entre os regressores, defasagens da variável dependente, geralmente apenas a primeira defasagem. Por exemplo, sendo $y_{i, t}$ a variável resposta, entre os regressores do modelo seria incluída também a variável $y_{i, t-1}$. Considerando que há a variável $M O M_{i, t}$, calculada conforme descrito na seção 3.3.2.6, entre as variáveis explicativas de algumas modelos, problemas de autocorrelação podem se tornar mais relevantes e prejudicar a estimação com os métodos apresentados até o momento.

Segundo Roodman (2009), o GMM é aplicável nas situações em que: (i) os painéis apresentam um $N$ grande e um $T$ fixo, ou seja, muitos indivíduos e uma série de tempo não muito longa; (ii) há uma relação linear entre as variáveis; (iii) há uma única variável dependente, de comportamento dinâmico e que pode depender de seus valores passados; (iv) existem variáveis independentes que não sejam estritamente exógenas, podendo ser correlacionadas com seus valores passados e correlacionadas com os erros; (v) há efeito fixo

\footnotetext{
${ }^{15}$ Em Castro Junior (2008), é apresentado um modelo de apreçamento com dados em painel, em que estes métodos tradicionais de estimação são discutidos com maior detalhe.
} 
para cada indivíduo; e (vi) existem heteroscedasticidade e autocorrelação nas observações dentro de cada empresa, mas não entre as mesmas.

Quando os regressores são correlacionados com os erros no modelo, a ideia é substituí-los por estimativas de seus valores que não o sejam. Esta abordagem é chamada de variáveis instrumentais e os regressores substitutos são denominados de instrumentos. Para que uma variável possa ser utilizada como instrumento, ela deve atender dois requisitos: (i) não deve ser correlacionada com as variáveis explicativas endógenas, e (ii) o instrumento não deve ser correlacionado com o termo de erro, ou seja, não deve apresentar o mesmo problema que a variável substituída.

Normalmente são utilizados como instrumentos as defasagens das variáveis regressoras, ou seja, para instrumentar $y_{i, t-1}$, usam-se $y_{i, t-2}, y_{i, t-3}, \ldots y_{i, t-n}$. Roodman (2009) coloca que embora esta seja a abordagem mais comum, é possível incluir outras variáveis externas como instrumentos.

A estratégia a ser adotada para a utilização dos instrumentos dependerá do grau de exogeneidade das variáveis. Conforme Cameron e Trivedi (2009), variáveis estritamente exógenas são não-correlacionadas com $\epsilon_{i, t}$ e não exigem nenhum tratamento diferenciado, sendo utilizadas como seus próprios instrumentos. Já variáveis predeterminadas ou fracamente exógenas são aquelas que são correlacionadas com os erros passados mas não-correlacionadas com os erros contemporâneos ou futuros: $\mathbb{E}\left[x_{i, t} \epsilon_{i, s}\right] \neq 0$ para $s<t$, e $\mathbb{E}\left[x_{i, t} \epsilon_{i, s}\right]=0$ para $s \geq t$. Neste caso, os regressores são instrumentados com suas defasagens, ou seja, $x_{i, t}$ é instrumentado por $x_{i, t-1}, x_{i, t-2}, \ldots$.

Outra possibilidade é os regressores serem contemporaneamente endógenos: $\mathbb{E}\left[x_{i, t} \epsilon_{i, s}\right] \neq 0$ para $s \leq t$, e $\mathbb{E}\left[x_{i, t} \epsilon_{i, s}\right]=0$ para $s>t$. Nesta situação, quando $\mathbb{E}\left[x_{i, t} \epsilon_{i, t}\right] \neq 0, x_{i, t-1}$ não é um instrumento válido para o modelo de primeiras diferenças, sendo utilizadas as variáveis a partir do instante $t-2$.

Seja esta a equação que representa um modelo geral cujos coeficientes serão estimados por GMM:

$$
\mathbf{y}=\mathbf{x}^{\top} \boldsymbol{\beta}+\boldsymbol{\epsilon}, \quad \mathbb{E}[\boldsymbol{\epsilon} \mid \mathbf{z}] \quad=0,
$$

em que $\boldsymbol{\beta}$ é um vetor coluna de coeficientes; $\mathbf{y}$ e $\boldsymbol{\epsilon}$ são variáveis aleatórias; $\mathbf{x}=\left[x_{1} \ldots x_{k}\right]^{\top}$ é um vetor coluna de $k$ regressores; $\mathbf{z}=\left[z_{1} \ldots z_{j}\right]^{\top}$ é um vetor de $j$ instrumentos, sendo que $\mathbf{x}$ e $\mathbf{z}$ podem compartilhar elementos; e $j \geq k$. Sejam $\mathbf{X}, \mathbf{Y}$ e $\mathbf{Z}$ as matrizes de $N$ observações para $\mathbf{x}, \mathbf{y}$ e $\mathbf{z}$, tem-se que $\mathbf{E}=\mathbf{Y}-\mathbf{X} \boldsymbol{\beta}$. Sendo $\widehat{\boldsymbol{\beta}}$ a estimativa de $\boldsymbol{\beta}$, os resíduos da estimação serão dados por $\widehat{\mathbf{E}}=\left[\hat{e}_{1} \ldots \hat{e}_{N}\right]^{\top}=\mathbf{Y}-\mathbf{X} \widehat{\boldsymbol{\beta}}$. Assume-se apenas que a matriz de covariâncias dos resíduos, $\mathbb{E}\left[\mathbf{E E}^{\top} \mid \mathbf{Z}\right] \equiv \Omega$, existe. 
Conforme Roodman (2009), o desafio de estimar este modelo está no fato de que, sendo todos os instrumentos teoricamente ortogonais ao termo de erro, ou seja, $\mathbb{E}[\mathbf{z} \boldsymbol{\epsilon}]=0$, impõe-se que o vetor dos momentos empíricos, $\mathbb{E}_{N}[\mathbf{z} \epsilon] \equiv \frac{1}{N} \mathbf{Z}^{\top} \widehat{\mathbf{E}}$, seja igual a zero. Isto leva a uma situação em que é criado um sistema com mais equações que a quantidade de variáveis, se $j>k$. Caso isto ocorra, há uma sobreidentificação do sistema, podendo não ser possível satisfazer todas as condições de momento simultaneamente. O objetivo será atendê-las da melhor forma, buscando minimizar a magnitude de $\mathbb{E}_{N}[\mathbf{z} \boldsymbol{\epsilon}]$.

No GMM, esta magnitude é definida por uma métrica generalizada, baseada em uma forma quadrática positiva semi-definida. Sendo A uma matriz quadrática, a referida é:

$$
\left\|\mathbb{E}_{N}[\mathbf{z} \boldsymbol{\epsilon}]\right\|_{\mathbf{A}}=\left\|\frac{1}{N} \mathbf{Z}^{\top} \widehat{\mathbf{E}}\right\|_{\mathbf{A}} \equiv N\left(\frac{1}{N} \mathbf{Z}^{\top} \widehat{\mathbf{E}}\right)^{\top} \mathbf{A}\left(\frac{1}{N} \mathbf{Z}^{\top} \widehat{\mathbf{E}}\right)=\frac{1}{N} \widehat{\mathbf{E}}^{\top} \mathbf{Z} \mathbf{A} \mathbf{Z}^{\top} \widehat{\mathbf{E}}
$$

Para resolver a equação (3.17) por GMM, deve-se encontrar a estimativa $\widehat{\boldsymbol{\beta}}_{\mathbf{A}}$ que minimize a equação (3.18), ou seja, $\widehat{\boldsymbol{\beta}}_{\mathbf{A}}=\arg \min _{\widehat{\beta}}\left\|\mathbf{Z}^{\top} \widehat{\mathbf{E}}\right\|_{\mathbf{A}}$. Assim, a solução será resolver $\frac{d}{d \widehat{\beta}}\left\|\mathbf{Z}^{\top} \widehat{\mathbf{E}}\right\|_{\mathbf{A}}=0$. Utilizando a regra da cadeia, tem-se:

$$
\begin{aligned}
0=\frac{d}{d \widehat{\boldsymbol{\beta}}}\left\|\mathbf{Z}^{\top} \widehat{\mathbf{E}}\right\|_{\mathbf{A}} & =\frac{d}{d \widehat{\mathbf{E}}}\left\|\mathbf{Z}^{\top} \widehat{\mathbf{E}}\right\|_{\mathbf{A}} \frac{d \widehat{\mathbf{E}}}{d \widehat{\boldsymbol{\beta}}}=\frac{d}{d \widehat{\mathbf{E}}}\left(\frac{1}{N} \widehat{\mathbf{E}}^{\boldsymbol{\top}}\left(\mathbf{Z} \mathbf{A} \mathbf{Z}^{\top}\right) \widehat{\mathbf{E}}\right) \frac{d(\mathbf{Y}-\mathbf{X} \widehat{\boldsymbol{\beta}})}{d \widehat{\boldsymbol{\beta}}} \\
& =\frac{2}{N} \widehat{\mathbf{E}}^{\top} \mathbf{Z} \mathbf{A} \mathbf{Z}^{\boldsymbol{\top}}(-\mathbf{X}) .
\end{aligned}
$$

Como a equação (3.19) é igual a 0, pode-se eliminar o termo $-2 / N$ e substituir $\widehat{\mathbf{E}}$ por $\mathbf{Y}-\mathbf{X} \widehat{\boldsymbol{\beta}}_{\mathbf{A}}$. Assim:

$$
\begin{aligned}
0 & =\widehat{\mathbf{E}}^{\top} \mathbf{Z} \mathbf{A} \mathbf{Z}^{\top} \mathbf{X}=\left(\mathbf{Y}-\mathbf{X} \widehat{\boldsymbol{\beta}}_{\mathbf{A}}\right)^{\top} \mathbf{Z} \mathbf{A} \mathbf{Z}^{\top} \mathbf{X}=\mathbf{Y}^{\top} \mathbf{Z} \mathbf{A} \mathbf{Z}^{\top} \mathbf{X}-\widehat{\boldsymbol{\beta}}_{\mathbf{A}}^{\top} \mathbf{X}^{\top} \mathbf{Z} \mathbf{A} \mathbf{Z}^{\top} \mathbf{X} \\
& \Rightarrow \mathbf{X}^{\top} \mathbf{Z} \mathbf{A} \mathbf{Z}^{\top} \mathbf{X} \widehat{\boldsymbol{\beta}}_{\mathbf{A}}=\mathbf{X}^{\top} \mathbf{Z} \mathbf{A} \mathbf{Z}^{\top} \mathbf{Y} \\
& \Rightarrow \widehat{\boldsymbol{\beta}}_{\mathbf{A}}=\left(\mathbf{X}^{\top} \mathbf{Z} \mathbf{A} \mathbf{Z}^{\top} \mathbf{X}\right)^{-1} \mathbf{X}^{\top} \mathbf{Z} \mathbf{A} \mathbf{Z}^{\top} \mathbf{Y}
\end{aligned}
$$

$\widehat{\boldsymbol{\beta}}_{\mathbf{A}}$ é a estimativa dos coeficientes da equação (3.17) obtida por GMM. Este estimador é consistente, ou seja, sob certas condições, converge em probabilidade ao $\boldsymbol{\beta}$, à medida em que o tamanho da amostra tende ao infinito (HANSEN, 1982). No entanto, assim como a estimação de dois estágios (2SLS), é em geral enviesada, pois em amostras finitas os instrumentos quase sempre são levemente correlacionados com os componentes endógenos dos regressores instrumentados. O viés do estimador GMM é dado pela seguinte equação:

$$
\begin{aligned}
\widehat{\boldsymbol{\beta}}_{\mathbf{A}}-\boldsymbol{\beta} & =\left(\mathbf{X}^{\top} \mathbf{Z} \mathbf{A} \mathbf{Z}^{\top} \mathbf{X}\right)^{-1} \mathbf{X}^{\top} \mathbf{Z} \mathbf{A} \mathbf{Z}^{\top}(\mathbf{X} \boldsymbol{\beta}+\mathbf{E})-\boldsymbol{\beta} \\
& =\left(\mathbf{X}^{\top} \mathbf{Z} \mathbf{A} \mathbf{Z}^{\top} \mathbf{X}\right)^{-1} \mathbf{X}^{\top} \mathbf{Z} \mathbf{A} \mathbf{Z}^{\top} \mathbf{X} \boldsymbol{\beta}+\left(\mathbf{X}^{\top} \mathbf{Z} \mathbf{A} \mathbf{Z}^{\top} \mathbf{X}\right)^{-1} \mathbf{X}^{\top} \mathbf{Z} \mathbf{A} \mathbf{Z}^{\top} \mathbf{E}-\boldsymbol{\beta}
\end{aligned}
$$


Como $\left(\mathbf{X}^{\top} \mathbf{Z} \mathbf{A} \mathbf{Z}^{\top} \mathbf{X}\right)^{-1} \mathbf{X}^{\top} \mathbf{Z} \mathbf{A} \mathbf{Z}^{\top} \mathbf{X}=1$, tem-se que o viés será:

$$
\widehat{\boldsymbol{\beta}}_{\mathbf{A}}-\boldsymbol{\beta}=\left(\mathbf{X}^{\top} \mathbf{Z} \mathbf{A} \mathbf{Z}^{\top} \mathbf{X}\right)^{-1} \mathbf{X}^{\top} \mathbf{Z} \mathbf{A} \mathbf{Z}^{\top} \mathbf{E}
$$

O próximo passo é discutir qual matriz A deve ser utilizada. Conforme Roodman (2009), uma primeira abordagem seria propor que $\mathbf{A}$ fosse escalar, mas isto seria válido somente se $\mathbb{V}[\mathbf{z} \boldsymbol{\epsilon}]$ fosse escalar também, o que exigiria que $\mathbf{z} \boldsymbol{\epsilon}$ fosse homoscedástico e nãocorrelacionado. Ademais, para que as diferenças de magnitude nas variâncias dos instrumentos não tornem o estimador ineficiente, A deve ponderar os momentos de maneira inversamente proporcional às variâncias e covariâncias dos instrumentos. Desta forma, a matriz eficiente por GMM (EGMM) é:

$$
\mathbf{A}_{E G M M} \equiv \mathbb{V}^{-1}[\mathbf{z} \boldsymbol{\epsilon}]=\operatorname{assint} \mathbb{V}^{-1}\left[\frac{1}{N} \mathbf{Z}^{\top} \mathbf{E}\right] \equiv\left(\operatorname{plim}_{N \rightarrow \infty} N \mathbb{V}\left[\frac{1}{N} \mathbf{Z}^{\top} \mathbf{E}\right]\right)^{-1}
$$

O estimador eficiente por GMM $^{16}$ será dado pela seguinte equação, decorrente da substituição de (3.23) em (3.20):

$$
\widehat{\beta}_{E G M M}=\left(\mathbf{X}^{\top} \mathbf{Z} \mathbb{V}^{-1}[\mathbf{z} \boldsymbol{\epsilon}] \mathbf{Z}^{\top} \mathbf{X}\right)^{-1} \mathbf{X}^{\top} \mathbf{Z} \mathbb{V}^{-1}[\mathbf{z} \boldsymbol{\epsilon}] \mathbf{Z}^{\top} \mathbf{Y}
$$

A menos que se conheça $\mathbb{V}[\mathbf{z} \boldsymbol{\epsilon}]$, não é possível obter $\widehat{\beta}_{E G M M}$. A solução é encontrar um estimador para a matriz de pesos, $\mathbb{V}^{-1}[\mathbf{z} \boldsymbol{\epsilon}]$. Partindo da equação (3.23), tem-se que $\mathbb{V}^{-1}[\mathbf{z} \boldsymbol{\epsilon}]$ é o limite de uma expressão que pode ser construída sobre uma matriz $\Omega \equiv \mathbb{E}\left[\mathbf{E E}^{\top} \mid \mathbf{Z}\right]$ :

$$
\begin{aligned}
\mathbb{V}[\mathbf{z} \boldsymbol{\epsilon}] & =\operatorname{plim}_{N \rightarrow \infty} N \mathbb{V}\left[\frac{1}{N} \mathbf{Z}^{\top} \mathbf{E}\right]=\operatorname{plim}_{N \rightarrow \infty} N \mathbb{E}\left[\frac{1}{N^{2}} \mathbf{Z}^{\top} \mathbf{E} \mathbf{E}^{\top} \mathbf{Z}\right]=\operatorname{plim}_{N \rightarrow \infty} \frac{1}{N} \mathbb{E}\left[\mathbb{E}\left[\mathbf{Z}^{\top} \mathbf{E} \mathbf{E}^{\top} \mathbf{Z} \mid \mathbf{Z}\right]\right] \\
& =\operatorname{plim}_{N \rightarrow \infty} \frac{1}{N} \mathbb{E}\left[\mathbf{Z}^{\top} \mathbb{E}\left[\mathbf{E} \mathbf{E}^{\top} \mid \mathbf{Z}\right] \mathbf{Z}\right]=\operatorname{plim}_{N \rightarrow \infty} \frac{1}{N} \mathbb{E}\left[\mathbf{Z}^{\top} \mathbf{\Omega Z}\right]
\end{aligned}
$$

A situação mais simples é quando se acredita que os erros são homoscedásticos e nãocorrelacionados, caso em que $\boldsymbol{\Omega}=\sigma^{2} \mathbf{I}$. Sob esta condição, a matriz de pesos $\mathbf{A}_{E G M M}$ será dada pelo inverso de $\sigma^{2} \operatorname{plim}_{N \rightarrow \infty} \frac{1}{N} \mathbb{E}\left[\mathbf{Z}^{\top} \mathbf{Z}\right]=\frac{\sigma^{2}}{N} \mathbf{Z}^{\top} \mathbf{Z}$ e o estimador viável e eficiente do coeficiente $\boldsymbol{\beta}$ para o caso em que os erros são i.i.d., $\widehat{\boldsymbol{\beta}}_{V E G M M_{i i d}}$, será:

$$
\widehat{\boldsymbol{\beta}}_{V E G M M_{i i d}}=\left(\mathbf{X}^{\top} \mathbf{Z}\left(\mathbf{Z}^{\top} \mathbf{Z}\right)^{-1} \mathbf{Z}^{\top} \mathbf{X}\right)^{-1} \mathbf{X}^{\top} \mathbf{Z}\left(\mathbf{Z}^{\top} \mathbf{Z}\right)^{-1} \mathbf{Z}^{\top} \mathbf{Y}
$$

Quando não é possível assumir que os erros são i.i.d, não se pode utilizar a simplificação apresentada anteriormente. Consequentemente, a equação do estimador GMM viável e

\footnotetext{
${ }^{16}$ A eficiência deste estimador é demonstrada em Roodman (2009).
} 
eficiente sem a suposição de erros i.i.d. é:

$$
\widehat{\boldsymbol{\beta}}_{V E G M M}=\left(\mathbf{X}^{\top} \mathbf{Z}\left(\mathbf{Z}^{\top} \widehat{\Omega} \mathbf{Z}\right)^{-1} \mathbf{Z}^{\top} \mathbf{X}\right)^{-1} \mathbf{X}^{\top} \mathbf{Z}\left(\mathbf{Z}^{\top} \widehat{\Omega} \mathbf{Z}\right)^{-1} \mathbf{Z}^{\top} \mathbf{Y}
$$

Contudo, uma vez que a matriz $\widehat{\Omega}$ é necessária para a estimação do coeficiente $\widehat{\boldsymbol{\beta}}_{V E G M M}$, e que $\widehat{\Omega}$ é função dos resíduos da estimação, precisa-se de uma estimativa inicial para o coeficiente $\boldsymbol{\beta}$. Conforme Roodman (2009), contanto que a estimativa inicial seja consistente, o estimador GMM será eficiente, ou seja, independentemente da matriz A escolhida, esta convergirá para a matriz ótima à medida em que $N$ cresce. Habitualmente, a matriz $\mathbf{A}=\left(\mathbf{Z}^{\top} \mathbf{H Z}\right)^{-1}$, tal que $\mathbf{H}$ é uma estimativa de $\boldsymbol{\Omega}$, calculada sob a suposição de que os erros são homoscedásticos.

Assim, para se obter a estimativa dos coeficientes por GMM, é estimada uma primeira regressão em que $\widehat{\boldsymbol{\Omega}}$ é substituído por uma matriz $\mathbf{H}$ arbitrária, encontrando-se $\widehat{\boldsymbol{\beta}}_{1}$ e obtêmse os resíduos desta estimação, gerando os resultados da versão GMM em um estágio. A partir destes, é gerada uma matriz $\widehat{\Omega}_{\widehat{\boldsymbol{\beta}}_{1}}$ e a regressão é novamente estimada com $\mathbf{A}=$ $\left(\mathbf{Z}^{\top} \widehat{\boldsymbol{\Omega}}_{\widehat{\boldsymbol{\beta}}_{1}} \mathbf{Z}\right)^{-1}$. O estimador obtido com este segundo procedimento, $\widehat{\boldsymbol{\beta}}_{2}$, será $\widehat{\boldsymbol{\beta}}_{V E G M M}$, um estimador eficiente e robusto a quaisquer formas de heteroscedasticidade e correlação. Este passo adicional caracteriza a estimação GMM em dois estágios. Resumidamente, tem-se:

$$
\begin{aligned}
& \widehat{\boldsymbol{\beta}}_{1}=\left(\mathbf{X}^{\top} \mathbf{Z}\left(\mathbf{Z}^{\top} \mathbf{H Z}\right)^{-1} \mathbf{Z}^{\top} \mathbf{X}\right)^{-1} \mathbf{X}^{\top} \mathbf{Z}\left(\mathbf{Z}^{\top} \mathbf{H Z}\right)^{-1} \mathbf{Z}^{\top} \mathbf{Y} \\
& \widehat{\boldsymbol{\beta}}_{2}=\widehat{\boldsymbol{\beta}}_{V E G M M}=\left(\mathbf{X}^{\top} \mathbf{Z}\left(\mathbf{Z}^{\top} \widehat{\boldsymbol{\Omega}}_{\widehat{\boldsymbol{\beta}}_{1}} \mathbf{Z}\right)^{-1} \mathbf{Z}^{\top} \mathbf{X}\right)^{-1} \mathbf{X}^{\top} \mathbf{Z}\left(\mathbf{Z}^{\top} \widehat{\boldsymbol{\Omega}}_{\widehat{\boldsymbol{\beta}}_{1}} \mathbf{Z}\right)^{-1} \mathbf{Z}^{\top} \mathbf{Y}
\end{aligned}
$$

O procedimento de dois estágios pode apresentar um viés para baixo no cálculo dos errospadrão dos coeficientes estimados. Contudo, este viés é minimizado com o uso da correção proposta por Windmeijer (2005).

\subsubsection{GMM em Diferenças}

Considerando a equação original do modelo:

$$
\begin{aligned}
y_{i, t} & =\alpha y_{i, t-1}+\boldsymbol{\beta}^{\boldsymbol{\top}} \mathbf{z}_{i, t}+\epsilon_{i, t} \\
\epsilon_{i, t} & =\eta_{i}+v_{i, t} \\
\mathbb{E}\left[\eta_{i}\right] & =\mathbb{E}\left[v_{i, t}\right]=\mathbb{E}\left[\eta_{i} v_{i, t}\right]=0 .
\end{aligned}
$$


O termo de erro possui dois componentes ortogonais: o efeito não-observado específico para cada empresa, $\eta_{i}$, e o termo de erro aleatório, $v_{i, t}$.

O método conhecido como GMM em Diferenças (GMM-Dif), desenvolvido por Arellano e Bond (1991), transforma todos os regressores ao extrair as primeiras diferenças das variáveis em relação aos seus valores passados. Aplicando esta transformação à equação (3.29), tem-se a equação do GMM-Dif:

$$
\Delta y_{i, t}=\alpha \Delta y_{i, t-1}+\boldsymbol{\beta}^{\mathbf{\top}} \Delta \mathbf{z}_{i, t}+\Delta v_{i, t}
$$

em que $\Delta y_{i, t} \equiv y_{i, t}-y_{i, t-1}, \Delta \mathbf{z}_{i, t} \equiv \mathbf{z}_{i, t}-\mathbf{z}_{i, t-1}$ e $\Delta \epsilon_{i, t} \equiv \epsilon_{i, t}-\epsilon_{i, t-1}$.

Este procedimento consequentemente elimina a heterogeneidade não-observada, uma vez que esta é invariante no tempo, implicando em $\Delta \eta_{i}=0$. A transformação de primeira diferença tem a vantagem de dispensar qualquer suposição acerca da correlação entre $\eta_{i}$ e $\mathbf{z}_{i, t}$.

Esta vantagem, entretanto, pode levar a uma redução considerável na quantidade de pontos, caso o painel tenha períodos sem observação no meio da série, ou empresas com poucas observações. Considerando que a amostra é um painel desbalanceado, o cálculo de diferenças pode reduzir drasticamente a quantidade de observações. Para lidar com este problema, foram utilizadas as transformações de desvios ortogonais, conforme proposto por Arellano e Bover (1995). Em vez de subtrair as observações anteriores, é subtraída a média das observações futuras. Na estimação tradicional, se há um $x_{i, t}$ faltante, levará à falta de $\Delta x_{i, t}$ e $\Delta x_{i, t+1}$. Com a transformação de desvios ortogonais, a observação $\Delta x_{i, t+1}$ não é perdida.

Para verificar a validade dos instrumentos utilizados na estimação por GMM, deve ser aplicado o teste de autocorrelação de Arellano e Bond nos termos de erro $v_{i, t}$. O termo de erro $\epsilon_{i, t}$ é presumidamente autocorrelacionado, pois ele contém o efeito fixo não-observado $\eta_{i}$, e o estimador GMM foi construído para eliminar este problema. No entanto, $v_{i, t}$ apresentará autocorrelação de primeira ordem se $y_{i, t-2}$ for endógeno a $v_{i, t-1}$ e consequentemente a $\Delta \epsilon_{i, t}=v_{i, t}-v_{i, t-1}$. Conforme Roodman (2009), isto tornaria o termo $y_{i, t-2}$ um instrumento inválido. Caso isto ocorra, é necessário restringir a defasagem dos instrumentos para 3 ou mais períodos. Se for encontrada uma autocorrelação de ordem 2, este processo teria que incluir defasagens maiores ainda, assim por diante.

Considerando-se que os estimadores de GMM-Dif são gerados a partir das primeiras diferenças, seus resíduos tendem a ser autocorrelacionados e por isso devem ser aplicados testes de autocorrelação. Como $\Delta v_{i, t}$ é matematicamente relacionado a $\Delta v_{i, t-1}$, por compartilharem o termo $v_{i, t-1}$, espera-se uma autocorrelação de primeira ordem negativa 
(estatística $m 1$ ). Para verificar a autocorrelação de primeira ordem nas diferenças, devese observar a autocorrelação de segunda ordem $(m 2)$, em que se espera encontrar $m 2$ não significante caso $\eta_{i}$ seja não-autocorrelacionado. Resumidamente, espera-se rejeitar a hipótese na primeira ordem, mas não em níveis superiores (segunda ordem em diante), isto é, deseja-se encontrar um valor negativo e significante para $m 1$ e não significante para $m 2$.

Um outro teste de especificação é o de sobreidentificação. Uma vez que a quantidade de instrumentos utilizados supera a quantidade de parâmetros a serem estimados, aplica-se o teste de restrições de Sargan (1958) para verificar a validade do conjunto de instrumentos. A hipótese nula do teste é que as variáveis instrumentais e os resíduos não são correlacionados e os instrumentos são válidos e podem ser utilizados no modelo.

Este teste é, entretanto, inconsistente quando se suspeita da não-esfericidade nos erros, conforme Roodman (2009). Neste caso, recomenda-se o teste de Hansen (1982), que calcula a estatística para uma estimativa de dois estágios. Baum, Schaffer e Stillman (2003) afirmam que a estatística do teste de Sargan (1958) é um caso específico do $J$ de Hansen (1982). Para uma situação de homoscedasticidade condicional, ambas apresentariam o mesmo valor.

\subsubsection{GMM Sistêmico}

O modelo de Blundell e Bond (1998) é um aperfeiçoamento da versão do GMM em Diferenças, com a adição da premissa de que as primeiras diferenças das variáveis instrumentais não são correlacionadas com os erros, ou seja, $\mathbb{E}\left[\Delta \mathbf{z}_{i, t-1} \epsilon_{i, t}\right]=0 \Rightarrow \mathbb{E}\left[\Delta \mathbf{z}_{i, t-1}\left(v_{i, t}+\eta_{i}\right)\right]=0$.

Esta restrição adicional de não-correlação entre $\Delta \mathbf{z}_{i, t-1}$ e $v_{i, t}$ permite a inclusão de mais instrumentos $\left(\Delta y_{i, t-1}\right.$ e as defasagens em nível), o que consequentemente melhora a eficiência da estimação. Este modelo, conhecido como GMM Sistêmico (GMM-Sys), baseia-se em um sistema de equações, em que os instrumentos usados nas equações em níveis são as primeiras diferenças defasadas das séries e os instrumentos usados nas equações em primeiras diferenças são os níveis defasados das séries (BOND; HOEFFLER; TEMPLE, 2001).

Conforme Blundell e Bond (1998), a não-correlação entre $\Delta \mathbf{z}_{i, t-1}$ e $v_{i, t}$ é garantida se o processo estocástico que gera $\mathbf{z}_{i, t-1}$ for estacionário. Tal condição é suficiente mas não necessária. Deste modo, o teste de raiz unitária para painel é aplicado com o objetivo de dar suporte à validade da premissa. A estimação por GMM-Sys é mais apropriada que o GMM-Dif para modelos cujas séries temporais apresentam um processo de raiz unitária (OLIVEIRA, 2007). 
Podem ser utilizados os mesmos testes de sobreidentificação que no GMM-Dif. Os testes de Sargan/Hansen avaliam todo o conjunto de restrições, mas o seu poder reduz-se à medida em que a proporção entre a quantidade de instrumentos e de observações aumenta. Há um problema adicional quando se tem suspeitas iniciais quanto à validade dos instrumentos empregados (BAUM; SCHAFFER; STILLMAN, 2003).

Na análise de diagnóstico do modelo, pode ser aplicado o teste DIF-Hansen. Este procedimento baseia-se na diferença entre as estatísticas dos testes de Hansen para um mesmo modelo, estimado por GMM-Sys e por GMM-Dif. A hipótese nula, se não rejeitada, indica que as condições adicionais para o uso do GMM-Sys são válidas.

Os estimadores GMM-Dif e GMM-Sys utilizam as condições de momentos para estimar os parâmetros, consistente e eficientemente, de acordo com duas variações: um ou dois estágios. O estimador em dois estágios é assintoticamente mais eficiente que o estimador do primeiro estágio, mas os erros-padrão resultantes podem ser enviesados para baixo (ARELlanO; BOND, 1991; BLUNDELL; BOND, 1998). Como consequência, os resultados podem ser imprecisos, especialmente para amostras finitas e com grande quantidade de instrumentos. Contudo, para a estimação do painel pelo estimador GMM-Sys de dois estágios, utilizou-se uma correção, proposta por Windmeijer (2005), na matriz de variâncias para tratar a heteroscedasticidade e resultar em estimativas corrigidas dos erros padrão em amostras finitas. Após serem feitas simulações, Windmeijer (2005) demonstrou que após a correção da matriz, as estimativas em dois estágios eram mais eficientes que as estimativas em um estágio mesmo para amostras finitas.

\subsection{Alternativas Robustas de Análise}

Além da preocupação com o método de estimação utilizado, diferentes especificações dos modelos são utilizadas para assegurar a estabilidade dos resultados quanto ao objetivo proposto pela pesquisa. Para isto, foram exploradas diferentes definições operacionais das variáveis, medindo-se um mesmo construto por diferentes proxies. Estimações através de métodos GMM-Dif e GMM-Sys, de um e de dois estágios, permitem comparar a magnitude do coeficiente e estabilidade dos resultados.

Uma outra preocupação foi quanto às observações extremas, comumente chamadas na literatura por outliers. Para lidar com este problema, foram utilizadas variáveis "Winsorizadas". A "Winsorização", procedimento originalmente proposto pelo bioestatístico Charles P. Winsor, consiste em gerar uma nova variável, sendo que são selecionados os "h" valores extremos (acima ou abaixo dos percentis mínimos e máximos definidos) e estes são substituídos respectivamente pelos valores menores e maiores adjacentes na distribuição. 
Esta quantidade "h" de valores pode também ser definida como uma proporção "p" da amostra. Neste estudo, adotou-se $p=0,01$, ou seja, $2 \%$ dos valores extremos foram substituídos, sendo $1 \%$ na parte inferior e $1 \%$ na parte superior. Conforme Barnett e Lewis (1994), esta abordagem possui a vantagem de não excluir nenhuma observação da amostra, apenas a torna menos extrema.

\subsection{Limitações do Modelo Empírico}

\subsubsection{Amostragem}

A criação do índice de sentimento no Brasil está limitada à existência de medidas com histórico suficiente para a análise estatística, ou mesmo à presença de instrumentos financeiros que permitam a geração de variáveis de sentimento sugeridas por estudos empíricos anteriores.

As empresas selecionadas para esta pesquisa foram aquelas que apresentaram disponibilidade de dados que permitissem testes estatísticos, o que incluía a questão da negociabilidade dos papéis na bolsa. Além disso, em função da inexistência ou mesmo da não-disponibilidade de dados para períodos anteriores a janeiro de 1999, houve um recorte temporal de janeiro de 1999 a dezembro de 2008. Esse critério leva a uma redução na possibilidade de generalização dos resultados da pesquisa, uma vez que cria um viés de seleção da amostra.

\subsubsection{Definição Operacional das Variáveis}

A possível influência de características não-racionais nos preços dos ativos financeiros não é uma questão de pesquisa com resposta definitiva em finanças. Pode-se questionar a validade das variáveis sugeridas neste estudo para medir o sentimento do investidor, ainda que estas tenham sido baseadas em outros estudos, com razoável aceitação pela comunidade

científica. Pode ser questionado o índice de mercado ou mesmo as definições utilizadas para estimação dos $\beta$ s de mercado dos ativos ou mesmo as definições das variáveis de controle. 


\subsubsection{Especificação do Modelo}

Conforme foi exposto ao longo deste capítulo, tentou-se limitar os problemas com relação à especificação do modelo, por meio do uso de testes de identificação e técnicas para a redução de problemas de estimação. No entanto, a especificação do modelo é uma limitação sempre presente nos estudos, que pode levar à inconsistência nas estimações. Além disso, apesar do uso de variáveis de controle conforme sugerido pela maior parte dos estudos empíricos de modelos de apreçamento, é possível que variáveis não incorporadas ao modelo sejam correlacionadas com os regressores. 


\section{Capítulo 4}

\section{Resultados}

"A scientist is happy, not in resting on his

attainments but in the steady acquisition of fresh

knowledge."

Max Planck

\section{$4.1 \quad$ Índice de Sentimento}

Nesta seção, serão apresentados e discutidos os resultados com relação à criação do índice de sentimento para o mercado brasileiro, conforme procedimento descrito na seção 3.4.

\subsubsection{Estatísticas Descritivas}

Dentre as variáveis de sentimento apresentadas nos trabalhos pesquisados, foram selecionadas para compor o índice de sentimento desta pesquisa aquelas que tivessem dados históricos disponíveis e que fossem aplicáveis ao mercado brasileiro. Não é possível, no mercado brasileiro, utilizar variáveis como $C E F D$ ou $P C R$, uma vez que não tem uma quantidade representativa de fundos fechados com cotações em bolsa ou mesmo um mercado líquido de opções de venda. Desta forma, as variáveis escolhidas para o cálculo do índice de sentimento para o mercado brasileiro foram: $S, N I P O, R I P O, T U R N, D I V$ e $T R I N$, cujas principais estatísticas descritivas são apresentadas na Tabela 4.1.

A variável $R I P O$, no período estudado, apresentou uma série com muitos dados faltantes ou mesmo séries intermitentes, o que torna a variável de pouca utilidade na diferenciação 
Tabela 4.1 - Estatísticas descritivas das variáveis de sentimento

\begin{tabular}{lrrrrccc}
\hline Variável & Média & \multicolumn{1}{c}{ DP } & Mínimo & $\mathbf{1}^{\mathbf{o}} \mathbf{q t .}$ & Mediana & $\mathbf{3}^{\mathbf{o}} \mathbf{q t .}$ & Máximo \\
\hline S & 0,326 & 0,239 & 0,025 & 0,125 & 0,312 & 0,513 & 0,878 \\
NIPO & 4,025 & 5,056 & 0 & 1 & 3 & 4,5 & 20 \\
RIPO & 0,027 & 0,166 & $-0,765$ & 0 & 0,014 & 0,058 & 0,498 \\
TURN & 0,189 & 0,093 & 0,072 & 0,098 & 0,169 & 0,266 & 0,423 \\
DIV & 0,018 & 0,215 & $-0,569$ & $-0,047$ & 0,030 & 0,080 & 0,955 \\
TRIN & 1,099 & 0,832 & 0,059 & 0,545 & 0,869 & 1,643 & 3,463 \\
\hline
\end{tabular}

As siglas utilizadas na tabela e seus significados são: DP - desvio-padrão, qt. - quartil.

As definições das variáveis desta tabela estão no Quadro B.1 do Apêndice B.

de sentimento ao longo do período. Desta forma, optou-se por eliminá-la do cálculo do índice de sentimento, permanecendo então cinco variáveis. O procedimento de geração do índice de sentimento a partir destas, com uso da técnica multivariada de componentes principais, é apresentado na próxima seção.

\subsubsection{Componentes Principais}

A construção do índice de sentimento utilizou, inicialmente, as cinco séries históricas disponíveis - S, NIPO, TURN, DIV e TRIN - e suas defasagens, com o objetivo de determinar a temporalidade correta de cada uma das variáveis. A partir deste índice de primeiro estágio, $S E N T_{10}$, são calculadas as correlações entre este índice e todas as variáveis, incluindo também suas defasagens, que estão apresentadas na Tabela 4.2. Permaneceu no índice o instante de tempo $(t$ ou $t-1)$ que apresentou maior correlação com o índice de primeiro estágio.

Tabela 4.2 - Correlação entre $S E N T_{10}$ e as variáveis de sentimento

\begin{tabular}{|c|c|}
\hline Variável & Correlação com $S E N T_{10}$ \\
\hline$S_{t}$ & $0,4510^{* *}$ \\
\hline$S_{t-1}$ & $0,4262^{* *}$ \\
\hline NIPO & $0,8614^{* *}$ \\
\hline$N I P O_{t-1}$ & $0,8160^{* *}$ \\
\hline$T U R N_{t}$ & $0,7839^{* *}$ \\
\hline$T U R N_{t-1}$ & $0,7916^{* *}$ \\
\hline$D I V_{t}$ & $-0,4795^{* *}$ \\
\hline$D I V_{t-1}$ & $-0,7036^{* *}$ \\
\hline$T R I N_{t}$ & $-0,3323^{*}$ \\
\hline$T R I N_{t-1}$ & $-0,3009^{\dagger}$ \\
\hline
\end{tabular}


Desta forma, foi possível determinar as variáveis e sua temporalidade para criar a variável $S E N T$, como um índice parcimonioso, composto pelas variáveis $S_{t}, N I P O_{t}, T U R N_{t-1}$, $D I V_{t-1}$ e $T R I N_{t}$. Observa-se que todas as correlações apresentaram-se significantemente diferentes de zero a $1 \%$, com exceção da variável $T R I N$, significante a $5 \%$.

Uma vez definidas as temporalidades de cada uma das variáveis, foi realizada a Análise de Componentes Principais (ACP) para a construção do índice parcimonioso. No Quadro 3.1, na página 77, foram apresentados os instantes de tempo esperados para cada uma das variáveis que compõem o índice. Pode-se observar que todas apresentaram o instante de tempo esperado para a formação da variável SENT, com exceção da variável TRIN. Esperava-se que esta apresentasse uma defasagem em relação ao índice, supondo-se que as negociações em bolsa antecipariam o sentimento do mercado.

Os autovalores para cada um dos componentes, apresentados na Tabela 4.3, indicam que o primeiro componente, SENT, explica 49,03\% da variância da amostra, o que é uma parcela relevante da variação comum das variáveis.

Tabela 4.3 - Autovalores dos componentes principais com variáveis de sentimento

\begin{tabular}{crrr}
\hline Componente & Autovalor & Proporção & Acumulada \\
\hline 1 & 2,4514 & 0,4903 & 0,4903 \\
2 & 0,9045 & 0,1809 & 0,6712 \\
3 & 0,7313 & 0,1463 & 0,8174 \\
4 & 0,5894 & 0,1179 & 0,9353 \\
5 & 0,3234 & 0,0647 & 1 \\
\hline & Número de observações: & 39 \\
& Quantidade de componentes: & 5 \\
\hline
\end{tabular}

A partir dos autovalores apresentados na Tabela 4.3, é possível obter o scree plot dos componentes, para analisar a relevância dos primeiros fatores na explicação da variância das variáveis utilizadas no modelo. Nota-se que apenas o primeiro componente apresenta um autovalor superior a 1, levando à formação de um "cotovelo" na Figura 4.1. Nela estão apresentados dois métodos de determinação do número de componentes a serem retidos, que indicam ser adequado permanecer com o primeiro componente apenas. A linha correspondente à ACP apresenta graficamente os autovalores obtidos para cada um dos cinco componentes, conforme Tabela 4.3. Pela regra de Kaiser (1960), o critério indica que o componente deverá permanecer somente se possuir um autovalor maior que 1, o que leva à retenção apenas do primeiro componente. Graficamente, observa-se que apenas o Componente 1 apresenta autovalor superior à linha horizontal indicadora do critério de Kaiser. Quanto à linha da análise paralela, os autovalores apresentados foram gerados 
por simulação, com o objetivo de comparar se os autovalores encontrados na ACP são superiores a outros gerados a partir de dados aleatórios. Desta forma, segundo este critério, devem permanecer no modelo os componentes que apresentarem autovalores superiores ao da análise paralela, pois apenas estes teriam um poder de explicação melhor que dados aleatórios. Os autovalores calculados para cada critério, representados graficamente na Figura 4.1, podem ser encontrados na Tabela A.2 do Apêndice A.

Um cuidado adicional deve ser tomado com relação ao autovalor do último componente. O intervalo de confiança (IC) a 95\% do autovalor do último componente para o índice de sentimento não deve conter o zero, pois indicaria a presença de variáveis dispensáveis no modelo. O IC de todos os autovalores estão apresentados na Tabela A.1 do Apêndice A, na página 141. Pode-se observar que o IC do Componente 5 não contém o zero. Desta forma, nenhuma das variáveis empregadas na construção do índice deve ser excluída do modelo, permanecendo então as cinco variáveis propostas.

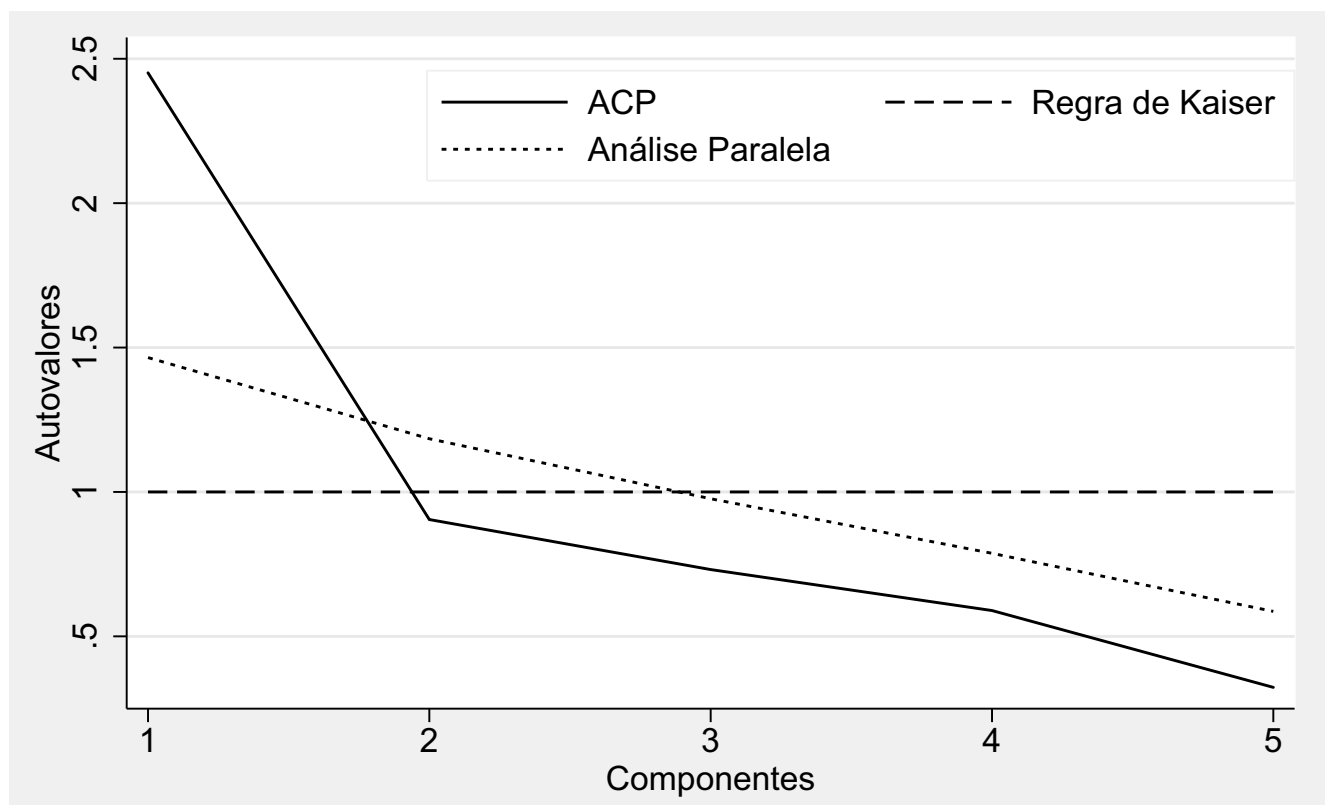

Figura 4.1 - Scree plot de SENT

Estando então validada a ACP com as cinco variáveis, e com a recomendação de permanecer apenas com o primeiro componente, a equação do índice de sentimento é:

$$
\begin{aligned}
S E N T_{t}= & +0,3941 S_{t}+0,5574 N I P O_{t}+0,4796 T U R N_{t-1} \\
& -0,4802 D I V_{t-1}-0,2708 T R I N_{t}
\end{aligned}
$$

Observando-se a equação (4.1) e comparando-a com o Quadro 3.1, nota-se que todas as variáveis apresentaram os sinais conforme esperado. A variável relacionada à maior movimentação na bolsa, $T U R N$, apresentou relação direta com o índice de sentimento. 
Além desta, variáveis que indicam a maior oferta de ações por parte das empresas $(S$ e NIPO), também apresentaram sinal positivo. Isto mostra que um aumento na proporção do volume total de emissões por meio de ações e uma maior quantidade de aberturas de capital estão associados a um aumento no nível de sentimento. Por outro lado, uma procura maior por empresas pagadoras de dividendos e um aumento no volume médio de ações em baixa em relação ao volume médio de ações em alta estão inversamente relacionados ao sentimento do mercado.

A Tabela 4.4 apresenta as estatísticas descritivas do índice de sentimento, com medidas de tendência central e dispersão. A média do índice é zero, mas a mediana indica que o índice apresenta mais de $50 \%$ das observações com sinal negativo.

Tabela 4.4 - Estatísticas descritivas do índice de sentimento SENT

\begin{tabular}{lr}
\hline Estatística & \multicolumn{1}{c}{ Valor } \\
\hline Média & 0,000 \\
Desvio-padrão & 1,566 \\
Mínimo & $-2,214$ \\
1 $^{0}$ quartil & $-1,254$ \\
Mediana & $-0,212$ \\
$3^{0}$ quartil & 0,647 \\
Máximo & 4,770 \\
\hline
\end{tabular}

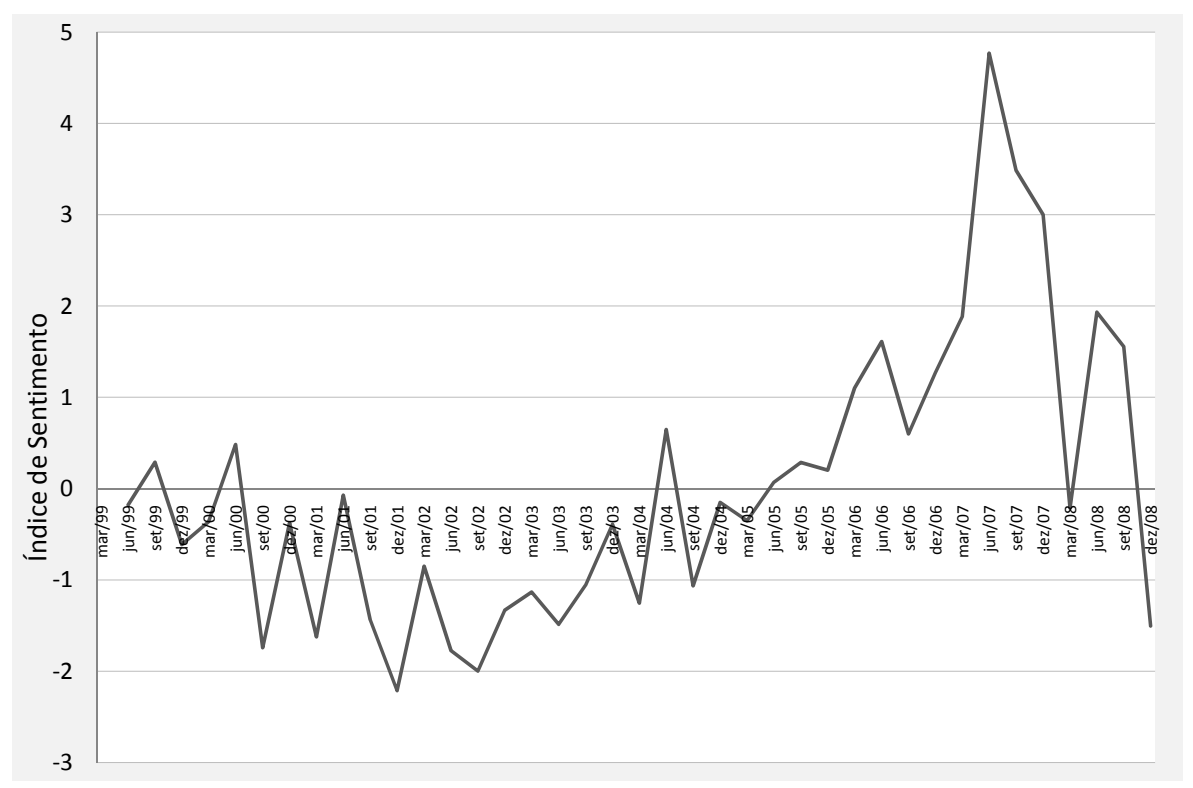

Figura 4.2 - Evolução do Índice de Sentimento

A Figura 4.2 apresenta a evolução do índice de sentimento calculado, desde o segundo trimestre de 1999 ao quarto trimestre de 2008. Como as variáveis TURN e DIV são 
medidas no instante $t-1$ para construir $S E N T$ no instante $t$, não há $S E N T$ para o primeiro trimestre da série. Observa-se que os resultados obtidos apresentam em geral valores negativos para os índices até o final de 2004/início de 2005. A variável SENT apresentou valores inferiores a zero em 23 dos 39 trimestres para os quais foi calculado o índice de sentimento. No quarto trimestre de 2001, o índice apresentou seu menor valor, período após os ataques de 11 de setembro de 2001 e seus reflexos na economia mundial. Houve uma evolução positiva no índice até atingir o seu pico máximo, no segundo trimestre de 2007. O ano de 2008 foi marcado por uma queda significativa no índice, mas sem atingir o seu valor mínimo.

Na Tabela 4.5, é apresentada a matriz de correlações entre SENT e as variáveis que o compõem. Observa-se que a correlação entre SENT e suas variáveis apresenta-se significantemente diferente de zero em todos os casos, a 1\%. Além disso, todas as variáveis apresentaram correlações com o sinal esperado com o índice de sentimento.

Tabela 4.5 - Matriz de correlação de $S E N T$ e suas variáveis

\begin{tabular}{ccccccc}
\hline & $S E N T_{t}$ & $S_{t}$ & $N I P O_{t}$ & $T U R N_{t-1}$ & $D I V_{t-1}$ & $T R I N_{t-1}$ \\
\hline$S E N T_{t}$ & 1,00 & & & & & \\
$S_{t}$ & $0,62^{* *}$ & 1,00 & & & & \\
$N I P O_{t}$ & $0,87^{* *}$ & $0,44^{* *}$ & 1,00 & & & \\
$T U R N_{t-1}$ & $0,75^{* *}$ & $0,34^{*}$ & $0,56^{* *}$ & 1,00 & & \\
$D I V_{t-1}$ & $-0,75^{* *}$ & $-0,27$ & $-0,62^{* *}$ & $-0,40^{*}$ & 1,00 & \\
$T R I N_{t}$ & $-0,42^{* *}$ & $-0,11$ & $-0,26$ & $-0,22$ & 0,20 & 1,00 \\
\hline
\end{tabular}

Níveis de significância: *: $5 \% \quad * *: 1 \%$

\subsection{Modelo de Apreçamento}

Nesta seção, serão discutidos os resultados do modelo de apreçamento, em que a variável $S E N T$ criada e apresentada na seção anterior é inserida como variável explicativa das taxas de retorno das ações no mercado brasileiro.

\subsubsection{Estatísticas Descritivas}

A amostra do estudo sobre o modelo de apreçamento nesta pesquisa é composta por 285 empresas, listadas na Tabela B.1 do Apêndice B. As estatísticas descritivas das variáveis de controle estão apresentadas na Tabela 4.6. 
Tabela 4.6 - Estatísticas descritivas das variáveis de controle

\begin{tabular}{lrcrrr}
\hline Variável & Média & Desvio-padrão & $\mathbf{1}^{\mathbf{o}} \mathbf{q t .}$ & Mediana & \multicolumn{1}{c}{$\mathbf{3}^{\mathbf{o}} \mathbf{q t .}$} \\
\hline$C R E S C$ & 0,091 & 2,030 & $-0,045$ & 0,042 & 0,141 \\
$D B A M$ & 0,273 & 0,231 & 0,093 & 0,225 & 0,397 \\
$D B A T$ & 0,514 & 3,271 & 0,117 & 0,268 & 0,419 \\
$\ln A T$ & 14,146 & 2,059 & 13,113 & 14,212 & 15,258 \\
$\ln R L O$ & 12,237 & 2,071 & 11,323 & 12,431 & 13,460 \\
$\ln V M$ & 13,340 & 2,227 & 12,077 & 13,537 & 14,870 \\
$M O M$ & 0,045 & 0,312 & $-0,105$ & 0,033 & 0,185 \\
$V M P L$ & 1,791 & 1,339 & 0,526 & 1,081 & 2,084 \\
\hline
\end{tabular}

As siglas utilizadas na tabela e seus significados são: qt. - quartil; $C R E S C$ é a variação na receita líquida; $D B A M$ é a dívida bruta sobre o ativo a mercado; $D B A T$ é a dívida bruta sobre o ativo total; $A T$ é o seu ativo total; $R L O$ é a receita líquida operacional da empresa; $V M$ é o valor de mercado da empresa; e $V M P L$ é a relação entre valor de mercado e valor contábil; $M O M$ é a variável de momentum, dada pelo retorno da ação no período anterior. A descriçãa operacional das variáveis está disponível na Tabela B.2 do Apêndice B.

\subsubsection{Modelo Linear Geral}

Determinar quais fatores explicam os retornos dos ativos individuais é um dos objetivos principais da pesquisa em finanças. A teoria de apreçamento de ativos tenta identificar quais fatores são relevantes no momento de se estimar os retornos esperados, sendo de vital importância para o entendimento de como funcionam os mercados de capitais. Para isso, adotou-se um modelo de regressão com dados em painel como forma de estimação e teste do modelo de apreçamento. O modelo estimado foi:

$$
R_{i, t}=\theta_{0}+\psi S E N T_{t-1}+\boldsymbol{\omega}^{\top} \Omega_{i, t}+\epsilon_{i, t}, \quad i=1, \ldots, N \quad \text { e } \quad t=1, \ldots, T
$$

tal que, para cada trimestre $t$, foi observado o índice de sentimento no trimestre anterior, $S E N T_{t-1}$. O parâmetro $\psi$ é o coeficiente associado ao índice de sentimento. O conjunto das $k$ variáveis de controle de cada empresa $i$ em um determinado trimestre $t$ está representado no vetor $\Omega_{i, t}$. O vetor $\boldsymbol{\omega}^{\top}$ de dimensão $(k \times 1)$, transposto, é o conjunto de parâmetros das variáveis de controle.

As variáveis de controle utilizadas foram baseadas em pesquisas empíricas anteriores, sendo consideradas fatores importantes em modelos de apreçamento. O objetivo da inserção destas variáveis no modelo é verificar a influência do sentimento na taxa de retorno das ações, expurgando-se o efeito dos seguintes controles, apurados trimestralmente:

(a) tamanho da empresa;

(b) valor de mercado sobre valor contábil das ações; 
(c) alavancagem;

(d) risco de mercado (medido pelo beta da ação);

(e) previsibilidade dos retornos;

(f) setor de atividade;

(g) dummies de tempo.

Especificações alternativas para as variáveis de controle são utilizadas para verificar a estabilidade dos resultados. Conforme apresentado na seção 3.3.2, foram utilizadas diferentes definições para os indicadores dos fundamentos para apreçamento dos ativos nos modelos de regressão. Os Quadros 4.1 e 4.2 mostram qual variável foi utilizada em cada um dos modelos estáticos e dinâmicos analisados, respectivamente. As variáveis $S E N T$, $\beta_{i, t}, V M P L_{i, t}$, bem como as variáveis binárias de setor e de trimestre, estão presentes em todos os modelos. Foram escolhidas medidas alternativas para o tamanho da empresa, alavancagem e previsibilidade de retornos. Para os modelos estáticos, a variável de previsibilidade de retornos foi $C R E S C$. No caso dos modelos dinâmicos, a variável utilizada para a previsibilidade de retornos foi $M O M$.

Quadro 4.1 - Variáveis utilizadas nos modelos estáticos

\begin{tabular}{lcccc}
\hline MODELO & $\mathbf{1}$ & $\mathbf{2}$ & $\mathbf{3}$ & $\mathbf{4}$ \\
\hline Tamanho & $\ln A T$ & $\ln A T$ & $\ln V M$ & $\ln R L O$ \\
Alavancagem & $D B A M$ & $D B A T$ & $D B A T$ & $D B A M$ \\
Previsibilidade & $C R E S C$ & $C R E S C$ & $C R E S C$ & $C R E S C$ \\
\hline
\end{tabular}

As definições das variáveis desta tabela estão no Quadro B.1 do Apêndice $\mathrm{B}$.

Quadro 4.2 - Variáveis utilizadas nos modelos dinâmicos

\begin{tabular}{lcccc}
\hline MODELO & $\mathbf{5}$ & $\mathbf{6}$ & $\mathbf{7}$ & $\mathbf{8}$ \\
\hline Tamanho & $\ln V M$ & $\ln V M$ & $\ln A T$ & $\ln R L O$ \\
Alavancagem & $D B A T$ & $D B A M$ & $D B A T$ & $D B A M$ \\
Previsibilidade & $M O M$ & $M O M$ & $M O M$ & $M O M$ \\
\hline
\end{tabular}

As definições das variáveis desta tabela estão no Quadro B.1 do Apêndice B. O caráter dinâmico do modelo é dado pela variável $M O M$, que é a taxa de retorno (variável dependente) em $t-1$.

Outro aspecto metodológico tratado por esta pesquisa foi em relação às observações extremas (outliers). Os modelos também foram estimados com o uso de variáveis Winsorizadas. Os parâmetros da equação 3.14 poderiam ser estimados pelo método dos Mínimos Quadrados Ordinário Agrupado $(P O L S)$, mas não o foram pois este método não leva 
em consideração a heterogeneidade não observada. Como consequência, seus parâmetros estimados não capturam características específicas das empresas, invariantes ao longo do período analisado e que podem influenciar o comportamento da variável dependente, conforme apresentado na Seção 3.5.

A heterogeneidade não observada pode ser, por exemplo, caracterizada pela imagem da empresa percebida pelo mercado ou mesmo a qualidade da gestão da empresa. Para considerar este aspecto, o modelo com dados em painel pode incluir um intercepto para cada empresa $i$, igual para todos os períodos $t$. Wooldridge (2002, p. 251-252) afirma que este efeito pode ser considerado fixo ou aleatório. O EA supõe que a correlação entre as variáveis explicativas e o efeito não-observado é nula. O EF permite a existência dessa correlação. Ambos os procedimentos de estimação, seja por EA ou EF, adotam o pressuposto de exogeneidade estrita dos regressores. Para verificar a condição de exogeneidade estrita dos regressores e assegurar que a estimação por efeitos aleatórios e fixos é válida, foram aplicados os testes de exogeneidade estrita conforme equações (3.15) e (3.16) apresentadas na seção 3.5.1. Os resultados levaram à rejeição da hipótese nula de regressores estritamente exógenos, o que indica a necessidade de se utilizar um método de estimação que trate adequadamente o problema de variáveis independentes endógenas.

Para os modelos estáticos, os dois testes de exogeneidade estrita foram aplicados e os resultados estão apresentados na Tabela 4.7. Para os modelos dinâmicos, há a inclusão da variável dependente defasada entre os regressores, o que torna o teste de exogeneidade estrita desnecessário ou até mesmo impraticável, no caso do teste de efeitos fixos.

Tabela 4.7 - Testes de exogeneidade estrita dos regressores: modelos estáticos

\begin{tabular}{llcll}
\hline MODELO & $\mathbf{1}$ & $\mathbf{2}$ & $\mathbf{3}$ & $\mathbf{4}$ \\
\hline Primeiras Diferenças & $3,54^{* *}$ & $3,13^{* *}$ & $6,81^{* *}$ & $4,87^{* *}$ \\
Efeitos Fixos & $8,71^{* *}$ & $25,11^{* *}$ & $5,84^{* *}$ & $6,82^{* *}$ \\
\hline
\end{tabular}

Reporta-se a estatística do teste $F$ e a sinalização indica seu nível de significância observado $(p$-value $)$. Os símbolos $\dagger,{ }^{*} \mathrm{e}^{* *}$ denotam a significância estatística da estimativa nos níveis de $10 \%, 5 \%$ e $1 \%$, respectivamente. Os procedimentos são robustos à presença de erros heteroscedásticos e/ou autocorrelacionados.

Os resultados destes testes de exogeneidade estrita aplicados aos modelos, conforme a Tabela 4.7, indicam claramente a rejeição da hipótese nula de regressores estritamente exógenos. Como consequência, há a necessidade de se utilizar um método de estimação que lide adequadamente com o problema de variáveis independentes endógenas. Assim, acredita-se que a estimação utilizando o GMM é mais adequada neste caso, considerando eventuais problemas com determinação simultânea de algumas variáveis do modelo, conforme discutido na seção 3.5.2. 


\subsubsection{Resultados dos Modelos Estáticos}

O método do GMM em Diferenças, conforme apresentado na Seção 3.5.2.1, transforma todos os regressores ao extrair as primeiras diferenças das variáveis em relação aos seus valores passados, o que consequentemente elimina a heterogeneidade não-observada. Já o estimador GMM Sistêmico consegue tratar os principais problemas de endogeneidade mesmo sem a disponibilidade de instrumentos estritamente exógenos para todos os regressores, com a condição de que não haja correlação das primeiras diferenças defasadas dos regressores endógenos com os erros em nível, incluindo o efeito específico. Conforme discutido na seção 3.5.2.2, o teste de raiz unitária é aplicado às variáveis regressoras com o propósito de verificar a estacionariedade das séries temporais.

Tabela 4.8 - Testes de raiz unitária para painéis das variáveis de controle

\begin{tabular}{|c|c|c|c|c|}
\hline \multirow{2}{*}{ Variável Indep. } & \multicolumn{2}{|c|}{ Dick-Fuller Aumentado } & \multicolumn{2}{|c|}{ Phillips-Perron } \\
\hline & Estatística $\chi^{2}$ & p-value & Estatística $\chi^{2}$ & $p$-value \\
\hline$B E T A$ & 452,18 & 0,264 & 524,66 & 0,060 \\
\hline $\ln A T$ & 1592,62 & 0,000 & 1201,31 & 0,000 \\
\hline $\ln V M$ & 533,2 & 0,750 & 733,45 & 0,000 \\
\hline $\ln R L O$ & 1032,75 & 0,000 & 869,95 & 0,000 \\
\hline$V M P L$ & 875,13 & 0,000 & 1166,84 & 0,000 \\
\hline$R E T$ & 2864,46 & 0,000 & 5622,07 & 0,000 \\
\hline$C R E S C$ & 4628,54 & 0,000 & 7888,01 & 0,000 \\
\hline$D B A M$ & 674,87 & 0,000 & 997,29 & 0,000 \\
\hline$D B A T$ & 1281,69 & 0,000 & 1576,79 & 0,000 \\
\hline
\end{tabular}

$H_{0}$ : todas as séries são não estacionárias e $H_{a}$ pelo menos uma série do painel é estacionária. Reporta-se a estatística do teste $\chi^{2}$ e seu nível de significância observado ( $p$-value). As definições das variáveis desta tabela estão no Quadro B.1 do Apêndice B.

Na Tabela 4.8, estão apresentados os resultados do teste de Fisher para painel, conforme proposto por Maddala e Wu (1999). Para cada variável independente, apresenta-se o valor da estatística qui-quadrado e o seu respectivo nível de significância observado. A hipótese nula do teste é que todas as séries da variável na dimensão transversal não são estacionárias, e a hipótese alternativa é que existe pelo menos uma série daquela variável no painel que é estacionária. Foram calculadas estatísticas qui-quadrado por dois testes: Phillips-Perron (PP) e Dick-Fuller aumentado (ADF). O teste PP utiliza erros-padrão ajustados para potencial autocorrelação, e o teste ADF utilizada defasagens adicionais das primeiras diferenças das variáveis testadas.

O teste de Fisher tem a vantagem de poder ser aplicado para painéis não-balanceados, o que não é permitido por outros testes. Para a variável SENT, foram realizados testes de PP e ADF separadamente, pois esta variável não é um painel de dados, mas sim uma 
série temporal, uma vez que não varia para cada empresa $i$ mas apenas a cada trimestre t. Da mesma forma que para as variáveis em painel, foram calculadas as estatísticas $Z$ por PP e ADF, só que para séries temporais, conforme apresentado na Tabela 4.9.

Tabela 4.9 - Testes de raiz unitária para $S E N T$

\begin{tabular}{lccc}
\hline \multicolumn{2}{c}{ Dick-Fuller } & Aumentado & \multicolumn{2}{c}{ Phillips-Perron } \\
Estatística $Z$ & $p$-value & Estatística $Z$ & $p$-value \\
\hline$-2,682$ & 0,077 & $-2,578$ & 0,097 \\
\hline$H_{0}:$ a série é não-estacionárias e $H_{a}$ a série é estacionária. Reporta-se a \\
estatística do teste $Z$ e seu nível de significância observado $(p$-value), com \\
correção de MacKinnon.
\end{tabular}

Os resultados apresentados na Tabela 4.8 apontam para rejeição da hipótese nula de raiz unitária para todos os regressores, no caso do teste PP e, no caso do ADF, todas as variáveis com exceção de $B E T A$ e $\ln V M$, que também rejeitaram a hipótese de raiz unitária.

Quanto à variável $S E N T$, o nível de significância observado dos testes poderia levar ou não à rejeição da hipótese nula de raiz unitária, dependendo do nível de significância adotado. A um nível de significância de 5\%, as hipóteses seriam rejeitadas, mas a 10\%, estas não seriam rejeitadas. Desta forma, serão reportados os resultados da estimação tanto por GMM-Dif como GMM-Sys, uma vez que a rejeição da hipótese nula é suscetível à escolha do nível de significância justamente para a variável de maior interesse nesta pesquisa.

As tabelas de resultados dos modelos apresentam os valores, os erros-padrão e o nível de significância observado para cada variável em quatro estimações: pelos métodos GMMDif e GMM-Sys, em suas versões de um ou dois estágios. No caso de estimação em um estágio, os parâmetros são estimados a partir de uma matriz de pesos inicial que não é atualizada, conforme discutido na seção 3.5.2. Já a versão de dois estágios calcula preliminarmente as estimativas dos parâmetros baseando-se numa matriz inicial. A partir destas estimativas provisórias, é calculada uma nova matriz de pesos e o modelo é então reestimado, obtendo-se novos coeficientes. Para os modelos de dois estágios, foi aplicada a correção proposta por Windmeijer (2005) com o objetivo de reduzir problemas com viés no cálculo dos erros-padrão em amostras finitas. A quantidade de estágios utilizada na estimação é reportada juntamente com o método, sendo que Dif1 e Dif2 referem-se à estimação por GMM em Diferenças, de um e dois estágios, respectivamente e Sys1 e Sys2 correspondem à estimação por GMM Sistêmico, de um e dois estágios.

Como apresentado no Quadro 4.1, todos os modelos estáticos estimados contém entre as variáveis regressoras o fator de risco sistêmico, medido pelo $\beta$. Espera-se que o sinal desta 
variável seja positivo, ou seja, quanto maior o risco sistêmico do ativo, maior a taxa de retorno esperada. Além do $\beta$, uma outra variável presente em todos os modelos foi o índice $V M P L$, o inverso do fator book-to-market utilizado no modelo de Fama e French (1992), sendo esperado um sinal negativo para este coeficiente.

A variável relacionada a tamanho, medida por três diferentes especificações, deve apresentar sinal negativo, partindo-se do pressuposto de que empresas menores têm retornos esperados superiores. A variável de alavancagem, por sua vez, deve apresentar sinal positivo, indicando que empresas mais endividadas são mais arriscadas e consequentemente, investidores demandam maiores taxas de retorno. Por fim, a variável relacionada ao crescimento das receitas, $C R E S C$, não apresenta um sinal esperado para seu coeficiente, pois há investidores que apostam tanto em um padrão de manutenção da tendência (sinal positivo) como em reversão de preços (sinal negativo).

A fim de verificar a relevância para o modelo dos dois conjuntos de variáveis dummy, de setor e de tempo, é conduzido um teste de Wald para cada conjunto, em cada um dos modelos, para verificar se os parâmetros de cada grupo de variáveis são conjuntamente iguais a zero. Em caso positivo, não haveria relevância estatística em manter tais variáveis no modelo, o que implicaria a necessidade de reestimação do modelo sem o conjunto de variáveis dummy. Em caso negativo, a presença destas variáveis é relevante e consequentemente, devem permanecer no modelo.

Com relação ao índice de sentimento, um coeficiente não significante indicaria que as taxas de retorno das ações não são influenciadas por componentes comportamentais, não sendo portanto um fator de risco a ser considerado no modelo de apreçamento. Um coeficiente significante indica que a influência do sentimento é relevante, sendo relevante discutir o sinal que este apresenta. Um sinal negativo mostra que o excesso de otimismo leva os preços acima do seu valor fundamental, e os preços são corrigidos posteriormente, ocorrendo uma reversão. Desta forma, as taxas de retorno futuras são negativamente impactadas pelo nível de sentimento corrente (BROWN; CLIFF, 2005).

Os resultados do modelo 01, apresentados na Tabela 4.10, indicam que o coeficiente de $S E N T_{t-1}$ é negativo e significante em todas as estimações, sendo a $1 \%$ no modelo GMM-Dif1 e em ambos GMM-Sys, e a 5\% no modelo Dif2. Tal resultado mostra a importância do fator comportamental no modelo de apreçamento e que o impacto na taxa de retorno futura é negativo. Isto indica uma reversão nos preços após os desvios no valor fundamental dos ativos. No caso da variável $B E T A_{i, t}$, o coeficiente mostrouse positivo e estatisticamente significante a $10 \%$ nos modelos estimados por GMM-Dif, conforme esperado inicialmente. Entretanto, nos modelos estimados por GMM-Sys, a variável não apresentou significância. 
Tabela 4.10 - Resultados das estimações por GMM: Modelo 01

\begin{tabular}{|c|c|c|c|c|}
\hline Variável & Dif1 & Dif2 & Sys1 & Sys2 \\
\hline$S E N T_{t-1}$ & $\begin{array}{c}-0,2905^{* *} \\
(0,105)\end{array}$ & $\begin{array}{r}-0,2665^{*} \\
(0,107)\end{array}$ & $\begin{array}{c}-0,3367^{* *} \\
(0,105)\end{array}$ & $\begin{array}{c}-0,3265^{* *} \\
(0,107)\end{array}$ \\
\hline$B E T A_{i, t}$ & $\begin{array}{l}0,1124^{\dagger} \\
(0,060)\end{array}$ & $\begin{array}{l}0,1077^{\dagger} \\
(0,066)\end{array}$ & $\begin{array}{l}0,0663 \\
(0,053)\end{array}$ & $\begin{array}{l}0,0661 \\
(0,056)\end{array}$ \\
\hline $\ln A T_{i, t}$ & $\begin{array}{r}-0,0056 \\
(0,025)\end{array}$ & $\begin{array}{l}0,0008 \\
(0,029)\end{array}$ & $\begin{array}{l}0,0004 \\
(0,014)\end{array}$ & $\begin{array}{l}0,0035 \\
(0,015)\end{array}$ \\
\hline$V M P L_{i, t}$ & $\begin{array}{l}0,0017^{*} \\
(0,001)\end{array}$ & $\begin{array}{l}0,0017^{*} \\
(0,001)\end{array}$ & $\begin{array}{l}0,0007^{* *} \\
(0,001)\end{array}$ & $\begin{array}{l}0,0008^{* *} \\
(0,000)\end{array}$ \\
\hline$D B A M_{i, t}$ & $\begin{array}{c}-0,8364^{* *} \\
(0,196)\end{array}$ & $\begin{array}{c}-0,8508^{* *} \\
(0,202)\end{array}$ & $\begin{array}{c}-1,1941^{* *} \\
(0,145)\end{array}$ & $\begin{array}{c}-1,2317^{* *} \\
(0,155)\end{array}$ \\
\hline$C R E S C_{i, t}$ & $\begin{array}{l}0,0032^{*} \\
(0,002)\end{array}$ & $\begin{array}{l}0,0033 \\
(0,002)\end{array}$ & $\begin{array}{l}0,0037^{* *} \\
(0,001)\end{array}$ & $\begin{array}{l}0,0032^{\dagger} \\
(0,002)\end{array}$ \\
\hline Dummies SETOR & SIM & SIM & SIM & SIM \\
\hline Dummies TEMPO & SIM & SIM & SIM & SIM \\
\hline Qtde. de observações & 2203 & 2203 & 2542 & 2542 \\
\hline Qtde. de instrumentos & 159 & 159 & 180 & 180 \\
\hline$m 1$ & $-6,33(0,000)$ & $-6,33(0,000)$ & $-6,31(0,000)$ & $-6,30(0,000)$ \\
\hline$m 2$ & $-0,34(0,733)$ & $-0,38(0,702)$ & $-0,44(0,658)$ & $-0,47(0,640)$ \\
\hline$J$ de Hansen & \multirow{2}{*}{\multicolumn{2}{|c|}{$130,84(117 ; 0,180)$}} & \multicolumn{2}{|c|}{$132,11(120 ; 0,212)$} \\
\hline DIF-Hansen & & & $1,09(3$ & $0,779)$ \\
\hline
\end{tabular}

A variável dependente é a taxa de retorno das ações, $R_{i, t}$, definida na seção 3.3.2. As definições das demais variáveis regressoras desta tabela estão resumidamente no Quadro B.1 do Apêndice B. Os estimadores utilizados são os GMM em Diferenças e o GMM Sistêmico de um e dois estágios, com transformações de desvios ortogonais. Foram utilizadas como instrumentos as transformações de primeiras diferenças em um período e as defasagens de BETA, VMPL e DBAM. Assume-se que os demais regressores são estritamente exógenos. Os erros-padrão foram obtidos utilizando-se dados agrupados por empresa, de maneira robusta a quaisquer formas de heteroscedasticidade e autocorrelação dos erros do modelo e figuram entre parênteses. Os símbolos $\dagger,{ }^{*} \mathrm{e}^{* *}$ denotam a significância estatística da estimativa nos níveis de $10 \%, 5 \%$ e 1\%, respectivamente. O teste da estatística $J$ de Hansen é uma versão robusta do teste de sobreidentificação de Sargan. $m 1$ e $m 2$ referem-se aos testes de autocorrelação de primeira e segunda ordem e DIF-Hansen baseia-se na diferença entre as estatísticas de Hansen e Sargan calculadas para o mesmo modelo estimado por GMM-Sys e GMM-Dif, ambos de dois estágios. Para os testes de Hansen e DIF-Hansen reporta-se a estatística do teste e, entre parênteses, o número de graus de liberdade e seu nível de significância observado, respectivamente. Para os testes $m 1$ e $m 2$ reporta-se a estatística do teste e, entre parênteses, o nível de significância correspondente. 
Conforme mostra a Tabela 4.10, a variável utilizada para medir o tamanho das empresas foi o logaritmo de seu ativo total, $\ln A T$, que não se mostrou significante por nenhum dos métodos. Desta forma, não foi possível atestar a presença de efeito tamanho no mercado brasileiro, medido pelos ativos. A variável $V M P L$, por sua vez, que representa o índice market-to-book, foi positiva e significante a $1 \%$ nos modelos estimados por GMM-Sys e a $5 \%$ nos modelos estimados por GMM-Dif. O sinal positivo indica que o mercado valoriza algo que não está sendo captado pela contabilidade ou que está sendo de forma incompleta, e exige taxas de retorno maiores quanto maior for a relação entre o valor de mercado das ações e seu valor contábil. O endividamento, medido por $D B A M$, mostrou um sinal contrário ao esperado, pois quanto maior o endividamento da empresa, menor a sua taxa de retorno. O coeficiente negativo foi encontrado em todas as estimações, sendo significante a $1 \%$.

A hipótese nula de que as variáveis dummy de tempo são conjuntamente iguais a zero foi rejeitada ao nível de significância de $1 \%$, devendo permanecer no modelo 01 . O mesmo procedimento foi adotado para as variáveis dummy de setor, e o resultado também indicou a relevância destas, mostrando que são capazes de capturar efeitos macroeconômicos que afetaram todas as empresas em um determinado período ou características particulares de setores de atividade aos quais elas pertencem.

Os modelos de dois estágios foram estimados com a correção proposta por Windmeijer (2005) para amostras finitas. As análises de diagnóstico do modelo 01 reportadas ao final da tabela apontam a favor das hipóteses de identificação: as estatísticas $m 1$, que medem as autocorrelações de primeira ordem nas diferenças, são negativas e significantes e as estatísticas $m 2$, que medem as autocorrelações de segunda ordem, não são significantes. Além disso, não se pode rejeitar as hipóteses nulas dos testes $J$ de Hansen em todos os quatro métodos de estimação. Isto significa que os instrumentos utilizados não são correlacionados com os erros e podem ser utilizados no modelo. O teste de DIF-Hansen testa a validade da restrição adicional requerida pelo GMM-Sys, sendo aplicável aos modelos Sys1 e Sys2.

O modelo 02 , cujos resultados estão apresentados na Tabela 4.11, foi estimado com a variável $D B A T$ como medida alternativa de alavancagem da empresa, ou seja, o nível de endividamento da empresa é calculado sobre o seu ativo contábil. Os demais parâmetros permaneceram idênticos aos modelo 01. O coeficiente da variável $S E N T$, assim como no modelo 01, apresentou coeficiente negativo e significante a um nível de $10 \%$ nos modelos estimados por GMM-Dif de 1 estágio e ambos estimados por GMM-Sys. O resultado indica que a reversão de preços após uma reação exagerada dos investidores quanto aos preços, tanto na alta como na baixa do mercado. 
Tabela 4.11 - Resultados das estimações por GMM: Modelo 02

\begin{tabular}{|c|c|c|c|c|}
\hline Variável & Dif1 & Dif2 & Sys1 & Sys2 \\
\hline$S E N T_{t-1}$ & $\begin{array}{r}-0,1967^{\dagger} \\
(0,106)\end{array}$ & $\begin{array}{r}-0,1689 \\
(0,106)\end{array}$ & $\begin{array}{r}-0,2030^{\dagger} \\
(0,107)\end{array}$ & $\begin{array}{r}-0,1767^{\dagger} \\
(0,106)\end{array}$ \\
\hline$B E T A_{i, t}$ & $\begin{array}{l}0,1082^{\dagger} \\
(0,059)\end{array}$ & $\begin{array}{l}0,1014 \\
(0,069)\end{array}$ & $\begin{array}{l}0,0641 \\
(0,051)\end{array}$ & $\begin{array}{l}0,0418 \\
(0,057)\end{array}$ \\
\hline $\ln A T_{i, t}$ & $\begin{array}{r}-0,0257 \\
(0,025)\end{array}$ & $\begin{array}{r}-0,0167 \\
(0,026)\end{array}$ & $\begin{array}{l}0,0040 \\
(0,006)\end{array}$ & $\begin{array}{l}0,0065 \\
(0,005)\end{array}$ \\
\hline$V M P L_{i, t}$ & $\begin{array}{l}0,0023^{* *} \\
(0,001)\end{array}$ & $\begin{array}{l}0,0023^{* *} \\
(0,001)\end{array}$ & $\begin{array}{l}0,0004^{* *} \\
(0,000)\end{array}$ & $\begin{array}{l}0,0005^{\text {** }} \\
(0,000)\end{array}$ \\
\hline$D B A T_{i, t}$ & $\begin{array}{c}-0,0026^{* *} \\
(0,001)\end{array}$ & $\begin{array}{c}-0,0025^{* *} \\
(0,001)\end{array}$ & $\begin{array}{l}0,0001 \\
(0,001)\end{array}$ & $\begin{array}{l}0,0002 \\
(0,001)\end{array}$ \\
\hline$C R E S C_{i, t}$ & $\begin{array}{l}0,0032^{* *} \\
(0,001)\end{array}$ & $\begin{array}{l}0,0035^{* *} \\
(0,001)\end{array}$ & $\begin{array}{l}0,0028^{* *} \\
(0,001)\end{array}$ & $\begin{array}{l}0,0030^{* *} \\
(0,001)\end{array}$ \\
\hline Dummies SETOR & SIM & SIM & SIM & SIM \\
\hline Dummies TEMPO & SIM & SIM & SIM & SIM \\
\hline Qtde. de observações & 2203 & 2203 & 2542 & 2542 \\
\hline Qtde. de instrumentos & 159 & 159 & 180 & 180 \\
\hline$m 1$ & $-6,39(0,000)$ & $-6,41(0,000)$ & $-6,45(0,000)$ & $-6,43(0,000)$ \\
\hline$m 2$ & $-0,12(0,902)$ & $-0,17(0,865)$ & $-0,15(0,881)$ & $-0,21(0,835)$ \\
\hline $\begin{array}{l}J \text { de Hansen } \\
\text { DIF-Hansen }\end{array}$ & $114,13(1$ & $17 ; 0,558)$ & $\begin{array}{r}112,64(1 \\
1,06(3\end{array}$ & $\begin{array}{l}20 ; 0,671) \\
0,786)\end{array}$ \\
\hline
\end{tabular}

A variável dependente é a taxa de retorno das ações, $R_{i, t}$, definida na seção 3.3.2. As definições das demais variáveis regressoras desta tabela estão resumidamente no Quadro B.1 do Apêndice B. Os estimadores utilizados são os GMM-Dif e o GMM-Sys de um e dois estágios, com transformações de desvios ortogonais. Foram utilizadas como instrumentos as transformações de primeiras diferenças em um período e as defasagens de BETA, VMPL e DBAT. Assume-se que os demais regressores são estritamente exógenos. Os erros-padrão foram obtidos utilizando-se dados agrupados por empresa, de maneira robusta a quaisquer formas de heteroscedasticidade e autocorrelação dos erros do modelo e figuram entre parênteses. Os símbolos $\dagger,{ }^{*} \mathrm{e}^{* *}$ denotam a significância estatística da estimativa nos níveis de $10 \%, 5 \%$ e 1\%, respectivamente. O teste da estatística $J$ de Hansen é uma versão robusta do teste de sobreidentificação de Sargan. $m 1$ e $m 2$ referem-se aos testes de autocorrelação de primeira e segunda ordem e DIF-Hansen baseia-se na diferença entre as estatísticas de Hansen e Sargan calculadas para o mesmo modelo estimado por GMM-Sys e GMM-Dif, ambos de dois estágios. Para os testes de Hansen e DIF-Hansen reporta-se a estatística do teste e, entre parênteses, o número de graus de liberdade e seu nível de significância observado, respectivamente. Para os testes $m 1$ e $m 2$ reporta-se a estatística do teste e, entre parênteses, o nível de significância correspondente. 
O coeficiente de BET A, no modelo 02 , mostrou-se positivo e significante a $10 \%$ apenas na estimação GMM-Dif1, indicando uma fraca evidência de relevância do fator de risco sistêmico neste modelo. A variável de tamanho $\ln A T$ não foi significante em nenhum dos modelos, assim como os resultados encontrados no modelo 01. A variável $V M P L$, de market-to-book, apresentou coeficiente positivo a um nível de significância de $1 \%$ em todas as estimações, assim como a variável CRESC, indicando que ambas impactam positivamente na taxa de retorno das ações. Ou seja, empresas de maior relação entre valor de mercado e contábil, têm taxas de retorno esperadas maiores, assim como empresas que tiveram variação positiva no faturamento líquido no último período.

O endividamento contábil, medido por $D B A T$, apresentou relação negativa com a taxa de retorno nos modelos estimados por GMM-Dif, contrário ao esperado, não sendo significante nos modelos GMM-Sys. Os testes aplicados aos dois grupos de variáveis dummy, tanto de tempo como de setor, rejeitaram a hipótese nula de cada conjunto ser diferente de zero ao nível de significância de $1 \%$, devendo permanecer no modelo estimado. Os testes de especificação apresentados ao final da tabela indicam a validade das estimações por GMM do modelo 02 .

Na Tabela 4.12 estão os resultados da estimação do modelo 03, em que a variável para tamanho utilizada foi o logaritmo natural do valor de mercado $(\ln V M)$, e a proxy para alavancagem foi o endividamento em relação ao ativo a mercado $(D B A M)$. Corroborando os resultados dos modelos anteriores, a variável SENT apresentou coeficiente negativo e significante a $1 \%$ em todas as quatro estimações. A variável de risco sistêmico, BET A, apresentou sinal positivo e significante a $10 \%$ apenas nos modelos GMM-Dif, sendo nãosignificantes nos modelos GMM-Sys. O tamanho, medido agora pela variável $\ln V M$, mostrou-se com coeficiente positivo e significante a $1 \%$ nos modelos estimados por GMMDif. Tal resultado é contrário ao esperado, pois indica que as empresas mais capitalizadas são as que apresentam maiores taxas de retorno. Se forem analisadas as estimações por GMM-Sys, não se pode atestar que o fator tamanho é relevante no modelo de apreçamento.

O índice $V M P L$ mostrou-se com coeficiente positivo e significante em todas as estimações, apresentando resultado contrário ao esperado inicialmente. A alavancagem a mercado, medida por $D B A M$ no modelo 03 , apresentou sinal negativo e significante a $5 \%$ nos modelos GMM-Dif e a 1\% nos modelos GMM-Sys, o que indica uma relação inversa entre endividamento e taxa de retorno esperada, contrária ao esperado. A variável CRESC não foi significante apenas no modelo Dif2, apresentando coeficiente com sinal positivo em todas as demais estimações. Tal resultado indica que empresas com variação positiva na receita têm taxas de retorno esperadas maiores. Os conjuntos de variáveis binárias de setor e de tempo foram testados, e resultados apontaram a favor da permanência destas no modelo. Testes de especificação do modelo GMM confirmam a validade do modelo, 
Tabela 4.12 - Resultados das estimações por GMM: Modelo 03

\begin{tabular}{|c|c|c|c|c|}
\hline Variável & Dif1 & Dif2 & Sys1 & Sys2 \\
\hline$S E N T_{t-1}$ & $\begin{array}{c}-0,3246^{* *} \\
(0,103)\end{array}$ & $\begin{array}{c}-0,2969^{* *} \\
(0,105)\end{array}$ & $\begin{array}{c}-0,3287^{* *} \\
(0,106)\end{array}$ & $\begin{array}{c}-0,3263^{* *} \\
(0,110)\end{array}$ \\
\hline$B E T A_{i, t}$ & $\begin{array}{l}0,1171^{\dagger} \\
(0,063)\end{array}$ & $\begin{array}{l}0,1124^{\dagger} \\
(0,067)\end{array}$ & $\begin{array}{l}0,0678 \\
(0,052)\end{array}$ & $\begin{array}{l}0,0749 \\
(0,055)\end{array}$ \\
\hline $\ln V M_{i, t}$ & $\begin{array}{l}0,0672^{* *} \\
(0,025)\end{array}$ & $\begin{array}{l}0,0709^{* *} \\
(0,026)\end{array}$ & $\begin{array}{r}-0,0175 \\
\quad(0,011)\end{array}$ & $\begin{array}{r}-0,0183 \\
(0,011)\end{array}$ \\
\hline$V M P L_{i, t}$ & $\begin{array}{l}0,0016^{*} \\
(0,001)\end{array}$ & $\begin{array}{l}0,0017^{*} \\
(0,001)\end{array}$ & $\begin{array}{l}0,0006^{*} \\
(0,000)\end{array}$ & $\begin{array}{l}0,0007^{* *} \\
(0,000)\end{array}$ \\
\hline$D B A M_{i, t}$ & $\begin{array}{r}-0,7062^{*} \\
(0,279)\end{array}$ & $\begin{array}{r}-0,7002^{*} \\
(0,284)\end{array}$ & $\begin{array}{c}-1,2256^{* *} \\
(0,158)\end{array}$ & $\begin{array}{c}-1,2576^{* *} \\
(0,169)\end{array}$ \\
\hline$C R E S C_{i, t}$ & $\begin{array}{l}0,0029^{\dagger} \\
(0,002)\end{array}$ & $\begin{array}{l}0,0030 \\
(0,002)\end{array}$ & $\begin{array}{l}0,0037^{* *} \\
(0,001)\end{array}$ & $\begin{array}{l}0,0032^{\dagger} \\
(0,002)\end{array}$ \\
\hline Dummies SETOR & SIM & SIM & SIM & SIM \\
\hline Dummies TEMPO & SIM & SIM & SIM & SIM \\
\hline Qtde. de observações & 2201 & 2201 & 2540 & 2540 \\
\hline Qtde. de instrumentos & 159 & 159 & 180 & 180 \\
\hline$m 1$ & $-6,34(0,000)$ & $-6,35(0,000)$ & $-6,29(0,000)$ & $-6,29(0,000)$ \\
\hline$m 2$ & $-0,32(0,750)$ & $-0,36(0,722)$ & $-0,43(0,668)$ & $-0,45(0,653)$ \\
\hline $\begin{array}{l}J \text { de Hansen } \\
\text { DIF-Hansen }\end{array}$ & \multicolumn{2}{|c|}{$132,94(117 ; 0,149)$} & $\begin{array}{r}130,50(1 \\
37,31 \quad(5\end{array}$ & $\begin{array}{l}20 ; 0,242) \\
6 ; 0,974)\end{array}$ \\
\hline
\end{tabular}

A variável dependente é a taxa de retorno das ações, $R_{i, t}$, definida na seção 3.3.2. As definições das demais variáveis regressoras desta tabela estão resumidamente no Quadro B.1 do Apêndice B. Os estimadores utilizados são os GMM em Diferenças e o GMM Sistêmico de um e dois estágios, com transformações de desvios ortogonais. Foram utilizadas como instrumentos as transformações de primeiras diferenças em um período e as defasagens de BETA, VMPL e DBAM. Assume-se que os demais regressores são estritamente exógenos. Os erros-padrão foram obtidos utilizando-se dados agrupados por empresa, de maneira robusta a quaisquer formas de heteroscedasticidade e autocorrelação dos erros do modelo e figuram entre parênteses. Os símbolos $\dagger,{ }^{*} \mathrm{e}^{* *}$ denotam a significância estatística da estimativa nos níveis de $10 \%, 5 \%$ e 1\%, respectivamente. O teste da estatística $J$ de Hansen é uma versão robusta do teste de sobreidentificação de Sargan. $m 1$ e $m 2$ referem-se aos testes de autocorrelação de primeira e segunda ordem e DIF-Hansen baseia-se na diferença entre as estatísticas de Hansen e Sargan calculadas para o mesmo modelo estimado por GMM-Sys e GMM-Dif, ambos de dois estágios. Para os testes de Hansen e DIF-Hansen reporta-se a estatística do teste e, entre parênteses, o número de graus de liberdade e seu p-value, respectivamente. Para os testes $m 1$ e $m 2$ reporta-se a estatística do teste e, entre parênteses, o $p$-value correspondente. 
conforme estatísticas apresentadas ao final da Tabela 4.12.

O modelo 04, apresentado na Tabela 4.13, teve a variável de tamanho substituída pelo logaritmo da receita líquida operacional, ln $R L O$. O coeficiente desta mostrou-se positivo e significante a $1 \%$ nos modelos estimados por GMM-Dif, o que não ocorreu nas estimações por GMM-Sys. A variável SENT, apresentou coeficientes com sinal negativo e significantes a 5\% nos modelos GMM-Dif e a 1\% nos modelos GMM-Sys, corroborando os resultados encontrados nos demais modelos estáticos.

Tabela 4.13 - Resultados das estimações por GMM: Modelo 04

\begin{tabular}{|c|c|c|c|c|}
\hline Variável & Dif1 & Dif2 & Sys1 & Sys 2 \\
\hline$S E N T_{t-1}$ & $\begin{array}{r}-0,2507^{*} \\
(0,098)\end{array}$ & $\begin{array}{r}-0,2216^{*} \\
(0,101)\end{array}$ & $\begin{array}{c}-0,3002^{* *} \\
(0,099)\end{array}$ & $\begin{array}{c}-0,2832^{* *} \\
(0,103)\end{array}$ \\
\hline$B E T A_{i, t}$ & $\begin{array}{l}0,1137^{\dagger} \\
(0,059)\end{array}$ & $\begin{array}{l}0,0987 \\
(0,065)\end{array}$ & $\begin{array}{l}0,0753 \\
(0,052)\end{array}$ & $\begin{array}{l}0,0692 \\
(0,055)\end{array}$ \\
\hline $\ln R L O_{i, t}$ & $\begin{array}{l}0,0612^{* *} \\
(0,021)\end{array}$ & $\begin{array}{l}0,0725^{* *} \\
(0,024)\end{array}$ & $\begin{array}{r}-0,0090 \\
(0,009)\end{array}$ & $\begin{array}{r}-0,0083 \\
(0,009)\end{array}$ \\
\hline$V M P L_{i, t}$ & $\begin{array}{l}0,0017^{*} \\
(0,001)\end{array}$ & $\begin{array}{l}0,0018^{*} \\
(0,001)\end{array}$ & $\begin{array}{l}0,0007^{* *} \\
(0,000)\end{array}$ & $\begin{array}{l}0,0008^{* *} \\
(0,000)\end{array}$ \\
\hline$D B A M_{i, t}$ & $\begin{array}{c}-0,8454^{* *} \\
(0,181)\end{array}$ & $\begin{array}{c}-0,8556^{* *} \\
(0,190)\end{array}$ & $\begin{array}{c}-1,1654^{* *} \\
(0,143)\end{array}$ & $\begin{array}{c}-1,2017^{* *} \\
(0,153)\end{array}$ \\
\hline$C R E S C_{i, t}$ & $\begin{array}{r}-0,0082 \\
(0,010)\end{array}$ & $\begin{array}{r}-0,0119 \\
(0,008)\end{array}$ & $\begin{array}{r}-0,0047 \\
(0,007)\end{array}$ & $\begin{array}{r}-0,0048 \\
(0,006)\end{array}$ \\
\hline Dummies SETOR & $\mathrm{SIM}$ & SIM & SIM & $\mathrm{SIM}$ \\
\hline Dummies TEMPO & SIM & SIM & SIM & SIM \\
\hline Qtde. de observações & 2191 & 2191 & 2529 & 2529 \\
\hline Qtde. de instrumentos & 159 & 159 & 180 & 180 \\
\hline$m 1$ & $-6,24(0,000)$ & $-6,26(0,000)$ & $-6,21(0,000)$ & $-6,21(0,000)$ \\
\hline$m 2$ & $-0,38(0,701)$ & $-0,42(0,672)$ & $-0,53(0,594)$ & $-0,56(0,577)$ \\
\hline $\begin{array}{l}J \text { de Hansen } \\
\text { DIF-Hansen }\end{array}$ & \multicolumn{2}{|c|}{$128,88(117 ; 0,213)$} & \multicolumn{2}{|c|}{$133,99(120 ; 0,181)$} \\
\hline
\end{tabular}

A variável dependente é a taxa de retorno das ações, $R_{i, t}$, definida na seção 3.3.2. As definições das demais variáveis regressoras desta tabela estão resumidamente no Quadro B.1 do Apêndice B. Os estimadores utilizados são os GMM em Diferenças e o GMM Sistêmico de um e dois estágios, com transformações de desvios ortogonais. Foram utilizadas como instrumentos as transformações de primeiras diferenças em um período e as defasagens de $B E T A, V M P L$ e $D B A M$. Assume-se que os demais regressores são estritamente exógenos. Os erros-padrão foram obtidos utilizando-se dados agrupados por empresa, de maneira robusta a quaisquer formas de heteroscedasticidade e autocorrelação dos erros do modelo e figuram entre parênteses. Os símbolos $\dagger,{ }^{*} \mathrm{e}^{* *}$ denotam a significância estatística da estimativa nos níveis de $10 \%, 5 \%$ e $1 \%$, respectivamente. O teste da estatística $J$ de Hansen é uma versão robusta do teste de sobreidentificação de Sargan. $m 1$ e $m 2$ referem-se aos testes de autocorrelação de primeira e segunda ordem e DIF-Hansen baseia-se na diferença entre as estatísticas de Hansen e Sargan calculadas para o mesmo modelo estimado por GMM-Sys e GMM-Dif, ambos de dois estágios. Para os testes de Hansen e DIF-Hansen reporta-se a estatística do teste e, entre parênteses, o número de graus de liberdade e seu nível de significância observado, respectivamente. Para os testes $m 1$ e $m 2$ reporta-se a estatística do teste e, entre parênteses, o nível de significância correspondente. 
A variável BET A apresentou sinal positivo e significante apenas na estimação GMM-Difl, a 10\%, não se mostrando relevante nas demais estimações. O tamanho da empresa, medido por $\ln R L O$, apresentou coeficiente positivo e significante a $1 \%$ nos modelos GMM-Dif, não sendo representativos nos modelos GMM-Sys. O índice $V M P L$, por sua vez, mostrou-se positivo e significante em todas as estimações, evidenciando a relação de que empresas com maior valor de mercado em relação ao seu valor contábil têm taxas de retorno esperadas maiores. A variável de alavancagem a mercado, $D B A M$, também apresentou coeficientes negativos e significantes a $1 \%$ em todas as estimações, sinalizando um efeito contrário ao esperado, pois quanto maior o endividamento, o impacto líquido na taxa de retorno é negativo. A variável $C R E S C$ não apresentou significância em nenhuma das quatro estimações, não indicando um padrão de previsibilidade a partir desta variável neste modelo. Os conjuntos de variáveis dummy de tempo e de setor mostraram-se relevantes e cada conjunto mostrou-se significativamente diferente de zero, permanecendo portanto no modelo. Testes de adequação do modelo e do método de estimação validaram a especificação do modelo 04, conforme estatísticas apresentadas ao final da Tabela 4.13.

Estes modelos estáticos apresentados indicam que a variável $S E N T$, que representa o índice de sentimento criado nesta pesquisa, é relevante na explicação da taxa de retorno das ações. O conceito de previsibilidade do retorno foi medido nestes modelos pela variável CRESC. Em todos, com especificações alternativas de tamanho e endividamento, o coeficiente do índice de sentimento sempre foi negativo.

Este resultado indica que a taxa de retorno responde em sentido contrário ao índice de sentimento do período anterior. Se o índice de sentimento em $t-1$ foi negativo, seu impacto líquido de outros fatores comumente utilizados nos modelos de apreçamento (como tamanho, risco sistêmico, relação entre valor de mercado e valor contábil, e crescimento da receita) é positivo, ou seja, espera-se um acréscimo na taxa de retorno das ações. Analogamente, um índice de sentimento positivo no período anterior teria um impacto negativo na taxa de retorno das ações.

\subsubsection{Resultados dos Modelos Dinâmicos}

Os modelos de 01 a 04 desconsideram a possível influência de observações de taxas de retorno passadas sobre a taxa de retorno subsequente. A inclusão da taxa de retorno passada no modelo de apreçamento, mais que apenas uma análise de robustez comumente utilizada nas estimações, é considerada por alguns estudos um fator relevante, chamado de momentum (JEGADEESH; TITMAN, 1993; CARHART, 1997; HONG; STEIN, 1999).

Desta forma, estimaram-se os modelos 05 a 08, conforme mostra o Quadro 4.2, utilizando 
entre os regressores a variável dependente defasada em um período. Esta variável foi chamada de $M O M$, uma vez que alguns investidores utilizam esta abordagem de momentum para prever retornos das ações. O objetivo é verificar se o índice de sentimento ainda se mostra com poder explicativo mesmo quando há variáveis que refletem estratégias de investimento comumente usadas para prever retornos futuros.

No modelo 05, a variável utilizada para tamanho foi o logaritmo do valor de mercado $(\ln V M)$ e o endividamento foi medido em relação ao ativo total contábil $(D B A T)$. O índice de sentimento, SENT, apresentou coeficiente negativo e significante a $1 \%$ nos modelos estimados por GMM-Dif e a $5 \%$ nos modelos estimados por GMM-Sys, indicando um padrão de reversão das taxas de retorno em sentido contrário ao sentimento do período anterior. O risco sistêmico, $B E T A$, não se mostrou significante em nenhum dos modelos estimados, indicando que esta variável tem o seu poder explicativo reduzido pelas demais do modelo.

O conceito de tamanho, medido pelo valor de mercado da empresa, mostrou-se relevante em todas as quatro estimações do modelo 05 . O coeficiente positivo indica que empresas maiores têm taxas de retorno superiores, o que não era o esperado conforme o argumento de Banz (1981). O índice $V M P L$ mostrou-se positivo e significante nas estimações por GMM-Sys, não sendo significante nas estimações GMM-Dif.

Com relação à variável de endividamento, $D B A T$, esta apresentou coeficientes negativos e significantes a $1 \%$ nos modelos GMM-Dif, mas positivos e significantes a $10 \%$ nos modelos GMM-Sys. O sinal positivo é de fato esperado supondo-se que aumento do endividamento está associado a um aumento no risco da empresa. A variável dependente defasada, $M O M$, não apresentou coeficientes significantes em nenhuma das estimações. Os conjuntos de variáveis dummy de setor e de tempo mostraram-se estatisticamente diferente de zero, devendo consequentemente permanecer no modelo. Análises de diagnóstico do modelo apresentadas ao final da Tabela 4.14 indicam que este modelo é adequado para estimação em GMM.

Na Tabela 4.15 estão os resultados da estimação do modelo 06, em que a variável para tamanho das empresas foi $\ln V M$, e a alavancagem foi medida em relação ao valor do ativo a mercado, pela variável $D B A M$. Pode-se observar, novamente, que o índice de sentimento SENT apresentou coeficientes negativos e significantes a $1 \%$ em todos os modelos estimados. Além disso, a magnitude dos coeficientes é razoavelmente similar, mesmo com procedimentos de estimação distintos.

A variável $B E T A$, por sua vez, não apresentou significância em nenhum dos modelos, sinalizando que outras variáveis apresentaram melhor poder explicativo no modelo. $\mathrm{O}$ tamanho, medido por $\ln V M$, tem coeficiente positivo e significante apenas nos modelos 
Tabela 4.14 - Resultados das estimações por GMM: Modelo 05

\begin{tabular}{|c|c|c|c|c|}
\hline Variável & Dif1 & Dif2 & Sys1 & Sys2 \\
\hline$S E N T_{t-1}$ & $\begin{array}{c}-0,3153^{* *} \\
(0,104)\end{array}$ & $\begin{array}{c}-0,3071^{* *} \\
(0,103)\end{array}$ & $\begin{array}{r}-0,2507^{*} \\
(0,109)\end{array}$ & $\begin{array}{r}-0,2540^{*} \\
(0,106)\end{array}$ \\
\hline$B E T A_{i, t}$ & $\begin{array}{l}0,0877 \\
(0,059)\end{array}$ & $\begin{array}{l}0,0698 \\
(0,060)\end{array}$ & $\begin{array}{l}0,0480 \\
(0,049)\end{array}$ & $\begin{array}{l}0,0435 \\
(0,047)\end{array}$ \\
\hline $\ln V M_{i, t}$ & $\begin{array}{l}0,1163^{* *} \\
(0,020)\end{array}$ & $\begin{array}{l}0,1162^{* *} \\
(0,019)\end{array}$ & $\begin{array}{l}0,0220^{* *} \\
(0,004)\end{array}$ & $\begin{array}{l}0,0219^{* *} \\
(0,004)\end{array}$ \\
\hline$V M P L_{i, t}$ & $\begin{array}{l}0,0004 \\
(0,001)\end{array}$ & $\begin{array}{l}0,0006 \\
(0,001)\end{array}$ & $\begin{array}{l}0,0004^{*} \\
(0,000)\end{array}$ & $\begin{array}{l}0,0005^{*} \\
(0,000)\end{array}$ \\
\hline$D B A T_{i, t}$ & $\begin{array}{c}-0,0030^{* *} \\
(0,001)\end{array}$ & $\begin{array}{c}-0,0030^{* *} \\
(0,001)\end{array}$ & $\begin{array}{l}0,0011^{\dagger} \\
(0,001)\end{array}$ & $\begin{array}{l}0,0011^{\dagger} \\
(0,001)\end{array}$ \\
\hline$M O M_{i, t}$ & $\begin{array}{r}-0,0444 \\
(0,032)\end{array}$ & $\begin{array}{r}-0,0452 \\
(0,032)\end{array}$ & $\begin{array}{r}-0,0343 \\
(0,030)\end{array}$ & $\begin{array}{r}-0,0355 \\
(0,030)\end{array}$ \\
\hline Dummies SETOR & SIM & SIM & SIM & SIM \\
\hline Dummies TEMPO & SIM & SIM & SIM & SIM \\
\hline Qtde. de observações & 2530 & 2530 & 2775 & 2775 \\
\hline Qtde. de instrumentos & 196 & 196 & 218 & 218 \\
\hline$m 1$ & $-6,65(0,000)$ & $-5,57(0,000)$ & $-6,58(0,000)$ & $-5,74(0,000)$ \\
\hline$m 2$ & $-0,89(0,374)$ & $-0,91(0,364)$ & $-0,81(0,417)$ & $-0,81(0,420)$ \\
\hline $\begin{array}{l}J \text { de Hansen } \\
\text { DIF-Hansen }\end{array}$ & \multicolumn{2}{|c|}{$159,36(154 ; 0,367)$} & $\begin{array}{r}161,08(1 \\
42,95(5\end{array}$ & $\begin{array}{l}58 ; 0,417) \\
5 ; 0,881)\end{array}$ \\
\hline
\end{tabular}

A variável dependente é a taxa de retorno das ações, $R_{i, t}$, definida na seção 3.3.2. As definições das demais variáveis regressoras desta tabela estão resumidamente no Quadro B.1 do Apêndice B. Os estimadores utilizados são os GMM em Diferenças e o GMM Sistêmico de um e dois estágios, com transformações de desvios ortogonais. Foram utilizadas como instrumentos as transformações de primeiras diferenças em um período e as defasagens de BET A, VMPL, DBAT e MOM. Assumese que os demais regressores são estritamente exógenos. Os erros-padrão foram obtidos utilizando-se dados agrupados por empresa, de maneira robusta a quaisquer formas de heteroscedasticidade e autocorrelação dos erros do modelo e figuram entre parênteses. Os símbolos $\dagger,{ }^{*} \mathrm{e}^{* *}$ denotam a significância estatística da estimativa nos níveis de $10 \%, 5 \%$ e 1\%, respectivamente. O teste da estatística $J$ de Hansen é uma versão robusta do teste de sobreidentificação de Sargan. $m 1$ e $m 2$ referem-se aos testes de autocorrelação de primeira e segunda ordem e DIF-Hansen baseia-se na diferença entre as estatísticas de Hansen e Sargan calculadas para o mesmo modelo estimado por GMM-Sys e GMM-Dif, ambos de dois estágios. Para os testes de Hansen e DIF-Hansen reporta-se a estatística do teste e, entre parênteses, o número de graus de liberdade e seu p-value, respectivamente. Para os testes $m 1$ e $m 2$ reporta-se a estatística do teste e, entre parênteses, o $p$-value correspondente. 
Tabela 4.15 - Resultados das estimações por GMM: Modelo 06

\begin{tabular}{|c|c|c|c|c|}
\hline Variável & Dif1 & Dif2 & Sys 1 & Sys 2 \\
\hline$S E N T_{t-1}$ & $\begin{array}{c}-0,3625^{* *} \\
(0,105)\end{array}$ & $\begin{array}{c}-0,3482^{* *} \\
(0,106)\end{array}$ & $\begin{array}{c}-0,3360^{* *} \\
(0,107)\end{array}$ & $\begin{array}{c}-0,3338^{* *} \\
(0,108)\end{array}$ \\
\hline$B E T A_{i, t}$ & $\begin{array}{l}0,0839 \\
(0,060)\end{array}$ & $\begin{array}{l}0,0768 \\
(0,062)\end{array}$ & $\begin{array}{l}0,0420 \\
(0,051)\end{array}$ & $\begin{array}{l}0,0381 \\
(0,050)\end{array}$ \\
\hline $\ln V M_{i, t}$ & $\begin{array}{l}0,0610^{\dagger} \\
(0,032)\end{array}$ & $\begin{array}{l}0,0635^{*} \\
(0,030)\end{array}$ & $\begin{array}{r}-0,0053 \\
(0,011)\end{array}$ & $\begin{array}{r}-0,0011 \\
(0,011)\end{array}$ \\
\hline$V M P L_{i, t}$ & $\begin{array}{l}0,0001 \\
(0,001)\end{array}$ & $\begin{array}{l}0,0001 \\
(0,001)\end{array}$ & $\begin{array}{l}0,0005^{*} \\
(0,000)\end{array}$ & $\begin{array}{l}0,0006^{*} \\
(0,000)\end{array}$ \\
\hline$D B A M_{i, t}$ & $\begin{array}{c}-0,9025^{* *} \\
(0,281)\end{array}$ & $\begin{array}{c}-0,8697^{* *} \\
(0,276)\end{array}$ & $\begin{array}{c}-1,0631^{* *} \\
(0,158)\end{array}$ & $\begin{array}{c}-1,0480^{* *} \\
(0,160)\end{array}$ \\
\hline$M O M_{i, t}$ & $\begin{array}{r}-0,0562^{\dagger} \\
(0,031)\end{array}$ & $\begin{array}{r}-0,0546^{\dagger} \\
(0,031)\end{array}$ & $\begin{array}{r}-0,0464 \\
(0,029)\end{array}$ & $\begin{array}{r}-0,0456 \\
(0,030)\end{array}$ \\
\hline Dummies SETOR & SIM & SIM & SIM & SIM \\
\hline Dummies TEMPO & SIM & SIM & SIM & SIM \\
\hline Qtde. de observações & 2530 & 2530 & 2775 & 2775 \\
\hline Qtde. de instrumentos & 196 & 196 & 218 & 218 \\
\hline$m 1$ & $-6,24(0,000)$ & $-5,48(0,000)$ & $-6,40(0,000)$ & $-5,55(0,000)$ \\
\hline$m 2$ & $-1,32(0,184)$ & $-1,26(0,207)$ & $-1,26(0,207)$ & $-1,22(0,225)$ \\
\hline$J$ de Hansen & \multirow{2}{*}{\multicolumn{2}{|c|}{$159,86(154 ; 0,357)$}} & \multicolumn{2}{|c|}{$165,72(158 ; 0,321)$} \\
\hline DIF-Hansen & & & \multicolumn{2}{|c|}{$36,13(56 ; 0,982)$} \\
\hline
\end{tabular}

A variável dependente é a taxa de retorno das ações, $R_{i, t}$, definida na seção 3.3.2. As definições das demais variáveis regressoras desta tabela estão resumidamente no Quadro B.1 do Apêndice B. Os estimadores utilizados são os GMM em Diferenças e o GMM Sistêmico de um e dois estágios, com transformações de desvios ortogonais. Foram utilizadas como instrumentos as transformações de primeiras diferenças em um período e as defasagens de BET A, VMPL, DBAM e MOM. Assumese que os demais regressores são estritamente exógenos. Os erros-padrão foram obtidos utilizando-se dados agrupados por empresa, de maneira robusta a quaisquer formas de heteroscedasticidade e autocorrelação dos erros do modelo e figuram entre parênteses. Os símbolos $\dagger,{ }^{*} \mathrm{e}^{* *}$ denotam a significância estatística da estimativa nos níveis de $10 \%, 5 \%$ e 1\%, respectivamente. O teste da estatística $J$ de Hansen é uma versão robusta do teste de sobreidentificação de Sargan. $m 1$ e $m 2$ referem-se aos testes de autocorrelação de primeira e segunda ordem e DIF-Hansen baseia-se na diferença entre as estatísticas de Hansen e Sargan calculadas para o mesmo modelo estimado por GMM-Sys e GMM-Dif, ambos de dois estágios. Para os testes de Hansen e DIF-Hansen reporta-se a estatística do teste e, entre parênteses, o número de graus de liberdade e seu nível de significância observado, respectivamente. Para os testes $m 1$ e $m 2$ reporta-se a estatística do teste e, entre parênteses, o nível de significância correspondente. 
GMM-Dif, indicando para estes casos a relação direta entre tamanho e taxa de retorno. O índice $V M P L$, por sua vez, tem coeficientes significantes nos modelos GMM-Sys, também apresentando relação direta com a taxa de retorno das ações. A variável de endividamento $D B A M$ mostrou-se significante em todas as estimações, a 1\%, com sinal negativo, indicando uma relação inversa entre endividamento e taxa de retorno das ações. A variável defasada $M O M$ apresentou significância apenas nos modelos GMM-Dif, com coeficiente negativo, o que reforça a ocorrência de reversão nas taxas de retornos. Os conjuntos de variáveis dummy mostraram-se estatisticamente diferentes de zero, a 1\%. Desta maneira, tanto as variáveis binárias de setor como as de tempo permaneceram no modelo 06. Estatísticas dos testes de diagnóstico do modelo apontam para a sua adequação, conforme Tabela 4.15 .

Os resultados das estimações do modelo 07 estão apresentadas na Tabela 4.16. A variável para medir o tamanho das empresas foi ln $A T$, e a alavancagem utilizada foi a contábil, $D B A T$. Os coeficientes da variável $S E N T$ apresentaram sinais negativos e significantes a $5 \%$ em todas as estimações. Já a variável $B E T A$, por sua vez, não se mostrou significante em nenhum dos casos.

O tamanho da empresa, assim como o endividamento, apresentaram coeficientes estatisticamente significantes apenas nas estimações GMM-Dif, tanto ln $A T$ como DBAT com sinais negativos. Neste modelo, a variável de tamanho mostrou-se conforme o proposto por Banz (1981), em que empresas menores apresentariam taxas de retornos maiores e vice-versa. O índice $V M P L$, da relação market-to-book, apresentou coeficiente positivo e significante a $5 \%$ nos modelos estimados por GMM-Sys, apenas. A variável MOM não apresentou significância estatística em nenhuma das quatro estimações. Os testes realizados com o objetivo de verificar se cada conjunto de variáveis dummy é estatisticamente diferente de zero mostraram que a presença destas variáveis é útil na especificação do modelo.

As últimas linhas reportadas na tabela indicam os testes de análise de diagnóstico para verificar se o modelo é plausível ou não. O valor da estatística dos testes de autocorrelação de primeira ordem $(m 1)$ é negativo e significante para todas as especificações, e não significante para $m 2$. Testes de restrições de Hansen mostram que a hipóteses nula não pode ser rejeitada em nenhum dos casos. Além disso, os testes de DIF-Hansen indicam a validade das suposições do modelo, inclusive das condições do GMM-Sys.

Por fim, o modelo 08, conforme apresentado na Tabela 4.17, utilizou como medida de tamanho a variável $\ln R L O$ e a alavancagem medida por $D B A M$. A variável $S E N T$ apresentou coeficiente negativo em todas as estimações, sendo significante a $10 \%$ nos modelos GMM-Dif e a 5\% nos modelos GMM-Sys. O risco sistêmico BET A apresentou 
Tabela 4.16 - Resultados das estimações por GMM: Modelo 07

\begin{tabular}{|c|c|c|c|c|}
\hline Variável & Dif1 & Dif2 & Sys 1 & Sys 2 \\
\hline$S E N T_{t-1}$ & $\begin{array}{r}-0,2395^{*} \\
(0,110)\end{array}$ & $\begin{array}{r}-0,2290^{*} \\
(0,110)\end{array}$ & $\begin{array}{r}-0,2407^{*} \\
(0,111)\end{array}$ & $\begin{array}{r}-0,2429^{*} \\
(0,108)\end{array}$ \\
\hline$B E T A_{i, t}$ & $\begin{array}{l}0,0724 \\
(0,056)\end{array}$ & $\begin{array}{l}0,0551 \\
(0,058)\end{array}$ & $\begin{array}{l}0,0503 \\
(0,049)\end{array}$ & $\begin{array}{l}0,0438 \\
(0,047)\end{array}$ \\
\hline $\ln A T_{i, t}$ & $\begin{array}{r}-0,0446^{*} \\
(0,019)\end{array}$ & $\begin{array}{r}-0,0481^{*} \\
(0,019)\end{array}$ & $\begin{array}{l}0,0006 \\
(0,004)\end{array}$ & $\begin{array}{l}0,0015 \\
(0,004)\end{array}$ \\
\hline$V M P L_{i, t}$ & $\begin{array}{l}0,0004 \\
(0,001)\end{array}$ & $\begin{array}{l}0,0006 \\
(0,001)\end{array}$ & $\begin{array}{l}0,0004^{*} \\
(0,000)\end{array}$ & $\begin{array}{l}0,0004^{*} \\
(0,000)\end{array}$ \\
\hline$D B A T_{i, t}$ & $\begin{array}{c}-0,0021^{* *} \\
(0,001)\end{array}$ & $\begin{array}{c}-0,0022^{* *} \\
(0,001)\end{array}$ & $\begin{array}{l}0,0000 \\
(0,001)\end{array}$ & $\begin{array}{l}0,0000 \\
(0,001)\end{array}$ \\
\hline$M O M_{i, t}$ & $\begin{array}{r}-0,0397 \\
(0,030)\end{array}$ & $\begin{array}{r}-0,0393 \\
(0,030)\end{array}$ & $\begin{array}{r}-0,0323 \\
(0,030)\end{array}$ & $\begin{array}{r}-0,0340 \\
(0,030)\end{array}$ \\
\hline Dummies SETOR & SIM & SIM & SIM & SIM \\
\hline Dummies TEMPO & SIM & SIM & SIM & SIM \\
\hline Qtde. de observações & 2532 & 2532 & 2777 & 2777 \\
\hline Qtde. de instrumentos & 196 & 196 & 218 & 218 \\
\hline$m 1$ & $-6,44(0,000)$ & $-5,72(0,000)$ & $-6,60(0,000)$ & $-5,76(0,000)$ \\
\hline$m 2$ & $-0,88(0,376)$ & $-0,88(0,381)$ & $-0,80(0,426)$ & $-0,80(0,422)$ \\
\hline$J$ de Hansen & \multirow{2}{*}{\multicolumn{2}{|c|}{$155,42(154 ; 0,453)$}} & \multicolumn{2}{|c|}{$159,82(158 ; 0,445)$} \\
\hline DIF-Hansen & & & \multicolumn{2}{|c|}{$39,27(55 ; 0,946)$} \\
\hline
\end{tabular}

A variável dependente é a taxa de retorno das ações, $R_{i, t}$, definida na seção 3.3.2. As definições das demais variáveis regressoras desta tabela estão resumidamente no Quadro B.1 do Apêndice B. Os estimadores utilizados são os GMM em Diferenças e o GMM Sistêmico de um e dois estágios, com transformações de desvios ortogonais. Foram utilizadas como instrumentos as transformações de primeiras diferenças em um período e as defasagens de BET A, VMPL, DBAT e MOM. Assumese que os demais regressores são estritamente exógenos. Os erros-padrão foram obtidos utilizando-se dados agrupados por empresa, de maneira robusta a quaisquer formas de heteroscedasticidade e autocorrelação dos erros do modelo e figuram entre parênteses. Os símbolos $\dagger,{ }^{*} \mathrm{e}^{* *}$ denotam a significância estatística da estimativa nos níveis de $10 \%, 5 \%$ e 1\%, respectivamente. O teste da estatística $J$ de Hansen é uma versão robusta do teste de sobreidentificação de Sargan. $m 1$ e $m 2$ referem-se aos testes de autocorrelação de primeira e segunda ordem e DIF-Hansen baseia-se na diferença entre as estatísticas de Hansen e Sargan calculadas para o mesmo modelo estimado por GMM-Sys e GMM-Dif, ambos de dois estágios. Para os testes de Hansen e DIF-Hansen reporta-se a estatística do teste e, entre parênteses, o número de graus de liberdade e seu nível de significância observado, respectivamente. Para os testes $m 1$ e $m 2$ reporta-se a estatística do teste e, entre parênteses, o nível de significância correspondente. 
Tabela 4.17 - Resultados das estimações por GMM: Modelo 08

\begin{tabular}{|c|c|c|c|c|}
\hline Variável & Dif1 & Dif2 & Sys1 & Sys2 \\
\hline$S E N T_{t-1}$ & $\begin{array}{r}-0,1704^{\dagger} \\
(0,103)\end{array}$ & $\begin{array}{r}-0,1708^{\dagger} \\
(0,102)\end{array}$ & $\begin{array}{r}-0,2326^{*} \\
(0,101)\end{array}$ & $\begin{array}{r}-0,2422^{*} \\
(0,101)\end{array}$ \\
\hline$B E T A_{i, t}$ & $\begin{array}{l}0,1125^{\dagger} \\
(0,058)\end{array}$ & $\begin{array}{l}0,1184^{\dagger} \\
(0,062)\end{array}$ & $\begin{array}{l}0,0632 \\
(0,053)\end{array}$ & $\begin{array}{l}0,0770 \\
(0,057)\end{array}$ \\
\hline $\ln R L O_{i, t}$ & $\begin{array}{l}0,0438^{* *} \\
(0,014)\end{array}$ & $\begin{array}{l}0,0447^{* *} \\
(0,014)\end{array}$ & $\begin{array}{r}-0,0030 \\
(0,010)\end{array}$ & $\begin{array}{r}-0,0022 \\
(0,009)\end{array}$ \\
\hline$V M P L_{i, t}$ & $\begin{array}{r}-0,0002 \\
(0,001)\end{array}$ & $\begin{array}{r}-0,0002 \\
(0,001)\end{array}$ & $\begin{array}{l}0,0004 \\
(0,000)\end{array}$ & $\begin{array}{l}0,0004 \\
(0,000)\end{array}$ \\
\hline$D B A M_{i, t}$ & $\begin{array}{c}-0,8095^{* *} \\
(0,228)\end{array}$ & $\begin{array}{c}-0,8111^{* *} \\
(0,228)\end{array}$ & $\begin{array}{c}-1,1826^{* *} \\
(0,157)\end{array}$ & $\begin{array}{c}-1,1957^{* *} \\
\quad(0,159)\end{array}$ \\
\hline$M O M_{i, t}$ & $\begin{array}{r}-0,0721^{*} \\
(0,029)\end{array}$ & $\begin{array}{r}-0,0724^{*} \\
(0,029)\end{array}$ & $\begin{array}{r}-0,0581^{*} \\
(0,029)\end{array}$ & $\begin{array}{r}-0,0579^{*} \\
(0,029)\end{array}$ \\
\hline Dummies SETOR & $\mathrm{NA} O$ & NÃO & NÃO & NÃO \\
\hline Dummies TEMPO & SIM & SIM & SIM & SIM \\
\hline Qtde. de observações & 2228 & 2228 & 2567 & 2567 \\
\hline Qtde. de instrumentos & 196 & 196 & 201 & 201 \\
\hline$m 1$ & $-6,35(0,000)$ & $-5,68(0,000)$ & $-6,41(0,000)$ & $-5,62(0,000)$ \\
\hline$m 2$ & $-0,63(0,526)$ & $-0,61(0,544)$ & $-0,67(0,500)$ & $-0,63(0,531)$ \\
\hline $\begin{array}{l}J \text { de Hansen } \\
\text { DIF-Hansen }\end{array}$ & \multicolumn{2}{|c|}{$164,86(154 ; 0,260)$} & \multicolumn{2}{|c|}{$\begin{array}{r}168,78(158 ; 0,264) \\
43,93(55 ; 0,858)\end{array}$} \\
\hline
\end{tabular}

A variável dependente é a taxa de retorno das ações, $R_{i, t}$, definida na seção 3.3.2. As definições das demais variáveis regressoras desta tabela estão resumidamente no Quadro B.1 do Apêndice B. Os estimadores utilizados são os GMM em Diferenças e o GMM Sistêmico de um e dois estágios, com transformações de desvios ortogonais. Foram utilizadas como instrumentos as transformações de primeiras diferenças em um período e as defasagens de BETA, VMPL, DBAM e MOM. Assumese que os demais regressores são estritamente exógenos. Os erros-padrão foram obtidos utilizando-se dados agrupados por empresa, de maneira robusta a quaisquer formas de heteroscedasticidade e autocorrelação dos erros do modelo e figuram entre parênteses. Os símbolos $\dagger,{ }^{*} \mathrm{e}^{* *}$ denotam a significância estatística da estimativa nos níveis de $10 \%, 5 \%$ e 1\%, respectivamente. O teste da estatística $J$ de Hansen é uma versão robusta do teste de sobreidentificação de Sargan. $m 1$ e $m 2$ referem-se aos testes de autocorrelação de primeira e segunda ordem e DIF-Hansen baseia-se na diferença entre as estatísticas de Hansen e Sargan calculadas para o mesmo modelo estimado por GMM-Sys e GMM-Dif, ambos de dois estágios. Para os testes de Hansen e DIF-Hansen reporta-se a estatística do teste e, entre parênteses, o número de graus de liberdade e seu nível de significância observado, respectivamente. Para os testes $m 1$ e $m 2$ reporta-se a estatística do teste e, entre parênteses, o nível de significância correspondente. 
coeficiente positivo e estatisticamente significante a $10 \%$ nos modelos estimados por GMMDif apenas. A variável de tamanho $\ln R L O$ apresentou coeficientes positivos e significantes a $1 \%$ nos modelos GMM-Dif, indicando uma relação direta entre tamanho e taxa de retorno.

O índice $V M P L$ não apresentou significância em nenhuma das estimações, ao contrário dos modelos anteriores (01 a 07 ) em que isto ocorria pelo menos nos modelos GMM-Sys, quando não em todos. A variável de alavancagem $D B A M$ mostrou-se significante a $1 \%$ nas quatro estimações, indicando uma relação inversa entre endividamento e taxa de retornos, contrária ao esperado. Quanto à variável dependente defasada $M O M$, esta mostrou-se negativa e significante a $5 \%$ em todas as estimações, evidenciando uma reversão das taxas de retorno.

As variáveis dummy de setor não rejeitaram a hipótese nula de que, conjuntamente, são diferentes de zero. Desta forma, o modelo 08 foi reestimado, sem a inclusão destas variáveis binárias de setor, permanecendo apenas as dummies de tempo. As estatísticas apresentadas ao final da tabela indicam a adequação do modelo para a estimação por GMM.

\subsubsection{Análise de Robustez}

Além da utilização de diferentes variáveis para medir os conceitos de tamanho da empresa e endividamento, foram inseridas alternativamente, as variáveis CRESC e MOM nos modelos estimados. Esta última confere à estimação um caráter dinâmico, uma vez que $M O M$ é dada pela variável dependente defasada. Ao todo foram geradas oito especificações distintas, com o objetivo de se verificar a estabilidade dos resultados encontrados com a utilização de proxies diferentes para um mesmo construto. Os quadros com as combinações de variáveis utilizadas em cada um dos modelos podem ser consultadas na página 98, Quadros 4.1 e 4.2 .

A sensibilidade dos resultados foi verificada também com a utilização de diferentes métodos de estimação para o modelo de apreçamento. Para isto, os modelos foram estimados por GMM em Diferenças e GMM Sistêmico, de um e dois estágios, conforme descrito na seção 3.5.2.

Por fim, foi verificado se a presença de observações extremas na amostra não afetava as inferências encontradas. Para isto, foram geradas variáveis Winsorizadas e os modelos foram reestimados. Para todas as variáveis, com exceção das variáveis binárias, seus menores e maiores valores (que representam $1 \%$ do número total de observações de cada 
variável, depois de ordenadas crescentemente) foram substituídos por observações adjacentes. Foram utilizadas as mesmas especificações anteriores para os modelos estáticos e dinâmicos.

A única exceção é quanto ao modelo 08, pois com as variáveis Winsorizadas não foi rejeitada a hipótese nula de que o conjunto de variáveis dummy de setor é igual a zero. Portanto, neste modelo com variáveis Winsorizadas, elas permaneceram na estimação. A Tabela 4.18 indica apenas o coeficiente da variável SENT, uma vez que os resultados encontrados são bastante similares aos apresentados nas seções 4.2.2.1 e 4.2.2.2. Os resultados completos das estimações estão apresentados nas Tabelas B.3 a B.10 do Apêndice B.

\section{Tabela 4.18 - Coeficientes estimados para a variável $S E N T$ para os modelos com variáveis Winsorizadas}

\begin{tabular}{lcccc}
\hline Modelo & Dif1 & Dif2 & Sys1 & Sys2 \\
\hline Modelo 01 & $-0,2863^{* *}$ & $-0,2696^{* *}$ & $-0,3219^{* *}$ & $-0,3180^{* *}$ \\
& $(0,106)$ & $(0,114)$ & $(0,104)$ & $(0,106)$ \\
Modelo 02 & $-0,2058^{*}$ & $-0,1712$ & $-0,2191^{*}$ & $-0,1991^{*}$ \\
& $(0,105)$ & $(0,114)$ & $(0,105)$ & $(0,110)$ \\
Modelo 03 & $-0,3310^{* *}$ & $-0,3136^{* *}$ & $-0,3123^{* *}$ & $-0,3143^{* *}$ \\
& $(0,104)$ & $(0,112)$ & $(0,106)$ & $(0,109)$ \\
Modelo 04 & $-0,2543^{*}$ & $-0,2467^{*}$ & $-0,2991^{* *}$ & $-0,3036^{* *}$ \\
& $(0,099)$ & $(0,109)$ & $(0,098)$ & $(0,101)$ \\
Modelo 05 & $-0,3053^{* *}$ & $-0,2782^{* *}$ & $-0,2572^{*}$ & $-0,2292^{*}$ \\
& $(0,106)$ & $(0,105)$ & $(0,110)$ & $(0,109)$ \\
Modelo 06 & $-0,3596^{* *}$ & $-0,3830^{* *}$ & $-0,3276^{* *}$ & $-0,3739^{* *}$ \\
& $(0,107)$ & $(0,110)$ & $(0,109)$ & $(0,114)$ \\
Modelo 07 & $-0,2408^{*}$ & $-0,2236^{*}$ & $-0,2573^{*}$ & $-0,2326^{*}$ \\
& $(0,110)$ & $(0,109)$ & $(0,110)$ & $(0,107)$ \\
Modelo 08 & $-0,1837^{\dagger}$ & $-0,1879^{\dagger}$ & $-0,2410^{*}$ & $-0,2543^{*}$ \\
& $(0,101)$ & $(0,106)$ & $(0,102)$ & $(0,104)$ \\
\hline
\end{tabular}

Os estimadores utilizados são os GMM em Diferenças e o GMM Sistêmico de um e dois estágios, com transformações de desvios ortogonais. As especificações dos modelos de 01 a 08 são as mesmas apresentadas nos Quadros 4.1 e 4.2. O erro-padrão de cada coeficiente figura entre parênteses. Os símbolos $\dagger, *$ e ** denotam a significância estatística da estimativa nos níveis de $10 \%, 5 \%$ e $1 \%$, respectivamente.

Os resultados apontam que a variável $S E N T$ apresenta coeficientes negativos e significantes nos níveis convencionais em todos os modelos e por todos os métodos, à exceção da estimação Dif2 do modelo 02. Tem-se um resultado consistente com os apresentados anteriormente. Embora a magnitude dos coeficientes varie um pouco, ele permanece razoavelmente estáveis mesmo em especificações com diferentes definições operacionais empregadas. 


\subsection{Síntese dos Principais Resultados}

A influência do sentimento dos investidores nas taxas de retorno das ações foi verificada por meio da investigação empírica com dados em painel. Inicialmente, foi criada a medida de sentimento do mercado, a partir de uma abordagem multivariada de componentes principais. A partir de variáveis sugeridas por estudos anteriores e disponíveis para o mercado brasileiro, foi construída uma série trimestral do índice de sentimento, do segundo trimestre de 1999 ao quatro trimestre de 2008.

Após o procedimento de construção do índice, foi estimado um modelo de apreçamento no qual se inseriu esta variável comportamental. Além de $S E N T$, outros fatores comumente utilizados nos estudos sobre apreçamento também foram incluídos, com o objetivo foi verificar a relevância ou não do sentimento do mercado na explicação das taxas de retorno das ações.

Embora sejam tradicionalmente utilizados os métodos de estimação por dados agrupados $(P O L S)$, efeitos aleatórios (EA) e efeitos fixos (EF), a validade de seus resultados depende da condição de exogeneidade estrita dos regressores. Foram aplicados dois testes de exogeneidade estrita para os modelos estimados, que indicaram a rejeição da hipótese de exogeneidade estrita para todos eles.

Para lidar com problemas de endogeneidade dos regressores, foi utilizado como método de estimação o GMM, nas suas formas GMM em Diferenças e GMM Sistêmico, em um e dois estágios. As estimações em dois estágios foram feitas com uso da correção proposta por Windmeijer (2005), para amostras finitas. Foram estimados modelos com diferentes definições operacionais de variáveis para os construtos tamanho, endividamento e previsibilidade dos retornos. Em função da variável escolhida como proxy para previsibilidade dos retornos, os modelos tornam-se estáticos ou dinâmicos.

As análise de diagnóstico, reportadas nas quatro últimas linhas das tabelas de resultado das estimações, são necessárias para verificar a plausibilidade das hipóteses de identificação dos modelos. Os testes de autocorrelação de primeira e segunda ordens $(m 1$ e $m 2$, respectivamente) validam a hipótese de não-autocorrelação dos erros, pois a estatística $m 1$ apresentou valores negativos e estatisticamente significantes e $m 2$ não foi significante em todas as especificações de todos os modelos. A estatística $J$ de Hansen indicou que a hipótese nula, de especificação linear correta e não-correlação entre o conjunto de instrumentos e os erros do modelo, não pôde ser rejeitada em nenhum dos casos. O último teste, DIF-Hansen, tem como hipótese nula a validade das suposições do modelo, incluindo a validade das condições adicionais do método GMM-Sys e não foi rejeitado em nenhum dos modelos. 
Com relação às variáveis de controle, BET A apresentou coeficientes positivos e significantes em alguns modelos apenas, o que indica que na presença de outras variáveis, seu poder de explicação das taxas de retornos das ações é diminuído. A variável de alavancagem, seja medida em relação ao ativo contábil $(D B A T)$ ou ao ativo a mercado $(D B A M)$, mostrou-se negativa e significante em alguns dos modelos. Este resultado indica que o endividamento tem uma relação inversa com a taxa de retorno das ações, indicando que empresas muito alavancadas têm uma taxa de retorno menor que empresas pouco alavancadas. Tal resultado não segue o argumento de que empresas mais endividadas deveriam apresentar maiores taxas de retorno.

O índice VMPL, market-to-book, inverso de um dos fatores utilizados por Fama e French (1992), mostrou-se positivo e significante para a maioria dos modelos. Empresas com valor de mercado superior em relação ao seu valor contábil apresentam taxas de retorno maiores, e vice-versa. As variáveis utilizadas como proxies para a previsibilidade de retornos apresentaram coeficientes significantes em alguns casos, mas não estáveis o suficiente para que fossem atestadas relações com a taxa de retorno.

As variáveis dummies de tempo mostraram-se relevantes para capturar efeitos macroeconômicos que afetam todas as empresas de maneira uniforme dentro de determinado trimestre. Em todos os modelos, estas se mostraram conjuntamente diferentes de zero, permanecendo portanto na especificação do modelo. As variáveis indicadoras de setor também mostraram-se conjuntamente diferentes de zero para os modelos de 01 a 07 , sendo retiradas da especificação apenas do modelo 08. Na estimação com variáveis Winsorizadas, no entanto, as dummies de tempo e de setor permaneceram em todos os modelos.

Em todos estes modelos, estimados por diferentes métodos, os coeficientes encontrados para a variável $S E N T$ foram negativos e, à exceção de um único caso (estimação por GMM-Dif2 do modelo 02), significantes nos níveis convencionais. Este resultado indica que a variável de índice de sentimento mostrou-se relevante no modelo de apreçamento, mesmo com a utilização de diferentes variáveis ou métodos de estimação.

Tais resultados são corroborados com a utilização de variáveis Winsorizadas, para analisar se o efeito do índice de sentimento nas taxas de retornos das ações não era alterado na ausência de outliers. O que se observou foi que a retirada de observações extremas não alterou os resultados anteriores, e a variável $S E N T$, nesta análise, apresentou coeficientes negativos e significantes em todas as estimações de todos os modelos. Isto reforça a constatação de que o índice de sentimento é relevante na explicação das taxas de retorno, e o sinal negativo revela a reversão nas taxas de retorno em relação ao sentimento anterior: se o sentimento foi positivo, espera-se um impacto negativo nas taxas de retorno do período seguinte, e vice-versa. 


\section{Capítulo 5}

\section{Conclusão}

"Science can only ascertain what is, but not what should be, and outside of its domain value judgments of all kinds remain necessary."

Albert Einstein

Na teoria clássica de finanças, o sentimento do investidor não é considerado um fator importante sobre os preços das ações. Mais que negar a existência do sentimento do investidor, as teorias normalmente partem do princípio, que em mercados financeiros competitivos, comportamentos de agentes quase-racionais são rapidamente eliminados. Os defensores deste argumento baseiam-se em duas premissas: (i) mercados financeiros são informacionalmente eficientes, ou seja, investidores têm acesso às mesmas informações ao mesmo tempo, e (ii) os agentes do mercado são racionais. Como consequência, assumese que os investidores, ao receberem uma informação, processariam-na da mesma maneira, formando a chamada expectativa homogênea.

Estudos vêm demonstrando que as teorias tradicionais não são capazes de capturar a intuição de que os indivíduos são imperfeitos, acreditam em fatos que parecem ser infundados, mas é possível que esse padrão de desvio da racionalidade seja sistemático (ZHANG, 2008). Dentre os conceitos que normalmente são analisados quando se discute vieses comportamentais estão o excesso de otimismo e a reação exagerada. A influência destas características nas decisões financeiras já vem sendo bastante constatado na literatura, tanto por parte dos gestores das empresas como por parte dos investidores.

Embora seja importante verificar a existência de falhas de análise por parte do indivíduo em suas decisões de investimento, talvez seja mais importante verificar se estas são relevantes de maneira agregada. Com este objetivo, esta tese propôs a análise da influência do 
sentimento, medido de uma forma agregada, nas taxas de retorno das ações no mercado brasileiro.

Partindo-se do conceito de que sentimento é o que leva a desvios de preços não explicados pela variação dos fundamentos das empresas, a pesquisa iniciou-se com a proposição de uma metodologia para a construção de um índice de sentimento. O objetivo era construir uma medida que pudesse representar um construto de difícil mensuração, de uma maneira intuitiva e parcimoniosa. Um primeiro passo foi identificar variáveis que estivessem relacionadas com o nível de otimismo/pessimismo e que fossem medidas reconhecidas em outros estudos como proxies para o sentimento do investidor. A partir das informações disponíveis para o mercado brasileiro e com uso da análise de componentes principais, foi possível a criação de um índice de sentimento. A ideia de se utilizar a ACP para a construção do índice foi justamente capturar parte da variação comum às variáveis utilizadas, gerando uma medida única que resumisse a parcela chamada de sentimento.

Foram selecionadas como variáveis relacionadas ao sentimento do mercado: (i) quantidade de aberturas de capital na bolsa; (ii) percentual de emissões de ações em relação ao total (ações e dívida); (iii) volume de ações negociado, medido pelo turnover; (iv) relação entre o volume transacionado de ações em baixa e ações em alta e (v) procura por empresas pagadoras de dividendos. As três primeiras variáveis apresentam relação direta com o nível de otimismo de mercado, e as duas últimas, relação inversa. Esta intuição foi confirmada pelos sinais obtidos na equação (4.1) do índice de sentimento, apresentada na página 94 .

Após a criação do índice de sentimento para o mercado brasileiro, verificou-se a relação entre o índice e a taxa de retorno das ações, no período de 1999 a 2008. A partir do corte do período, a amostra foi composta por empresas não-financeiras com ações listadas na BOVESPA, com uma negociabilidade mínima que garantisse observações suficientes e representativas para validar os resultados encontrados na pesquisa.

Para que fosse possível atestar a influência do sentimento nas taxas de retorno das ações, foi estimado um modelo de apreçamento levando em consideração o índice de sentimento de mercado, o risco sistêmico das empresas (medido pelo beta) e fatores como valor de mercado, índice market-to-book, alavancagem e previsibilidade dos retornos. Empregaramse diferentes procedimentos para estimar os parâmetros dos modelos empíricos formulados. O motivo foi tentar isolar influências espúrias, como a presença de heterogeneidade nãoobservada, observações extremas ou a possível endogeneidade dos regressores.

Embora procedimentos de estimação com dados em painel de mínimos quadrados ordinário, efeitos aleatórios e fixos sejam comumente adotados, seus resultados podem ser comprometidos caso não se comprove a condição de exogeneidade estrita dos regressores. Problemas como variáveis omitidas, erros de mensuração e simultaneidade podem causar 
a endogeneidade dos regressores e comprometer a consistência destes métodos habituais.

Foram aplicados testes de exogeneidade estrita, conforme proposto por Wooldridge (2002), e as análises de diagnóstico sugeriram o GMM, conforme proposto por Arellano e Bond (1991), Arellano e Bover (1995) e Blundell e Bond (1998), como método de estimação mais adequado às características dos dados disponíveis. Segundo Roodman (2009), o GMM é aplicável nas situações em que: (i) os painéis apresentam um $N$ grande e um $T$ fixo, ou seja, muitos indivíduos e uma série de tempo não muito longa; (ii) há uma relação linear entre as variáveis; (iii) há uma única variável dependente, de comportamento dinâmico e que pode depender de seus valores passados; (iv) existem variáveis independentes que não sejam estritamente exógenas, podendo ser correlacionadas com seus valores passados e correlacionadas com os erros; (v) há efeito fixo para cada indivíduo; e (vi) existem heteroscedasticidade e autocorrelação nas observações dentro de cada empresa, mas não entre as mesmas.

A grande vantagem deste método é que a consistência do estimador GMM depende de hipóteses menos restritivas que os métodos tradicionalmente empregados e lida apropriadamente com a endogeneidade dos regressores. Desta forma, resultados reportados apresentam apenas as estimações GMM, pelo método GMM em Diferenças e GMM Sistêmico, nas versões com procedimentos de um e de dois estágios, com o objetivo de verificar a robustez das estimações por métodos distintos e com procedimentos de estimação diferenciados. As estimações em dois estágios foram feitas com uso da correção proposta por Windmeijer (2005), para amostras finitas, o que reduz o eventual viés do estimador de dois estágios (ROODMAN, 2009). As diferenças entre estes métodos foi discutida na seção 3.5 .2 .

O GMM em Diferenças transforma todos os regressores ao extrair as primeiras diferenças das variáveis em relação aos seus valores passados, o que consequentemente elimina a heterogeneidade não-observada. Já o estimador GMM Sistêmico consegue tratar os principais problemas de endogeneidade mesmo sem a disponibilidade de instrumentos estritamente exógenos para todos os regressores, com a condição de que não haja correlação das primeiras diferenças defasadas dos regressores endógenos com os erros em nível, incluindo o efeito específico. Com o propósito de verificar a estacionariedade das séries temporais, foi aplicado às variáveis regressoras o teste de raiz unitária de Fisher para painel, conforme proposto por Maddala e Wu (1999). Os resultados apontaram a rejeição da hipótese nula de raiz unitária para todos os regressores, no caso do teste Phillips-Perron e, no caso do Dick-Fuller aumentado, todas as variáveis, com exceção de $B E T A$ e $\ln V M$, também rejeitaram a hipótese de raiz unitária. Quanto à variável $S E N T$, o nível descritivo dos testes poderia levar ou não à rejeição da hipótese nula de raiz unitária, dependendo do nível de significância adotado. A um nível de significância de 5\%, as hipóteses seriam 
rejeitadas, mas a 10\%, estas não seriam rejeitadas. Desta forma, foram reportados os resultados da estimação tanto por GMM-Dif como GMM-Sys, uma vez que a rejeição da hipótese nula é suscetível à escolha do nível de significância justamente para a variável de maior interesse nesta pesquisa.

Além dos diferentes métodos de estimação, foram criados modelos com diferentes definições operacionais de variáveis para os construtos tamanho, endividamento e previsibilidade dos retornos. Em função da variável escolhida como proxy para previsibilidade dos retornos, os modelos tornam-se estáticos ou dinâmicos. Foram aplicados testes para a análise de diagnóstico do modelo, com o objetivo de verificar se os modelos estão corretamente identificados. Os resultados indicaram a adequação dos modelos para estimação por GMM. Estes modelos, definidos nos Quadros 4.1 e 4.2, foram estimados por diferentes métodos: GMM em Diferenças e GMM Sistêmico, com um ou com dois estágios. Os coeficientes encontrados para a variável $S E N T$ foram negativos e, à exceção de uma única estimação em um dos modelos, significantes nos níveis convencionais. Este resultado indica que a variável de índice de sentimento mostrou-se relevante no modelo de apreçamento, mesmo com a utilização de diferentes variáveis ou métodos de estimação. Tais resultados são corroborados com a utilização de variáveis Winsorizadas para analisar se o efeito do índice de sentimento nas taxas de retornos das ações não era alterado pela possível existência de outliers. O que se observou foi que a retirada de observações extremas não alterou os resultados anteriores, e a variável $S E N T$, nesta análise, apresentou coeficientes negativos e significantes em todas as estimações de todos os modelos.

Os resultados deste estudo empírico sugerem que o sentimento é um fator relevante no apreçamento das ações no mercado brasileiro. O coeficiente negativo encontrado indica que existe um padrão de reversão nas taxas de retornos, ou seja, após um período de sentimento positivo, o impacto nas taxas de retorno no período seguinte é negativo, e vice-versa. Para garantir a solidez das conclusões encontradas, foram inseridas no modelo de apreçamento algumas variáveis de controle. O objetivo foi justamente verificar se o sentimento está relacionado com as taxas de retorno mesmo quando se controlam por outros fatores, como risco sistêmico, tamanho, índice market-to-book e previsibilidade dos retornos.

Com relação às variáveis de controle, $B E T A$ apresentou coeficientes positivos e significantes em alguns modelos apenas, o que indica que na presença do índice de sentimento e de dos demais controles, seu poder de explicação sobre as taxas de retornos das ações é diminuído. A variável de alavancagem, seja ela medida em relação ao ativo contábil $(D B A T)$ ou ao ativo a mercado $(D B A M)$, mostrou-se negativa e significante em alguns dos modelos. Este resultado indica que o endividamento tem uma relação inversa com a taxa de retorno das ações, sugerindo que empresas muito alavancadas têm uma taxa 
de retorno menor que empresas pouco alavancadas, diferentemente do esperado pela teoria. O índice $V M P L$, market-to-book, mostrou-se positivo e significante para a maioria dos modelos. Empresas com valor de mercado superior em relação ao seu valor contábil apresentam taxas de retorno maiores, e vice-versa. As variáveis utilizadas como proxies para a previsibilidade de retornos $(C R E S C$, para os modelos estáticos e $M O M$, para os dinâmicos) apresentaram coeficientes significantes em alguns casos, mas não estáveis o suficiente para que fossem atestadas relações com a taxa de retorno.

A consistência observada nos resultados desta pesquisa dá fortes indícios da validade empírica do modelo de apreçamento adotado nesta tese. A inclusão de uma variável que tenta capturar o sentimento do mercado, ou seja, o seu nível de otimismo ou pessimismo, é contributiva para explicar as taxas de retorno das ações das empresas.

Esta tese proporcionou a primeira evidência empírica com dados brasileiros de um modelo de apreçamento baseado em um índice de sentimento construído a partir de medidas indiretas, controlando-se por anomalias comumente reportadas e com utilização de dados em painel com estimação GMM. Os resultados indicam que a formulação clássica do $C A P M$ é falha ao não considerar outros fatores que se mostram relevantes para a determinação dos preços dos ativos. A abordagem aqui apresentada é inovadora, também, por realizar esta pesquisa com métodos de estimação mais robustos a problemas de endogeneidade e heterogeneidade não-observada.

Existem várias possibilidades de pesquisas futuras nesta área. A incorporação de características como o sentimento do investidor é bastante recente nos estudos. Ainda não existe um consenso com relação a como medir este conceito, ficando abertas novas possibilidades de variáveis que possam quantificar o sentimento. Além disso, pode-se explorar se outras variáveis de controle, ou mesmo outra periodicidade de dados, aplicados a outras amostras, produzem resultados que confirmem ou não os encontrados nesta pesquisa. 


\section{Referências}

ALCHIAN, Armen A. Uncertainty, Evolution, and Economic Theory. The Journal of Political Economy, v. 58, n. 3, p. 211-221, Jun 1950.

ALEXANDER, Carol. Practical Financial Econometrics. In: Market Risk Analysis, Volume II. Chichester: Wiley, 2008.

AMIHUD, Yakov; MENDELSON, Haim. Liquidity and Stock Returns. Financial Analysts Journal, v. 42, n. 3, p. 43-48, 1986.

ARELlanO, Manuel; BOND, Stephen R. Some Tests of Specification for Panel Data: Monte Carlo Evidence and an Application to Employment Equations. The Review of Economic Studies, p. 277-297, 1991.

ARELLANO, Manuel; BOVER, Olympia. Another Look at the Instrumental Variable Estimation of Error-Components Models. Journal of Econometrics, v. 68, n. 1, p. 29-52, 1995.

ARMSTRONG, J. Scott. Individual Differences in Reasoning: Implications for the Rationality Debate? Technology Review, v. 82, p. 16-24, June/July 1980.

ARROW, Kenneth J.; DEBREU, Gerard. Existence of an Equilibrium for a Competitive Economy. Econometrica, v. 22, n. 3, p. 265-290, 1954.

BACHELIER, Louis. Théorie de la Spéculation. Annales Scientifiques de l'École Normale Superiéure, v. 3, n. 17, p. 21-86, 1900.

BAKER, Malcolm P.; RUBACK, Richard S.; WURGLER, Jeffrey A. Behavioral Corporate Finance: A Survey. In: ECKBO, B. Espen (Ed.). Handbook of Corporate Finance: Empirical Corporate Finance. New Hampshire: Elsevier/North-Holland, 2006. v. 1, cap. 4, p. $145-188$.

BAKER, Malcolm P.; STEIN, Jeremy C. Market Liquidity as a Sentiment Indicator. Journal of Financial Markets, v. 7, n. 3, p. 271-299, 2004. 
BAKER, Malcolm P.; WURGLER, Jeffrey A. The Equity Share in New Issues and Aggregate Stock Returns. The Journal of Finance, v. 55, n. 5, p. 2219-2257, 2000.

. A Catering Theory of Dividends. The Journal of Finance, v. 59, n. 3, p. 1125-1165, 2004.

. Investor Sentiment and the Cross-Section of Stock Returns. The Journal of Finance, v. 61, n. 4, p. 1645-1680, 2006.

. Investor Sentiment in the Stock Market. Journal of Economic Perspectives, v. 21, n. 2, p. 129-151, Spring 2007.

BANDOPADHYAYA, Arindam. Measures of Investor Sentiment: Who wins the Horse Race. 2006. Acessado em 11 de novembro de 2008. Disponível em: http://www . financialforum. umb.edu/documents/HorseRace.pdf.

BANDOPADHYAYA, Arindam; JONES, Anne Leah. Measuring Investor Sentiment in Equity Markets. Journal of Asset Management, v. 7, p. 208-215, 2006.

BANZ, Rolf W. The Relationship between Return and Market Value of Common Stocks. Journal of Financial Economics, v. 9, n. 1, p. 3-18, 1981.

BARBERIS, Nicholas C.; SHLEIFER, Andrei; VISHNY, Robert W. A Model of Investor Sentiment. Journal of Financial Economics, v. 49, n. 3, p. 307-343, 1998.

BARNETT, Vic; LEWIS, Toby. Outliers in Statistical Data. 3. ed. Chichester: Wiley, 1994.

BARROS, Lucas A. B. C. Decisões de Financiamento e de Investimento das Empresas sob a Ótica de Gestores Otimistas e Excessivamente Confiantes. Tese (Tese - Doutorado em Administração) — Universidade de São Paulo, 2005.

BASU, Sandip K. Investment Performance of Common Stocks in Relation to Their PriceEarnings Ratios: A Test of the Efficient Market Hypothesis. Journal of Finance, v. 32, n. 3, p. 663-682, 1977.

BAUM, Christopher F.; SCHAFFER, Mark E.; STILLMAN, Steven. Instrumental Variables and GMM: Estimation and Testing. Stata Journal, v. 3, n. 1, p. 1-31, 2003.

BAZERMAN, Max H. Judgment in Managerial Decision Making. 6th. ed. New York: Wiley, 2006.

BEKAERT, Geert et al. Distributional Characteristics of Emerging Market Returns and Asset Allocation. Journal of Portfolio Management, v. 24, p. 102-116, Winter 1998. 
BEnTES, Fabio G. M. O Poder Preditivo do Índice de Confiança do Consumidor no Brasil: uma Análise através de Vetores Autoregressivos. Dissertação (Programa de Mestrado Profissionalizante em Economia) — Faculdade IBMEC São Paulo, São Paulo, 2006.

BERNOULLI, Daniel. Exposition of a New Theory of the Measurement of Risk. Econometrica, v. 22, n. 1, p. 23-36, 1954. Tradução do latim para o inglês do original: Specimen Theoriae Novae de Mensura Sortis (1738).

BERNSTEIN, Peter L. Capital Ideas Evolving. New Jersey: Wiley, 2007.

BHANDARI, Laxmi Chand. Debt/Equity Ratio and Expected Common Stock Returns: Empirical Evidence. Journal of Finance, v. 43, n. 2, p. 507-528, 1988.

BLACK, Fischer. Capital Market Equilibrium with Restricted Borrowing. Journal of Business, v. 45, n. 3, p. 444, Jul 1972.

. Noise. The Journal of Finance, v. 41, n. 3, p. 529-543, Jul 1986.

BLACK, Fischer; JENSEN, Michael C.; SCHOLES, Myron. The Capital Asset Pricing Model: Some Empirical Tests. Studies in the Theory of Capital Markets, v. 81, p. 79-121, 1972 .

BLACK, Fischer; SCHOLES, Myron. The Pricing of Options and Corporate Liabilities. The Journal of Political Economy, v. 81, n. 3, p. 637-654, May 1973.

BLUNDELL, Richard; BOND, Stephen R. Initial Conditions and Moment Restrictions in Dynamic Panel Data Models. Journal of Econometrics, v. 87, n. 1, p. 115-143, 1998.

BOND, Stephen R.; HOEFFLER, Anke; TEMPLE, Jonathan R. GMM Estimation of Empirical Growth Models. SSRN eLibrary, 2001. Acessado em 01 de setembro de 2009. Disponível em: http://ssrn. com/paper=290522.

BREEDEN, Douglas. An Intertemporal Asset Pricing Model with Stochastic Investment and Consumption Opportunities. Journal of Financial Economics, v. 7, p. 265-296, 1979.

BROWN, Gregory W.; CLIFF, Michael T. Investor Sentiment and the Near-term Stock Market. Journal of Empirical Finance, v. 11, n. 1, p. 1-27, 2004.

. Investor Sentiment and Asset Valuation. The Journal of Business, v. 78, n. 2, p. 405-440, 2005.

BROWN, Stephen J. et al. Investor Sentiment in Japanese and U.S. Daily Mutual Fund Flows. NBER Working Paper, 2003. Acessado em 20 de outubro de 2008. Disponível em: http://ssrn. com/paper=375322. 
CAMERER, Colin F. Behavioral Game Theory: Experiments in Strategic Interaction. New Jersey: Princeton University Press, 2003.

CAMERON, Adrian Colin; TRIVEDI, Pravin K. Microeconometrics Using Stata. Texas: Stata Press, 2009.

CAMPBELL, John Y. Asset Pricing at the Millennium. The Journal of Finance, v. 55, n. 4, p. 1515-1567, Aug 2000.

CAMPBELL, John Y.; LO, Andrew W.; MACKINLAY, Craig. The Econometrics of Financial Markets. New Jersey: Princeton University Press, 1997.

CARHART, Mark M. On Persistence in Mutual Fund Performance. Journal of Finance, v. 52, n. 1, p. 57-82, 1997.

CASTRO JUNIOR, Francisco Henrique F. Apreçamento de Ativos com Assimetria e Curtose: um Teste de Comomentos com Dados em Painel. Tese (Tese - Doutorado em Administração) - Universidade de São Paulo, 2008.

CATTELL, Raymond B. The Scree Test For The Number Of Factors. Journal of Multivariate Behavioral Research, v. 1, n. 2, p. 245-276, 1966.

CHEN, Nai-Fu; KAN, Raymond; MILLER, Merton H. Are the Discounts on Closed-End Funds a Sentiment Index? Journal of Finance, v. 48, n. 2, p. 795-800, 1993.

CHOPRA, Navin et al. Yes, Discounts on Closed-End Funds are a Sentiment Index. Journal of Finance, v. 48, n. 2, p. 801-808, 1993a.

Summing Up. Journal of Finance, v. 48, n. 2, p. 811-812, 1993 b.

DANIEL, Kent; HIRSHLEIFER, David A.; SUBRAHMANYAM, Arati. Investor Psychology and Security Market Under- and Overreactions. The Journal of Finance, v. 53, n. 6, p. 1839-1885, Dec 1998.

DE ANGELO, Harry; MASULIS, Ronald W. Leverage and Dividend Irrelevancy Under Corporate and Personal Taxation. The Journal of Finance, v. 35, n. 2, p. 453-464, 1980.

DE BONDT, Werner F. M.; THALER, Richard H. Does the Stock Market Overreact? Journal of Finance, v. 40, n. 3, p. 793-805, Jul 1985.

. Further Evidence on Investor Overreaction and Stock Market Seasonality. Journal of Finance, v. 42, n. 3, p. 557-581, 1987.

DE LONG, John Bradford. The Market Valuation of Cash Dividends: A Case to Consider. Journal of Financial Economics, v. 6, n. 2/3, p. 235-264, 1978. 
DE LONG, John Bradford et al. Noise Trader Risk in Financial Markets. Journal of Political Economy, v. 98, n. 4, p. 703-738, Aug 1990.

DIAMOND, Peter; VARTIAINEN, Hannu. Behavioral Economics and Its Applications. New Jersey: Princeton University Press, 2007.

DIMSON, Elroy; MUSSAVIAN, Massoud. Three Centuries of Asset Pricing. Journal of Banking and Finance, v. 23, n. 12, p. 1745-1769, 1999.

DOMINGUES, Ronald. Previsibilidade de Retornos Diários no Mercado de Ações a partir de Indicadores de Sentimento do Investidor. Dissertação (Programa de Mestrado Profissionalizante em Economia) — Faculdade IBMEC São Paulo, São Paulo, 2008.

EDMANS, Alex; GARCIA, Diego; NORLI, Øyvind. Sports Sentiment and Stock Returns. The Journal of Finance, v. 62, n. 4, p. 1967-1998, 2007.

ELTON, Edwin J.; GRUBER, Martin J.; BUSSE, Jeffrey A. Do Investors Care about Sentiment? The Journal of Business, v. 71, n. 4, p. 477-500, 1998.

FAMA, Eugene F. The Behavior of Stock-Market Prices. Journal of Business, v. 38, n. 1, p. 34,1965 .

. Efficient Capital Markets: A Review of Theory and Empirical Work. The Journal of Finance, v. 25, n. 2, p. 383-417, May 1970.

. Efficient Capital Markets II. The Journal of Finance, v. 46, n. 5, p. 1575-1617, Dec 1991.

. Market Efficiency, Long-term Returns, and Behavioral Finance. Journal of Financial Economics, v. 49, n. 3, p. 283-306, Sep 1998.

FAMA, Eugene F.; FRENCH, Kenneth R. Permanent and Temporary Components of Stock Prices. The Journal of Political Economy, v. 96, n. 2, p. 246-273, 1988.

. The Cross-Section of Expected Stock Returns. The Journal of Finance, v. 47, n. 2, p. 427-465, Spr 1992.

. Disappearing Dividends: Changing Firm Characteristics or Lower Propensity to Pay? Journal of Financial Economics, v. 60, n. 1, p. 3-43, 2001.

- The Capital Aasset Pricing Model: Theory and Evidence. Journal of Economic Perspectives, p. 25-46, 2004.

. Financing Decisions: Who Issues Stock? Journal of Financial Economics, v. 76, n. 3, p. 549-582, 2005. 
. Dissecting Anomalies. SSRN eLibrary, SSRN, 2007. Acessado em 22 de maio de 2009. Disponível em: http://ssrn . com/paper=911960.

FAMA, Eugene F.; MACBETH, James D. Risk, Return, and Equilibrium: Empirical Tests. Journal of Political Economy, v. 81, n. 3, p. 607-636, 1973.

FISHER, Kenneth L.; STATMAN, Meir. Consumer Confidence and Stock Returns. Journal of Portfolio Management, v. 30, n. 1, p. 115-127, 2003.

FRANKLIN, Scott B. et al. Parallel Analysis: a Method for Determining Significant Principal Components. Journal of Vegetation Science, p. 99-106, 1995.

FULLER, Russell J. Behavioral Finance and the Sources of Alpha. Journal of Pension Plan Investing, v. 2, n. 3, 1998.

GERBER, Anke; HENS, Thorsten; VOGT, Bodo. Rational Investor Sentiment. SSRN eLibrary, 2002. Acessado em 03 de novembro de 2008. Disponível em: http://ssrn. com/ paper $=326802$.

GOETZMAnN, William N.; MASSA, Massimo; ROUWENHORST, K. Geert. Behavioral Factors in Mutual Fund Flows. SSRN eLibrary, 1999. Acessado em 03 de dezembro de 2008. Disponível em: http: //ssrn. com/paper=201035.

HAIR JR., Joseph F. et al. Multivariate Data Analysis. 5. ed. New Jersey: Prentice Hall, 1998.

HANSEN, Lars Peter. Large Sample Properties of Generalized Method of Moments Estimators. Econometrica, v. 50, n. 4, p. 1029-1054, 1982.

HARDY, Charles Oscar. Odd-lot Trading on the New York Stock Exchange. Menasha: Brookings Institution, 1975.

HIRSHLEIFER, David A. Investor Psychology and Asset Pricing. The Journal of Finance, v. 56, n. 4, p. 1533-1597, 2001.

HIRSHLEIFER, David A.; SHUMWAY, Tyler. Good Day Sunshine: Stock Returns and the Weather. The Journal of Finance, v. 58, n. 3, p. 1009-1032, 2003.

HONG, Harrison; STEIN, Jeremy C. A Unified Theory of Underreaction, Momentum Trading, and Overreaction in Asset Markets. The Journal of Finance, v. 54, n. 6, p. 2143-2184, 1999.

HORN, John L. A Rationale and Test for the Number of Factors in Factor Analysis. Psychometrica, v. 30, n. 2, p. 179-185, June 1965. 
JEGADEESH, Narasimhan. Evidence of Predictable Behavior of Security Returns. Journal of Finance, v. 45, n. 3, p. 881-898, 1990.

JEGADEESH, Narasimhan; TITMAN, Sheridan. Returns to Buying Winners and Selling Losers: Implications for Stock Market Efficiency. Journal of Finance, v. 48, n. 1, p. 65-91, 1993.

JENSEN, Michael C.; MECKLING, William H. Theory of the Firm: Managerial Behavior. Journal of Financial Economics, v. 3, n. 4, p. 305-360, 1976.

JOHNSON, Richard A.; WICHERN, Dean W. Applied Multivariate Statistical Analysis. 5. ed. New Jersey: Prentice Hall, 2002.

JOLlifFE, Ian T. Principal Component Analysis. 2. ed. New York: Springer, 2002.

JONES, Charles M. A Century of Stock Market Liquidity and Trading Costs. SSRN eLibrary, 2002. Acessado em 28 de dezembro de 2008. Disponível em: http://ssrn.com/ paper $=313681$.

KAISER, Henry F. The Application of Electronic Computers to Factor Analysis. Educational and Psychological Measurement, v. 20, n. 1, p. 141-151, 1960.

KAMSTRA, Mark J.; KRAMER, Lisa A.; LEVI, Maurice D. Winter Blues: Seasonal Affective Disorder (SAD) and Stock Returns. American Economic Review, v. 93, n. 1, p. 324-43, 2003.

KERLINGER, Fred Nichols. Metodologia da Pesquisa em Ciências Sociais: Um Tratamento Conceitual. São Paulo: EPU, 1980.

KEYNES, John Maynard. The General Theory of Employment Interest and Money. [S.1.]: Macmillan, 1936.

KNIGHT, Frank H. Risk, Uncertainty and Profit. Boston: Houghton Mifflin, 1921.

LAKONISHOK, Josef; SHLEIFER, Andrei; VISHNY, Robert W. Do Institutional Investors Destabilize Stock Prices? Evidence on Herding and Feedback Trading. SSRN eLibrary, 1991. Acessado em 28 de março de 2009. Disponível em: http://ssrn.com/ paper $=226729$.

LANCASTER, Kelvin J. A New Approach to Consumer Theory. The Journal of Political Economy, v. 74, n. 2, p. 132, 1966.

LEE, Charles M.; SHLEIFER, Andrei; THALER, Richard H. Investor Sentiment and the Closed-End Fund Puzzle. Journal of Finance, v. 46, n. 1, p. 75-109, 1991. 
LINTNER, John. The Valuation of Risk Assets and the Selection of Risky Investments in Stock Portfolios and Capital Budgets. Review of Economics and Statistics, v. 47, n. 1, p. 13-37, 1965.

LJUNGQVIST, Alexander; NANDA, Vikram; SINGH, Rajdeep. Hot Markets, Investor Sentiment, and IPO Pricing. The Journal of Business, v. 79, n. 4, p. 1667-1702, 2006.

LOWRY, Michelle. Why does IPO Volume Fluctuate so much? Journal of Financial Economics, v. 67, n. 1, p. 3-40, 2003.

LUCAS, Deborah J.; MCDONALD, Robert L. Equity Issues and Stock Price Dynamics. Journal of Finance, v. 45, n. 4, p. 1019-1043, 1990.

MADDALA, G.S.; WU, Shaowen. A Comparative Study of Unit Root Tests with Panel Data and a New Simple Test. Oxford Bulletin of Economics and Statistics, v. 61, n. S1, p. 631-652, 1999.

MALKIEL, Burton G. The Valuation of Closed-End Investment-Company Shares. Journal of Finance, v. 32, n. 3, p. 847-59, 1977.

MANDELBROT, Benoit B.; HUDSON, Richard L. The (Mis)Behavior of Markets. New York: Basic Books, 2004.

MARCONI, Marina de Andrade; LAKATOS, Eva Maria. Fundamentos de Metodologia Cientifica. 5. ed. São Paulo: Atlas, 2003.

MARKOWITZ, Harry. Portfolio Selection. The Journal of Finance, v. 7, n. 1, p. 77-91, Mar 1952.

MAYERS, David. Nonmarketable Assets and Capital Market Equilibrium Under Uncertainty. Studies in the Theory of Capital Markets, p. 223-248, 1972.

MERTON, Robert C. An Intertemporal Capital Asset Pricing Model. Econometrica, v. 41, n. 5, p. 867-887, 1973.

. On Market Timing and Investment Performance. I. An Equilibrium Theory of Value for Market Forecasts. Journal of Business, v. 54, n. 3, p. 363-406, 1981.

MILLER, Merton H. Behavioral Rationality in Finance: The Case of Dividends. The Journal of Business, v. 59, n. 4, p. 451-468, Oct 1986.

MILLER, Merton H.; MODIGLIANI, Franco. Dividend Policy, Growth, and the Valuation of Shares. Journal of Business, v. 34, n. 4, p. 411, 1961. 
MODIGLIANI, Franco; MILLER, Merton H. The Cost of Capital, Corporation Finance and the Theory of Investment. The American Economic Review, v. 48, n. 3, p. 261-297, 1958.

. Corporate Income Taxes and the Cost of Capital: A Correction. The American Economic Review, v. 53, n. 3, p. 433-443, 1963.

MOSSIN, Jan. Equilibrium in a Capital Asset Market. Econometrica, v. 34, n. 4, p. 768-783, 1966.

MULLAINATHAN, Sendhil; THALER, Richard H. Behavioral Economics. SSRN eLibrary, 2000. Acessado em 22 de novembro de 2008. Disponível em: http://ssrn.com/ paper $=245828$.

MYERS, Stewart C. The Capital Structure Puzzle. The Journal of Finance, v. 39, n. 3, 1984.

NEAL, Robert; WHEATLEY, Simon M. Do Measures of Investor Sentiment Predict Stock Returns? Journal of Financial and Quantitative Analysis, v. 34, n. 523-547, 1998.

OLIVEIRA, Raquel de F. Estudo da Percepção de Risco por Parte dos Depositantes de Bancos - O Caso do Mercado Brasileiro de 1999 a 2006. Tese (Tese - Doutorado em Administração) - Universidade de São Paulo, 2007.

OTOO, Maria W. Consumer Sentiment and the Stock Market. SSRN eLibrary, 1999. Acessado em 23 de dezembro de 2008. Disponível em: http://ssrn. com/paper=205028.

PALOMINO, Frederic; RENNEBOOG, Luc; ZHANG, Chendi. Information Salience, Investor Sentiment, and Stock Returns: The Case of British Soccer Betting. Journal of Corporate Finance, 2008. Acessado em 25 de dezembro de 2008. Disponível em: doi:10.1016/j.jcorpfin.2008.12.001.

PÁSTOR, Ľuboš; STAMBAUGH, Robert F. Liquidity Risk and Expected Stock Returns. Journal of Political Economy, v. 111, n. 3, p. 642-685, 2003.

PEROBELli, Fernanda F. C.; PEROBELli, Fernando S.; ARBEX, Marcelo A. Expectativas Racionais e Eficiência Informacional: Análise do Mercado Acionário Brasileiro no Período 1997-1999. Revista de Administração Contemporânea, v. 4, n. 2, Mai-Ago 2000.

POPPER, Karl R. A Lógica da Pesquisa Científica. São Paulo: Cultrix, 1975.

POTERBA, James M. The Market Valuation of Cash Dividends: The Citizens Utilities case reconsidered. Journal of Financial Economics, v. 15, n. 3, p. 395-405, 1986. 
POTERBA, James M.; SUMMERS, Lawrence H. Mean Reversion in Stock Returns: Evidence and Implications. Journal of Financial Economics, v. 22, n. 1, p. 27-59, 1988.

RENCHER, Alvin C. Methods of Multivariate Analysis. 2. ed. New York: Wiley, 2001.

RITTER, Jay R.; WELCH, Ivo. A Review of IPO Activity, Pricing, and Allocations. The Journal of Finance, v. 57, n. 4, p. 1795-1828, 2002.

ROLL, Richard; ROSS, Stephen A. An Empirical Investigation of the Arbitrage Pricing Theory. Journal of Finance, v. 35, n. 5, p. 1073-1103, 1980.

ROODMAN, David M. How to do xtabond2: An introduction to difference and system gmm in stata. Stata Journal, v. 9, n. 1, p. 86-136, March 2009.

ROSS, Stephen A. The Arbitrage Pricing Theory of Capital Asset Pricing. Journal of Economic Theory, v. 13, n. 3, p. 341-360, 1976.

. Neoclassical Finance, Alternative Finance and the Closed End Fund Puzzle. European Financial Management, v. 8, n. 2, p. 129-137, 2002.

RUBINSTEIN, Mark. Rational Markets: Yes or No? The Affirmative Case. Financial Analysts Journal, v. 57, n. 3, p. 15-29, May-Jun 2001.

SAITO, Richard; BUENO, Rodrigo De Losso da Silveira. Fundamentos Teóricos e Empíricos de Apreçamento de Ativos. Revista de Administração de Empresas, v. 47, p. 81-85, Abr./Jun. 2007.

SAMUELSON, Paul A. The Fundamental Approximation Theorem of Portfolio Analysis in terms of Means, Variances and Higher Moments. The Review of Economic Studies, v. 37, n. 4 , p. 537-542, Oct 1970.

SARGAN, John Denis. The Estimation of Economic Relationships Using Instrumental Variables. Econometrica, v. 26, p. 393-415, 1958.

SAVAGE, Leonard J. The Foundations of Statistics. New York: Wiley, 1954.

SCHEINKMAN, José Alexandre; XIONG, Wei. Overconfidence and Speculative Bubbles. Journal of Political Economy, v. 111, n. 6, p. 1183-1220, 2003.

SCHLICK, Moritz. Die Kausalität in der gegenwärtigen Physik. Naturwissenschaften, v. 19, n. 7, p. 145-162, 1931.

SEVERINO, Antonio Joaquim. Metodologia do Trabalho Cientifico. 19. ed. São Paulo: Cortez, 1993. 
SEYHUN, H. Nejat. Overreaction or Fundamentals: Some lessons from Insiders' Response to the Market Crash of 1987. Journal of Finance, v. 45, n. 5, p. 1363-1388, 1990.

SHARPE, William F. Capital Asset Prices: A Theory of Market Equilibrium under Conditions of Risk. The Journal of Finance, v. 19, n. 3, p. 425-442, Sep 1964.

SHARPE, William F.; GORDON, Alexander J.; BAILEY, Jeffrey V. Investments. 5th. ed. New Jersey: Prentice-Hall International, 1995.

SHEFRIN, Hersh M. Behavioral Corporate Finance. Journal of Applied Corporate Finance, v. 14, n. 3, Fall 2001.

. A Behavioral Approach to Asset Pricing. Burlington: Academic Press, 2005.

SHEFRIN, Hersh M.; BELOTTI, Mario L. Behavioral Finance: Biases, Mean-Variance Returns, and Risk Premiums. CFA Institute Conference Proceedings, v. 24, n. 2, p. 4-12, June 2007.

SHEFRIN, Hersh M.; STATMAN, Meir. Behavioral Capital Asset Pricing Theory. Journal of Financial and Quantitative Analysis, v. 29, n. 3, p. 323-349, 1994.

SHILLER, Robert J. Do Stock Prices Move too Much to be Justified by Subsequent Changes in Dividends? The American Economic Review, p. 421-436, 1981.

. Stock prices and Social Dynamics. Brookings Papers on Economic Activity, v. 2, n. 1984, p. 457-498, 1984.

SHLEIFER, Andrei. Inefficient Markets: An Introduction to Behavioral Finance. Oxford: Oxford University Press, 2000.

SHLEIFER, Andrei; SUMMERS, Lawrence H. The Noise Trader Approach to Finance. Journal of Economic Perspectives, v. 4, n. 2, p. 19-33, 1990.

SHLEIFER, Andrei; VISHNY, Robert W. The Limits of Arbitrage. The Journal of Finance, v. 52, n. 1, p. 35-55, 1997.

SIL, Rudra; DOHERTY, Eileen M. Beyond Boundaries: Disciplines, Paradigms, and Theoretical Integration in International Studies. New York: State University of New York Press, 2000.

SIMON, Herbert A. A Behavioral Model of Rational Choice. The Quarterly Journal of Economics, v. 69, n. 1, p. 99-118, 1955.

SMIDT, Seymour. A New Look at the Random Walk Hypothesis. Journal of Financial and Quantitative Analysis, v. 3, n. 3, p. 235-261, 1968. 
SOLT, Michael E.; STATMAN, Meir. How Useful is the Sentiment Index? Financial Analysts Journal, v. 44, n. 5, p. 45-55, 1988.

STANOVICH, Keith E.; WEST, Richard F. Individual Differences in Reasoning: Implications for the Rationality Debate? Behavioral and Brain Sciences, v. 23, p. 645-726, 2000 .

STATMAN, Meir. Behavioral Finance: Past Battles and Future Engagements. Financial Analysts Journal, v. 55, n. 6, p. 18-27, 1999.

TALEB, Nassim Nicholas. Fooled by Randomness: The Hidden Role of Chance in Life and in the Markets. London: Penguin Books, 2004.

TARLING, Roger. Statistical Modelling for Social Researchers: Principles and Practice. New York: Routledge, 2008.

THALER, Richard H. From Homo Economicus to Homo Sapiens. The Journal of Economic Perspectives, v. 14, n. 1, p. 133-141, 2000.

THALER, Richard H.; BARBERIS, Nicholas C. A Survey of Behavioral Finance. In: . Handbook of the Economics of Finance. New York: Elsevier Science, 2003. p. $1053-1116$.

TOBIN, James. Liquidity Preference as Behavior Towards Risk. Review of Economic Studies, v. 25, n. 2, p. 65-86, 1958.

TREYNOR, Jack. Toward a Theory of Market Value of Risky Assets. Unpublished Manuscript, 1961.

TVERSKY, Amos; KAHNEMAN, Daniel. Judgment under Uncertainty: Heuristics and Biases. Science, v. 185, n. 4157, p. 1124, Sep 1974.

VERMA, Rahul; SOYDEMIR, Gökçe. The Impact of Individual and Institutional Investor Sentiment on the Market Price of Risk. Quarterly Review of Economics and Finance, 2008.

VON NEUMANN, John; MORGENSTERN, Oskar. Theory of Games and Economic Behavior. New Jersey: Princeton University Press, 1944.

WAISMANN, Friedrich. Logische Analyse des Wahrscheinlichkeitsbegriffs. Erkenntnis, v. 1, p. 228-248, 1930.

WANG, Yaw-huei; KESWANI, Aneel; TAYLOR, Stephen J. The Relationships between Sentiment, Returns and Volatility. International Journal of Forecasting, v. 22, n. 1, p. 109-123, 2006. 
WASHINGTON, Simon P.; KARLAFTIS, Matthew G.; MANNERING, Fred L. Statistical and Econometric Methods for Transportation Data Analysis. Florida: Chapman \& Hall, 2003.

WHALEY, Robert E. Understanding VIX. SSRN eLibrary, 2008. Acessado em 03 de janeiro de 2009. Disponível em: http://ssrn.com/paper=1296743.

WILliAMS, Joseph T. Capital Asset Prices with Heterogeneous Beliefs. Journal of Financial Economics, v. 5, n. 2, p. 219-239, 1977.

WILLIAMSON, Oliver E. Corporate Finance and Corporate Governance. The Journal of Finance, v. 43, n. 3, p. 567-591, Jul 1988.

WINDMEIJER, Frank. A Finite Sample Correction for the Variance of Linear Efficient Two-step GMM Estimators. Journal of Econometrics, v. 126, n. 1, p. 25-51, 2005.

WOOLDRIDGE, Jeffrey M. Econometric Analysis of Cross Section and Panel Data. Cambridge: MIT Press, 2002.

YOSHINAGA, Claudia E. et al. Finanças Comportamentais: uma Introdução. Revista de Gestão USP, v. 15, n. 3, jul-set 2008.

ZHANG, Cathy. Defining, Modeling, and Measuring Investor Sentiment. Tese (Tese Doutorado em Economia) — University of California, Berkeley, 2008.

ZWEIG, Martin E. An Investor Expectations Stock Price Predictive Model Using ClosedEnd Fund Premiums. The Journal of Finance, v. 28, n. 1, p. 67-78, 1973. 


\section{Apêndice A}

\section{Índice de Sentimento}

Tabela A.1 - Intervalos de confiança dos autovalores com as variáveis de sentimento

\begin{tabular}{lrcc}
\hline Componente & Autovalor & Limite Inferior & Limite Superior \\
\hline Componente 1 & 2,2736 & 1,4669 & 3,5242 \\
Componente 2 & 0,9412 & 0,6072 & 1,4588 \\
Componente 3 & 0,8917 & 0,5753 & 1,3822 \\
Componente 4 & 0,5049 & 0,3258 & 0,7826 \\
Componente 5 & 0,3886 & 0,2507 & 0,6023 \\
\hline
\end{tabular}

A tabela acima apresenta os autovalores gerados para cada um dos componentes a partir das variáveis, com um intervalo de confiança de 95\%. É importante observar que o último autovalor é não-nulo, o que indica que não há variáveis dispensáveis no modelo.

Tabela A.2 - Autovalores calculados para a determinação da quantidade de componentes

\begin{tabular}{cccc}
\hline Componentes & ACP & Análise Paralela & Regra de Kaiser \\
\hline 1 & 2,4514 & 1,4652 & 1 \\
2 & 0,9045 & 1,1842 & 1 \\
3 & 0,7313 & 0,9765 & 1 \\
4 & 0,5894 & 0,7876 & 1 \\
5 & 0,3234 & 0,5865 & 1 \\
\hline
\end{tabular}




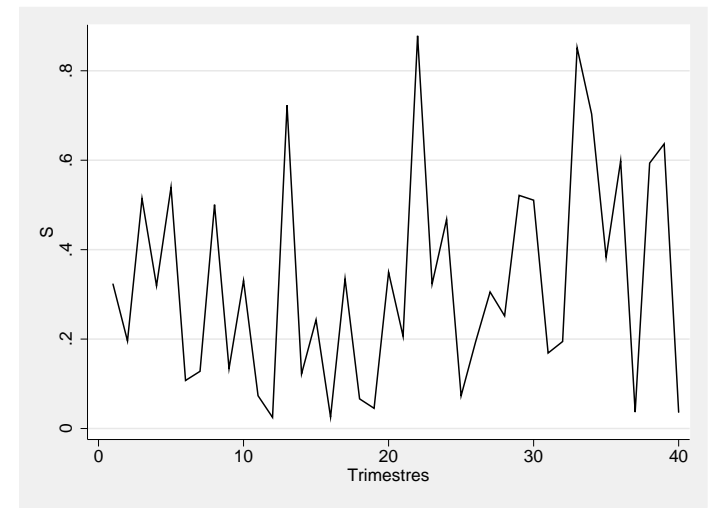

(a) Proporção de ações, $S$

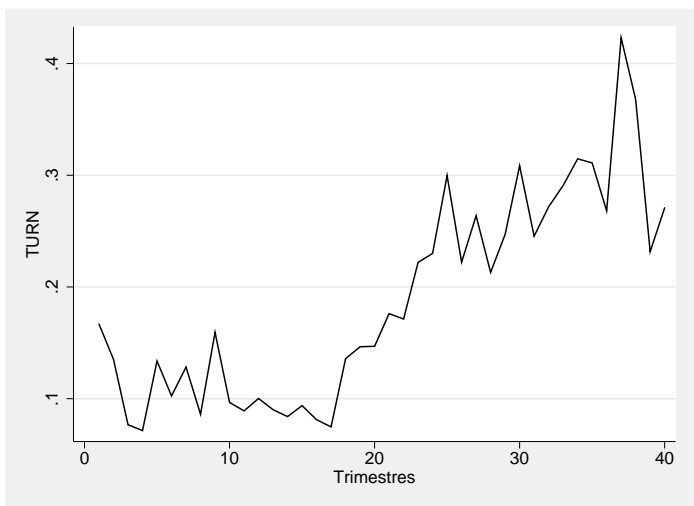

(c) Turnover, TURN

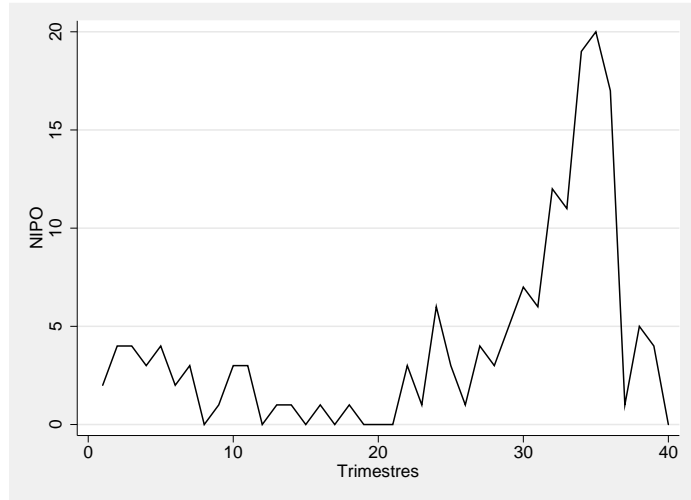

(b) Quantidade de IPOs, NIPO

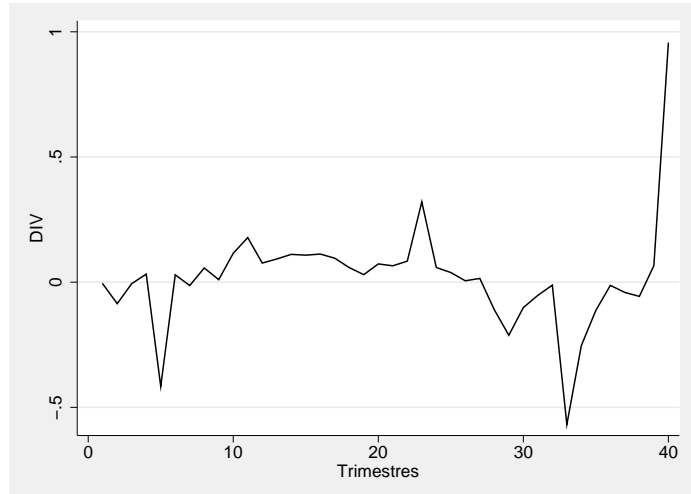

(d) Prêmio de dividendos, $D I V$

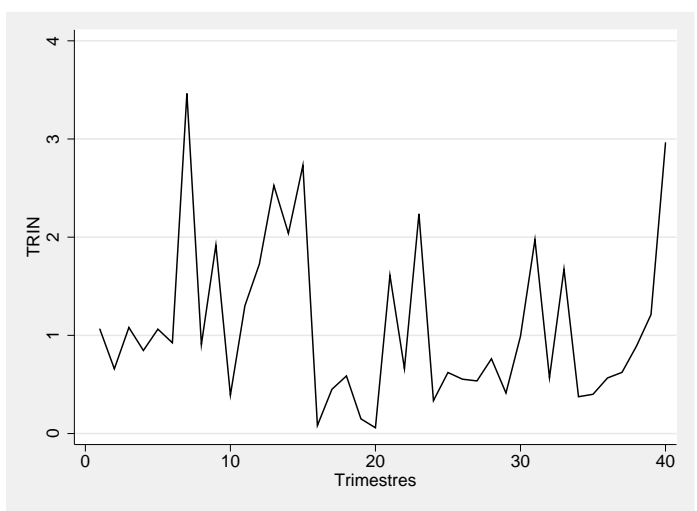

(e) Índice $T R I N$

Figura A.1 - Evolução das Variáveis que compõem o Índice de Sentimento. O gráfico (a) apresenta a evolução trimestral, de janeiro de 1999 a dezembro de 2008, da variável $S$, dada pelo volume total de ações emitido dividido pelo volume total de ações e dívidas emitidas. Os dados foram coletados da CVM. O segundo apresenta a variável $N I P O$, quantidade de $I P O$ s realizados a cada trimestre, coletada também a partir de informações disponibilizadas pela CVM. O gráfico (c) mostra a variável $T U R N$, dada pela proporção de ações negociadas em relação ao total de ações listado. O gráfico (d) mostra o prêmio de dividendos, $D I V$, dado pela diferença dos logaritmos do índice market-tobook das empresas pagadoras e não-pagadoras de dividendos. O gráfico (e) apresenta o indicador $T R I N$, que relaciona quantidade e volumes de ações em alta e em baixa. 


\section{Apêndice B}

\section{Modelo de Apreçamento}

\section{B.1 Amostra do Modelo de Apreçamento}

Tabela B.1 - Empresas que compõem a amostra do modelo de apreçamento

\begin{tabular}{lllll}
\hline$\#$ & Empresa & Classe & Código & Setor \\
\hline 1 & Abnote & ON & ABNB3 & Outros \\
2 & Abyara & ON & ABYA3 & Construção \\
3 & Aços Villares & ON & AVIL3 & Siderurgia e Metalurgia \\
4 & AES Elpa & ON & AELP3 & Energia Elétrica \\
5 & AES Tietê & PN & GETI4 & Energia Elétrica \\
6 & Agra Incorporadora & ON & AGIN3 & Construção \\
7 & Agrenco & ON & AGEN11 & Agro e Pesca \\
8 & Albarus & ON & ALBA3 & Veículos e peças \\
9 & ALL América Latina & UNT N2 & ALLL11 & Transporte Serviços \\
10 & Alpargatas & PN & ALPA4 & Têxtil \\
11 & Am Inox Br & PN & ACES4 & Siderurgia e Metalurgia \\
12 & Ambev & PN & AMBV4 & Alimentos e Bebidas \\
13 & Amil & ON & AMIL3 & Outros \\
14 & Ampla Energ & ON & CBEE3 & Energia Elétrica \\
15 & Anglo Brazil & ON & IRON3 & Mineração \\
16 & Anhanguera & UNT N2 & AEDU11 & Outros \\
17 & Antarct Nordeste & PNA & IBAN5 & Alimentos e Bebidas \\
18 & Aracruz & PNB & ARCZ6 & Papel e Celulose \\
19 & Arcelor BR & ON & ARCE3 & Siderurgia e Metalurgia \\
20 & B2W Varejo & ON & BTOW3 & Comércio \\
21 & Bahia Sul & PNA & BSUL5 & Papel e Celulose \\
22 & Bandeirante Energia & PN & EBEN4 & Energia Elétrica \\
23 & Bardella & PN & BDLL4 & Máquinas Industriais \\
24 & Bematech & ON & BEMA3 & Eletroeletrônicos \\
\hline & & Continua na próxima página & \\
\hline & & & \\
& & & \\
\hline
\end{tabular}


Tabela B.1: continuação da página anterior

\begin{tabular}{|c|c|c|c|c|}
\hline$\#$ & Empresa & Classe & Código & Setor \\
\hline 25 & Bombril & $\mathrm{PN}$ & BOBR4 & Química \\
\hline 26 & Bompreço & $\mathrm{PN}$ & $\mathrm{BPCO} 4$ & Comércio \\
\hline 27 & Botucatu Tex & $\mathrm{PN}$ & STRP4 & Têxtil \\
\hline 28 & Br Brokers & $\mathrm{ON}$ & BBRK3 & Outros \\
\hline 29 & BR Malls Par & $\mathrm{ON}$ & BRML3 & Outros \\
\hline 30 & Bradespar & $\mathrm{PN}$ & BRAP4 & Outros \\
\hline 31 & Brascan Res & $\mathrm{ON}$ & BISA3 & Construção \\
\hline 32 & Brasil T Par & $\mathrm{ON}$ & BRTP3 & Telecomunicações \\
\hline 33 & Brasil Telec & $\mathrm{PN}$ & BRTO4 & Telecomunicações \\
\hline 34 & Brasilit & $\mathrm{ON}$ & LITS3 & Minerais não Metálicos \\
\hline 35 & Braskem & PNA & BRKM5 & Química \\
\hline 36 & Brasmotor & $\mathrm{PN}$ & BMTO4 & Eletroeletrônicos \\
\hline 37 & Bunge Alimentos & $\mathrm{ON}$ & CEVA3 & Alimentos e Bebidas \\
\hline 38 & Bunge Brasil & $\mathrm{ON}$ & MSAN3 & Alimentos e Bebidas \\
\hline 39 & Bunge Fertilizantes & $\mathrm{PN}$ & MAHS4 & Química \\
\hline 40 & Caemi & $\mathrm{PN}$ & CMET4 & Mineração \\
\hline 41 & CC Des. Imob & $\mathrm{ON}$ & CCIM3 & Construção \\
\hline 42 & CCR Rodovias & $\mathrm{ON}$ & CCRO3 & Transporte Serviços \\
\hline 43 & Celesc & PNB & CLSC6 & Energia Elétrica \\
\hline 44 & Cemar & $\mathrm{ON}$ & ENMA3B & Energia Elétrica \\
\hline 45 & Cemig & $\mathrm{PN}$ & CMIG4 & Energia Elétrica \\
\hline 46 & Cesp & $\mathrm{PNB}$ & CESP6 & Energia Elétrica \\
\hline 47 & Ceterp & $\mathrm{PN}$ & CETE4 & Telecomunicações \\
\hline 48 & Chapecó & $\mathrm{ON}$ & CHAP3 & Alimentos e Bebidas \\
\hline 49 & Cia Hering & $\mathrm{ON}$ & HGTX3 & Têxtil \\
\hline 50 & Cobrasma & $\mathrm{PN}$ & CBMA4 & Veículos e peças \\
\hline 51 & Coelba & $\mathrm{ON}$ & CEEB3 & Energia Elétrica \\
\hline 52 & Coelce & PNA & COCE5 & Energia Elétrica \\
\hline 53 & Comgas & PNA & CGAS5 & Petróleo e Gás \\
\hline 54 & Company & $\mathrm{ON}$ & CPNY3 & Construção \\
\hline 55 & Confab & $\mathrm{PN}$ & $\mathrm{CNFB} 4$ & Siderurgia e Metalurgia \\
\hline 56 & Contax & $\mathrm{PN}$ & CTAX4 & Outros \\
\hline 57 & Copasa & $\mathrm{ON}$ & CSMG3 & Outros \\
\hline 58 & Copel & PNB & CPLE6 & Energia Elétrica \\
\hline 59 & Copesul & $\mathrm{ON}$ & CPSL3 & Química \\
\hline 60 & Cosan & $\mathrm{ON}$ & CSAN3 & Alimentos e Bebidas \\
\hline 61 & Cosan Ltd & ON A & CZLT11 & Alimentos e Bebidas \\
\hline 62 & Cosipa & $\mathrm{PN}$ & CSPC4 & Siderurgia e Metalurgia \\
\hline 63 & Coteminas & $\mathrm{PN}$ & CTNM4 & Têxtil \\
\hline 64 & CPFL Energia & $\mathrm{ON}$ & CPFE3 & Energia Elétrica \\
\hline 65 & Cremer & $\mathrm{ON}$ & CREM3 & Têxtil \\
\hline 66 & CRT Celular & PNA & CRTP5 & Telecomunicações \\
\hline 67 & CRT CiaRGTelec & PNA & CRGT5 & Telecomunicações \\
\hline 68 & CSU CardSystem & $\mathrm{ON}$ & CARD3 & Outros \\
\hline
\end{tabular}


Tabela B.1: continuação da página anterior

\begin{tabular}{|c|c|c|c|c|}
\hline$\#$ & Empresa & Classe & Código & Setor \\
\hline 69 & Cyre Com-ccp & $\mathrm{ON}$ & CCPR3 & Outros \\
\hline 70 & Cyrela Realty & $\mathrm{ON}$ & CYRE3 & Construção \\
\hline 71 & Dasa & $\mathrm{ON}$ & DASA3 & Outros \\
\hline 72 & Datasul & $\mathrm{ON}$ & DSUL3 & Software e Dados \\
\hline 73 & Dixie Toga & $\mathrm{PN}$ & DXTG4 & Outros \\
\hline 74 & Doc Imbituba & $\mathrm{PN}$ & IMBI4 & Transporte Serviços \\
\hline 75 & Drogasil & $\mathrm{ON}$ & DROG3 & Comércio \\
\hline 76 & Dufrybras & $\mathrm{ON}$ & DUFB11 & Comércio \\
\hline 77 & Duratex & $\mathrm{PN}$ & DURA4 & Outros \\
\hline 78 & Ecodiesel & $\mathrm{ON}$ & ECOD3 & Outros \\
\hline 79 & Eletrobras & $\mathrm{ON}$ & ELET3 & Energia Elétrica \\
\hline 80 & Eletropar & $\mathrm{ON}$ & LIPR3 & Energia Elétrica \\
\hline 81 & Eletropaulo & PNB & ELPL6 & Energia Elétrica \\
\hline 82 & Eleva & $\mathrm{ON}$ & ELEV3 & Alimentos e Bebidas \\
\hline 83 & Elevad Atlas & $\mathrm{ON}$ & ELAT3 & Máquinas Industriais \\
\hline 84 & EMAE & $\mathrm{PN}$ & EMAE4 & Energia Elétrica \\
\hline 85 & Embraco & $\mathrm{PN}$ & $\mathrm{EBCO} 4$ & Máquinas Industriais \\
\hline 86 & Embraer & $\mathrm{ON}$ & EMBR3 & Veículos e peças \\
\hline 87 & Embratel Part & $\mathrm{PN}$ & EBTP4 & Telecomunicações \\
\hline 88 & Energias BR & $\mathrm{ON}$ & ENBR3 & Energia Elétrica \\
\hline 89 & EPTE & $\mathrm{PN}$ & EPTE4 & Energia Elétrica \\
\hline 90 & Equatorial & $\mathrm{ON}$ & EQTL3 & Energia Elétrica \\
\hline 91 & Ericsson & $\mathrm{PN}$ & ERIC4 & Eletroeletrônicos \\
\hline 92 & Estrela & $\mathrm{PN}$ & ESTR4 & Outros \\
\hline 93 & Eternit & $\mathrm{ON}$ & ETER3 & Minerais não Metálicos \\
\hline 94 & Even & $\mathrm{ON}$ & EVEN3 & Construção \\
\hline 95 & Eztec & $\mathrm{ON}$ & EZTC3 & Construção \\
\hline 96 & F Cataguazes & PNA & FLCL5 & Energia Elétrica \\
\hline 97 & Fer Heringer & $\mathrm{ON}$ & FHER3 & Química \\
\hline 98 & Ferbasa & $\mathrm{PN}$ & FESA4 & Siderurgia e Metalurgia \\
\hline 99 & Ferro Ligas & $\mathrm{PN}$ & CPFL4 & Siderurgia e Metalurgia \\
\hline 100 & Fertibras & $\mathrm{PN}$ & FBRA4 & Química \\
\hline 101 & Forjas Taurus & $\mathrm{PN}$ & FJTA4 & Siderurgia e Metalurgia \\
\hline 102 & Fosfertil & $\mathrm{PN}$ & FFTL4 & Química \\
\hline 103 & Fras-Le & $\mathrm{PN}$ & FRAS4 & Veículos e peças \\
\hline 104 & Gafisa & $\mathrm{ON}$ & GFSA3 & Construção \\
\hline 105 & Gazola & $\mathrm{PN}$ & GAZO4 & Siderurgia e Metalurgia \\
\hline 106 & Ger Paranap & $\mathrm{ON}$ & GEPA3 & Energia Elétrica \\
\hline 107 & Gerdau & $\mathrm{PN}$ & GGBR4 & Siderurgia e Metalurgia \\
\hline 108 & Gerdau Met & $\mathrm{PN}$ & GOAU4 & Siderurgia e Metalurgia \\
\hline 109 & Gol & $\mathrm{PN}$ & GOLL4 & Transporte Serviços \\
\hline 110 & GP Invest & $\mathrm{A}$ & GPIV11 & Outros \\
\hline 111 & GPC Part & $\mathrm{ON}$ & GPCP3 & Outros \\
\hline 112 & Gradiente & $\mathrm{ON}$ & IGBR3 & Eletroeletrônicos \\
\hline
\end{tabular}


Tabela B.1: continuação da página anterior

\begin{tabular}{|c|c|c|c|c|}
\hline$\#$ & Empresa & Classe & Código & Setor \\
\hline 113 & Grendene & $\mathrm{ON}$ & GRND3 & Têxtil \\
\hline 114 & Guarani & $\mathrm{ON}$ & ACGU3 & Alimentos e Bebidas \\
\hline 115 & Guararapes & $\mathrm{ON}$ & GUAR3 & Têxtil \\
\hline 116 & GVT Holding & $\mathrm{ON}$ & GVTT3 & Telecomunicações \\
\hline 117 & Helbor & $\mathrm{ON}$ & HBOR3 & Construção \\
\hline 118 & Hypermarcas & $\mathrm{ON}$ & HYPE3 & Outros \\
\hline 119 & Ideiasnet & $\mathrm{ON}$ & IDNT3 & Outros \\
\hline 120 & Ienergia & $\mathrm{ON}$ & IENG3 & Energia Elétrica \\
\hline 121 & Iguatemi & $\mathrm{ON}$ & IGTA3 & Construção \\
\hline 122 & Inds Romi & $\mathrm{ON}$ & ROMI3 & Máquinas Industriais \\
\hline 123 & Inepar & $\mathrm{PN}$ & INEP4 & Outros \\
\hline 124 & Inepar Tel & $\mathrm{ON}$ & INET3 & Telecomunicações \\
\hline 125 & Inpar S/A & $\mathrm{ON}$ & INPR3 & Construção \\
\hline 126 & Invest Tur & $\mathrm{ON}$ & IVTT3 & Outros \\
\hline 127 & Iochpe-Maxion & $\mathrm{ON}$ & MYPK3 & Veículos e peças \\
\hline 128 & Ipiranga Dis & $\mathrm{PN}$ & DPPI4 & Petróleo e Gás \\
\hline 129 & Ipiranga Pet & $\mathrm{PN}$ & PTIP4 & Petróleo e Gás \\
\hline 130 & Ipiranga Ref & $\mathrm{PN}$ & RIPI4 & Petróleo e Gás \\
\hline 131 & Itausa & $\mathrm{PN}$ & ITSA4 & Outros \\
\hline 132 & Itautec & $\mathrm{ON}$ & ITEC3 & Eletroeletrônicos \\
\hline 133 & J B Duarte & $\mathrm{PN}$ & JBDU4 & Alimentos e Bebidas \\
\hline 134 & JBS & $\mathrm{ON}$ & JBSS3 & Alimentos e Bebidas \\
\hline 135 & Jereissati & $\mathrm{PN}$ & MLFT4 & Outros \\
\hline 136 & JHSF Part & $\mathrm{ON}$ & JHSF3 & Construção \\
\hline 137 & João Fortes & $\mathrm{ON}$ & JFEN3 & Construção \\
\hline 138 & Kepler Weber & $\mathrm{ON}$ & KEPL3 & Siderurgia e Metalurgia \\
\hline 139 & Klabin S/A & $\mathrm{PN}$ & KLBN4 & Papel e Celulose \\
\hline 140 & Klabinsegall & $\mathrm{ON}$ & KSSA3 & Construção \\
\hline 141 & Kroton & UNT N2 & KROT11 & Outros \\
\hline 142 & Kuala & $\mathrm{PN}$ & ARTE4 & Têxtil \\
\hline 143 & Laep & $\mathrm{A}$ & MILK11 & Alimentos e Bebidas \\
\hline 144 & Light $\mathrm{S} / \mathrm{A}$ & $\mathrm{ON}$ & LIGT3 & Energia Elétrica \\
\hline 145 & Lix da Cunha & $\mathrm{PN}$ & LIXC4 & Construção \\
\hline 146 & LLX Log & $\mathrm{ON}$ & LLXL3 & Outros \\
\hline 147 & Localiza & $\mathrm{ON}$ & RENT3 & Outros \\
\hline 148 & Log-In & $\mathrm{ON}$ & LOGN3 & Transporte Serviços \\
\hline 149 & Lojas Americanas & $\mathrm{PN}$ & LAME4 & Comércio \\
\hline 150 & Lojas Renner & $\mathrm{ON}$ & LREN3 & Comércio \\
\hline 151 & Lopes Brasil & $\mathrm{ON}$ & LPSB3 & Construção \\
\hline 152 & Lupatech & $\mathrm{ON}$ & LUPA3 & Siderurgia e Metalurgia \\
\hline 153 & M G Poliest & $\mathrm{ON}$ & RHDS3 & Química \\
\hline 154 & M. Diasbranco & $\mathrm{ON}$ & MDIA3 & Alimentos e Bebidas \\
\hline 155 & Magnesita & PNA & MAGS5 & Mineração \\
\hline 156 & Magnesita SA & $\mathrm{ON}$ & MAGG3 & Mineração \\
\hline
\end{tabular}


Tabela B.1: continuação da página anterior

\begin{tabular}{|c|c|c|c|c|}
\hline$\#$ & Empresa & Classe & Código & Setor \\
\hline 157 & Makro & $\mathrm{ON}$ & MAKR3 & Comércio \\
\hline 158 & Mangels Indl & $\mathrm{PN}$ & MGEL4 & Siderurgia e Metalurgia \\
\hline 159 & Mannesmann & $\mathrm{ON}$ & MANM3 & Siderurgia e Metalurgia \\
\hline 160 & Marcopolo & $\mathrm{PN}$ & POMO4 & Veículos e peças \\
\hline 161 & Marfrig & $\mathrm{ON}$ & MRFG3 & Alimentos e Bebidas \\
\hline 162 & Marisa & $\mathrm{ON}$ & MARI3 & Comércio \\
\hline 163 & Medial Saúde & $\mathrm{ON}$ & MEDI3 & Outros \\
\hline 164 & Metal Leve & $\mathrm{PN}$ & LEVE4 & Veículos e peças \\
\hline 165 & Metalfrio & $\mathrm{ON}$ & FRIO3 & Máquinas Industriais \\
\hline 166 & Minerva & $\mathrm{ON}$ & BEEF3 & Alimentos e Bebidas \\
\hline 167 & Minupar & $\mathrm{ON}$ & MNPR3 & Alimentos e Bebidas \\
\hline 168 & MMX Miner & $\mathrm{ON}$ & MMXM3 & Mineração \\
\hline 169 & MPX Energia & $\mathrm{ON}$ & MPXE3 & Energia Elétrica \\
\hline 170 & MRV & $\mathrm{ON}$ & MRVE3 & Construção \\
\hline 171 & Multiplan & $\mathrm{ON}$ & MULT3 & Outros \\
\hline 172 & Mundial & $\mathrm{PN}$ & MNDL4 & Siderurgia e Metalurgia \\
\hline 173 & Natura & $\mathrm{ON}$ & NATU3 & Comércio \\
\hline 174 & Net & $\mathrm{PN}$ & NETC4 & Outros \\
\hline 175 & Odontoprev & $\mathrm{ON}$ & ODPV3 & Outros \\
\hline 176 & Ogx Petróleo & $\mathrm{ON}$ & OGXP3 & Petróleo e Gás \\
\hline 177 & OHL Brasil & $\mathrm{ON}$ & OHLB3 & Transporte Serviços \\
\hline 178 & P.Açúcar-CBD & $\mathrm{PN}$ & PCAR4 & Comércio \\
\hline 179 & Paranapanema & $\mathrm{ON}$ & PMAM3 & Siderurgia e Metalurgia \\
\hline 180 & Paul F Luz & $\mathrm{ON}$ & PALF3 & Energia Elétrica \\
\hline 181 & PDG Realt & $\mathrm{ON}$ & PDGR3 & Construção \\
\hline 182 & Perdigão S/A & $\mathrm{ON}$ & PRGA3 & Alimentos e Bebidas \\
\hline 183 & Petrobras & $\mathrm{PN}$ & PETR4 & Petróleo e Gás \\
\hline 184 & Petrobras Distrib & $\mathrm{PN}$ & BRDT4 & Petróleo e Gás \\
\hline 185 & Petroquisa & $\mathrm{PN}$ & PTQS4 & Química \\
\hline 186 & Pirelli & $\mathrm{PN}$ & PIRE4 & Eletroeletrônicos \\
\hline 187 & Plascar Part & $\mathrm{ON}$ & PLAS3 & Veículos e peças \\
\hline 188 & Polialden & $\mathrm{PN}$ & PLDN4 & Química \\
\hline 189 & Politeno & PNB & PLTO6 & Química \\
\hline 190 & Positivo Inf & $\mathrm{ON}$ & POSI3 & Eletroeletrônicos \\
\hline 191 & Pro Metalurg & PNB & PMET6 & Veículos e peças \\
\hline 192 & Profarma & $\mathrm{ON}$ & PFRM3 & Comércio \\
\hline 193 & Providencia & $\mathrm{ON}$ & PRVI3 & Química \\
\hline 194 & Quattor Petr & $\mathrm{PN}$ & SZPQ4 & Química \\
\hline 195 & Randon Part & $\mathrm{PN}$ & RAPT4 & Veículos e peças \\
\hline 196 & Rasip Agro & $\mathrm{PN}$ & RSIP4 & Agro e Pesca \\
\hline 197 & Recrusul & $\mathrm{PN}$ & RCSL4 & Veículos e peças \\
\hline 198 & Redecard & $\mathrm{ON}$ & RDCD3 & Outros \\
\hline 199 & Renar & $\mathrm{ON}$ & RNAR3 & Agro e Pesca \\
\hline 200 & Ripasa & $\mathrm{PN}$ & RPSA4 & Papel e Celulose \\
\hline
\end{tabular}


Tabela B.1: continuação da página anterior

\begin{tabular}{|c|c|c|c|c|}
\hline$\#$ & Empresa & Classe & Código & Setor \\
\hline 201 & Rodobensimob & $\mathrm{ON}$ & RDNI3 & Construção \\
\hline 202 & Rossi Resid & $\mathrm{ON}$ & RSID3 & Construção \\
\hline 203 & S Gobain Canal & $\mathrm{PN}$ & BARB4 & Siderurgia e Metalurgia \\
\hline 204 & S Gobain Vidro & $\mathrm{ON}$ & VSMA3 & Minerais não Metálicos \\
\hline 205 & Sabesp & $\mathrm{ON}$ & SBSP3 & Outros \\
\hline 206 & Sadia S/A & $\mathrm{PN}$ & SDIA4 & Alimentos e Bebidas \\
\hline 207 & Samitri & $\mathrm{PN}$ & SAMI4 & Mineração \\
\hline 208 & Sanepar & $\mathrm{PN}$ & SAPR4 & Outros \\
\hline 209 & Sansuy & PNA & SNSY5 & Outros \\
\hline 210 & Santista Alimentos & $\mathrm{ON}$ & MFLU3 & Alimentos e Bebidas \\
\hline 211 & Santistextil & $\mathrm{PN}$ & ASTA4 & Têxtil \\
\hline 212 & Santos Brasil & UNT N2 & STBR11 & Transporte Serviços \\
\hline 213 & Santos BRP & UNT N2 & STBP11 & Transporte Serviços \\
\hline 214 & São Carlos & $\mathrm{ON}$ & SCAR3 & Outros \\
\hline 215 & São Martinho & $\mathrm{ON}$ & SMTO3 & Alimentos e Bebidas \\
\hline 216 & Saraiva Livr & $\mathrm{PN}$ & SLED4 & Outros \\
\hline 217 & Satipel & $\mathrm{ON}$ & SATI3 & Outros \\
\hline 218 & Savarg & $\mathrm{PN}$ & VAGV4 & Transporte Serviços \\
\hline 219 & Seara Alim & $\mathrm{PN}$ & SALM4 & Alimentos e Bebidas \\
\hline 220 & Seb & UNT N2 & SEBB11 & Outros \\
\hline 221 & Sharp & $\mathrm{PN}$ & SHAP4 & Eletroeletrônicos \\
\hline 222 & Sibra & $\mathrm{PNC}$ & SIBR7 & Siderurgia e Metalurgia \\
\hline 223 & Sid Nacional & $\mathrm{ON}$ & CSNA3 & Siderurgia e Metalurgia \\
\hline 224 & Sid Tubarão & $\mathrm{PN}$ & CSTB4 & Siderurgia e Metalurgia \\
\hline 225 & SLC Agrícola & $\mathrm{ON}$ & SLCE3 & Agro e Pesca \\
\hline 226 & Sola & $\mathrm{PN}$ & SLAL4 & Alimentos e Bebidas \\
\hline 227 & Souza Cruz & $\mathrm{ON}$ & CRUZ3 & Outros \\
\hline 228 & Springs & $\mathrm{ON}$ & SGPS3 & Têxtil \\
\hline 229 & Submarino & $\mathrm{ON}$ & SUBA3 & Comércio \\
\hline 230 & Sultepa & $\mathrm{PN}$ & SULT4 & Construção \\
\hline 231 & Suzano Papel & PNA & SUZB5 & Papel e Celulose \\
\hline 232 & $\mathrm{TAM} \mathrm{S} / \mathrm{A}$ & $\mathrm{PN}$ & TAMM4 & Transporte Serviços \\
\hline 233 & Tecnisa & $\mathrm{ON}$ & TCSA3 & Construção \\
\hline 234 & Tectoy & $\mathrm{PN}$ & TOYB4 & Outros \\
\hline 235 & Tegma & $\mathrm{ON}$ & TGMA3 & Transporte Serviços \\
\hline 236 & Teka & $\mathrm{PN}$ & TEKA4 & Têxtil \\
\hline 237 & Tel B Campo & $\mathrm{PN}$ & ТВCP4 & Telecomunicações \\
\hline 238 & Tele Centroeste Cel & $\mathrm{ON}$ & TCOC3 & Telecomunicações \\
\hline 239 & Tele Leste Celular & $\mathrm{PN}$ & TLCP4 & Telecomunicações \\
\hline 240 & Tele Nordeste Celul & $\mathrm{ON}$ & TNEP3 & Telecomunicações \\
\hline 241 & Tele Nort Cl & $\mathrm{PN}$ & TNCP4 & Telecomunicações \\
\hline 242 & Tele Sudeste Celula & $\mathrm{ON}$ & TSEP3 & Telecomunicações \\
\hline 243 & Telebahia & PNA & TEBA5 & Telecomunicações \\
\hline 244 & Telebras & $\mathrm{PN}$ & TELB4 & Telecomunicações \\
\hline
\end{tabular}


Tabela B.1: continuação da página anterior

\begin{tabular}{|c|c|c|c|c|}
\hline$\#$ & Empresa & Classe & Código & Setor \\
\hline 245 & Telebrasilia & $\mathrm{PN}$ & TBRS4 & Telecomunicações \\
\hline 246 & Telefonica Data Hld & $\mathrm{ON}$ & TDBH3 & Telecomunicações \\
\hline 247 & Telemar & $\mathrm{PN}$ & TNLP4 & Telecomunicações \\
\hline 248 & Telemar N L & PNA & TMAR5 & Telecomunicações \\
\hline 249 & Telemig & PNB & TMGR6 & Telecomunicações \\
\hline 250 & Telemig Part & $\mathrm{PN}$ & TMCP4 & Telecomunicações \\
\hline 251 & Telerj Cel & PNB & TRJC6 & Telecomunicações \\
\hline 252 & Telesp & $\mathrm{PN}$ & TLPP4 & Telecomunicações \\
\hline 253 & Telesp Cel & $\mathrm{ON}$ & TSPC3 & Telecomunicações \\
\hline 254 & Telesp Part & $\mathrm{ON}$ & TLPP3F & Telecomunicações \\
\hline 255 & Tempo Part & $\mathrm{ON}$ & TEMP3 & Outros \\
\hline 256 & Tenda & $\mathrm{ON}$ & TEND3 & Construção \\
\hline 257 & Terna Part & UNT N2 & TRNA11 & Energia Elétrica \\
\hline 258 & Tex Renaux & $\mathrm{PN}$ & TXRX4 & Têxtil \\
\hline 259 & Tim Nordeste & PNB & TPEC6B & Telecomunicações \\
\hline 260 & Tim Part S/A & PN & TCSL4 & Telecomunicações \\
\hline 261 & Tim Sul & PNB & TPRC6 & Telecomunicações \\
\hline 262 & Totvs & $\mathrm{ON}$ & TOTS3 & Software e Dados \\
\hline 263 & Tractebel & $\mathrm{ON}$ & TBLE3 & Energia Elétrica \\
\hline 264 & Trafo & $\mathrm{PN}$ & TRFO4 & Eletroeletrônicos \\
\hline 265 & Tran Paulist & $\mathrm{PN}$ & TRPL4 & Energia Elétrica \\
\hline 266 & Trikem & PN & $\mathrm{CPCA} 4$ & Química \\
\hline 267 & Trisul & $\mathrm{ON}$ & TRIS3 & Construção \\
\hline 268 & Triunfo Part & $\mathrm{ON}$ & TPIS3 & Transporte Serviços \\
\hline 269 & Tupy & $\mathrm{ON}$ & TUPY3 & Veículos e peças \\
\hline 270 & Ultrapar & $\mathrm{PN}$ & UGPA4 & Química \\
\hline 271 & Unipar & PNB & UNIP6 & Química \\
\hline 272 & Uol & $\mathrm{PN}$ & UOLL4 & Software e Dados \\
\hline 273 & Usiminas & PNA & USIM5 & Siderurgia e Metalurgia \\
\hline 274 & $\mathrm{~V} \mathrm{C} \mathrm{P}$ & $\mathrm{PN}$ & VCPA4 & Papel e Celulose \\
\hline 275 & Vale R Doce & PNA & VALE5 & Mineração \\
\hline 276 & Vigor & $\mathrm{PN}$ & VGOR4 & Alimentos e Bebidas \\
\hline 277 & Vivax & UNT N2 & VVAX11 & Outros \\
\hline 278 & Vivo & $\mathrm{PN}$ & VIVO4 & Telecomunicações \\
\hline 279 & Weg & $\mathrm{ON}$ & WEGE3 & Máquinas Industriais \\
\hline 280 & Wetzel S/A & $\mathrm{PN}$ & MWET4 & Veículos e peças \\
\hline 281 & Whirlpool & $\mathrm{PN}$ & WHRL4 & Eletroeletrônicos \\
\hline 282 & White Martins & $\mathrm{ON}$ & WHMT3 & Química \\
\hline 283 & Wilson Sons & $\mathrm{ON}$ & WSON11 & Transporte Serviços \\
\hline 284 & Wlm Ind Com & $\mathrm{PN}$ & SGAS4 & Petróleo e Gás \\
\hline 285 & Yara Brasil & $\mathrm{PN}$ & ILMD4 & Química \\
\hline
\end{tabular}


Tabela B.2 - Setores de atividade das empresas da amostra

\begin{tabular}{lrc}
\hline Setor & Quantidade & Percentual de empresas no setor \\
\hline Agro e Pesca & 4 & $1,40 \%$ \\
Alimentos e Bebidas & 23 & $8,07 \%$ \\
Comércio & 12 & $4,21 \%$ \\
Construção & 25 & $8,77 \%$ \\
Eletroeletrônicos & 10 & $3,51 \%$ \\
Energia Elétrica & 28 & $9,82 \%$ \\
Máquinas Industriais & 6 & $2,11 \%$ \\
Mineração & 7 & $2,46 \%$ \\
Minerais não Metálicos & 3 & $1,05 \%$ \\
Outros & 42 & $14,74 \%$ \\
Papel e Celulose & 6 & $2,11 \%$ \\
Petróleo e Gás & 8 & $2,81 \%$ \\
Química & 18 & $6,32 \%$ \\
Siderurgia e Metalurgia & 22 & $7,72 \%$ \\
Software e Dados & 3 & $1,05 \%$ \\
Telecomunicações & 30 & $10,53 \%$ \\
Têxtil & 12 & $4,21 \%$ \\
Transporte Serviços & 13 & $4,56 \%$ \\
Veículos e peças & 13 & $4,56 \%$ \\
\hline Total & 285 & $100,00 \%$ \\
\hline
\end{tabular}




\section{B.2 Resumo das Variáveis}

Quadro B.1 - Definições resumidas de algumas variáveis

\begin{tabular}{|c|c|}
\hline Variável & Definição \\
\hline$A T$ & Ativo total da empresa \\
\hline$C R E S C$ & $\begin{array}{l}\text { Variação percentual da receita líquida da empresa no último } \\
\text { trimestre }\end{array}$ \\
\hline$D B$ & $\begin{array}{l}\text { Soma dos financiamentos de curto e longo prazos com as de- } \\
\text { bêntures de curto e longo prazos emitidas pelas empresas }\end{array}$ \\
\hline$D B A M$ & $\begin{array}{l}\text { Dívida bruta sobre o valor de ativo a valor de mercado da } \\
\text { empresa }\end{array}$ \\
\hline$D B A T$ & Dívida bruta sobre o valor de ativo contábil da empresa \\
\hline$D I V$ & $\begin{array}{l}\text { Diferença dos logaritmos do índice market-to-book das em- } \\
\text { presas pagadoras e não-pagadoras de dividendos, sendo que } \\
\text { para agregar as razões de market-to-book de todas as empre- } \\
\text { sas pagadoras e das não-pagadoras foi calculada uma média } \\
\text { ponderada pelo valor de mercado de cada empresa }\end{array}$ \\
\hline $\ln A T$ & Logaritmo natural do ativo total da empresa \\
\hline $\ln R L O$ & Logaritmo natural da receita líquida operacional da empresa \\
\hline $\ln V M$ & Logaritmo natural do valor de mercado da empresa \\
\hline$N E G$ & Índice de negociabilidade da empresa \\
\hline$M O M$ & Momentum, dado pelo retorno da ação no trimestre anterior \\
\hline NIPO & Quantidade de IPOs realizados no trimestre \\
\hline$P$ & Preço de mercado da ação \\
\hline$P L$ & Patrimônio líquido da empresa \\
\hline$R$ & Taxa de retorno contínua da ação \\
\hline$R I P O$ & Retorno médio dos IPOs em seu primeiro dia de cotação \\
\hline$S$ & $\begin{array}{l}\text { Volume total de ações emitido sobre o volume total de ações } \\
\text { e dívidas emitidas }\end{array}$ \\
\hline$T R I N$ & $\begin{array}{l}\text { Quantidade de ações por volume (em } R \$ \text { ) de ações em alta } \\
\text { sobre quantidade de ações por volume (em } R \$ \text { ) de ações em } \\
\text { baixa }\end{array}$ \\
\hline$T U R N$ & $\begin{array}{l}\text { Proporção de ações negociadas em relação ao total de ações } \\
\text { listado }\end{array}$ \\
\hline$V M$ & $\begin{array}{l}\text { Valor de mercado das ações ordinárias e preferenciais da em- } \\
\text { presa }\end{array}$ \\
\hline$V M P L$ & Valor de mercado sobre o valor contábil da empresa \\
\hline
\end{tabular}




\section{B.3 Resultados das estimações com variáveis Winsori- zadas}

Tabela B.3 - Resultados das estimações por GMM com variáveis Winsorizadas: Modelo Estático 01

\begin{tabular}{|c|c|c|c|c|}
\hline Variável & Dif1 & Dif2 & Sys1 & Sys 2 \\
\hline$w-S E N T_{t-1}$ & $\begin{array}{c}-0,2863^{* *} \\
(0,106)\end{array}$ & $\begin{array}{r}-0,2696^{*} \\
(0,114)\end{array}$ & $\begin{array}{c}-0,3219^{* *} \\
(0,104)\end{array}$ & $\begin{array}{c}-0,3180^{* *} \\
(0,106)\end{array}$ \\
\hline$w-B E T A_{i, t}$ & $\begin{array}{l}0,1283^{\dagger} \\
(0,068)\end{array}$ & $\begin{array}{l}0,1159 \\
(0,076)\end{array}$ & $\begin{array}{l}0,0700 \\
(0,058)\end{array}$ & $\begin{array}{l}0,0669 \\
(0,060)\end{array}$ \\
\hline$w-\ln A T_{i, t}$ & $\begin{array}{r}-0,0182 \\
(0,024)\end{array}$ & $\begin{array}{r}-0,0136 \\
(0,029)\end{array}$ & $\begin{array}{r}-0,0016 \\
(0,014)\end{array}$ & $\begin{array}{l}0,0011 \\
(0,015)\end{array}$ \\
\hline$w-V M P L_{i, t}$ & $\begin{array}{l}0,0184^{*} \\
(0,008)\end{array}$ & $\begin{array}{l}0,0181^{*} \\
(0,009)\end{array}$ & $\begin{array}{l}0,0226^{* *} \\
(0,008)\end{array}$ & $\begin{array}{l}0,0238^{* *} \\
(0,008)\end{array}$ \\
\hline$w-D B A M_{i, t}$ & $\begin{array}{c}-0,6719^{* *} \\
(0,234)\end{array}$ & $\begin{array}{c}-0,7807^{* *} \\
(0,258)\end{array}$ & $\begin{array}{c}-1,0085^{* *} \\
(0,139)\end{array}$ & $\begin{array}{c}-1,0817^{* *} \\
(0,147)\end{array}$ \\
\hline$w-C R E S C_{i, t}$ & $\begin{array}{l}0,0424^{\dagger} \\
(0,025)\end{array}$ & $\begin{array}{l}0,0401 \\
(0,028)\end{array}$ & $\begin{array}{l}0,0323 \\
(0,023)\end{array}$ & $\begin{array}{l}0,0291 \\
(0,025)\end{array}$ \\
\hline Dummies SETOR & SIM & SIM & SIM & SIM \\
\hline Dummies TEMPO & SIM & SIM & SIM & SIM \\
\hline Qtde. de observações & 2203 & 2203 & 2542 & 2542 \\
\hline Qtde. de instrumentos & 159 & 159 & 180 & 180 \\
\hline$m 1$ & $-6,34(0,000)$ & $-6,29(0,000)$ & $-6,24(0,000)$ & $-6,21(0,000)$ \\
\hline$m 2$ & $-0,30(0,765)$ & $-0,33(0,740)$ & $-0,41(0,686)$ & $-0,41(0,683)$ \\
\hline $\begin{array}{l}J \text { de Hansen } \\
\text { DIF-Hansen }\end{array}$ & \multicolumn{2}{|c|}{$136,91(117 ; 0,101)$} & \multicolumn{2}{|c|}{$133,52(120 ; 0,188)$} \\
\hline
\end{tabular}

Variável dependente: taxa de retorno das ações. Demais variáveis regressoras estão resumidas na Tabela B.1 do Apêndice B, sendo que " $w-$ " indica que a variável foi Winsorizada, com $p=1 \%$. Os estimadores utilizados são os GMM-Dif e o GMM Sys de um e dois estágios, com transformações de desvios ortogonais. Foram utilizadas como instrumentos as transformações de primeiras diferenças em um período e as defasagens de $B E T A, V M P L$ e $D B A M$. Assume-se que os demais regressores são estritamente exógenos. Os erros-padrão figuram entre parênteses. Os símbolos $\dagger$, * e ** denotam a significância estatística da estimativa nos níveis de $10 \%, 5 \%$ e $1 \%$, respectivamente. O teste da estatística $J$ de Hansen é uma versão robusta do teste de sobreidentificação de Sargan. $m 1$ e $m 2$ referem-se aos testes de autocorrelação de primeira e segunda ordem e DIF-Hansen baseia-se na diferença entre as estatísticas de Hansen e Sargan calculadas para o mesmo modelo estimado por GMM-Sys e GMM-Dif, ambos de dois estágios. Para os testes de Hansen e DIF-Hansen reporta-se a estatística do teste e, entre parênteses, o número de graus de liberdade e seu nível de significância observado, respectivamente. Para os testes $m 1$ e $m 2$ reporta-se a estatística do teste e, entre parênteses, o nível de significância correspondente. 
Tabela B.4 - Resultados das estimações por GMM com variáveis Winsorizadas: Modelo Estático 02

\begin{tabular}{lcccc}
\hline Variável & Dif1 & Dif2 & Sys1 & Sys2 \\
\hline$w-S E N T_{t-1}$ & $-0,2058^{*}$ & $-0,1712$ & $-0,2191^{*}$ & $-0,1991^{\dagger}$ \\
$w-B E T A_{i, t}$ & $(0,105)$ & $(0,114)$ & $(0,105)$ & $(0,110)$ \\
& $0,1081^{\dagger}$ & 0,0969 & 0,0533 & 0,0604 \\
$w-\ln A T_{i, t}$ & $(0,063)$ & $(0,063)$ & $(0,057)$ & $(0,057)$ \\
& $-0,0255$ & $-0,0268$ & $-0,0056$ & $-0,0038$ \\
$w-V M P L_{i, t}$ & $(0,032)$ & $(0,030)$ & $(0,010)$ & $(0,008)$ \\
& $0,0289^{* *}$ & $0,0312^{* *}$ & $0,0309^{* *}$ & $0,0329^{* *}$ \\
$w-D B A T_{i, t}$ & $(0,010)$ & $(0,010)$ & $(0,009)$ & $(0,009)$ \\
& 0,1073 & 0,1368 & $-0,0631$ & $-0,0817$ \\
$w-C R E S C_{i, t}$ & $(0,203)$ & $(0,209)$ & $(0,059)$ & $(0,070)$ \\
& $0,0520^{*}$ & $0,0507^{\dagger}$ & $0,0430^{*}$ & $0,0399^{\dagger}$ \\
Dummies $S E T O R$ & $(0,026)$ & $(0,029)$ & $(0,022)$ & $(0,024)$ \\
Dummies $T E M P O$ & SIM & SIM & SIM & SIM \\
Qtde. de observações & SIM & SIM & SIM & SIM \\
Qtde. de instrumentos & 2203 & 2203 & 2542 & 2542 \\
m1 & 159 & 159 & 180 & 180 \\
m2 & $-6,35(0,000)$ & $-6,30(0,000)$ & $-6,33(0,000)$ & $-6,27(0,000)$ \\
$J$ de Hansen & $-0,10(0,922)$ & $-0,14(0,887)$ & $-0,18(0,854)$ & $-0,24(0,807)$ \\
DIF-Hansen & $126,81(117 ; 0,252)$ & $126,37(120 ; 0,327)$ \\
\hline A & & & $31,28(56 ; 0,998)$ \\
\hline
\end{tabular}

A variável dependente é a taxa de retorno das ações, $R_{i, t}$, definida na seção 3.3.2. As definições das demais variáveis regressoras desta tabela estão resumidamente na Tabela B.1 do Apêndice B, sendo que " $w$-" indica que a variável foi Winsorizada, com $p=1 \%$. Os estimadores utilizados são os GMM em Diferenças e o GMM Sistêmico de um e dois estágios, com transformações de desvios ortogonais. Foram utilizadas como instrumentos as transformações de primeiras diferenças em um período e as defasagens de BET A, VMPL e DBAT. Assume-se que os demais regressores são estritamente exógenos. Os erros-padrão foram obtidos utilizando-se dados agrupados por empresa, de maneira robusta a quaisquer formas de heteroscedasticidade e autocorrelação dos erros do modelo e figuram entre parênteses. Os símbolos $\dagger,{ }^{*} \mathrm{e}^{* *}$ denotam a significância estatística da estimativa nos níveis de 10\%, 5\% e 1\%, respectivamente. O teste da estatística $J$ de Hansen é uma versão robusta do teste de sobreidentificação de Sargan. $m 1$ e $m 2$ referem-se aos testes de autocorrelação de primeira e segunda ordem e DIF-Hansen baseia-se na diferença entre as estatísticas de Hansen e Sargan calculadas para o mesmo modelo estimado por GMM-Sys e GMMDif, ambos de dois estágios. Para os testes de Hansen e DIF-Hansen reporta-se a estatística do teste e, entre parênteses, o número de graus de liberdade e seu nível de significância observado, respectivamente. Para os testes $m 1$ e $m 2$ reporta-se a estatística do teste e, entre parênteses, o nível de significância correspondente. 
Tabela B.5 - Resultados das estimações por GMM com variáveis Winsorizadas: Modelo Estático 03

\begin{tabular}{|c|c|c|c|c|}
\hline Variável & Dif1 & Dif2 & Sys1 & Sys2 \\
\hline$w-S E N T_{t-1}$ & $\begin{array}{c}-0,3310^{* *} \\
(0,104)\end{array}$ & $\begin{array}{c}-0,3136^{* *} \\
(0,112)\end{array}$ & $\begin{array}{c}-0,3123^{* *} \\
(0,106)\end{array}$ & $\begin{array}{c}-0,3143^{* *} \\
(0,109)\end{array}$ \\
\hline$w-B E T A_{i, t}$ & $\begin{array}{l}0,1238^{\dagger} \\
(0,073)\end{array}$ & $\begin{array}{l}0,1060 \\
(0,079)\end{array}$ & $\begin{array}{l}0,0777 \\
(0,057)\end{array}$ & $\begin{array}{l}0,0743 \\
(0,059)\end{array}$ \\
\hline$w-\ln V M_{i, t}$ & $\begin{array}{l}0,0491^{\dagger} \\
(0,028)\end{array}$ & $\begin{array}{l}0,0494^{\dagger} \\
(0,029)\end{array}$ & $\begin{array}{r}-0,0261^{*} \\
(0,012)\end{array}$ & $\begin{array}{r}-0,0266^{*} \\
(0,013)\end{array}$ \\
\hline$w-V M P L_{i, t}$ & $\begin{array}{l}0,0160^{\dagger} \\
(0,009)\end{array}$ & $\begin{array}{l}0,0159^{\dagger} \\
(0,009)\end{array}$ & $\begin{array}{l}0,0244^{* *} \\
(0,009)\end{array}$ & $\begin{array}{l}0,0251^{* *} \\
(0,009)\end{array}$ \\
\hline$w-D B A M_{i, t}$ & $\begin{array}{c}-0,7676^{* *} \\
(0,260)\end{array}$ & $\begin{array}{c}-0,8384^{* *} \\
(0,273)\end{array}$ & $\begin{array}{c}-1,0803^{* *} \\
(0,150)\end{array}$ & $\begin{array}{c}-1,1576^{* *} \\
(0,163)\end{array}$ \\
\hline$w-C R E S C_{i, t}$ & $\begin{array}{l}0,0382 \\
(0,025)\end{array}$ & $\begin{array}{l}0,0392 \\
(0,028)\end{array}$ & $\begin{array}{l}0,0324 \\
(0,023)\end{array}$ & $\begin{array}{l}0,0305 \\
(0,026)\end{array}$ \\
\hline Dummies SETOR & SIM & SIM & SIM & SIM \\
\hline Dummies TEMPO & SIM & SIM & SIM & SIM \\
\hline Qtde. de observações & 2201 & 2201 & 2540 & 2540 \\
\hline Qtde. de instrumentos & 159 & 159 & 180 & 180 \\
\hline$m 1$ & $-6,34(0,000)$ & $-6,29(0,000)$ & $-6,21(0,000)$ & $-6,18(0,000)$ \\
\hline$m 2$ & $-0,33(0,739)$ & $-0,36(0,720)$ & $-0,40(0,690)$ & $-0,41(0,683)$ \\
\hline $\begin{array}{l}J \text { de Hansen } \\
\text { DIF-Hansen }\end{array}$ & \multicolumn{2}{|c|}{$138,10(117 ; 0,089)$} & \multicolumn{2}{|c|}{$133,45(120 ; 0,189)$} \\
\hline
\end{tabular}

A variável dependente é a taxa de retorno das ações, $R_{i, t}$, definida na seção 3.3.2. As definições das demais variáveis regressoras desta tabela estão resumidamente na Tabela B.1 do Apêndice B, sendo que " $w$-' indica que a variável foi Winsorizada, com $p=1 \%$. Os estimadores utilizados são os GMM em Diferenças e o GMM Sistêmico de um e dois estágios, com transformações de desvios ortogonais. Foram utilizadas como instrumentos as transformações de primeiras diferenças em um período e as defasagens de $B E T A, V M P L$ e $D B A M$. Assume-se que os demais regressores são estritamente exógenos. Os erros-padrão foram obtidos utilizando-se dados agrupados por empresa, de maneira robusta a quaisquer formas de heteroscedasticidade e autocorrelação dos erros do modelo e figuram entre parênteses. Os símbolos $\dagger,{ }^{*} \mathrm{e}^{* *}$ denotam a significância estatística da estimativa nos níveis de $10 \%, 5 \%$ e 1\%, respectivamente. O teste da estatística $J$ de Hansen é uma versão robusta do teste de sobreidentificação de Sargan. $m 1$ e $m 2$ referem-se aos testes de autocorrelação de primeira e segunda ordem e DIF-Hansen baseia-se na diferença entre as estatísticas de Hansen e Sargan calculadas para o mesmo modelo estimado por GMM-Sys e GMMDif, ambos de dois estágios. Para os testes de Hansen e DIF-Hansen reporta-se a estatística do teste e, entre parênteses, o número de graus de liberdade e seu nível de significância observado, respectivamente. Para os testes $m 1$ e $m 2$ reporta-se a estatística do teste e, entre parênteses, o nível de significância correspondente. 
Tabela B.6 - Resultados das estimações por GMM com variáveis Winsorizadas: Modelo Estático 04

\begin{tabular}{lcccc}
\hline Variável & Dif1 & Dif2 & Sys1 & Sys2 \\
\hline$w-S E N T_{t-1}$ & $-0,2543^{*}$ & $-0,2467^{*}$ & $-0,2991^{* *}$ & $-0,3036^{* *}$ \\
$w-B E T A_{i, t}$ & $(0,099)$ & $(0,109)$ & $(0,098)$ & $(0,101)$ \\
& $0,1275^{\dagger}$ & 0,1064 & 0,0750 & 0,0666 \\
$w-\ln R L O_{i, t}$ & $(0,068)$ & $(0,076)$ & $(0,057)$ & $(0,060)$ \\
& $0,0419^{*}$ & $0,0464^{*}$ & $-0,0125$ & $-0,0118$ \\
$w-V M P L_{i, t}$ & $(0,020)$ & $(0,023)$ & $(0,010)$ & $(0,010)$ \\
& $0,0186^{*}$ & $0,0186^{*}$ & $0,0232^{* *}$ & $0,0245^{* *}$ \\
$w-D B A M_{i, t}$ & $(0,008)$ & $(0,009)$ & $(0,008)$ & $(0,009)$ \\
& $-0,6912^{* *}$ & $-0,7749^{* *}$ & $-0,9876^{* *}$ & $-1,0390^{* *}$ \\
$w-C R E S C_{i, t}$ & $(0,218)$ & $(0,249)$ & $(0,139)$ & $(0,149)$ \\
& 0,0172 & 0,0158 & 0,0309 & 0,0338 \\
Dummies $S E T O R$ & $(0,025)$ & $(0,028)$ & $(0,023)$ & $(0,026)$ \\
Dummies $T E M P O$ & SIM & SIM & SIM & SIM \\
Qtde. de observações & SIM & SIM & SIM & SIM \\
Qtde. de instrumentos & 2191 & 2191 & 2529 & 2529 \\
m1 & 159 & 159 & 180 & 180 \\
m2 & $-6,26(0,000)$ & $-6,22(0,000)$ & $-6,17(0,000)$ & $-6,14(0,000)$ \\
$J$ de Hansen & $-0,35(0,726)$ & $-0,38(0,703)$ & $-0,50(0,616)$ & $-0,51(0,614)$ \\
DIF-Hansen & $136,73(117 ; 0,103)$ & & $134,91(120 ; 0,167)$ \\
\hline A & & & $34,82(56 ; 0,988)$ \\
\hline
\end{tabular}

A variável dependente é a taxa de retorno das ações, $R_{i, t}$, definida na seção 3.3.2. As definições das demais variáveis regressoras desta tabela estão resumidamente na Tabela B.1 do Apêndice B, sendo que " $w-$ ' indica que a variável foi Winsorizada, com $p=1 \%$. Os estimadores utilizados são os GMM em Diferenças e o GMM Sistêmico de um e dois estágios, com transformações de desvios ortogonais. Foram utilizadas como instrumentos as transformações de primeiras diferenças em um período e as defasagens de BET $A, V M P L$ e $D B A M$. Assume-se que os demais regressores são estritamente exógenos. Os erros-padrão foram obtidos utilizando-se dados agrupados por empresa, de maneira robusta a quaisquer formas de heteroscedasticidade e autocorrelação dos erros do modelo e figuram entre parênteses. Os símbolos $\dagger,{ }^{*} \mathrm{e}^{* *}$ denotam a significância estatística da estimativa nos níveis de 10\%, 5\% e 1\%, respectivamente. O teste da estatística $J$ de Hansen é uma versão robusta do teste de sobreidentificação de Sargan. $m 1$ e $m 2$ referem-se aos testes de autocorrelação de primeira e segunda ordem e DIF-Hansen baseia-se na diferença entre as estatísticas de Hansen e Sargan calculadas para o mesmo modelo estimado por GMM-Sys e GMMDif, ambos de dois estágios. Para os testes de Hansen e DIF-Hansen reporta-se a estatística do teste e, entre parênteses, o número de graus de liberdade e seu nível de significância observado, respectivamente. Para os testes $m 1$ e $m 2$ reporta-se a estatística do teste e, entre parênteses, o nível de significância correspondente. 
Tabela B.7 - Resultados das estimações por GMM com variáveis Winsorizadas: Modelo Dinâmico 05

\begin{tabular}{|c|c|c|c|c|}
\hline Variável & Dif1 & Dif2 & Sys1 & Sys2 \\
\hline$w-S E N T_{t-1}$ & $\begin{array}{c}-0,3053^{* *} \\
(0,106)\end{array}$ & $\begin{array}{c}-0,2782^{* *} \\
(0,105)\end{array}$ & $\begin{array}{r}-0,2572^{*} \\
(0,110)\end{array}$ & $\begin{array}{r}-0,2292^{*} \\
(0,109)\end{array}$ \\
\hline$w-B E T A_{i, t}$ & $\begin{array}{l}0,0915 \\
(0,066)\end{array}$ & $\begin{array}{l}0,0662 \\
(0,071)\end{array}$ & $\begin{array}{l}0,0343 \\
(0,055)\end{array}$ & $\begin{array}{l}0,0239 \\
(0,050)\end{array}$ \\
\hline$w-\ln V M_{i, t}$ & $\begin{array}{l}0,1001^{* *} \\
(0,022)\end{array}$ & $\begin{array}{l}0,0951^{* *} \\
(0,021)\end{array}$ & $\begin{array}{l}0,0025 \\
(0,007)\end{array}$ & $\begin{array}{l}0,0011 \\
(0,007)\end{array}$ \\
\hline$w-V M P L_{i, t}$ & $\begin{array}{l}0,0204^{*} \\
(0,008)\end{array}$ & $\begin{array}{l}0,0206^{*} \\
(0,009)\end{array}$ & $\begin{array}{l}0,0348^{* *} \\
(0,010)\end{array}$ & $\begin{array}{l}0,0356^{* *} \\
(0,010)\end{array}$ \\
\hline$w-D B A T_{i, t}$ & $\begin{array}{l}0,0902 \\
(0,156)\end{array}$ & $\begin{array}{l}0,0481 \\
(0,146)\end{array}$ & $\begin{array}{r}-0,0211 \\
\quad(0,066)\end{array}$ & $\begin{array}{r}-0,0381 \\
\quad(0,061)\end{array}$ \\
\hline$w-M O M_{i, t}$ & $\begin{array}{r}-0,0385 \\
(0,036)\end{array}$ & $\begin{array}{r}-0,0386 \\
(0,036)\end{array}$ & $\begin{array}{r}-0,0252 \\
(0,035)\end{array}$ & $\begin{array}{r}-0,0276 \\
(0,034)\end{array}$ \\
\hline Dummies SETOR & SIM & SIM & SIM & SIM \\
\hline Dummies TEMPO & SIM & SIM & SIM & SIM \\
\hline Qtde. de observações & 2530 & 2530 & 2775 & 2775 \\
\hline Qtde. de instrumentos & 196 & 196 & 218 & 218 \\
\hline$m 1$ & $-6,22(0,000)$ & $-5,56(0,000)$ & $-6,17(0,000)$ & $-5,66(0,000)$ \\
\hline$m 2$ & $-0,81(0,421)$ & $-0,81(0,418)$ & $-0,71(0,480)$ & $-0,72(0,470)$ \\
\hline $\begin{array}{l}J \text { de Hansen } \\
\text { DIF-Hansen }\end{array}$ & \multicolumn{2}{|c|}{$157,05(154 ; 0,417)$} & \multicolumn{2}{|c|}{$162,94(158 ; 0,377)$} \\
\hline
\end{tabular}

A variável dependente é a taxa de retorno das ações, $R_{i, t}$, definida na seção 3.3.2. As definições das demais variáveis regressoras desta tabela estão resumidamente na Tabela B.1 do Apêndice B, sendo que " $w$-' indica que a variável foi Winsorizada, com $p=1 \%$. Os estimadores utilizados são os GMM em Diferenças e o GMM Sistêmico de um e dois estágios, com transformações de desvios ortogonais. Foram utilizadas como instrumentos as transformações de primeiras diferenças em um período e as defasagens de BET A, VMPL, DBAT e MOM. Assume-se que os demais regressores são estritamente exógenos. Os erros-padrão foram obtidos utilizando-se dados agrupados por empresa, de maneira robusta a quaisquer formas de heteroscedasticidade e autocorrelação dos erros do modelo e figuram entre parênteses. Os símbolos $\dagger,{ }^{*} \mathrm{e}^{* *}$ denotam a significância estatística da estimativa nos níveis de $10 \%, 5 \%$ e 1\%, respectivamente. O teste da estatística $J$ de Hansen é uma versão robusta do teste de sobreidentificação de Sargan. $m 1$ e $m 2$ referem-se aos testes de autocorrelação de primeira e segunda ordem e DIF-Hansen baseia-se na diferença entre as estatísticas de Hansen e Sargan calculadas para o mesmo modelo estimado por GMM-Sys e GMMDif, ambos de dois estágios. Para os testes de Hansen e DIF-Hansen reporta-se a estatística do teste e, entre parênteses, o número de graus de liberdade e seu nível de significância observado, respectivamente. Para os testes $m 1$ e $m 2$ reporta-se a estatística do teste e, entre parênteses, o nível de significância correspondente. 
Tabela B.8 - Resultados das estimações por GMM com variáveis Winsorizadas: Modelo Dinâmico 06

\begin{tabular}{lcccc}
\hline Variável & Dif1 & Dif2 & Sys1 & Sys2 \\
\hline$w-S E N T_{t-1}$ & $-0,3596^{* *}$ & $-0,3830^{* *}$ & $-0,3276^{* *}$ & $-0,3739^{* *}$ \\
$w-B E T A_{i, t}$ & $(0,107)$ & $(0,110)$ & $(0,109)$ & $(0,114)$ \\
& 0,0873 & 0,0759 & 0,0334 & 0,0175 \\
$w-\ln V M_{i, t}$ & $(0,068)$ & $(0,075)$ & $(0,054)$ & $(0,054)$ \\
$w-V M P L_{i, t}$ & 0,0390 & 0,0416 & $-0,0166$ & $-0,0134$ \\
& $(0,031)$ & $(0,030)$ & $(0,011)$ & $(0,011)$ \\
$w-D B A M_{i, t}$ & $0,0157^{*}$ & $0,0151^{\dagger}$ & $0,0291^{* *}$ & $0,0291^{* *}$ \\
& $(0,008)$ & $(0,008)$ & $(0,009)$ & $(0,009)$ \\
$w-M O M_{i, t}$ & $-0,9722^{* *}$ & $-0,9766^{* *}$ & $-0,9430^{* *}$ & $-0,9439^{* *}$ \\
& $(0,264)$ & $(0,260)$ & $(0,150)$ & $(0,152)$ \\
Dummies SETOR & $-0,0568$ & $-0,0535$ & $-0,0412$ & $-0,0386$ \\
Dummies TEMPO & $(0,035)$ & $(0,035)$ & $(0,034)$ & $(0,034)$ \\
Qtde. de observações & SIM & SIM & SIM & SIM \\
Qtde. de instrumentos & SIM & SIM & SIM & SIM \\
$m 1$ & 2530 & 2530 & 2775 & 2775 \\
m2 & 196 & 196 & 218 & 218 \\
$J$ de Hansen & $-5,90(0,000)$ & $-5,45(0,000)$ & $-6,02(0,000)$ & $-5,52(0,000)$ \\
DIF-Hansen & $1,32(0,187)$ & $-1,24(0,215)$ & $-1,15(0,249)$ & $-1,08(0,279)$ \\
\hline A varasim & $166,72(154 ; 0,229)$ & $166,26(158 ; 0,311)$ \\
\hline
\end{tabular}

A variável dependente é a taxa de retorno das ações, $R_{i, t}$, definida na seção 3.3.2. As definições das demais variáveis regressoras desta tabela estão resumidamente na Tabela B.1 do Apêndice B, sendo que " $w$-' indica que a variável foi Winsorizada, $\operatorname{com} p=1 \%$. Os estimadores utilizados são os GMM em Diferenças e o GMM Sistêmico de um e dois estágios, com transformações de desvios ortogonais. Foram utilizadas como instrumentos as transformações de primeiras diferenças em um período e as defasagens de $B E T A, V M P L, D B A M$ e $M O M$. Assume-se que os demais regressores são estritamente exógenos. Os erros-padrão foram obtidos utilizando-se dados agrupados por empresa, de maneira robusta a quaisquer formas de heteroscedasticidade e autocorrelação dos erros do modelo e figuram entre parênteses. Os símbolos $\dagger,{ }^{*} \mathrm{e}^{* *}$ denotam a significância estatística da estimativa nos níveis de 10\%, 5\% e 1\%, respectivamente. O teste da estatística $J$ de Hansen é uma versão robusta do teste de sobreidentificação de Sargan. $m 1$ e $m 2$ referem-se aos testes de autocorrelação de primeira e segunda ordem e DIF-Hansen baseia-se na diferença entre as estatísticas de Hansen e Sargan calculadas para o mesmo modelo estimado por GMM-Sys e GMMDif, ambos de dois estágios. Para os testes de Hansen e DIF-Hansen reporta-se a estatística do teste e, entre parênteses, o número de graus de liberdade e seu nível de significância observado, respectivamente. Para os testes $m 1$ e $m 2$ reporta-se a estatística do teste e, entre parênteses, o nível de significância correspondente. 
Tabela B.9 - Resultados das estimações por GMM com variáveis Winsorizadas: Modelo Dinâmico 07

\begin{tabular}{|c|c|c|c|c|}
\hline Variável & Dif1 & Dif2 & Sys1 & Sys2 \\
\hline$w-S E N T_{t-1}$ & $\begin{array}{r}-0,2408^{*} \\
(0,110)\end{array}$ & $\begin{array}{r}-0,2236^{*} \\
(0,109)\end{array}$ & $\begin{array}{r}-0,2573^{*} \\
(0,110)\end{array}$ & $\begin{array}{r}-0,2326^{*} \\
(0,107)\end{array}$ \\
\hline$w-B E T A_{i, t}$ & $\begin{array}{l}0,0790 \\
(0,061)\end{array}$ & $\begin{array}{l}0,0597 \\
(0,064)\end{array}$ & $\begin{array}{l}0,0361 \\
(0,055)\end{array}$ & $\begin{array}{l}0,0260 \\
(0,050)\end{array}$ \\
\hline$w-\ln A T_{i, t}$ & $\begin{array}{c}-0,0547^{* *} \\
(0,019)\end{array}$ & $\begin{array}{c}-0,0508^{* *} \\
(0,018)\end{array}$ & $\begin{array}{r}-0,0050 \\
(0,008)\end{array}$ & $\begin{array}{r}-0,0039 \\
(0,007)\end{array}$ \\
\hline$w-V M P L_{i, t}$ & $\begin{array}{l}0,0257^{* *} \\
(0,008)\end{array}$ & $\begin{array}{l}0,0259^{* *} \\
(0,008)\end{array}$ & $\begin{array}{l}0,0350^{* *} \\
(0,009)\end{array}$ & $\begin{array}{l}0,0358^{* *} \\
(0,010)\end{array}$ \\
\hline$w-D B A T_{i, t}$ & $\begin{array}{c}-0,9722^{* *} \\
(0,264)\end{array}$ & $\begin{array}{c}-0,9766^{* *} \\
(0,260)\end{array}$ & $\begin{array}{c}-0,9430^{* *} \\
(0,150)\end{array}$ & $\begin{array}{c}-0,9439^{* *} \\
(0,152)\end{array}$ \\
\hline$w-M O M_{i, t}$ & $\begin{array}{r}-0,0405 \\
(0,035)\end{array}$ & $\begin{array}{r}-0,0433 \\
(0,035)\end{array}$ & $\begin{array}{r}-0,0251 \\
(0,035)\end{array}$ & $\begin{array}{r}-0,0276 \\
(0,034)\end{array}$ \\
\hline Dummies SETOR & SIM & SIM & SIM & SIM \\
\hline Dummies TEMPO & SIM & SIM & SIM & SIM \\
\hline Qtde. de observações & 2532 & 2532 & 2777 & 2777 \\
\hline Qtde. de instrumentos & 196 & 196 & 218 & 218 \\
\hline$m 1$ & $-6,06(0,000)$ & $-5,62(0,000)$ & $-6,18(0,000)$ & $-5,67(0,000)$ \\
\hline$m 2$ & $-0,89(0,372)$ & $-0,88(0,378)$ & $-0,73(0,468)$ & $-0,74(0,459)$ \\
\hline $\begin{array}{l}J \text { de Hansen } \\
\text { DIF-Hansen }\end{array}$ & \multicolumn{2}{|c|}{$156,61(154 ; 0,426)$} & \multicolumn{2}{|c|}{$163,11(158 ; 0,374)$} \\
\hline
\end{tabular}

A variável dependente é a taxa de retorno das ações, $R_{i, t}$, definida na seção 3.3.2. As definições das demais variáveis regressoras desta tabela estão resumidamente na Tabela B.1 do Apêndice B, sendo que " $w$-' indica que a variável foi Winsorizada, com $p=1 \%$. Os estimadores utilizados são os GMM em Diferenças e o GMM Sistêmico de um e dois estágios, com transformações de desvios ortogonais. Foram utilizadas como instrumentos as transformações de primeiras diferenças em um período e as defasagens de $B E T A, V M P L, D B A T$ e $M O M$. Assume-se que os demais regressores são estritamente exógenos. Os erros-padrão foram obtidos utilizando-se dados agrupados por empresa, de maneira robusta a quaisquer formas de heteroscedasticidade e autocorrelação dos erros do modelo e figuram entre parênteses. Os símbolos $\dagger,{ }^{*} \mathrm{e}^{* *}$ denotam a significância estatística da estimativa nos níveis de $10 \%, 5 \%$ e 1\%, respectivamente. O teste da estatística $J$ de Hansen é uma versão robusta do teste de sobreidentificação de Sargan. $m 1$ e $m 2$ referem-se aos testes de autocorrelação de primeira e segunda ordem e DIF-Hansen baseia-se na diferença entre as estatísticas de Hansen e Sargan calculadas para o mesmo modelo estimado por GMM-Sys e GMMDif, ambos de dois estágios. Para os testes de Hansen e DIF-Hansen reporta-se a estatística do teste e, entre parênteses, o número de graus de liberdade e seu nível de significância observado, respectivamente. Para os testes $m 1$ e $m 2$ reporta-se a estatística do teste e, entre parênteses, o nível de significância correspondente. 
Tabela B.10 - Resultados das estimações por GMM com variáveis Winsorizadas: Modelo Dinâmico 08

\begin{tabular}{lcccc}
\hline Variável & Dif1 & Dif2 & Sys1 & Sys2 \\
\hline$w-S E N T_{t-1}$ & $-0,1837^{\dagger}$ & $-0,1879^{\dagger}$ & $-0,2410^{*}$ & $-0,2543^{*}$ \\
$w-B E T A_{i, t}$ & $(0,101)$ & $(0,106)$ & $(0,102)$ & $(0,104)$ \\
& $0,1159^{\dagger}$ & $0,1174^{\dagger}$ & 0,0462 & 0,0377 \\
$w-\ln R L O_{i, t}$ & $(0,068)$ & $(0,070)$ & $(0,055)$ & $(0,067)$ \\
& $0,0426^{*}$ & $0,0398^{*}$ & $-0,0076$ & $-0,0055$ \\
$w-V M P L_{i, t}$ & $(0,017)$ & $(0,017)$ & $(0,010)$ & $(0,011)$ \\
& $0,0164^{\dagger}$ & $0,0168^{\dagger}$ & $0,0236^{* *}$ & $0,0243^{* *}$ \\
$w-D B A M_{i, t}$ & $(0,009)$ & $(0,009)$ & $(0,009)$ & $(0,009)$ \\
& $-0,8801^{* *}$ & $-0,8608^{* *}$ & $-1,0140^{* *}$ & $-1,0221^{* *}$ \\
$w-M O M_{i, t}$ & $(0,211)$ & $(0,209)$ & $(0,134)$ & $(0,173)$ \\
& $-0,0405$ & $-0,0433$ & $-0,0251$ & $-0,0276$ \\
Dummies SETOR & $(0,035)$ & $(0,035)$ & $(0,035)$ & $(0,034)$ \\
Dummies TEMPO & $\mathrm{SIM}$ & $\mathrm{SIM}$ & $\mathrm{SIM}$ & SIM \\
Qtde. de observações & $\mathrm{SIM}$ & $\mathrm{SIM}$ & $\mathrm{SIM}$ & $\mathrm{SIM}$ \\
Qtde. de instrumentos & 2228 & 2228 & 2567 & 2567 \\
$m 1$ & 196 & 196 & 218 & 218 \\
m2 & $-6,14(0,000)$ & $-5,53(0,000)$ & $-6,19(0,000)$ & $-5,56(0,000)$ \\
$J$ de Hansen & $-0,63(0,529)$ & $-0,62(0,533)$ & $-0,54(0,592)$ & $-0,49(0,625)$ \\
DIF-Hansen & $162,83(154 ; 0,298)$ & & $160,00(158 ; 0,441)$ \\
\hline A & & & $33,96(55 ; 0,989)$ \\
\hline
\end{tabular}

A variável dependente é a taxa de retorno das ações, $R_{i, t}$, definida na seção 3.3.2. As definições das demais variáveis regressoras desta tabela estão resumidamente na Tabela B.1 do Apêndice B, sendo que " $w-$ ' indica que a variável foi Winsorizada, com $p=1 \%$. Os estimadores utilizados são os GMM em Diferenças e o GMM Sistêmico de um e dois estágios, com transformações de desvios ortogonais. Foram utilizadas como instrumentos as transformações de primeiras diferenças em um período e as defasagens de $B E T A, V M P L, D B A M$ e $M O M$. Assume-se que os demais regressores são estritamente exógenos. Os erros-padrão foram obtidos utilizando-se dados agrupados por empresa, de maneira robusta a quaisquer formas de heteroscedasticidade e autocorrelação dos erros do modelo e figuram entre parênteses. Os símbolos $\dagger,{ }^{*} \mathrm{e}^{* *}$ denotam a significância estatística da estimativa nos níveis de 10\%, 5\% e 1\%, respectivamente. O teste da estatística $J$ de Hansen é uma versão robusta do teste de sobreidentificação de Sargan. $m 1$ e $m 2$ referem-se aos testes de autocorrelação de primeira e segunda ordem e DIF-Hansen baseia-se na diferença entre as estatísticas de Hansen e Sargan calculadas para o mesmo modelo estimado por GMM-Sys e GMMDif, ambos de dois estágios. Para os testes de Hansen e DIF-Hansen reporta-se a estatística do teste e, entre parênteses, o número de graus de liberdade e seu nível de significância observado, respectivamente. Para os testes $m 1$ e $m 2$ reporta-se a estatística do teste e, entre parênteses, o nível de significância correspondente. 


\section{Índice Remissivo de Autores}

Alchian, A. A. 25, 127

Alexander, C. 79, 127

Amihud, Y. 45, 127

Arbex, M. A. 24, 135

Arellano, M. 81, 86, 88, 123, 127

Armstrong, J. S. 35, 127

Arrow, K. J. 28, 127

Bachelier, L. 26, 127

Bailey, J. V. 28, 136

Baker, M. P. 16, 32, 33, 37, 39, 40, 45-51, 61, 62, 72, $76,127,128$

Bandopadhyaya, A. 51, 58, 128

Banz, R. W. 19, 30, 66, 70, 110, 113, 128

Barberis, N. C. $16,27,31,37$, 39, 40, 128, 138

Barnett, V. 89, 128

Barros, L. A. B. C. 81,128

Basu, S. K. 19, 30, 128

Baum, C. F. 87, 88, 128

Bazerman, M. H. 31, 128

Bekaert, G. 19, 128

Belotti, M. L. 37, 137

Bentes, F. G. M. 42, 128

Bernoulli, D. 27, 129

Bernstein, P. L. 32, 33, 129

Bhandari, L. C. 66, 71, 129

Black, F. 16, 29, 35, 39, 56, $65,66,129$

Blundell, R. 81, 87, 88, 123, 129

Bond, S. R. 81, 86-88, 123, 127, 129

Bover, O. 81, 86, 123, 127

Breeden, D. 29, 129
Brown, G. W. 37, 40, 43, 58, $59,76,102,129$

Brown, S. J. 54-56, 129

Bueno, R. D. L. S. 18, 19, 136

Busse, J. A. 36, 54, 131

Camerer, C. F. 30, 129

Cameron, A. C. $80,82,129$

Campbell, J. Y. 38, 47, 130

Carhart, M. M. 66, 72, 109, 130

Castro Junior, F. H. F. 81, 130

Cattell, R. B. 75, 130

Chen, N.-F. 54, 130

Chopra, N. 54, 130

Cliff, M. T. 37, 40, 43, 58, 59, $76,102,129$

Daniel, K. 16, 39, 130

De Angelo, H. 49, 130

De Bondt, W. F. M. 16, $36-38,130$

De Long, J. B. 16, 17, 35, 40, $47,53,130$

Debreu, G. 28, 127

Diamond, P. 31, 130

Dimson, E. 28, 131

Doherty, E. M. 25, 137

Domingues, R. 44, 131

Edmans, A. 57, 131

Elton, E. J. 36, 54, 131

Fama, E. F. 16, 18, 19, 24-27, $30,33,46,49,56,62,65$, $66,71,72,102,119,131$

Fisher, K. L. 42, 44, 132

Franklin, S. B. 75, 132
French, K. R. 16, 18, 19, 30, $46,49,62,65,66,71,72$, 102, 119, 131

Fuller, R. J. 32, 132

Garcia, D. 57, 131

Gerber, A. 39, 132

Goetzmann, W. N. 55, 132

Gordon, A. J. 28, 136

Gruber, M. J. 36, 54, 131

Hair Jr., J. F. 40, 132

Hansen, L. P. 19, 83, 87, 132

Hardy, C. O. 41, 132

Hens, T. 39, 132

Hirshleifer, D. A. 16, 27, 36, $38,39,57,130,132$

Hoeffler, A. 87, 129

Hong, H. 16, 39, 109, 132

Horn, J. L. 75, 132

Hudson, R. L. 26, 33, 134

Jegadeesh, N. 36, 38, 109, 132

Jensen, M. C. 49, 65, 66, 129, 133

Johnson, R. A. 73-75, 133

Jolliffe, I. T. 74, 75, 133

Jones, A. L. 58, 128

Jones, C. M. 45, 46, 133

Kahneman, D. 37, 138

Kaiser, H. F. 75, 93, 133

Kamstra, M. J. 57, 133

Kan, R. 54, 130

Karlaftis, M. G. 74, 138

Kerlinger, F. N. 63, 66, 133

Keswani, A. 50, 52, 76, 138

Keynes, J. M. 34, 133

Knight, F. H. 28, 133

Kramer, L. A. 57, 133 
Lakatos, E. M. 64, 134

Lakonishok, J. 16, 133

Lancaster, K. J. 16, 133

Lee, C. M. 31, 39, 40, 52-54, 133

Levi, M. D. 57, 133

Lewis, T. 89, 128

Lintner, J. 28, 31, 65, 133

Ljungqvist, A. 48, 133

Lo, A. W. 47, 130

Lowry, M. 48, 133

Lucas, D. J. 50, 134

MacBeth, J. D. 19, 56, 65, 66, 131

MacKinlay, C. 47, 130

Maddala, G. 100, 123, 134

Malkiel, B. G. 53, 134

Mandelbrot, B. B. 26, 33, 134

Mannering, F. L. 74, 138

Marconi, M. d. A. 64, 134

Markowitz, H. 18, 26, 28, 32, 134

Massa, M. 55, 132

Masulis, R. W. 49, 130

Mayers, D. 29, 134

McDonald, R. L. 50, 134

Meckling, W. H. 49, 133

Mendelson, H. 45, 127

Merton, R. C. 29, 32, 134

Miller, M. H. 31, 46, 48, 49, 54, 130, 134

Modigliani, F. 46, 48, 49, 134

Morgenstern, O. 24, 28, 138

Mossin, J. 28, 31, 134

Mullainathan, S. 33, 35, 135

Mussavian, M. 28, 131

Myers, S. C. 49, 135

Nanda, V. 48, 133

Neal, R. 37, 135

Norli, Ø. 57, 131

Oliveira, R. F. 87, 135

Otoo, M. W. 43, 135

Palomino, F. 57, 135

Pástor, L. 45, 135

Perobelli, F. F. C. 24, 135

Perobelli, F. S. 24, 135
Popper, K. R. 63, 135

Poterba, J. M. 16, 47, 135

Rencher, A. C. 74, 135

Renneboog, L. 57, 135

Ritter, J. R. 48, 135

Roll, R. 30, 135

Roodman, D. M. 81-87, 123, 135

Ross, S. A. 24, 30, 33, 36, 52, 135, 136

Rouwenhorst, K. G. 55, 132

Ruback, R. S. 32, 127

Rubinstein, M. 25, 33, 136

Saito, R. 18, 19, 136

Samuelson, P. A. 26, 136

Sargan, J. D. 87, 136

Savage, L. J. 24, 28, 136

Schaffer, M. E. 87, 88, 128

Scheinkman, J. A. 45, 136

Schlick, M. 64, 136

Scholes, M. 56, 65, 66, 129

Severino, A. J. 19, 63, 136

Seyhun, H. N. 51, 136

Sharpe, W. F. 18, 28, 31, 65, 136

Shefrin, H. M. 16, 24, 26, 31, $32,37,136,137$

Shiller, R. J. 16, 39, 137

Shleifer, A. 16, 26, 27, 31, 35, $37,39,40,52-54,128,133$, 137

Shumway, T. 57, 132

Sil, R. 25, 137

Simon, H. A. 32,137

Singh, R. 48, 133

Smidt, S. 39, 137

Solt, M. E. 43, 137

Soydemir, G. 59, 138

Stambaugh, R. F. 45, 135

Stanovich, K. E. 37, 137

Statman, M. 16, 31, 42-44, 132,137

Stein, J. C. 16, 39, 40, 45, 49, 109, 127, 132

Stillman, S. 87, 88, 128

Subrahmanyam, A. 16, 39, 130
Summers, L. H. 16, 31, 135, 137

Taleb, N. N. 63, 137

Tarling, R. 44, 138

Taylor, S. J. 50, 52, 76, 138

Temple, J. R. 87, 129

Thaler, R. H. 16, 26, 31, 33, 35-40, 52-54, 130, 133, 135, 138

Titman, S. 36, 38, 109, 132

Tobin, J. 28, 138

Treynor, J. 28, 138

Trivedi, P. K. 80, 82, 129

Tversky, A. 37, 138

Vartiainen, H. 31, 130

Verma, R. 59, 138

Vishny, R. W. 16, 26, 27, 31, $37,39,40,128,133,137$

Vogt, B. 39, 132

von Neumann, J. 24, 28, 138

Waismann, F. 64, 138

Wang, Y.-h. 50, 52, 76, 138

Washington, S. P. 74, 138

Welch, I. 48, 135

West, R. F. 37, 137

Whaley, R. E. 56, 57, 138

Wheatley, S. M. 37, 135

Wichern, D. W. 73-75, 133

Williams, J. T. 29, 138

Williamson, O. E. 49, 138

Windmeijer, F. 85, 88, 101, 104, 118, 123, 138

Wooldridge, J. M. 77, 78, 80, 99, 123, 139

Wu, S. 100, 123, 134

Wurgler, J. A. 16, 32, 33, 37, $39,40,45-48,50,51,61$, $62,72,76,127,128$

Xiong, W. 45, 136

Yoshinaga, C. E. 31, 139

Zhang, C. 16, 39, 57, 121, 135, 139

Zweig, M. E. 39, 139 